\title{
ESTUDO DA INFLUÊNCIA DA MODELAGEM ESTRUTURAL DO NÚCLEO NOS PAINÉIS DE CONTRAVENTAMENTO DE EDIFÍCIOS ALTOS
}

\author{
Ana Claudia de Oliveira Pereira
}

Dissertação apresentada à Escola de engenharia de São Carlos da Universidade de São Paulo, como parte dos requisitos para obtenção do título de Mestre em Engenharia de Estruturas

ORIENTADOR: Prof. Dr.Dagoberto Dario Mori

São Carlos

2000 


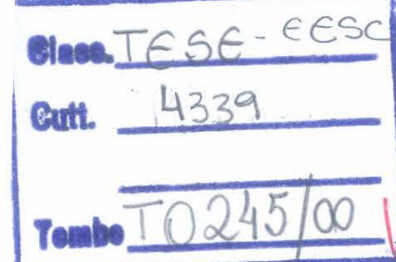

Ficha catalográfica preparada pela Seção de Tratamento da Informação do Serviço de Biblioteca - EESC/USP

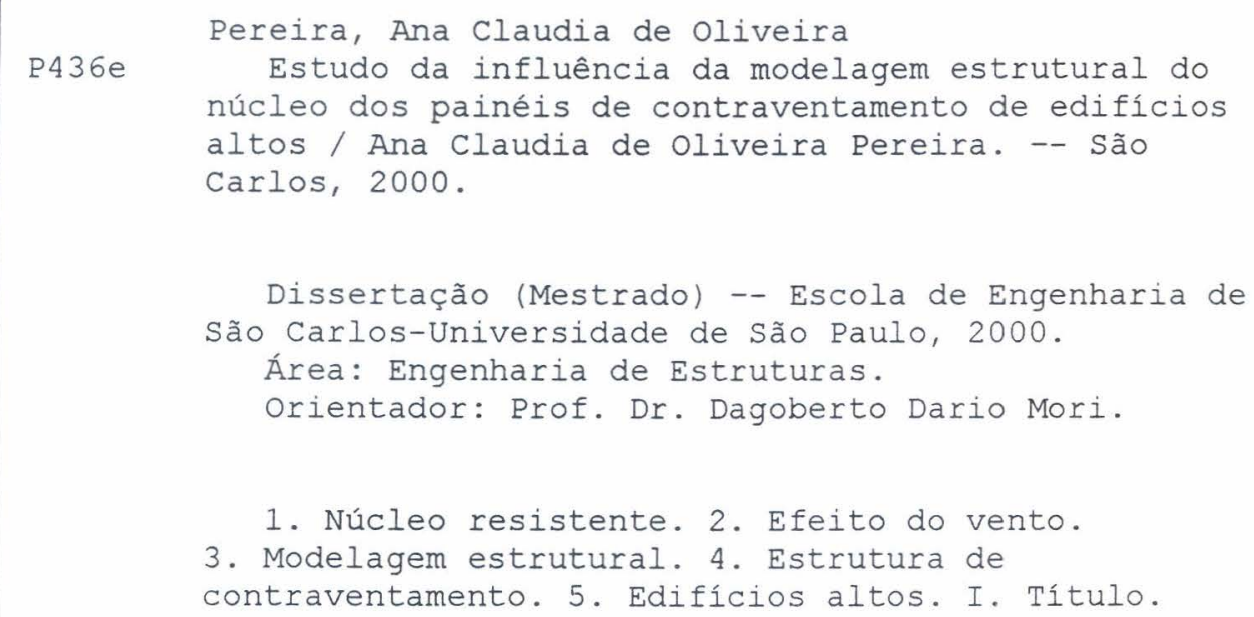




\section{FOLHA DE APROVACÃO}

Candidata: Engenheira ANA CLAUDIA DE OLIVEIRA PEREIRA

Dissertação defendida e aprovada em 30-08-2000 pela Comissão Julgadora:

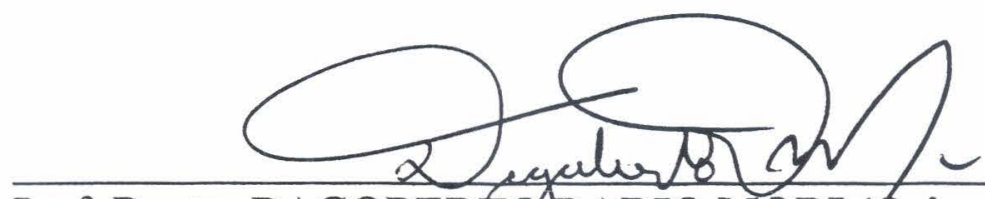

Prof. Doutor DAGOBERTO DARIO MORI (Orientador)

(Escola de Engenharia de Săo Carlos - Universidade de São Paulo)

teluna famo

Profa. Doutora HELENA MARIA CUNHA DO CARMO ANTUNES

(Escola de Engenharia de São Carlos - Universidade de São Paulo)

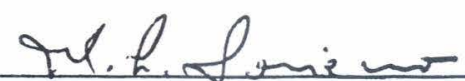

Prof. Titular HUMBERTO LIMA SORIANO

(Universidade Estadual do Rio de Janeiro - UERJ)

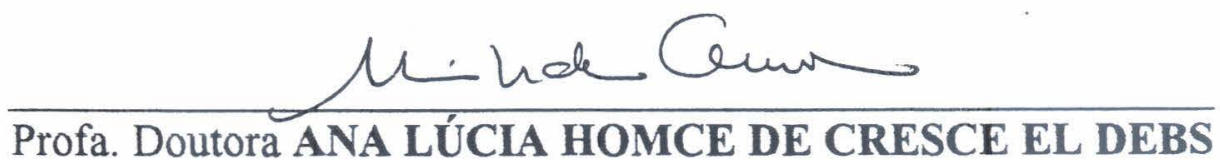

Coordenadora do Programa de Pós-Graduação

em Engenharia de Estruturas

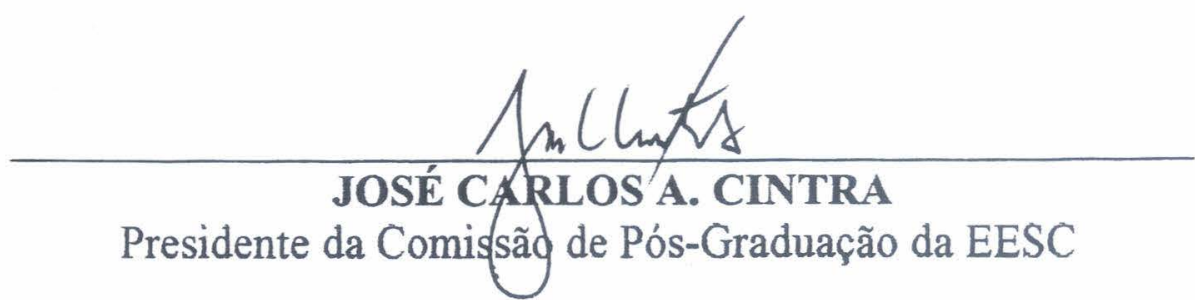


"Existe uma beleza divina na aprendizagem. Aprender significa aceitar o postulado de que a vida não começou no momento de meu nascimento. Antes de mim já vieram outros, e eu caminho por cima de suas pegadas. Os livros que ll foram escritos por gerações de pals e filhos...., professores e discípulos. Eu sou o resultado de suas experiências..." 


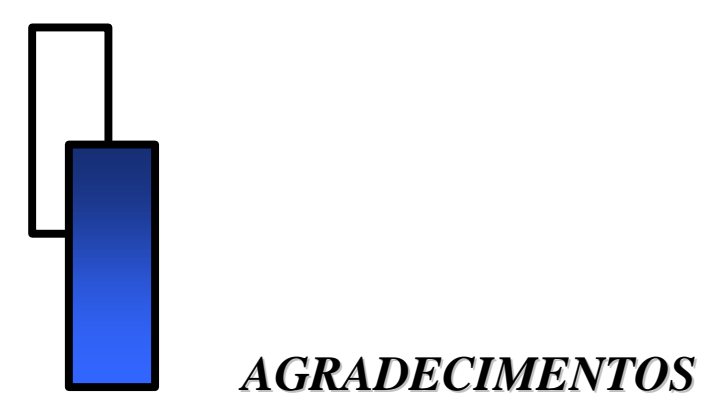

Primeiramente à DEUS, por sempre iluminar o meu caminho.

Aos meus pais que são minha vida e minha fonte de amor, de carinho e de compreensão. Aos meus irmãos, pela força, e ao Marcelo S., pela grande amizade.

À Fundação de Amparo à Pesquisa do Estado de São Paulo - FAPESP, pela da Bolsa de estudos e material permanente concedido.

Ao Prof. Dr. Dagoberto Dario Mori que, mais que um orientador, se mostrou também um amigo durante todos esse anos. A direção que tomei, iniciando esta caminhada, devo à ele.

Ao amigo Prof. Dr. José Jairo, por sua grande ajuda neste projeto, por seus conselhos e por sua amizade.

Às minhas grandes amigas, Palmira e Patrícia, pelo convívio, pela amizade, pelo carinho e pela força que sempre me deram nos momentos difíceis, amenizando a tristeza de estar longe do lar. O que vivemos estará sempre marcado na memória.

À três pessoas muito especiais, Fernando, Cristina (Crés) e Suzana, que com seus corações enormes, palavras e gestos de carinho e conforto, proporcionaram-me momentos de grande paz.

Aos professores e doutores, Helena M. C. Antunes e José Serra, pelas sugestões propostas, contribuindo muito no trabalho desenvolvido.

Ao Eng. Matias, pelas importantes informações concedidas e pela pronta disposição em ajudar.

À todos os colegas que, dispondo de parte do seu tempo, foram fonte de conhecimento, contribuindo na elaboração deste trabalho, em especial Carlos Humberto Martins, Ivan Torres, Edgard Souza Junior, Valério e Roberto.

Aos amigos que entraram juntamente comigo nesta difícil jornada e, com a amizade, tornaram mais agradável o caminho percorrido. Em especial, Palmira, Patrícia Garcia, Valentim, Rejane, Yuri, Patrícia Lizi, Rodrigo, Marcelo Greco, George e Roberto. E também às amigas Tatiana Almeida e Aline Barros, pela força.

Aos professores e funcionários do Departamento de estruturas que colaboraram para o desenvolvimento deste trabalho. 


\section{SUMÁRIO}

\section{LISTA DE FIGURAS}

\section{LISTA DE TABELAS}

LISTA DE QUADROS

\section{RESUMO}

ABSTRACT

\section{1 - INTRODUÇÃO}

1.2 - Objetivo da Pesquisa 5

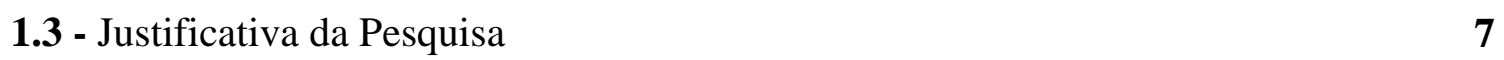

1.4 - Resumo dos Capítulos $\quad 7$

2 - REVISÃO BIBLIOGRÁFICA 9

2.1 - Introdução 9

2.2 - Processo Contínuo $\quad \mathbf{1 0}$

2.3 - Processo Discreto 12

2.4 - Método dos Elementos Finitos

3 - NÚCLEO RESISTENTE

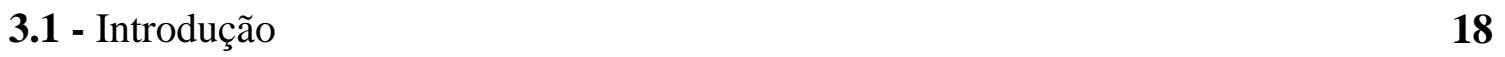

3.2 - Caracterização 19

3.3 - Lintéis

4 - CARACTERÍSTICAS ESTRUTURAIS DOS MODELOS PROPOSTOS PARA O NÚCLEO

4.1 - Introdução

4.2 - Modelagem por Pilares Parede Isolados $\quad \mathbf{2 4}$

4.2.1 - Considerações sobre a modelagem por pilar parede isolado 25

4.3 - Modelagem por Barra de Seção Delgada com a Consideração da Teoria de Flexo-torção.

4.3.1 - Considerações sobre a modelagem por Barra de Seção Delgada com a Consideração da Teoria de flexo-torção

4.4 - Modelagem por Barra de Seção Delgada sem a Consideração da Teoria de Flexo-torção. 
4.4.1 - Considerações sobre a modelagem por Barra de Seção Delgada Sem a Consideração da Teoria de flexo-torção

4.5 - Modelagem pelo Métodos dos Elementos Finitos

4.6 - Modelo Proposto por YAGUI

4.6.1 - Considerações sobre o modelo proposto por YAGUI

4.6.2 - Composição da estrutura e deslocamento do sistema

4.7 - Modelo Proposto por SMITH et al

4.7.1 - Problemas gerados por modelos discretos

4.7.2 - Modelos propostos para correção

4.7.3 - Características geométricas para os novos modelos

4.7.3.1 - Rigidez à flexão

4.7.3.2 - Rigidez ao cisalhamento

5 - MATRIZ DE RIGIDEZ DOS ELEMENTOS E SUA CONTRIBUIÇÃO NA SUBESTRUTURA

5.1 - Introdução

5.2 - Determinação da Matriz de Rigidez dos Elementos

5.2.1 - Modelagem por barra de seção delgada considerando a teoria de Flexo-torção

5.2.2 - Modelagem por barra de seção delgada sem a consideração da teoria de Flexo-torção

5.2.3 - Modelagem por pilar parede isolada

5.2.4 - Modelo proposto por YAGUI

5.2.4.1 - Consideração do efeito de Segunda ordem na matriz de rigidez dos elementos de parede

5.2.5 - Modelo proposto por SMITH

5.3 - Contribuição dos Elementos na Subestrutura

5.3.1 - Generalidades.

5.3.1.1 - Processo de subestruturação

5.3.1.2 - Coordenadas da subestrutura

5.3.2 - Contribuição do elemento na subestrutura para a modelagem por 
5.3.3 - Contribuição do elemento na subestrutura para a modelagem por barra de seção delgada não considerando a teoria de flexo-torção

5.3.4 - Contribuição do elemento na subestrutura para a modelagem por Pilar parede isolado

5.3.5 - Contribuição do elemento na subestrutura para o modelo

proposto por YAGUI

5.3.6 - Contribuição do elemento na subestrutura para o modelo por

6.1 - Introdução

6.2 - Exemplo 1

6.3 - Exemplo 2

6.4 - Exemplo 3

7 - CONSIDERAÇÕES FINAIS E SUGESTÕES 


\section{LISTA DE FIGURAS}

Figura 1a - Centro de Toronto/ Canadá - Edifício TD BANK 1

Figura 1b - Edifício Amoco Building - Chicago/U.S.A.

Figura 2 - Alguns subsistemas verticais $\quad 3$

Figura 3 - Elemento finito de membrana de núcleo - SMITH \& COULL (1991)

Figura 4 - Classificação dos Núcleos Resistentes - SMITH \& COULL (1991)

Figura 5 - Empenamento da seção do núcleo - SMITH \& COULL (1991) 20

Figura 6 - Condição de restrição do lintéis

Figura 7 - Modelagem do núcleo por pilar parede isolado 25

Figura 8 - Coordenadas deslocamentos para o elemento de pilar parede isolado - MATIAS (1997)

Figura 9 - Elemento de discretização utilizado por TARANATH

Figura 10 - Coordenadas deslocamento do elemento de núcleo - MATIAS (1997).

Figura 11 - Modelagem do núcleo resistente - eixo no centro de cisalhamento 30

Figura 12 - Coordenadas deslocamento do elemento de núcleo 3

Figura 13 - Elemento de Placa SHELL63 - Software ANSYS 34

Figura 14 - Modelagem estrutural do núcleo - Elemento YAGUI (1971) 34

Figura 15 - Elemento de parede do núcleo resistente. 36

Figura 16 - Coordenadas dos lintéis e vinculações 37

Figura 17 - Ligação entre a parede e o lintel $\mathbf{3 8}$

Figura 18 - Planta típica e Coordenadas de um Núcleo - SERRA(1994) 39

Figura 19 - Momento parasita no elemento de parede $\mathbf{4 2}$

Figura 20 - Núcleo resistente sujeito a forças de torção - GUILARDI (1999) 43 
Figura 21 - Modelos propostos por SMITH et al - GUILARDI (1999)

Figura 22 - Modelo adotado - GUILARDI (1999) 45

Figura 23 - Parede sujeita à flexão uniforme - GUILARDI (1999) 46

Figura 24 - Parede sujeita cisalhamento puro - GUILARDI (1999) 47

Figura 25 - Parede sujeita a esforços axiais - GUILARDI (1999) 49

Figura 26 - Coordenadas do elemento de parede $\quad \mathbf{5 7}$

Figura 27 - Coordenadas do elemento de barra e coeficientes de rigidez $\quad 62$

Figura 28 - Estados básicos de deslocamentos

Figura 29 - Modelo e suas coordenadas - GUILARDI (1999) 65

Figura 30 - Expressões de rigidez - GUILARDI (1999) 66

Figura 31 - Esquema simplificado do processo de subestruturação MATIAS(1997) $\quad \mathbf{7 0}$

Figura 32 - Sistema de coordenadas de uma subestrutura modelo $\quad 71$

Figura 33 - Rotação das coordenadas do elemento - Modelagem por barra de seção delgada considerando a flexo-torção

Figura 34 - Rotação das coordenadas do elemento - Modelagem de barra de seção delgada sem a consideração da teoria flexo-torção

Figura 35 - Rotação das coordenadas do elemento - Modelagem por pilar parede isolado - Representação de apenas um segmento de parede de núcleo

Figura 36 - Sistema de eixo local do elemento ELM-0Y $\mathbf{8 0}$

Figura 37 - Translação de coordenadas do ELM-0Y para o nó mestre 82

$\begin{array}{lll}\text { Figura } 38 \text { - Semelhança entre as modelagens } & \mathbf{8 4}\end{array}$

Figura 39 - Estrutura teórica de núcleo idealizada por YAGUI(1971) 87

Figura 40 - Translação na direção $\mathrm{Zg}(\mathrm{cm})$ do nó mestre $-1^{\mathrm{a}}$ Ordem $\mathbf{8 8}$

Figura 41 - Valores de rotação em torno do eixo Xg, em cada pavimento $(\mathrm{rad})$

Figura 42 - Pontos sobre o esqueleto do núcleo - Sentido positivo dos deslocamentos

Figura 43 - Deslocamento Longitudinal dos pontos sobre o núcleo $10^{\circ}$ Pavimento - Borda superior 
Figura 44 - Deslocamento Longitudinal dos pontos sobre o núcleo $10^{\circ}$ Pavimento - Borda inferior

Figura 45 - Detalhe da estrutura de núcleo discretizada e sua vinculação Ansys

Figura 46 - Adaptações no modelo - extremidade superior do núcleo

Figura 47 - Translação na direção Zg para cada pavimento

Figura 48 - Rotação em torno do eixo Xg para cada pavimento

Figura 49 - Planta baixa da estrutura de contraventamento idealizada por SILVA (1989)

Figura 50 - Elemento vertical de pórtico espacial 99

Figura 51 - Elemento vertical de pórtico plano 99

Figura 52 - Elemento horizontal de pórtico plano 100

Figura 53 - Translação em Yg do nó mestre 102

Figura 54 - Rotação das lajes em torno de Xg 104

$\begin{array}{lll}\text { Figura } 55 \text { - Momento fletor em torno do eixo z na base do pilar } 9 & 107\end{array}$

$\begin{array}{lll}\text { Figura } 56 & \text { - Esforço cortante na direção do eixo y do pilar } 7 & 109\end{array}$

Figura 57 - Vista geral da estrutura discretizada em elementos finitos Ansys5.5.

Figura 58 - Detalhe da estrutura discretizada - Ansys 5.5. 112

Figura 59 - Translação na direção de aplicação do vento - $(\mathrm{cm}) \quad 113$

$\begin{array}{lll}\text { Figura } 60 & \text { - Deformação final da estrutura - Ansys } 5.5 & 114\end{array}$

Figura 61 - Rotação em torno de y - Ansys 5.5. 115

Figura 62 - Elemento de Viga - Elemento vertical de pórtico espacial 117

Figura 63 - Planta baixa da estrutura de contraventamento - TORRES (1999) 118

Figura 64 - Translação do nó mestre na direção Zg 121

$\begin{array}{ll}\text { Figura } 65 \text { - Rotação do nó mestre em torno do eixo Xg } & 123\end{array}$

Figura 66 - Momento Fletor do pilar 7 na direção do eixo Yg 126

Figura 67 - Esforço cortante no pilar 20, direção do eixo $\mathrm{Zg} \quad \mathbf{1 2 8}$

Figura 68 - Momento Fletor do pilar 7 na direção do eixo Yg - 1a ordem 130

Figura 69 - Esforço cortante no pilar 20, direção do eixo Zg - 1a ordem 131

Figura 70 - Diferença percentual em deslocamentos entre os modelos 4 e 3 Exemplo 2 
Figura 71 - Diferença percentual em esforços entre os modelos 4 e 3 Exemplo 2

Figura 72 - Diferença percentual em deslocamentos entre os modelos 4 e 3 Exemplo 3

Figura 73 - Diferença percentual em esforços entre os modelos 4 e 3 - 136 Exemplo 3

Figura 74 - Diferença em \% entre os resultados dos modelos 4 e 1-Exemplo 2137

Figura 75 - Diferença em \% entre os resultados dos modelos 4 e 1-Exemplo 3137 


\section{LISTA DE TABELAS}

Tabela 1 - Características da coluna e diagonais $\quad 49$

Tabela 2 - Valores da translação na direção $\mathrm{Zg}(\mathrm{cm})$, em cada pavimento $\quad \mathbf{8 8}$

Tabela 3 - Valores de rotação em torno do eixo Xg, em cada pavimento - $1^{\mathrm{a}} \mathbf{8 9}$

Tabela 4 - Valores de rotação em torno do eixo Xg, em cada pavimento - $2^{\mathrm{a}} \mathbf{8 9}$

Tabela 5 - Deslocamento Longitudinal dos pontos sobre o núcleo no $10^{\circ}$ pavimento $\quad 92$

Tabela 6 - Translação na direção Zg para cada pavimento $(\mathrm{E}-03 \mathrm{~cm}) \quad \mathbf{9 5}$

Tabela 7 - Rotação em torno do eixo Xg para cada pavimento 96

Tabela 8 - Translação em Yg do nó mestre $-1^{\mathrm{a}}$ Ordem - $(\mathrm{cm}) \quad 101$

Tabela 9 - Translação em Yg do nó mestre $-2^{\mathrm{a}}$ Ordem $-(\mathrm{cm}) \quad 101$

Tabela 10 - Rotação Xg do nó mestre $-1^{\text {a }}$ Ordem $-\left(10^{-3} \mathrm{rad}\right) \quad \mathbf{1 0 3}$

Tabela 11 - Rotação Xg do nó mestre $-2^{\text {a }}$ Ordem $-\left(10^{-3} \mathrm{rad}\right) \quad \mathbf{1 0 3}$

Tabela 12 - Momento Fletor em torno do eixo z do PILAR $9-1^{\text {a }}$ Ordem 106

Tabela 13 - Momento Fletor em torno do eixo z do PILAR $9-2^{\mathrm{a}}$ Ordem 106

Tabela 14 - Esforço cortante na direção do eixo y do pilar $8-1^{\mathrm{a}}$ Ordem $\quad 108$

Tabela 15 - Esforço cortante na direção do eixo y do pilar $8-2^{\text {a }}$ Ordem $\quad 108$

Tabela 16 - Deslocamentos máximos das lajes a cada pavimento 112

$\begin{array}{ll}\text { Tabela } 17 \text { - Dimensões dos Pilares } & 116\end{array}$

$\begin{array}{ll}\text { Tabela } 18 \text { - Dimensões das vigas } & 116\end{array}$

$\begin{array}{ll}\text { Tabela } 19 \text { - Carregamento aplicado à estrutura } & 119\end{array}$

Tabela 20 - Translação $\mathrm{Zg}$ do nó mestre $-1^{\mathrm{a}}$ ordem - $(\mathrm{cm}) \quad 120$

Tabela 21 - Translação Zg do nó mestre $-2^{\mathrm{a}}$ ordem - $(\mathrm{cm}) \quad 120$

Tabela 22 - Rotação em torno do eixo Xg do nó mestre- $1^{\text {a }}$ ordem - (E-03rad) 122

Tabela 23 - Rotação em torno do eixo Xg do nó mestre- $2^{\text {a }}$ ordem - (E-03rad) 122

Tabela 24 - Momento Fletor do pilar 7, direção do eixo Yg $-1^{\text {a }}$ ordem (kN.cm) 
Tabela 25 Momento Fletor do pilar 7, direção do eixo Yg - $2^{\mathrm{a}}$ ordem (kN.cm)

Tabela 26 - Esforço cortante no pilar 20, direção eixo $\mathrm{Zg}-1^{\mathrm{a}}$ ordem-(kN.cm)

Tabela 27 - Esforço cortante no pilar 20, direção eixo Zg-2a ordem-(kN.cm)

Tabela 28 - Momento Fletor do pilar 7, direção do eixo $\mathrm{Yg}-1^{\mathrm{a}}$ ordem (kN.cm)

Tabela 29 - Esforço cortante no pilar 20, direção eixo $\mathrm{Zg}-1^{\mathrm{a}}$ ordem-(kN.cm)

Tabela 30 - Diferença em porcentagem entre a modelagem do núcleo por pilar parede isolado e demais modelagens adotadas

Tabela 31 - Resumo das vantagens e desvantagens observadas com a utilização das modelagens de núcleo proposta 



\section{LISTA DE QUADROS}

Quadro 1 - Coeficientes de rigidez do modelo proposto por YAGUI (1971) 58

Quadro 2 - Expressões de rigidez - Formulário 63

Quadro 3 - Matriz de rigidez do modelo - GUILARDI (1999) 67 


\section{RESUMO}

PEREIRA, A. C. O. (2000). Estudo da influência da modelagem estrutural do núcleo nos painéis de contraventamento de edifícios altos. São Carlos, 2000. 148p. Dissertação (Mestrado) - Escola de Engenharia de São Carlos, Universidade de São Paulo.

O núcleo resistente, considerado um dos principais elementos componentes dos sistemas estruturais de edifícios de andares múltiplos, quando associado ao sistema de contraventamento, consegue conferir à estrutura um razoável acréscimo de rigidez. O núcleo é ainda o único elemento estrutural capaz de resistir isoladamente a todos os esforços atuantes na estrutura de um edifício, contribuindo na determinação mais precisa dos seus deslocamentos. Baseado nestes fatores, acredita-se que as diferentes modelagens, adotadas para o núcleo, proporcionarão diferentes resultados para a mesma estrutura de contraventamento. Este trabalho tem como principal objetivo analisar a influência que estas modelagens exercem na estrutura de contraventamento. Inicialmente, são apresentadas algumas das modelagens mais utilizadas para o núcleo. Com estas modelagens foram processadas algumas estruturas, e os diversos resultados obtidos utilizados no processo comparativo. Para o processamento foram consideradas análises em teoria de primeira e segunda ordem e, para as fundações, vinculação rígida. Não serão consideradas as deformações por esforço cortante nos elementos.

Palavras chave: Núcleo rigidez - Efeito do Vento - Modelagem estrutural; Estrutura de contraventamento - Edifícios Altos 


\begin{abstract}
PEREIRA, A. C. O. (2000). Study of the influence of the structural modeling of the cores in the bracing panels of tall buildings. São Carlos, 2000. 148p. Dissertação (Mestrado) - Escola de Engenharia de São Carlos, Universidade de São Paulo.
\end{abstract}

Resistant cores, are considered one of the principal elements of the structural systems of multistory buildings. When associated to the bracing structure, it gives to the structure a reasonable stiffness increment. The core is still the only structural element capable to resist separately all the efforts in the structure of a building, contributing to a more accurate determination of its displacements. Based on these factors, it is believed that different modeling adopted for the cores will provide different results for the same bracing structure. The main aim of this work is to analyze the influence that these modeling exerts on the bracing structure. First, some of the most used core modeling were presented. Then some structures were processed, using these modeling. The several obtained results were compared. For all the analysis it was considered the first and second order theory and rigid connections for the foundations. Shear deformation were not considered in the elements.

Keywords: Resistant Cores - Wind Effect - Structural modeling - Bracing Structure - Tall Building 


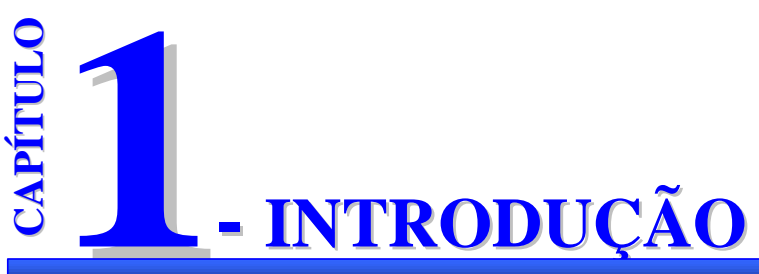

Uma longa viagem começa com um

único passo.

Lao-Tse

\section{1 - GENERALIDADES}

As estruturas de edifícios altos vem se tornando uma das soluções habitacionais e comerciais mais utilizadas na atualidade, principalmente nos grandes centros urbanos. A sua capacidade de abrigar um número maior de ambientes em espaços de terrenos cada vez menores, faz dessa concepção estrutural uma das melhores opções dentre as existentes.

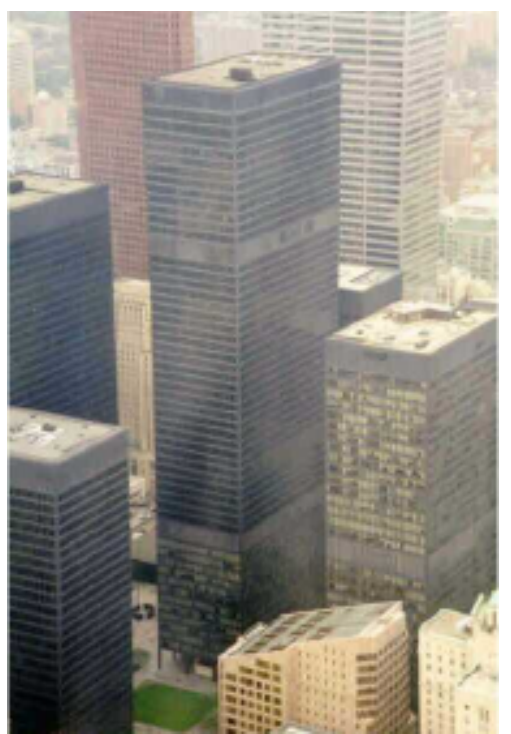

Fig.1.a- Centro de Toronto/ Canadá Edifício TD BANK

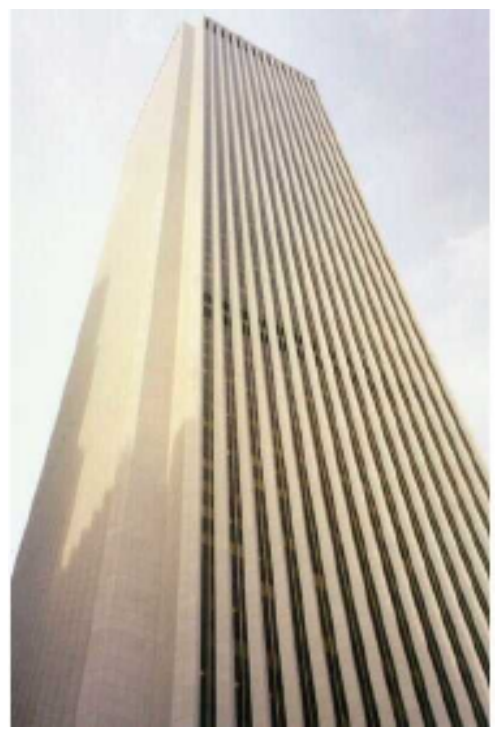

Fig.1.b- Edifício AMOCO BUILDING Chicago/USA 
Procurando identificar os edifícios altos, TARANATH (1988) comenta não existir nenhum conceito que, a partir de relações de altura, número de pavimentos ou proporções, seja capaz de classificar uma estrutura como alta. Sendo assim, do ponto de vista estrutural, serão tratados como edifícios altos todos aqueles onde a análise estrutural e projeto forem, de alguma forma, afetados pela ação do vento. Isto ocorre, quando a altura do edifício começa a se elevar muito e as ações horizontais passam a exercer um papel significativo na determinação do seu sistema estrutural.

Como o efeito das ações horizontais é extremamente variável e aumenta rapidamente com o aumento da altura, grande parte das estruturas esbeltas, tendem a apresentar deslocamentos que comprometem a estabilidade global da estrutura.

Sendo função prioritária das estruturas suportar todas as solicitações a que possa estar exposta, mantendo a sua forma espacial e integridade física, se faz necessário o estudo dos possíveis arranjos estruturais que garantam à estrutura o desenvolvimento do papel a que se destina.

Os edifícios altos, muitas vezes classificados como estruturas esbeltas, necessitam de um sistema estrutural onde a rigidez e a estabilidade sejam consideradas como fatores prioritários durante a concepção do seu projeto. Este estudo é parte importante da engenharia estrutural e vital para a garantia de que a estrutura principal não apresente deslocamentos que, de alguma forma, prejudiquem a segurança da edificação.

Os sistemas estruturais de contraventamento são os grandes responsáveis pela seguridade das estruturas tridimensionais de edifícios altos, sendo formados pelos elementos que as compõem ou mesmo por seus arranjos. Tais sistemas de contraventamento dividem-se em: pórticos planos ou tridimensionais, painéis treliçados, painéis parede, núcleos resistentes e pilares isolados. As lajes e as vigas integram este grupo sendo denominadas de elementos horizontais de contraventamento. 


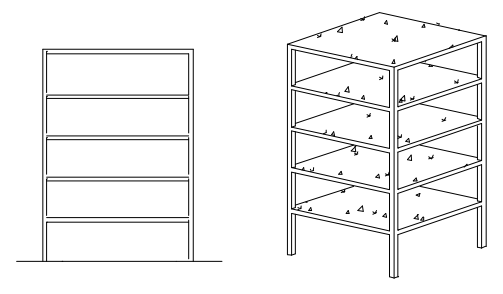

Pórtico Plano

Tridimensional

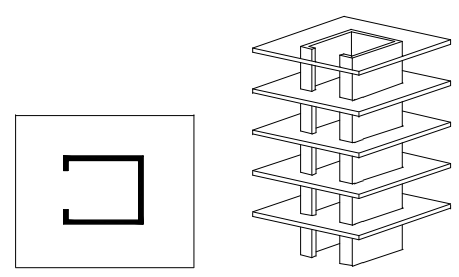

Núcleo Resistente

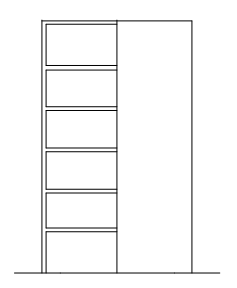

Pórtico e Parede associados

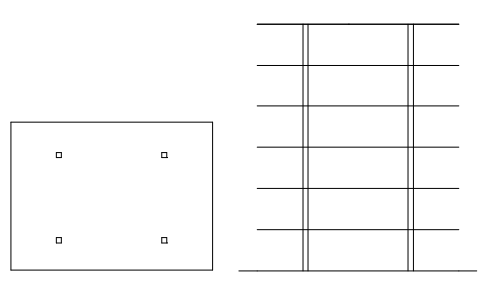

Pilares

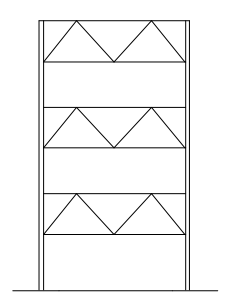

Treliça Inter pavimentos

Figura 2 - Alguns subsistemas verticais

Dentre os diversos sistemas de contraventamento existentes, os núcleos resistentes são os únicos elementos capazes de resistir, isoladamente, a todos os tipos de ações atuantes no edifício. Tais elementos são compostos pela associação tridimensional de paredes, formando assim uma seção transversal aberta, cuja função arquitetônica é, comumente, a de abrigar as caixas de elevadores e escadas.

$\mathrm{Na}$ prática, a rigidez real do núcleo resistente ainda não é considerada por muitos escritórios de cálculo durante o processo de análise estrutural do edifício. $\mathrm{Na}$ maioria destas estruturas de edifício, a modelagem do núcleo é feita de maneira incorreta, ou seja, incoerente com o comportamento estrutural deste elemento. É de se presumir que tal fator impossibilite uma análise mais fiel da influência da rigidez do núcleo resistente sobre o restante da estrutura. Devido a essa pouca familiaridade apresentada por muitos calculistas, em simular o comportamento do núcleo resistente, sua utilização acaba ficando inibida, o que prejudica muito a avaliação dos resultados finais da estrutura global diante da importante presença do núcleo resistente. 
É de absoluta necessidade para a engenharia estrutural, a determinação dos deslocamentos e esforços atuantes nos diversos elementos componentes das estruturas de edifício. Contudo, para que tais resultados sejam determinados de maneira eficiente é necessário que o calculista desenvolva, previamente, uma série de análises e procedimentos.

A determinação dos elementos que participarão do sistema de contraventamento é uma das análises a ser desenvolvida. Esta análise pode ser considerada de grande importância para a obtenção de bons resultados de processamento. Porém, é importante ressaltar que quanto maior o número de elementos estruturais participantes deste sistema, maiores serão os esforços de cálculo mobilizados, uma vez que estes recaem em um grande número de incógnitas e na resolução de sistemas de equações lineares. Atualmente, a resolução destes sistemas de equações deixou de ser um problema. Pode-se observar que a utilização dos microcomputadores aliados ao aumento da sua capacidade, proporcionou um rápido desenvolvimento das técnicas de análise estrutural.

Outra importante análise se faz na escolha da técnica de cálculo a ser utilizada para a determinação dos esforços e deslocamentos atuantes na estrutura. Considerado também um fator de grande importância neste processo, a técnica escolhida deverá permitir uma boa aproximação do comportamento real da estrutura diante das ações atuantes.

$\mathrm{Na}$ análise estrutural de edifícios altos a técnica de análise matricial, através do processo dos deslocamentos, é a técnica mais utilizada na automatização dos cálculos. Neste processo, os elementos componentes são tratados como elementos de barra onde, de acordo com o papel estrutural desempenhado na estrutura, apresentam uma rigidez representativa transferida aos seus nós de extremidade. Essa técnica permite também a análise da estrutura a partir da substituição dos elementos estruturais por elementos planos, placas ou cascas, além dos elementos lineares. 
Para a análise dos núcleos resistentes, em especial, são utilizados dois métodos: os que utilizam o processo contínuo e os que utilizam o processo discreto, através do processo dos deslocamentos.

\section{2 - OBJETIVO DA PESQUISA}

Este trabalho tem como objetivo principal a realização de análises comparativas entre os resultados fornecidos pelo processamento de estruturas de edifícios altos, enrijecidas por núcleo resistente, adotando para o elemento de núcleo diferentes tipos de modelagens. Cada estrutura de contraventamento, formada pela associação de pilares, vigas e núcleo, possuirá o mesmo projeto estrutural variando somente a modelagem do núcleo. Esta estrutura será submetida simultaneamente às forças horizontais do vento e às ações de origem gravitacional, sendo a partir daí, analisado o comportamento da estrutura de contraventamento, elementos de pilares e vigas, diante do efeito destas ações e da modelagem do núcleo.

Serão utilizadas diversas modelagens distintas para o núcleo resistente. Dentre elas estão: modelagem por pilares paredes ligados entre si em duas opções, considerando ou não o efeito do bimomento, modelagem proposta por YAGUI (1971) e a modelagem utilizando o software Ansys 5.5, considerando o método dos elementos finitos (M.E.F). É dado destaque à modelagem proposta por YAGUI por possuir apenas um trabalho - SILVA (1987), de conhecimento do autor, que considera, além da presença do elemento de núcleo, a presença dos demais elementos componentes da estrutura de contraventamento, no processamento estrutural. Além destas modelagens, serão extraídos resultados utilizando um modelo proposto por SMITH et al (1981/1984). A modelagem por pilar parede isolado também será analisada neste trabalho. Devido a utilização, preferencial, desta modelagem por alguns escritórios de cálculo durante um certo período, achou-se interessante executar o processamento de uma estrutura com o intuito de verificar a eficiência estrutural deste modelo. Todos os resultados extraídos serão utilizados no processo comparativo e apresentados neste trabalho em capítulo especial. 
As análises, das estruturas de edifícios altos, serão tridimensionais, considerando cada uma das modelagens apresentadas e podendo se levar em conta a sua não linearidade geométrica, ou seja, desenvolvimento da análise em teoria de $2^{\mathrm{a}}$ ordem.

Tais análises serão realizadas por meio de implementações e alterações desenvolvidas no programa denominado CEASO 01. Este programa, CEASO 01, de autoria de MATIAS (1997), foi baseado no programa CEASO, desenvolvido em linguagem FORTRAN 90 por MORI (1992) e utilizado para cálculo de estruturas de edifícios altos em teoria de segunda ordem. MATIAS (1997), analisa as estruturas de edifícios a partir da interação entre os diversos elementos, de forma plana ou tridimensional. Foram definidos, nesta versão, cinco tipos de elementos verticais, inclusive o núcleo resistente, dois elementos horizontais de viga e dois elementos diagonais. Em todas as versões, as lajes foram consideradas como um diafragma rígido.

O programa desenvolvido durante este trabalho, denominado de MODNUC, permite a escolha do tipo de modelagem desejada, entre quatro modelos, para a consideração do núcleo resistente.

Com as diversas análises efetuadas, de forma simples, o trabalho procura orientar, principalmente os engenheiros de projeto sobre, as diversas modelagens usualmente utilizadas para a simulação do núcleo resistente. Essas informações têm como objetivo, alertar os engenheiros sobre as possíveis dificuldades que cada modelagem pode apresentar, bem como as suas vantagens e desvantagens.

É importante salientar que além de se analisar e adotar como resposta modelos de núcleo que forneçam resultados mais representativos, a utilização de modelos que simplifiquem os cálculos, sem que se afete a confiabilidade dos resultados, foi também tida como meta na elaboração deste trabalho. 


\section{3 - JUSTIFICATIVA DA PESQUISA}

A análise estrutural de um edifício não é tarefa simples, exigindo do calculista grandes conhecimentos, principalmente na tomada de decisões feitas antes e ao longo do processo de cálculo.

Dentre as várias decisões a serem tomadas, a escolha dos elementos que participarão do arranjo estrutural e a adoção dos modelos utilizados para simular o seu comportamento, são as de maior importância para a obtenção de êxito nos resultados de cálculo a serem fornecidos.

Aliando estes fatores à influência que a presença do núcleo resistente exerce na absorção de esforços, pode-se concluir que a modelagem do núcleo é um fator de elevada importância no desenvolvimento dos cálculos. Diante de tal verificação podemos concluir que os resultados obtidos, de acordo com o modelo adotado, poderão ou não representar adequadamente o comportamento da estrutura de edifício diante das ações previstas.

Dessa forma, é esperado que as diferentes modelagens, adotadas para o núcleo resistente, forneçam diferentes resultados em deslocamentos e esforços para a mesma estrutura de contraventamento. São portanto estes resultados que tornarão possível a avaliação da estrutura de edifício quanto ao melhor modelo a ser adotado, de acordo com o projeto estrutural proposto, justificando assim a realização deste trabalho.

\section{4 - RESUMO DOS CAPÍTULOS}

No segundo capítulo é apresentada a revisão bibliográfica inicialmente desenvolvida à partir dos processos de cálculo existentes para a resolução de estruturas: processo contínuo e processo discreto. São apresentados diversos 
trabalhos desenvolvidos na área de edifícios altos, divididos de acordo com os processos utilizados em cada trabalho.

O terceiro capítulo apresenta uma introdução conceitual sobre os núcleos resistentes ou de rigidez, bem como a sua caracterização. Ainda neste capítulo é comentada a influência que este elemento de contraventamento exerce na estrutura global.

No quarto capítulo são apresentadas as diversas modelagens utilizadas para o desenvolvimento deste trabalho. São feitos ainda alguns comentários fundamentais à visualização do modelo, possibilitando a compreensão do comportamento da estrutura de núcleo, para cada uma das modelagens, diante das ações.

O quinto capítulo contém o desenvolvimento das matrizes de rigidez para os elementos de núcleo utilizados em cada uma das modelagens. Neste capítulo serão apresentadas também algumas considerações tidas como importantes no processo de resolução da estrutura.

No sexto capítulo são apresentadas as estruturas de edifícios processadas e utilizadas no desenvolvimento do processo comparativo dos resultados. São apresentados três exemplos de estruturas, onde o primeiro tem como objetivo principal a aferição dos resultados fornecidos pelo programa desenvolvido. Os demais exemplos, retirados de trabalhos de outros autores, foram adotados com a finalidade de se obter melhor representatividade das considerações finais extraídas das análises comparativas realizadas entre as diferentes modelagens. As estruturas serão processadas adotando-se, para todas as modelagens, elementos de barra na simulação do comportamento das vigas e pilares, alternado-se apenas os modelos adotados para o núcleo.

O sétimo capítulo apresenta as conclusões finais extraídas das análises efetuadas nas estruturas de contraventamento utilizando as modelagens propostas, assim como sugestões para trabalhos futuros que abordem este mesmo tema.

Ao final deste trabalho são apresentadas todas as referências bibliográficas utilizadas, bem como outras obras e artigos citados ao longo da dissertação aqui desenvolvida. Uma lista com as diversas bibliografias complementares, relacionadas ao tema deste trabalho, são também apresentadas. 


\section{2-REVISÃo BibLIOGRÁFICA}

Sábio é aquele que recolhe a sabedoria dos demais.

Juan Guerra Cáceres

\section{1 - INTRODUÇÃO}

Diversos trabalhos foram desenvolvidos na área de edifícios altos onde, de acordo com o tipo de análise proposta para cada um, era ou não considerada a presença do núcleo resistente fazendo parte da estrutura de contraventamento.

A linha de pesquisa bibliográfica abordada inicialmente foi dividida e estudada de acordo com os processos de análise utilizados para resolução das estruturas elásticas de edifícios. Tais processos podem ser classificados basicamente em dois tipos, um conhecido como processo contínuo e o outro como processo discreto.

Dentre os processos discretos, o método dos elementos finitos, considerado por alguns autores como um terceiro processo de análise, pode ser também utilizada na resolução de estruturas, necessitando porém, de ferramentas computacionais mais avançadas. Isto ocorre, pois seu método de cálculo envolve um grande número de parâmetros. Atualmente existem no mercado inúmeros softwares que utilizam este método para a resolução das mais diversas estruturas.

Nos itens que se seguem, são comentados alguns dos trabalhos desenvolvidos na área de edifícios altos levando em consideração o tipo de processo de análise utilizado. 


\section{2 - PROCESSO CONTÍNUO}

O Processo Contínuo, pela técnica do meio contínuo, trata os fechamentos horizontais, constituídos pelas lajes e lintéis, como um meio contínuo com propriedades de rigidez uniformemente distribuída ao longo da altura do edifício.

Os deslocamentos horizontais dos elementos verticais são compatibilizados, a partir da consideração de diafragmas rígidos para as lajes, conferindo assim um movimento horizontal de corpo rígido.

Este processo se desenvolve a partir da resolução de uma equação diferencial ou um sistema de equações diferenciais, fornecendo como resultados de análise os esforços e deslocamentos na estrutura.

A utilização deste método apresenta grandes vantagens quando se analisam estruturas que apresentem características elásticas e geométricas constantes ao longo da altura, levando a um número reduzido de parâmetros, podendo-se até, com isto, eliminar a utilização de ferramentas computacionais para resolução do problema. Já quando a estrutura analisada apresenta carregamento, características geométricas e elásticas variáveis ao longo da altura, esta facilidade não é mais encontrada, requerendo por parte do calculista uma manipulação matemática bastante exaustiva. Porém, este processo apresenta uma importante característica, encontrada na sua capacidade de fornecer indícios do comportamento da estrutura de uma maneira bem simplificada.

Alguns trabalhos foram desenvolvidos a fim de aprimorar esta técnica. $\mathrm{Na}$ área de análise estrutural de edifícios, um trabalho pioneiro foi desenvolvido por STAMATO (1971), que aborda a associação tridimensional de pilares-paredes e pórticos, comprovando a fidelidade matemática dos resultados obtidos a partir de modelo experimental.

Tratando da análise de estruturas sobre fundações flexíveis, MANCINI (1972) desenvolve um trabalho onde procura simular a flexibilidade das fundações dos pilares-paredes.

Baseado na teoria de flexo-torção e nas análises desenvolvidas por HEIDEBRECHT e SMITH (1973), BARBOSA (1977) desenvolve um estudo comparativo dos núcleos submetidos a esforço de torção, através de processos 
contínuos considerando o comportamento das paredes de barras de seção aberta como barras de seção delgada. Outro processo analisa a estrutura dividida em painéis paredes.

Já CARVALHO (1980), utiliza-se da técnica do meio contínuo para a determinação da carga crítica de flambagem em edifícios com paredes de seção aberta. De acordo com o processo é feita, basicamente, a consideração dos elementos horizontais, que conectam as paredes, uniformemente distribuídos ao longo da altura. Para o desenvolvimento da análise, foi considerado que as paredes de seção aberta teriam comportamento análogo ao das vigas de seção delgada. Neste trabalho foi utilizada a teoria de flexo-torção.

Nesta mesma linha de estudo de MANCINI (1972), COSTA (1984), utilizando a técnica contínua e discreta, analisa esforços nas paredes de núcleos estruturais, contraventados por lintéis com vinculação elástica ao nível da fundação, onde em tratamento contínuo, utiliza a teoria de flexo-torção, considerando para o núcleo o mesmo comportamento das barras de seção aberta constituída de paredes delgadas.

XAVIER (1987), analisa os núcleos estruturais contraventados ou não por lintéis, através de processo contínuo. Aliada à teoria de flexo-torção, considera estudo análogo às barras de seção delgada, onde o comportamento das estruturas fica expresso através de equações diferenciais, ou um sistema de três equações diferenciais, solucionadas a partir de métodos numéricos.

MANCINI \& BATTISTELLA (1990), (1991), (1995) e BATTISTELLA (1991), desenvolveram vários estudos a partir das diversas associações entre os elementos (paredes, pórticos e lintéis) considerando a deformação axial dos pilares para os vários arranjos estruturais em teoria de $2^{\mathrm{a}}$ ordem.

Pode-se observar ampla contribuição, no estudo da técnica do meio contínuo, por parte de MANCINI que, em 1995, apresenta trabalho onde desenvolve cálculo de esforços e deslocamentos produzidos por forças horizontais em uma estrutura de edifício alto, constituída por um núcleo estrutural de concreto armado, contraventado por treliça de topo e pilares periféricos tracionados de aço. Posteriormente apresenta uma sequência de cálculo alternativo considerando a flexibilidade das fundações na estrutura constituída pela associação de pilares-paredes por vigas horizontais . 
A resolução dos sistemas de equações gerados a partir das diversas associações de elementos, levou a uma gama de trabalhos voltados a este estudo. Muitos foram os pesquisadores que utilizando métodos numéricos obtiveram a resolução das equações diferenciais, necessárias na utilização deste processo. Entre eles podem ser citados, SAVASSI (1975), LAIER (1978), ATAÍDE (1981), OLIVEIRA (1981), RAMALHO (1983) e PROENÇA (1986).

\section{3 - PROCESSO DISCRETO}

O tratamento discreto consiste basicamente na análise da estrutura como um conjunto de subestruturas ou elementos bases de comportamento estrutural conhecido. A estrutura assim discretizada pode ser resolvida por técnicas matriciais utilizando o processo dos esforços ou o processo dos deslocamentos, sendo este último o mais utilizado devido a facilidade de automatização dos cálculos. Aqui também as lajes são consideradas como diafragmas rígidos, só transmitindo forças horizontais e momentos torçores aos elementos verticais da estrutura.

Apesar do grande número de incógnitas que envolvem tal processo, este se torna de grande interesse quando se analisam estruturas que apresentem variações geométricas ao longo da sua altura.

Vários foram os pesquisadores que em muito contribuíram para o desenvolvimento dos estudos nesta área. Dentre eles, podem ser citados os pesquisadores HEIDEBRECHT e SWIFT (1971), SMITH e TARANATH (1972)

e TARANATH (1975) que utilizando a análise matricial discreta, consideraram o tramo do núcleo entre lajes como um elemento linear tridimensional, que relaciona o bimomento com a primeira derivada do deslocamento angular de torção.

YAGUI (1971) foi outro pesquisador que, se utilizando do processo discreto, tratou as paredes de seção transversal, como pórticos planos formados por um conjunto de vigas horizontais, com as suas extremidades em balanço e engastadas no centro em pilares verticais. Tais vigas possuem rigidez infinita à flexão no plano do pórtico. A idéia é fazer com que tais planos sejam capazes de simular a interação ao 
longo de suas intersecções, devido às de forças de cisalhamento longitudinais e de possíveis forças horizontais aplicadas nos diafragmas.

Outro trabalho que pode ser citado foi desenvolvido por SORIANO (1971), que além de apresentar um desenvolvimento teórico, apresenta também um programa capaz de realizar o cálculo automático de estruturas carregadas lateralmente, idealizadas como um conjunto de painéis ortogonais, interagindo em suas interseções verticais através da lajes.

A fim de determinar o carregamento crítico de flambagem, ANTUNES (1978), analisou estruturas tridimensionais de edifícios altos constituídas por pórticos planos e pilares isolados. As matrizes de rigidez dos pilares foram determinadas utilizando-se as equações diferenciais do equilíbrio em teoria de $2^{\mathrm{a}}$ ordem. Os parâmetros de instabilidade foram obtidos exclusivamente a partir do esforço axial.

A partir do trabalho desenvolvido no doutorado, YAGUI (1978), procedeu a análise da influência do esforço normal em três sistemas estruturais, tendo o núcleo resistente como elemento básico de estudo, modelado a partir de elementos formados por barras horizontais rígidas ao nível dos andares, unidas por uma coluna central. $\mathrm{Na}$ determinação da matriz de rigidez da estrutura tridimensional equivalente ao núcleo, são considerados os efeitos dos esforços normais sobre a flexão e sobre a torção dos pilares. Este trabalho aborda também problemas de instabilidade geral, com determinação do carregamento crítico a partir de programa desenvolvido com esta finalidade.

COSTA (1984), faz um estudo comparativo utilizando os dois processos, contínuo e discreto, para análise de esforços nos núcleos sobre fundações flexíveis. Para a análise discreta, foi utilizado o processo dos deslocamentos com técnicas matriciais, onde o elemento utilizado foi o mesmo proposto por YAGUI (1971).

YOSHIDA (1988), analisa o comportamento do edifício constituído de núcleo de concreto armado e pilares, utilizando a técnica da partição em subestruturas, considerando teoria de $1^{\mathrm{a}}$ ordem.

Com a finalidade de se analisar o efeito da iteração entre pórticos planos, pilares isolados, núcleo resistente e elementos horizontais, BECKER (1989), desenvolveu um programa, onde os núcleos resistentes foram modelados considerando-se a teoria de flexo-torção desenvolvida por VLASSOV (1962) e 
estudos desenvolvidos por HEIDEBRECHT e SWIFT (1971) e SMITH e TARANATH (1972). Os núcleos foram tratados como elementos lineares apresentando sete coordenadas deslocamentos, sendo sua matriz de rigidez determinada a partir do processo dos deslocamentos. Nesta análise foram desprezadas as deformações por força cortante e por momento fletor.

SILVA (1989), utilizando a modelagem para núcleos proposta por YAGUI (1972), desenvolve análise de estruturas tridimensionais formadas por pórticos e núcleos resistentes, levando em consideração a deformação por esforço cortante e também trechos rígidos. A análise da estrutura se faz a partir da consideração dos esforços de $2^{\mathrm{a}}$ ordem, necessitando da utilização de processo iterativo para sua resolução. Este processo consiste basicamente na utilização de um programa de análise em $1^{\text {a }}$ ordem que simula o efeito P- $\Delta$ através de acréscimos de esforços cortantes e torçores fictícios.

MORI (1992), a partir do trabalho desenvolvido por BECKER (1989), introduz a análise em teoria de $2^{\mathrm{a}}$ ordem, procedendo a alteração da matriz de rigidez dos elementos afetada pelos esforços de $2^{\mathrm{a}}$ ordem. As matriz de rigidez dos núcleos resistentes foram determinadas a partir da solução das equações diferenciais, obtidas para um elemento genérico.

Baseando-se também no trabalho desenvolvido por BECKER (1989) e MORI (1992), MATIAS (1997) analisa a interação tridimensional entre núcleos e as estruturas de contraventamento, tais como treliças, pórticos e pilares isolados, considerando a influência das suas fundações no equilíbrio final da estrutura, principalmente quando são introduzidos os efeitos da não linearidade geométrica. Para a automação dos cálculos foram utilizados o processo dos deslocamentos e as técnicas matriciais. As matrizes de rigidez foram determinadas aplicando-se o princípio da energia potencial total mínima. Os efeitos de $2^{\mathrm{a}}$ ordem são considerados através de processo de cálculo iterativo, onde a matriz de rigidez da estrutura tem seus coeficientes afetados pelos esforços normais e no caso dos sistemas com núcleos, além deste, os momentos fletores e os bimomentos.

Procurando comprovar a importante influência que o núcleo resistente exerce na estrutura, PEREIRA (1997) realiza em seu trabalho algumas análises considerando modelos diferentes para o núcleo resistente. Para tanto o autor utiliza 
um programa desenvolvido em elementos finitos, onde o modelo YAGUI (1971) é simulado a partir da associação de barras.

Foi desenvolvido por GUILARDI (1999), um trabalho cujos objetivos principais foram o de analisar estruturas de núcleo resistente, através de processo discreto, eliminando ou amenizando os efeitos provocados pelo aparecimento do momento parasita e a incompatibilidade de giro existente entre a ligação paredelintel.

TORRES (1999), objetivando considerar a deformação pelo esforço cortante nas análises estruturais de edifícios que apresentem núcleo resistente, desenvolve um programa onde o comportamento à flexão dos elementos verticais de contraventamento passa a ser regidos pela teoria de barras de Timoshenko e não mais pela de Euler-Bernoulli. Para tanto são calculados fatores de forma de quaisquer seções transversais abertas de paredes delgadas pertencentes a núcleos estruturais, bem como a distribuição de tensão de cisalhamento na seção transversal em função do esforço cortante atuante.

\section{4 - MÉTODO DOS ELEMENTOS FINITOS}

Este método consiste na discretização da estrutura em elementos de dimensões finitas e reduzidas, a partir do qual há a possibilidade de se expressar matematicamente o comportamento global da estrutura através de sistemas de algébricos. De acordo com SORIANO (2000), este método faz uma divisão do domínio de definição do modelo matemático em um número discreto de subdomínios ou elementos de dimensões finitas, interligados por meio de um número reduzido de pontos nodais.

A utilização do método dos elementos finitos implica no aparecimento de um grande número de parâmetros, mobilizando desta forma, um esforço computacional relativamente grande para o processamento do modelo. O tempo gasto na preparação dos dados é outro fator que contribui para a pouca utilização desta análise em edifícios. $\mathrm{O}$ método também costuma conduzir a alguns erros geralmente cometidos 
durante a discretização dos elementos, integração numérica ou mesmo na solução do sistema de equação.

Alguns trabalhos foram desenvolvidos com o intuito de analisar, comparativamente, os resultados fornecidos pelos processos específicos de estudo e os obtidos à partir do método dos elementos finitos (M.E.F.). A pouca diferença constada entre os resultados, acaba levando à valorização dos resultados obtidos por um processo mais simplificado que os obtidos através do M.E.F.

O núcleo resistente discretizado com elementos de casca, com seis graus de liberdades por ponto nodal, aumentaria muito a matriz de rigidez global da estrutura, pois exigiria que as lajes também fossem discretizadas com elementos de casca para possibilitar a compatibilização dos deslocamentos, e não como elementos de placa, que possuem apenas três graus de liberdade por ponto nodal. Dessa forma, o número de parâmetros de entrada de dados pode inviabilizar o cálculo. Para a resolução deste problema tem-se a necessitando de utilizar um poderoso pré-processador.

ZIENKIEWICS (1971), citado por PEREIRA (1997), utiliza-se desta técnica para modelar uma estrutura de edifício, onde para as paredes adota um elemento plano de tensões, para os lintéis e pórticos elementos de barra e para as lajes elementos de placa. Para a discretização dos núcleos estruturais, desenvolveu um estudo comparativo entre elementos de cascas e elementos de membrana.

Outra modelagem para os núcleos, utilizando esta mesma técnica, foi apresentada por SMITH \& COULL (1991), que consideraram para as paredes do núcleo um elemento finito de membrana. O modelo pode ser analisado através de elementos quadrangulares de membrana com estado plano de tensões em associação com elementos de barra. Os lintéis podem ser discretizados em elementos de membrana ou ainda em elementos de barras, ver figura 03 . 


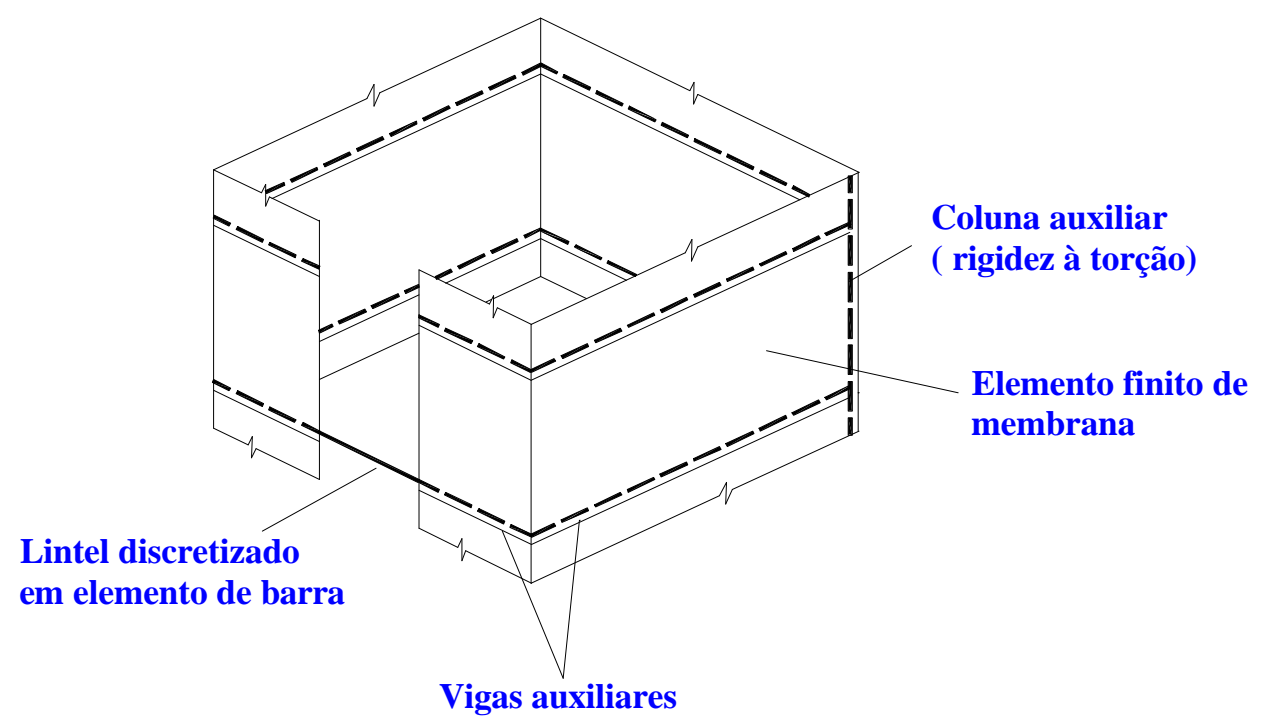

Figura 3 - Elemento finito de membrana de núcleo - SMITH \& COULL (1991)

Com a utilização deste método, tem-se a vantagem de não ser necessário conhecimento específico sobre o efeito do empenamento no núcleo e nem, dependendo da seção transversal, do cálculo das propriedades setoriais da teoria da flexo-torção, muitas vezes complexa.

Um software conhecido que utiliza a técnica de elementos finitos, para a resolução de estruturas, é o Ansys, atualmente encontrado na versão 5.5, e muito utilizado na área de estruturas metálicas e no cálculo de vigas e lajes de pavimentos de edifícios. Este software oferece a possibilidade de se trabalhar com vários elementos diferentes na mesma estrutura, pois possui, em seu banco de dados, uma quantidade variada de elementos geralmente utilizados para a discretização estrutural de pavimentos. A possibilidade de refinamento das malhas de discretização, ou seja, o aumento na quantidade de elementos gerados, é uma outra ferramenta importante fornecida pelo software. 


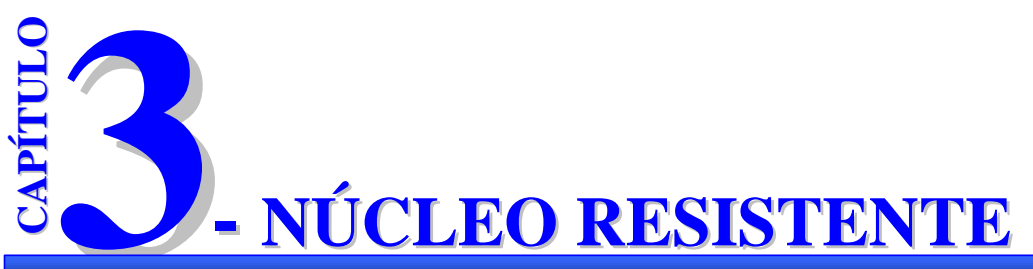

Procure primeiro entender, e só depois ser entendido.

\section{1 - INTRODUÇÃO}

As estruturas de edifícios altos requerem, do projetista e calculista, grandes conhecimentos relacionados à estabilidade estrutural, principalmente no que diz respeito ao controle dos deslocamentos provenientes da ação do vento.

De acordo com ANTUNES, MORI e SOUSA (1995), dentre os vários sistemas de contraventamento existentes, os núcleos estruturais ou resistentes podem ser considerados como essenciais à estruturação dos edifícios de andares múltiplos, pois com o seu acoplamento aos outros sistemas estruturais, consegue-se conferir à estrutura global um razoável acréscimo de rigidez.

PEREIRA (1997), através de análises de resultados obtidos em seu trabalho, conclui que a atuação do núcleo resistente é bastante benéfica para a estrutura de contraventamento, auxiliando na redução das translações dos pavimentos e contribuindo na redução dos esforços internos nos demais componentes da estrutura.

A teoria desenvolvida por VLASSOV(1962), pode ser considerada de grande precisão quando se deseja analisar o comportamento dos núcleos resistentes. No entanto, para a utilização desta análise é necessário que se tenha conhecimento da teoria de flexo-torção, que considera, além dos esforços solicitantes mais conhecidos, a existência de um outro esforço solicitante, o bimomento. A complexidade 
matemática que envolve tal teoria, acaba por desencorajar alguns profissionais na consideração deste esforço atuante na estrutura.

Independente de toda complexidade que a análise considerando o núcleo resistente possa gerar, sua participação no controle dos deslocamentos provocados pela ação do vento é de grande interesse estrutural. Com este mesmo raciocínio, PEREIRA (1997) comenta que, sendo os esforços internos desenvolvidos em cada elemento diretamente proporcional à sua rigidez, a consideração da influência do núcleo resistente na rigidez global da estrutura, leva à obtenção de projetos mais econômicos. Isto ocorre pois com essa consideração é gerado um modelo mais representativo da estrutura, onde as ações externas estarão sendo distribuídas de uma forma mais coerente entre os elementos que a compõem.

\section{2 - CARACTERIZAÇÃO}

Vários autores, assim como MATIAS (1997), denominam de núcleos resistentes ou estruturais os elementos de elevada rigidez, constituído pela associação tridimensional de paredes retas ou curvas, formando seções transversais abertas ou semi-fechadas. Suas dimensões transversais são bem superiores às dos demais elementos que normalmente compõem as estruturas de contraventamento, sendo sua rigidez a flexão responsável por grande parte da resistência global da estrutura.

Estes elementos são usualmente posicionados nas áreas centrais dos edifícios, ou seja, em torno das escadas, elevadores, depósitos ou espaços reservados para a instalação de tubulação hidráulica ou elétrica. Ao nível das lajes apresentam seção parcialmente fechada devido a presença desta ou de lintéis, ver figura 04. 

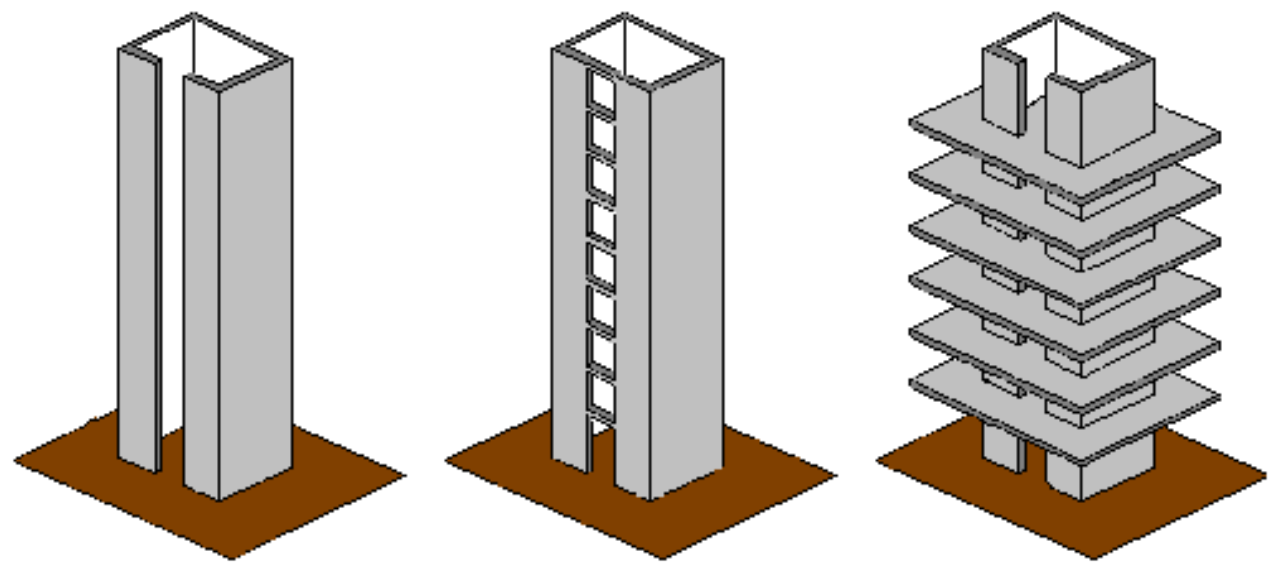

Figura 04 - Classificação dos Núcleos Resistentes - SMITH \& COULL (1991)

De acordo com MATIAS (1997), a característica principal que o distingue dos demais elementos que compõem a estrutura, se encontra na sua capacidade de restrição ao empenamento, que nada mais é que o deslocamento na direção longitudinal da seção causado pela rotação da mesma em torno do centro de torção, como esquematizado na figura 05 .

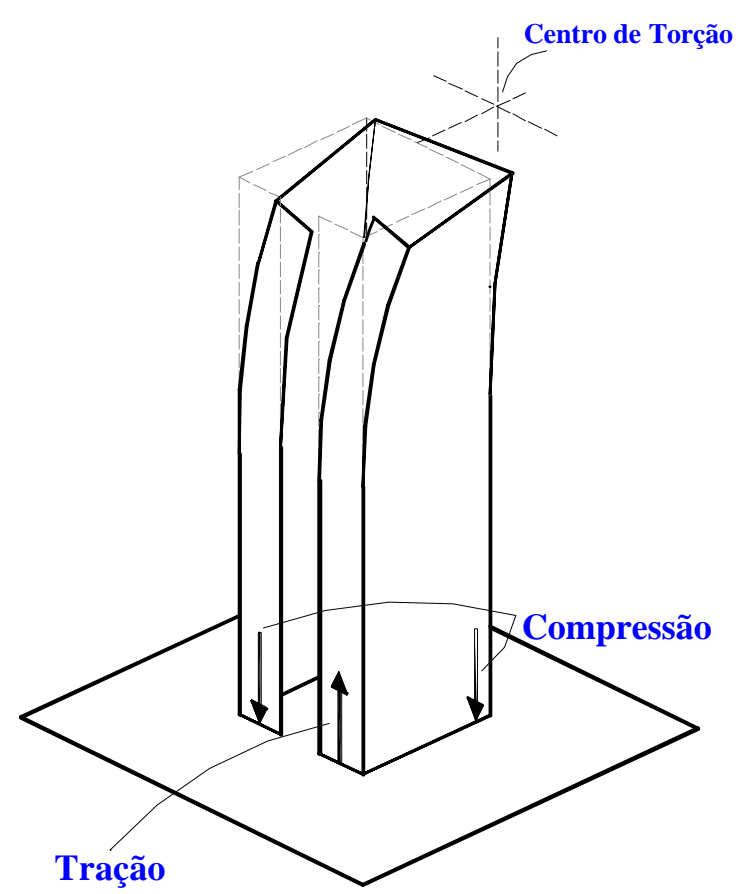

Figura 05 - Empenamento da seção do núcleo - SMITH \& COULL (1991) 
MATIAS e MORI (1997), abordam esse fenômeno do empenamento, como sendo consequência das proporções do núcleo, ou seja, seu comportamento estrutural assemelha-se ao de um perfil delgado que quando submetido à torção faz com que suas seções transversais, originalmente planas, empenem, provocando tensões normais de tração e compressão. O produto destas tensões com a área setorial, integradas na área da seção transversal do núcleo, fornece uma nova grandeza introduzida por VLASSOV (1962) e denominada de bimomento. Esse esforço solicitante desempenha uma função na flexo-torção equivalente ao momento fletor na flexão simples.

As tensões normais suplementares, responsáveis pelo aparecimento do bimomento, surgem em consequência da variação do momento torçor aplicado ao longo de sua altura ou quando existirem vínculos que impeçam total ou parcialmente o empenamento da seção da base, sendo este último característico dos núcleos resistentes.

A presença das vigas, lintéis ou lajes, contribuem com a resistência à flexão para diminuir o empenamento.

Devido a grande rigidez que as lajes apresentam no seu plano, podem ser consideradas como diafragmas rígidos, impedindo as seções transversais, desses sistemas estruturais, de sofrerem qualquer distorção. Como vinculação externa, os núcleos geralmente são considerados engastados na sua base, permitindo assim a absorção de todos os esforços resultantes.

\section{3 - LINTÉIS}

De acordo com YAGUI (1978), os lintéis são as vigas de grande altura relativamente aos seus vãos, encontrando-se geralmente ao nível dos pisos, propiciando um fechamento parcial da seção dos núcleos.

Para as vinculações dos lintéis a consideração de engaste se dará na presença de paredes a eles coplanares. Quando está coplanaridade não ocorrer, os lintéis serão considerados articulados. A condição de engastamento, confere ao núcleo resistente 
um enrijecimento, que quando submetido à esforços de torção, garante também a restrição ao empenamento da seção.

No sistema estrutural equivalente, proposto por YAGUI (1978), os lintéis estarão interligados às extremidades das vigas horizontais e serão considerados engastados ou articulados nessas vigas, de acordo com as condições de transmissão do esforço momento fletor. As condições de restrição são definidas de acordo com a figura 06.

Os lintéis podem influenciar tanto na distribuição dos esforços nas estruturas, como na deformação final do edifício.

Visto que os lintéis auxiliam na resistência à flexão das estruturas, pode-se concluir que estes desempenham um significativo papel na análise estrutural dos edifícios.

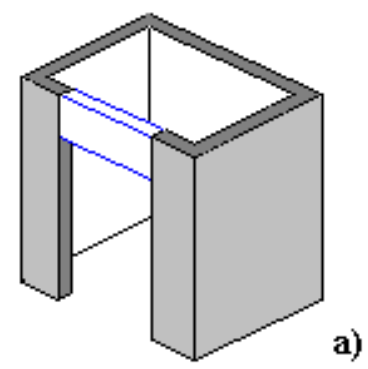

a) engaste-engaste

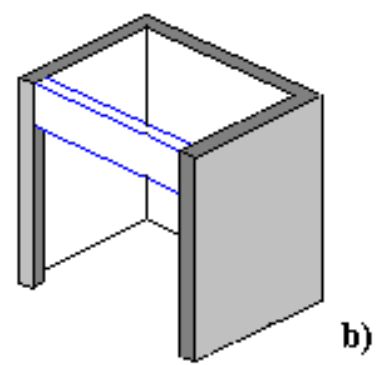

b) articulado-articulado

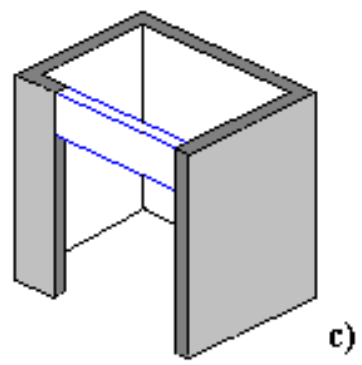

c)engaste-articulado

Figura 06: Condição de restrição do lintéis 


\section{CARACTERÍSTICAS ESTRUTURAIS DOS MODELOS PROPOSTOS PARA O NÚCLEO}

A pessoa não pode existir sem esforço. Os seres humanos não nascem com a alma pré-fabricada; recebem os materiais para construí-la.

J.L.Martin

\section{1 - INTRODUÇÃO}

O processo discreto permite a análise do núcleo resistente através da sua modelagem utilizando elementos de barra ou elementos planos. Os diferentes modelagens, adotadas para o núcleo, poderão ou não levar a comportamentos diferentes quando analisada a mesma estrutura de contraventamento. Esse fator dependerá diretamente das considerações adotadas para cada modelo e do tipo de estrutura a ser processada. Neste trabalho, as estruturas de contraventamento serão estudados utilizando algumas destas diferentes modelagens para o núcleo resistente.

Os modelos selecionados, para a modelagem do núcleo e desenvolvimento das análises comparativas, foram escolhidos com o objetivo de se extrair resultados distintos entre si e com o maior interesse prático possível. Sendo assim, foram adotados os seguintes modelos:

> Modelo proposto por YAGUI (1971);

$>$ Barras de seção delgada sem a consideração do efeito da flexo-torção; 
Barras de seção delgada com a consideração do efeito da flexo-torção, VLASSOV (1962);

Outras análises consideradas de grande interessante serão desenvolvidas com o auxílio dos seguintes modelos:

Modelo proposto por SMITH et al (1981/1984)

$>$ Modelagem utilizando o software Ansys 5.5.

Serão extraídos também resultados para uma estrutura de edifício considerando a seguinte modelagem:

Pilares-paredes tridimensionais isolados

Apesar de se saber que esta modelagem não é considerada adequada para a representação do núcleo, achou-se interessante a apresentação destes resultados principalmente para mostrar, em valores numéricos, as deficiências apresentadas por este modelo.

\section{2 - MODELAGEM POR PILAR PAREDE ISOLADO}

Neste tipo de modelagem, cada parte plana que forma o núcleo resistente é tratada como um pilar isolado, ou seja, nesta modelagem as forças de cisalhamento existentes nas interseções do núcleo não são levadas em consideração.

A não consideração dessas forças cisalhantes, faz com que uma parte da inércia à flexão do núcleo resistente seja desprezada, uma vez que analisa o núcleo discretizado em partes independentes uns dos outros, e não como um único elemento estrutural. 


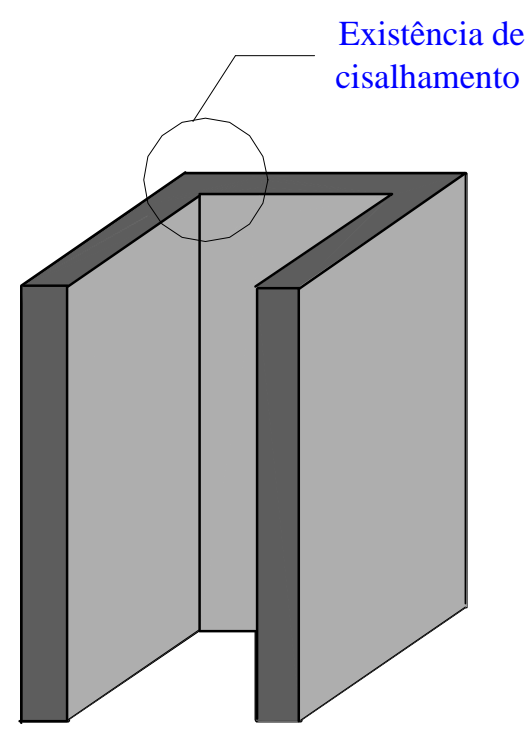

a) Núcleo Resistente

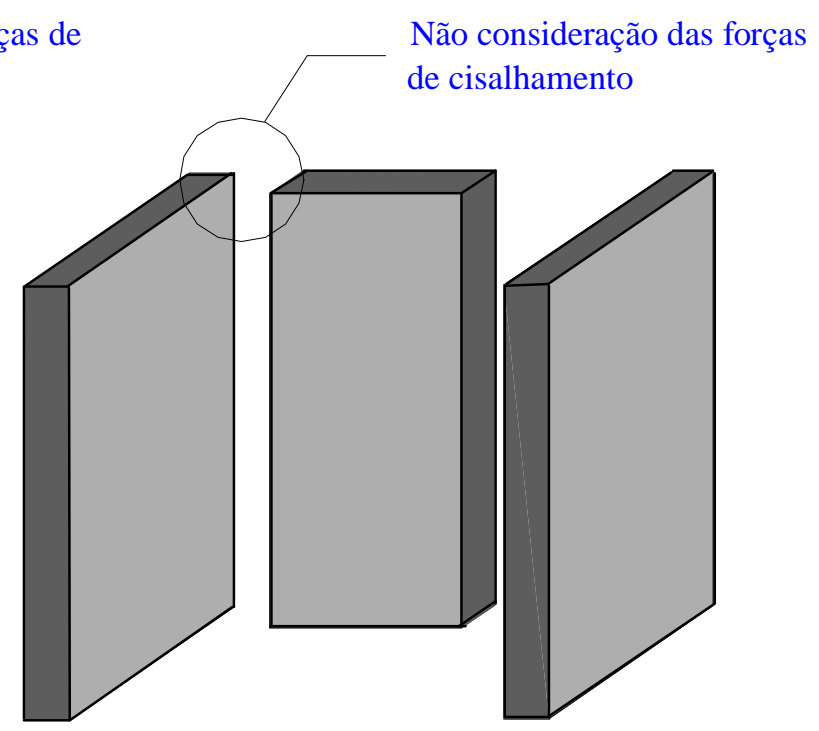

b)Modelagem de paredes isoladas

Figura 07 - Modelagem do núcleo por pilar parede isolado

Esta modelagem, denominada também por alguns autores de processo prático, foi bastante utilizada em escritórios de cálculo estrutural, durante muito tempo. A simplificação dada ao tratamento dos tramos de parede, facilita muita a contribuição do elemento na análise do edifício, sendo esse o principal responsável pela difusão desta modelagem no meio prático.

\subsection{1 - CONSIDERAÇÕES SOBRE A MODELAGEM POR PILAR PAREDE ISOLADO.}

O núcleo resistente, ao ser modelado como um pilar parede isolado, tem os tramos de parede, situados entre duas lajes, substituídos por elementos de barras tridimensionais com seis coordenadas deslocamento por extremidade, ver figura 08. 


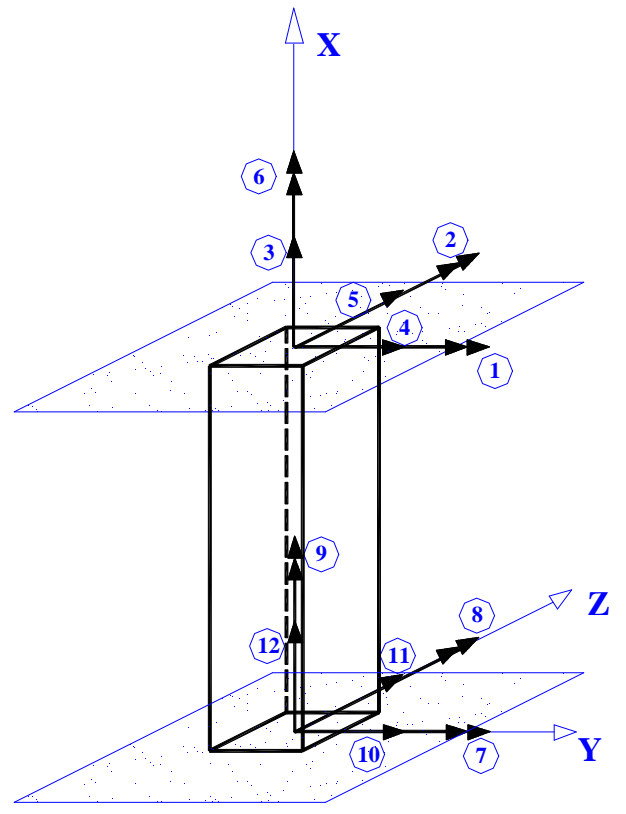

Figura 08 - Coordenadas deslocamentos para o elemento de pilar parede isolado MATIAS (1997)

Os esforços internos considerados atuantes na seção de cada elemento serão: dois momentos fletores na direção dos eixos principais de inércia, duas forças cortantes, uma força axial e um momento torçor.

MATIAS (1997), utiliza em seu trabalho um elemento que reúne todas as características e considerações necessárias ao desenvolvimento desta modelagem, denominando-o de ELM-04. Portanto, para simulação do comportamento do núcleo resistente, a partir desta modelagem, será utilizado este elemento.

\section{3 - BARRA DE SEÇÃo DELGADA COM A CONSIDERAÇÃo DA TEORIA DA FLEXO-TORÇÃO}

Por apresentarem um comportamento distinto, as estruturas constituídas de paredes delgadas necessitam de análises mais particularizadas. Tais análises implicam no conhecimento da teoria desenvolvida por VLASSOV (1962), utilizada para o tratamento de barras longas de seção delgada. 
Essa teoria considera a presença de um novo esforço solicitante denominado de bimomento. Esse esforço é responsável pelo aparecimento de tensões normais suplementares às causadas pela força normal e momentos fletores nas seções transversais.

De acordo com a modelagem proposta e as características geométricas do núcleo, a teoria de barras longas de seção delgada, desenvolvida por VLASSOV (1962), será adotada nesta modelagem e utilizada na simulação do comportamento do núcleo resistente.

O núcleo será modelado com um comportamento tridimensional, onde a deformação por esforço cortante não será considerada. Estudos que levam em conta o efeito da deformação por esse esforço, nas paredes do núcleo, foram desenvolvidos por diversos autores. Entre eles podemos citar TORRES (1997), que analisa a influência desta consideração nos elementos componentes das estruturas contraventamento de edifícios (pilares, vigas e núcleo).

As análises serão desenvolvidas considerando as coordenadas, do elemento de núcleo, localizadas no centro de cisalhamento da seção.

Esta consideração é tida como um dos inconvenientes do processo, pois para alguns tipos de seções de núcleo, a determinação da posição do centro de cisalhamento pode ser trabalhosa. Porém, o programa utilizado no processamento das estruturas de edifícios, deste trabalho, já possui em sua estrutura rotina capaz de determinar automaticamente o centro de cisalhamento para qualquer tipo de seção transversal de núcleo, possibilitando assim a análise de núcleos estruturais com as mais diversas formas. 


\subsection{1 - CONSIDERAÇÕES SOBRE A MODELAGEM DE BARRAS DE SEÇÃO DELGADA CONSIDERANDO A TEORIA DE FLEXO-TORÇÃO.}

Esta modelagem trata o tramo de núcleo, compreendido entre duas lajes, como um elemento de barra tridimensional, com sete coordenadas deslocamentos por nó. Estas coordenadas deslocamentos são apresentadas na figura 09, através da discretização do elemento elástico de barra formulado por TARANATH (1968). Para este elemento é considerado o efeito do empenamento da seção transversal no seu comportamento estrutural.

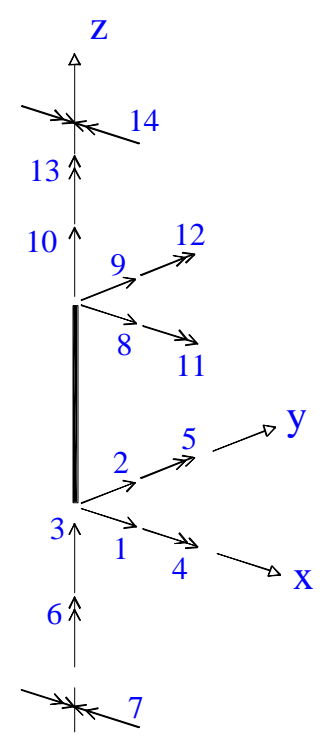

Figura 09 - Elemento de discretização utilizado por TARANATH.

Este elemento, além dos seis esforços internos relativos aos dois momentos fletores, às duas forças cortantes, à uma força axial e à um momento torçor, considera também um sétimo esforço relativo ao empenamento, denominado de bimomento.

MATIAS (1997) considerando em seu trabalho este tipo de modelagem para o núcleo resistente, desenvolve estudos e utiliza um elemento contendo todas estas características. Este elemento, denominando por MATIAS (1997) de ELM-05, será 
utilizado na modelagem proposta neste item. O elemento especificado possui as catorze coordenadas deslocamento, sete por extremidade, sendo seis relacionadas aos deslocamentos do comportamento tridimensional e a sétima derivada da rotação em torno do eixo $\mathrm{X}$, cuja direção do eixo está de acordo com a figura 10 . Todas as coordenadas, em sentido positivo, são apresentadas na figura 10.

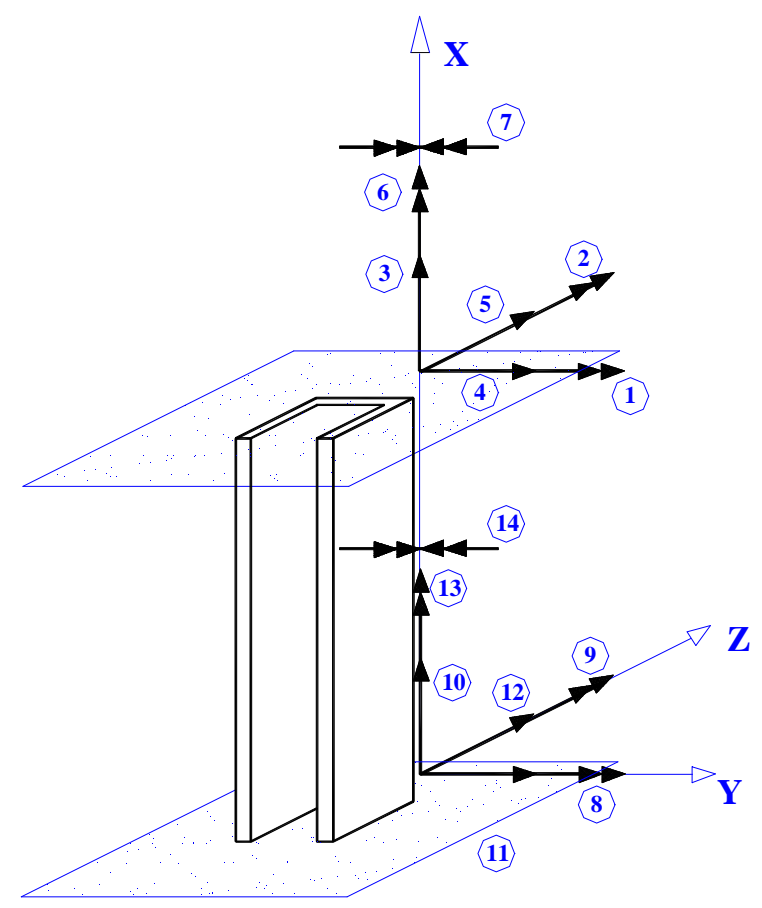

Figura 10 - Coordenadas deslocamento do elemento de núcleo - MATIAS (1997).

Este elemento de núcleo, apesar de possuir um comportamento semelhante aos membros verticais de pórtico espacial (ELM-04), ao levar em conta as propriedades setoriais da sua seção transversal, acaba por dotá-lo de uma rigidez ao empenamento. Essa rigidez é a responsável pelo aparecimento do esforço interno bimomento.

De acordo com estas características, este elemento é capaz de simular muito bem o comportamento estrutural dos núcleos resistentes, bem como dos pilares cujas seções transversais possuam propriedades setoriais. 


\section{4 - BARRA DE SEÇÃO DELGADA SEM A CONSIDERAÇÃO DA TEORIA DA FLEXO-TORÇÃO}

Para o desenvolvimento desta modelagem, não serão utilizados os conceitos relativos à teoria de flexo-torção, ou seja, na análise do comportamento do núcleo, não será levado em conta o efeito do empenamento da seção transversal. Este processo pode ser considerado como uma simplificação do processo anterior onde o esforço bimomento não é levado em conta.

Esta modelagem, denominado por alguns autores de processo simplificado, considera o tramo de núcleo, entre duas lajes, como um elemento de barra tridimensional com seis graus de liberdade por extremidade localizados no centro de torção da seção do núcleo e com rigidez equivalente, ver figura 11.

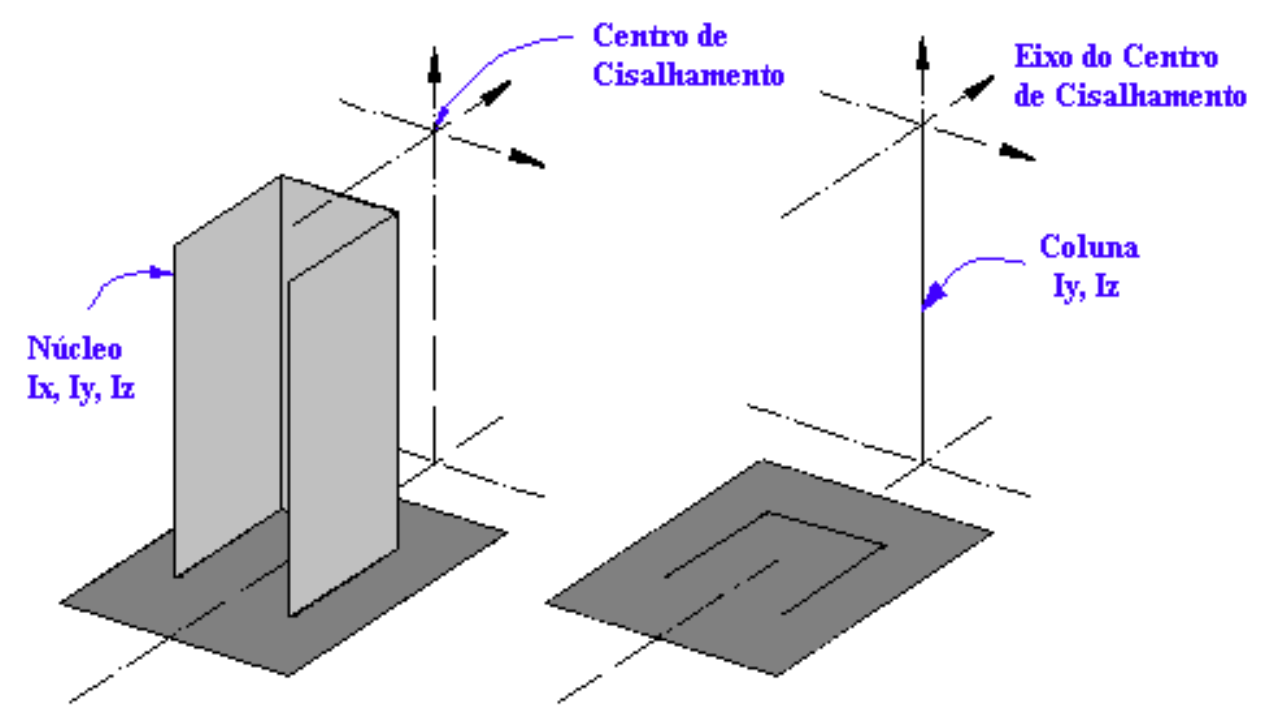

Figura 11 - Modelagem do núcleo resistente - eixo no centro de cisalhamento

PEREIRA (1997), tendo executado algumas análises utilizando essa modelagem, comenta sobre a impossibilidade, do processo em questão, de fornecer bom desempenho no comportamento do núcleo diante da torção, bem como a existência de outros inconvenientes que podem ocorrer pela utilização dessa modelagem. A dificuldade de modelar as vigas que se conectam ao núcleo estrutural, 
de acordo com PEREIRA (1997), é o mais grave problema encontrado ao se utilizar essa modelagem. O programa utilizado neste trabalho permite a modelagem destas vigas através da translação das suas rigidezes para as respectivas coordenadas do núcleo na qual são incidentes. Sendo assim, este fato atualmente não mais representa um problema na análise estrutural.

A determinação do centro de cisalhamento da seção do núcleo, também nesta modelagem, poderia ser considerada um inconveniente para a resolução estrutural.

\subsection{1 - CONSIDERAÇÕES SOBRE A MODELAGEM DE BARRAS DE SEÇÃO DELGADA SEM A CONSIDERAÇÃO DA TEORIA DE FLEXO- TORÇÃO.}

Para esta modelagem o tramo de núcleo resistente será modelado como um elemento tridimensional com doze graus de liberdade, sendo seis graus de liberdade por extremidade, ver figura 12. O elemento será o mesmo adotado na análise do núcleo como pilar parede isolado.

Nesta modelagem toda a seção do núcleo será considerada e a análise desenvolvida para um pilar de seção qualquer, onde as características geométricas dessa seção serão consideradas na elaboração da matriz de rigidez do elemento.

Para esse elemento, compreendido entre dois diafragmas os esforços internos considerados serão os mesmos determinados na modelagem por pilar parede isolado: dois momentos fletores contidos no plano principal de inércia, duas forças cortantes, uma força axial e um momento torçor. Portanto este elemento simula o comportamento estrutural dos membros verticais dos pórticos espaciais. 


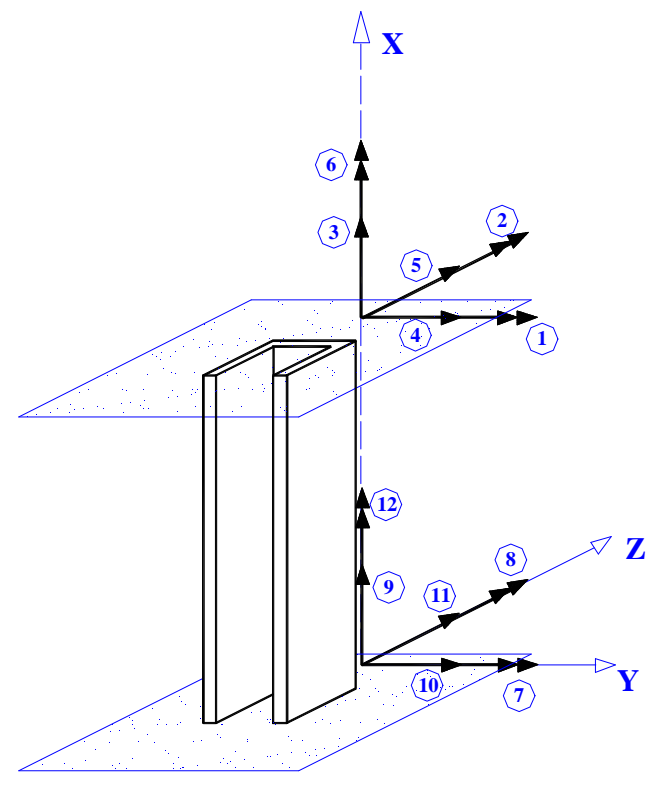

Figura 12 - Coordenadas deslocamento do elemento de núcleo

\section{5 - MODELAGEM PELO MÉTODO DOS ELEMENTOS FINITOS}

A análise das estruturas vem recebendo uma grande contribuição decorrente do avanço tecnológico em desenvolvimento na área de informática. Um exemplo disto está na utilização do M.E.F., que durante muito tempo ficou limitada apenas à alguns tipos de análises, e hoje é amplamente utilizado no processamento das mais diversas estruturas. Grande parte desse avanço foi possível graças à ampliação das capacidades computacionais existentes.

A maior dificuldade encontrada com a utilização do M.E.F. está na confecção do modelo discreto. Para este tipo de método é necessário que se tenha um bom pré e pós-processador de dados. Esse método pode, ainda, demandar um grande esforço computacional, o que poderia acabar inviabilizando a sua utilização. Porém, na atualidade, já existem diversos softwares no mercado, voltados para o tratamento das estruturas, que utilizam o M.E.F. 
Para o desenvolvimento das análises propostas, o software Ansys, foi utilizado como ferramenta no processamento das estruturas de contraventamento que compõem os edifícios altos.

Os elementos estruturais que compõem os edifícios foram modelados utilizando elementos de discretização específicos fornecidos pelo software. Dentre tais elementos podem ser citados os elementos de chapa, os elementos de viga, os elementos de placa e os elementos de barra.

Estudos desenvolvidos, com a finalidade de se adquirir conhecimentos nesta área, levaram à constatação da pouca utilização deste software no tratamento de estruturas de edifícios de andares múltiplos. Inúmeros trabalhos foram desenvolvidos na área de estruturas metálicas e na discretização de lajes, vigas de pavimentos e até mesmo o processamento de paredes, sendo ainda poucos os trabalhos envolvendo o processamento de toda a estrutura do edifício. As dificuldades encontradas na geração, processamento e análises da estrutura de edifício utilizando este software vêm confirmar os motivos que o tornam pouco utilizado no processamento de edifícios de andares múltiplos.

De acordo com as características apresentadas pelo método serão utilizados exemplos de estruturas mais simplificadas, procurando garantir, com isso, a validade dos resultados adquiridos, uma vez que diminuem-se os erros decorrentes da modelagem e processamento.

A discretização dos elementos componentes da estrutura obedeceram a seguinte classificação:

- Para as vigas e pilares foi utilizado o elemento beam4, que possui seis graus de liberdade, simulando um elemento vertical de pórtico espacial.

- Para as lajes e o núcleo foi utilizado o elemento shell63, que também possui seis graus de liberdade por nó. A esquematização deste elemento pode ser visualizada na figura 13. 


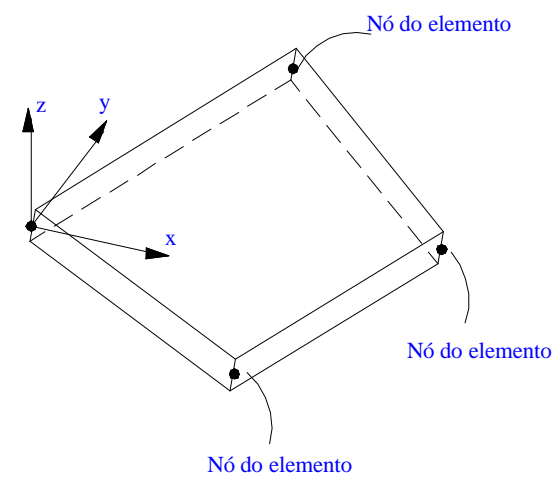

Figura 13 - Elemento de Placa SHELL63 - Software ANSYS 5.5

\section{6 - MODELO PROPOSTO POR YAGUI}

Esta modelagem, proposta por YAGUI (1971), é um tipo de processo alternativo que possibilita a análise das estruturas delgadas, a partir da utilização de técnicas matriciais.

YAGUI (1971) diz que nesta modelagem, para efeito de cálculo, as paredes planas, são substituídas por um conjunto de vigas horizontais, com suas extremidades em balanço e engastada ao meio em pilares verticais. Sendo assim, o modelo permite a análise de estruturas tridimensionais a partir da substituição das paredes de núcleos por pórticos equivalentes, esquematizados na figura 14.

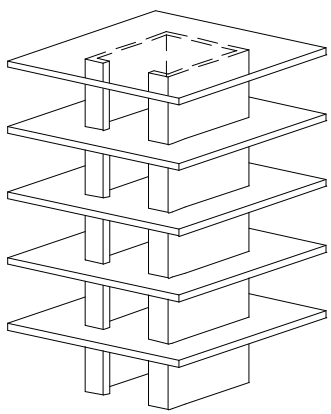

a) Núcleo resistente

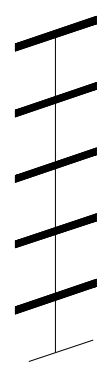

b) Segmentode paredePórtico plano equivalente

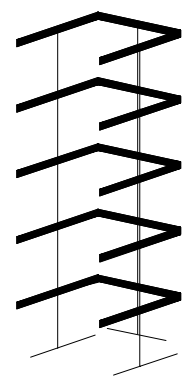

c)Associação de pórticos

Figura 14 - Modelagem estrutural do núcleo - Elemento YAGUI (1971) 
Estruturalmente o elemento é idealizado da seguinte forma:

> Para as vigas é considerada uma rigidez infinita à flexão, no plano da parede em que se situam, pois esta possui deformações axiais que variam linearmente ao longo de suas seções transversais;

$>$ As lajes são consideradas como diafragmas rígidos, impedindo as distorções das seções transversais do núcleo;

$>$ As vigas estão sempre dispostas aos níveis dos diafragmas;

$>\mathrm{O}$ comprimento dos pilares será igual ao afastamento entre diafragmas e conservando todas as características elásticas e geométricas do segmento de parede que substitui;

A rigidez à força normal, à flexão, à torção e à força cortante, de um tramo de pilar, são correspondentes às da parede substituída;

$>$ O sistema contínuo, constituído por paredes planas, fica substituído pelo sistema discreto de pórticos de um único pilar e vigas em balanço;

$>$ As interações entre os painéis, ao longo das suas intersecções, ficam representadas pelas ações verticais entre vigas concorrentes. Portanto as únicas interações a serem consideradas entre estes painéis são as forças de cisalhamento longitudinais.

De acordo com as características deste modelo a variação da espessura das paredes entre pavimentos e a sua descontinuidade poderão ser consideradas nesta modelagem.

Com a utilização desta modelagem de núcleo no processamento de estruturas, considerando a contribuição conjunta do elemento de núcleo e demais elementos estruturais existentes, foi constatada a dificuldade da modelagem das vigas que por ventura se apóiem no núcleo. Ao menos não é possível a utilização do processo de translação da rigidez da viga para as coordenadas do núcleo, uma vez que existe incompatibilidade entre ambas. 


\subsection{1 -CONSIDERAÇÕES SOBRE O MODELO PROPOSTO POR YAGUI}

SERRA (1994), tendo desenvolvido seu trabalho a partir do modelo YAGUI (1971), faz alguns comentários sobre essa modelagem, relacionando o comportamento estrutural do núcleo, diante das ações incidentes na estrutura, com as características deste modelo. Alguns destes comentários são apresentados a seguir.

Como já citado anteriormente, os elementos de parede, situados entre dois diafragmas, são formados por duas vigas de rigidez infinita engastadas à uma coluna central. Na figura 15 é apresentado esse elemento e seus oito graus de liberdade.
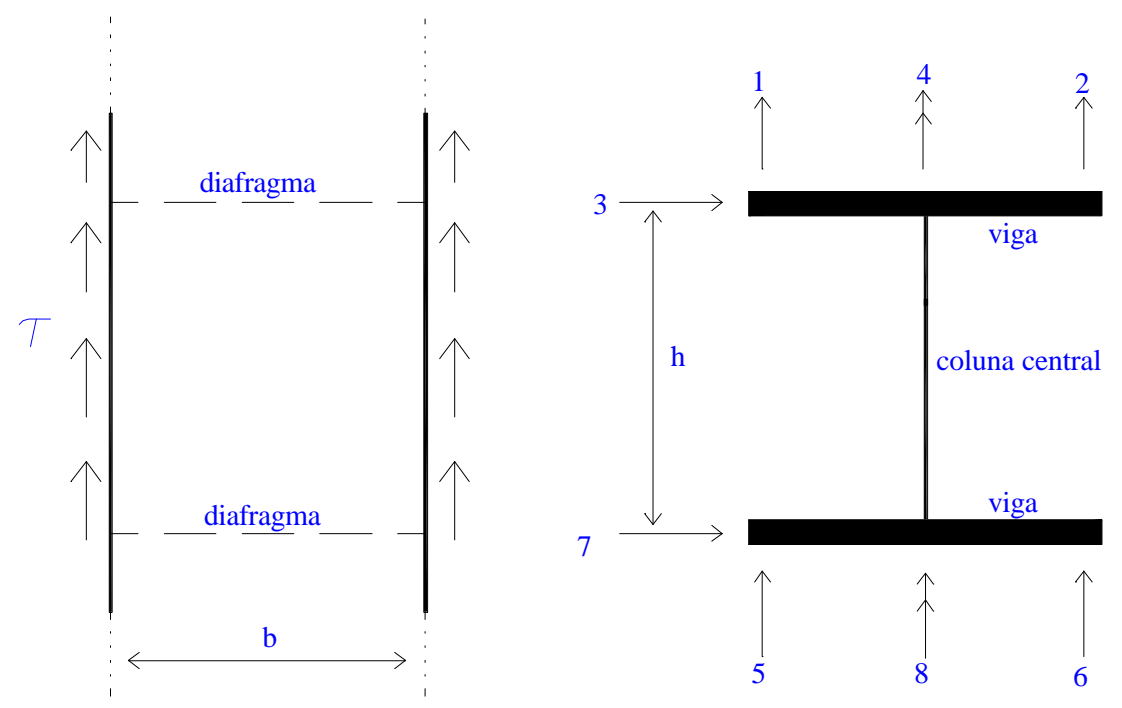

Figura 15 - Elemento de parede do núcleo resistente.

Os deslocamentos são divididos em, dois horizontais, quatro verticais e dois de rotação. As coordenadas deslocamento 4 e 8 são responsáveis pela consideração da rigidez a torção da coluna. As coordenadas 112 e 516 procuram concentrar os cortantes que ocorrem à meia altura dos andares adjacentes.

A contribuição dos lintéis, quando existirem, será considerada a partir da sua ligação com as extremidades dos elementos de parede adjacentes. Estes lintéis serão considerados como elementos de barra, e que devido a presença das lajes, consideradas como diafragmas rígidos, terão rigidez axial infinita, necessitando, para 
a sua representação, de coordenadas deslocamentos que dependerão da sua ligação com os painéis. A figura 16 ilustra o elemento de lintel e suas coordenadas deslocamento.

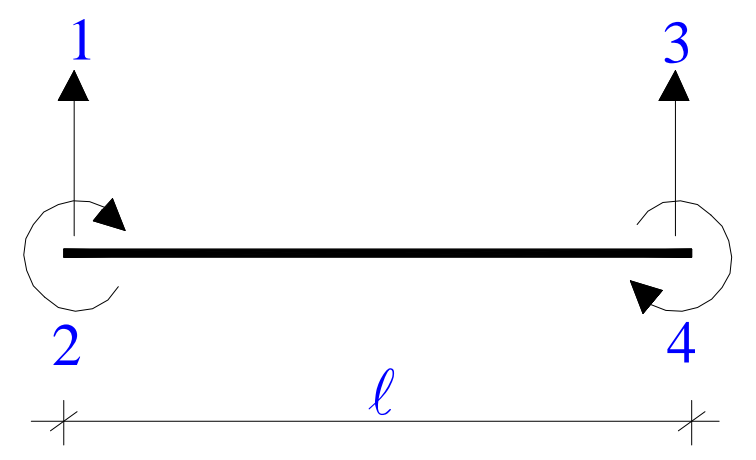

Figura 16 - Coordenadas dos lintéis e vinculações

Os núcleos resistentes, devido às suas características estruturais, comportamse como estruturas de paredes delgadas, que com a presença dos lintéis passam a apresentar seções parcialmente fechadas. A presença dessas vigas (lintéis), diante dos vários tipos de esforços, é capaz de produzir um substancial fluxo de tensões de cisalhamento ao redor do núcleo. A consideração das deformações por cisalhamento, na análise da estrutura, diante da presença dos lintéis, é de grande importância e no modelo YAGUI considerada através da coluna central.

Para se preservar a compatibilidade de deslocamentos entre as ligações parede-lintel e a perpendicularidade existente entre elas, a deformação por cortante nos lintéis não poderá ser considerada. Sendo assim, as coordenadas rotações dos lintéis deverão corresponder aos giros das fibras horizontais do elemento de parede aos níveis dos diafragmas, ver esquema na figura 17. 


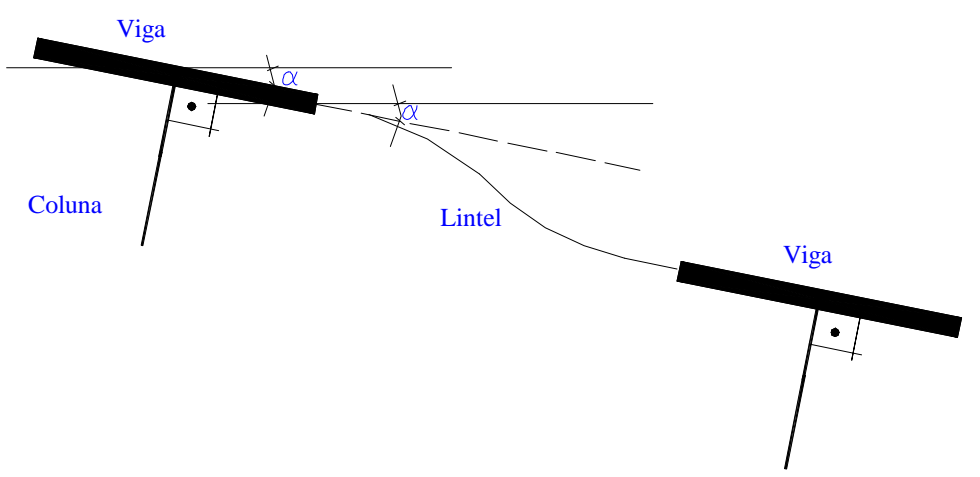

Figura 17 - Ligação entre a parede e o lintel

SERRA(1994), diante de estudos desenvolvidos durante seu trabalho e procurando a obtenção de melhores resultados, propõem duas alterações para a utilização do modelo proposto por YAGUI.

A primeira alteração inside sobre a consideração do fator de forma, cujo valor mais utilizado é calculado através da Teoria da Elasticidade, valendo:

$$
c=\frac{1,2+1,1 v}{1+v}
$$

Onde $v$ é o coeficiente de Poisson do material.

De acordo com SERRA (1994), sendo este coeficiente de forma utilizado para o caso de vigas onde a tensão de cisalhamento é nula nas bordas, a sua adoção, para o caso de núcleos resistentes, não se justifica, uma vez que para este elemento isto não ocorre dessa maneira. Nem mesmo nos casos de núcleos resistentes abertos, onde em uma das bordas das paredes periféricas a tensão de cisalhamento é nula, a adoção desse coeficiente não é justificada. Assim, SERRA (1994) adota para esse coeficiente de forma, no caso de núcleos resistentes, valor unitário.

Outra alteração que se julgou necessária, está na consideração mais criteriosa da rigidez à torção das paredes. De acordo com TIMOSHENKO (1963), a constante de torção para as barras prismáticas de seção retangular de dimensões b.t vale, nos casos de $\mathrm{b}>1,2 \mathrm{t}$ : 


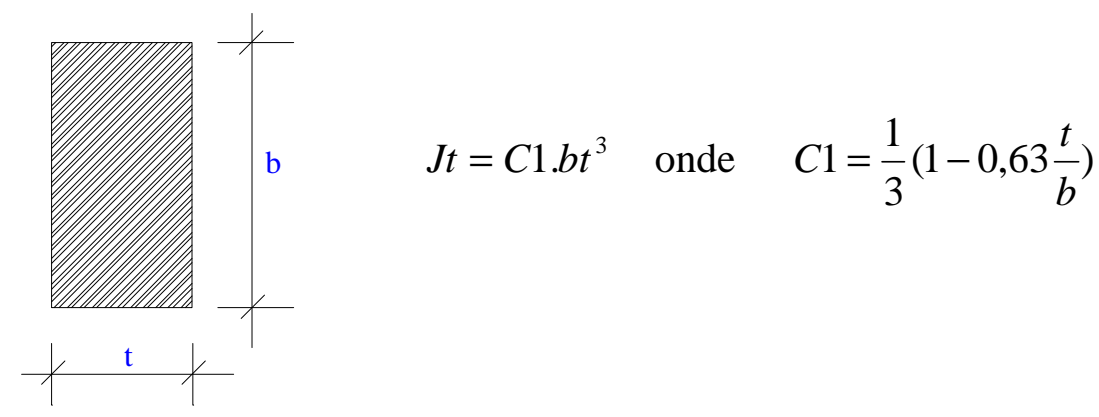

Sendo bastante comum núcleos estruturais formados por paredes com relação largura/espessura inferior a 10, a utilização do coeficiente dado por (2), de acordo com SERRA (1994), se faz justificada.

\subsection{2 -COMPOSIÇÃO DA ESTRUTURA E DESLOCAMENTO DO SISTEMA}

Para a ilustração do sistema de coordenadas, será considerado o núcleo típico apresentado na figura 18. As coordenadas deslocamento do núcleo ilustrado apresentam ordem numérica diferentes da adotada por SERRA (1994). Além desta, algumas outras alterações também foram realizadas, objetivando a adequação do modelo proposto por YAGUI ao processo de automação de cálculo utilizado pelo programa desenvolvido.

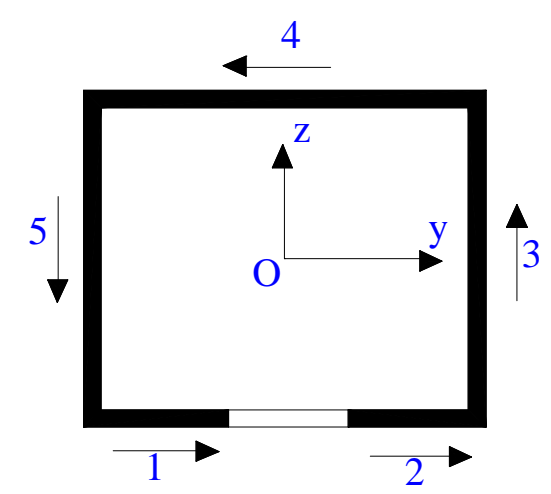

a) planta típica, numeração e orientação dos painéis.

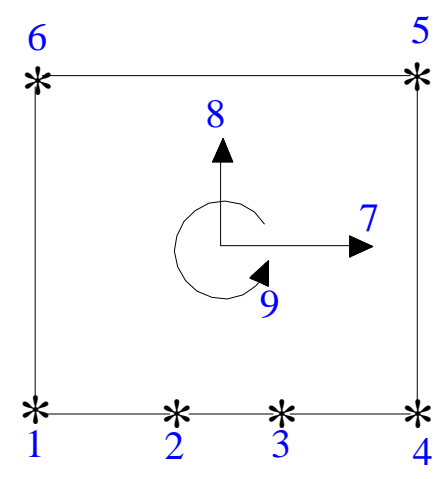

b) coordenadas. (* indica coord. vertical)

Figura 18 - Planta típica e Coordenadas de um Núcleo - SERRA(1994) 
A associação desses painéis, em diversos arranjos, é responsável pela formação dos núcleos resistentes. De acordo com a figura 18(a), os painéis são numerados sequencialmente e orientados arbitrariamente, assim como os lintéis, devendo sempre ser observados da esquerda para direita. Com a automação dos cálculos, os seguimentos de núcleos serão orientados de acordo com a ordem numérica dos pontos, sobre o núcleo, fornecidos na entrada de dados.

Adotando-se um ponto $\mathrm{O}$ no plano da base, fica então definida a origem do sistema cartesiano ortogonal xyz, com os eixos y e $\mathrm{z}$ no plano e o eixo x orientado verticalmente da base para o topo.

De acordo com a figura 18(b), as coordenadas deslocamento lineares 7 e 8 , são definidas paralelas aos eixos coordenados y e $\mathrm{z}$, respectivamente e a coordenada deslocamento angular 9 paralela e no sentido do eixo x. Em todas as extremidades ou intersecções dos painéis serão adotadas coordenadas verticais, positivas no sentido de Ox.

Analogamente, para todos os outros diafragmas, será definido igual número de coordenadas calculado da seguinte forma:

$$
\begin{aligned}
& n d=3+n j \\
& n d=\text { número de coordenadas por diafragma } \\
& n j=\text { número de extremidades ou interseções dos painéis (pontos nodais de } \\
& \text { extremidade) }
\end{aligned}
$$

Cabe salientar aqui que as análises que procedem neste capítulo consideram apenas a presença do núcleo como elemento resistente da estrutura, o que facilita a explanação teórica. Porém, para as análises estruturais que serão efetuadas posteriormente, além do elemento de núcleo serão consideradas também a presença dos demais elementos componentes da estrutura de contraventamento.

De acordo com a técnica de cálculo utilizada neste trabalho, serão sempre analisados sistemas formados pelo conjunto de coordenadas compreendidas entre dois diafragmas, denominado de subestrutura. Tal consideração resulta em um número de coordenadas deslocamento igual a: 


$$
\begin{aligned}
& n c=2 * n d \\
& n c=\text { número de coordenadas da subestrutura. }
\end{aligned}
$$

Em uma abordagem matricial tem-se para os sistema da figura 18, chamandose de Oj o ponto de intersecção do eixo Ox com o diafragma j, as nd coordenadas do sistema para esse diafragma:

$\mathrm{v}_{\mathrm{j} 1}, \mathrm{v}_{\mathrm{j} 2}, \ldots \ldots, \mathrm{v}_{\mathrm{jnd}-3}$ - Deslocamento verticais dos nj nós da estrutura ao nível do diafragma $\mathrm{j}$ (positivo para cima)

$\mathrm{V}_{\text {jnd-2 }}$ - Deslocamento de Oj, na direção do eixo Oy.

Vjnd-1 - Deslocamento de Oj, na direção do eixo Oz.

$\mathrm{V}_{\text {jnd }}$ - Rotação do diafragma j em torno do eixo Ox (positivo se anti-horário).

O vetor deslocamento do sistema ao nível do diafragma j, fica:

$$
V_{j}=\left\{\begin{array}{c}
v_{j 1} \\
v_{j 2} \\
\cdots \\
v_{j n d}
\end{array}\right\}_{n d}
$$

Para o sistema utilizado no processo de cálculo adotado, o vetor deslocamento do sistema $\mathrm{V}$, subestrutura tipo, será:

$$
V=\left\{\begin{array}{c}
v_{1} \\
v_{2} \\
\cdots \\
v_{n c}
\end{array}\right\}_{n c} .
$$

$\mathrm{O}$ vetor deslocamento $V$ contém todas as coordenadas deslocamento de ambos os diafragmas, sendo armazenadas inicialmente as coordenadas do diafragma superior seguidas das coordenadas do diafragma inferior. 


\section{7 - MODELO PROPOSTO POR SMITH et al}

\subsection{1 - PROBLEMAS GERADOS POR MODELOS DISCRETOS}

A partir do final do anos 70 e início dos anos 80, pesquisadores como SMITH et al (1981/1984) perceberam que com a utilização dos métodos discretos convencionais, quando as paredes eram sujeitas a tensões de cisalhamento puro, estes eram afetados por um momento inexistente fisicamente. Este momento foi denominado de momento parasita.

Este fenômeno pode ser facilmente compreendido ao se analisar duas paredes que, sujeitas a um estado de cisalhamento puro, produzem entre elas tensões de cisalhamento distribuídas uniformemente ao longo das duas faces, ver figura 19 a). No processo de discretização das paredes, utilizado pelo modelo, a face contínua que une duas paredes é substituída por dois nós, e as tensões de cisalhamento representadas por duas forças concentradas nestes nós. Estas tensões são responsáveis pelo aparecimento de um momento na coluna central que realmente não deveria existir, uma vez que a peça está sujeita apenas ao estado de cisalhamento puro. Este comportamento pode ser melhor visualizado na figura $19 \mathrm{~b}$ ).

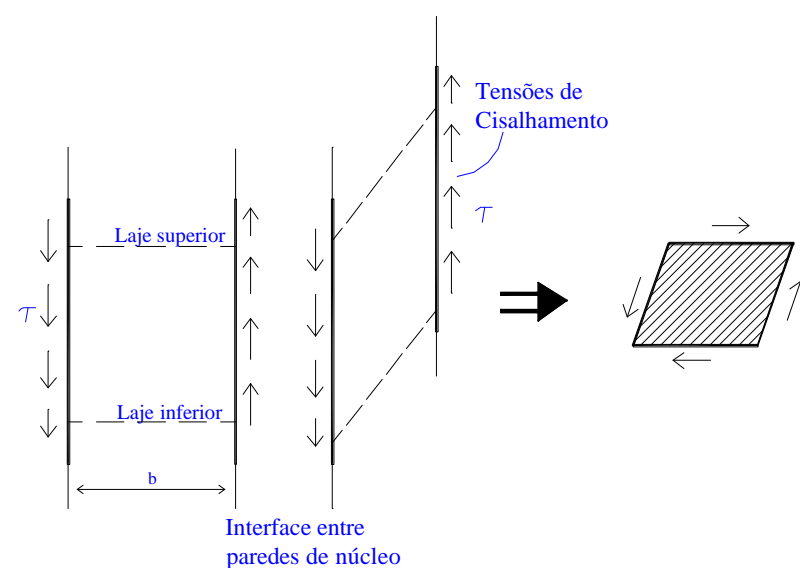

a)

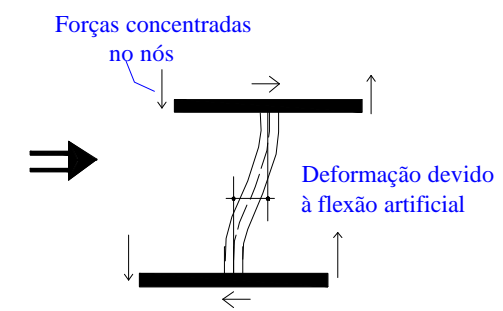

b)

Figura 19 - Momento parasita no elemento de parede 
Com base nestas informações, pode-se afirmar que a rigidez determinada pelo modelo não corresponde à rigidez real da parede, pois aquele momento provoca uma deformação de flexão adicional na coluna, levando a uma diminuição da rigidez ao cisalhamento do modelo.

É importante salientar que embora o exemplo citado esteja sujeito ao estado de cisalhamento puro, este problema será constatado sempre que existirem tensões de cisalhamento. Isto porque, o problema é uma consequência, única e exclusiva, da discretização da interface das paredes, cujos infinitos pontos estão sendo substituídos por dois nós.

No caso de um núcleo parcialmente fechado sujeito a esforços de torção, este problema exercerá uma importante influência sobre o comportamento da estrutura devido à presença de substanciais forças cortantes.

GUILARDI (1999), apresenta em seu trabalho uma análise de resultados discretizando uma estrutura de núcleo, ver figura 20, considerando para cada processamento, um e dois elementos por andar. O objetivo destas análises foi o de quantificar o efeito do referido momento no comportamento do núcleo resistente. Para a rotação foi obtido, no caso de um elemento por andar, resultado $16 \%$ maior que o obtido para o caso de dois elementos por andar. De acordo com GUILARDI (1999), este resultado já era esperado, pois quanto maior a discretização vertical menor o efeito do momento parasita, responsável pela perda de rigidez do núcleo.
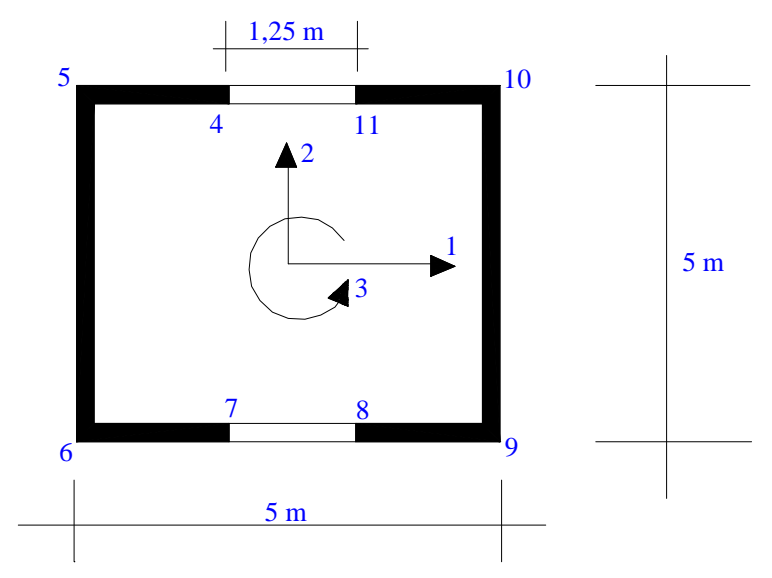

\section{Dados da Estrutura:}

10 andares

$\mathrm{E}=3 \times 10^{\wedge} 4 \mathrm{MPa}$

Poisson $=0,2$

Carga aplicada:

Momento torçor no topo $=10 \mathrm{kN} \cdot \mathrm{m}$

Figura 20 - Núcleo resistente sujeito à forças de torção - GUILARDI (1999) 
Para este exemplo foram consideradas apenas as ações de torção, que mal interpretadas poderiam levar à condenação do modelo. Tal interpretação seria exagerada, pois certamente o núcleo estará sujeito a outras ações solicitantes, transformando as ações de torção em apenas uma fração da solicitação geral.

\subsection{2 - MODELOS PROPOSTOS PARA CORREÇÃO}

Na figura 21, são ilustrados alguns dos modelos propostos por SMITH et al (1981/1984), a fim de suprimir a deficiência apontada.

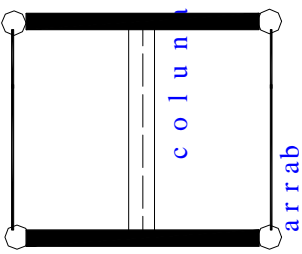

a)

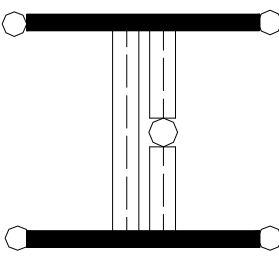

b)

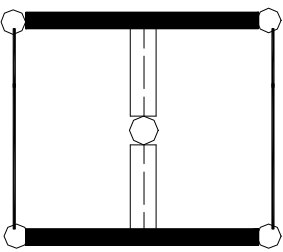

c)

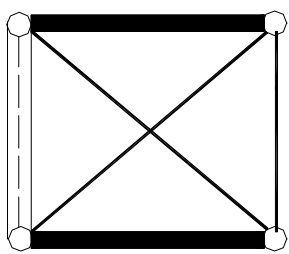

d)

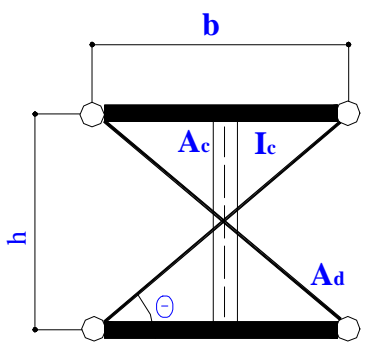

e)

Figura 21 - Modelos propostos por SMITH et al - GUILARDI (1999)

Como o sistema de coordenadas e as hipóteses adotadas para a determinação das características dos modelos propostos são os mesmos, todos estes modelos, se tratados como um único elemento, terão as mesmas matrizes de rigidez. 
Nos trabalhos desenvolvidos por SMITH et al (1981/1984), o elemento não foi tratado como único, mas sim formado por um conjunto de várias barras e nós, levando à obtenção de resultados diferentes entre os diferentes modelos propostos. Neste caso, as características, posições, número de barras e número de nós não são iguais para todos os modelos, conduzindo a resultados não exatamente iguais.

Segundo SMITH e GIRGIS ( 1981 ), os modelos da figura 21 d) e e) forneceram os melhores resultados, dando-se preferência ao da figura $21 \mathrm{~d}$ ), que por apresentar uma barra e dois nós a menos diminuiria o número de graus de liberdade da estrutura e facilitaria em muito o fornecimento dos dados.

No trabalho desenvolvido por GUILARDI (1999) o modelo, utilizado para discretizar as paredes e núcleos, foi tratado como um único elemento. Sabendo que as matrizes de rigidez são idênticas caso os modelos sejam tratados desta forma, GUILARDI (1999) adotou o modelo da figura 21 e). Este elemento por apresentar simetria e relativa similaridade com os modelos tradicionais, tendo como diferença apenas dois novos elementos de barra diagonais, permite estabelecer para o modelo a mesma rigidez ao cisalhamento da parede original. Sendo assim, o modelo a ser adotado é repetido na figura 22.

b

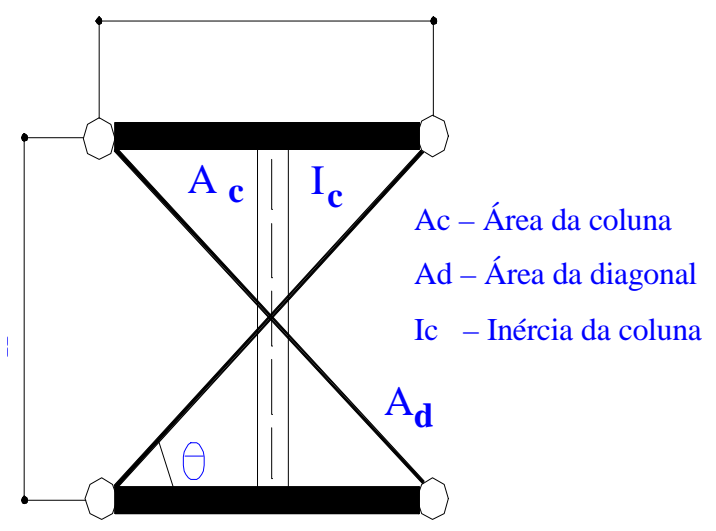

$\mathbf{t}=$ espessura

Figura 22 - Modelo adotado - GUILARDI (1999) 
Para este novo modelo, é necessária a determinação das novas características geométricas da coluna central e barras diagonais. Estes valores são determinados igualando-se os coeficientes de rigidez à flexão, ao cisalhamento e axial do modelo com os respectivos coeficientes de rigidez da parede que ela representa. Sendo assim, modelo e parede serão submetidos a um estado de flexão uniforme, estado puro de cisalhamento e esforços normais.

As coordenadas deslocamento adotadas para este modelo serão as mesmas adotadas para o modelo YAGUI: duas horizontais, quatro verticais e duas de torção.

\subsection{3 - CARACTERÍSTICAS GEOMÉTRICAS PARA O NOVO MODELO}

\subsubsection{1 - Rigidez à flexão}

Neste modelo, as propriedade elásticas do material das barras são consideradas idênticas à do material do pilar parede correspondente. Sendo assim ambos terão o mesmo módulo de elasticidade longitudinal (E) e transversal $(\mathrm{G})$ para todos os elementos envolvidos.

Para a determinação da inércia da coluna é inicialmente suposto que a parede e o modelo que a representa estejam sujeitos a um momento fletor uniforme, como visto na figura 23.

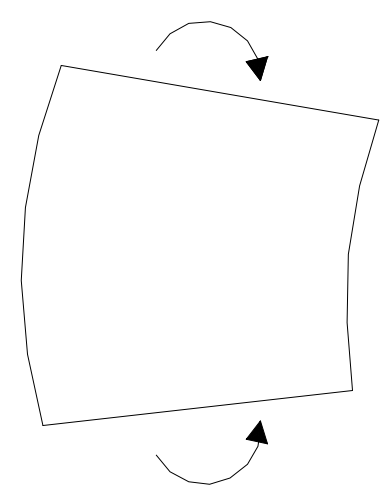

a) parede

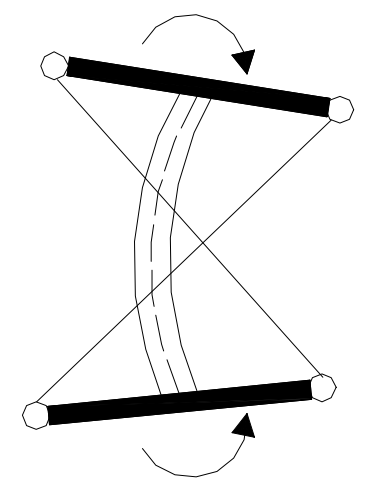

b) modelo

Figura 23 - Parede sujeita à flexão uniforme - GUILARDI (1999) 
De acordo com a particularidade da deformação do modelo, as barras diagonais não sofrem variação do seu comprimento não contribuindo para a resistência à flexão. Portanto essa resistência é dada apenas pela coluna central.

Sendo assim a coluna central terá inércia $I_{c}$ idêntica a da parede $I_{p}$.

$$
I_{c}=I_{p}=\frac{t b^{3}}{12}
$$

\subsubsection{2 - Rigidez ao cisalhamento}

Para a determinação da área das diagonais $\mathrm{A}_{\mathrm{d}}$, admite-se que a parede e o modelo estejam sujeitos a um estado de cisalhamento puro de acordo com a figura 24. A partir daí a rigidez ao cisalhamento dos dois elementos são igualadas.

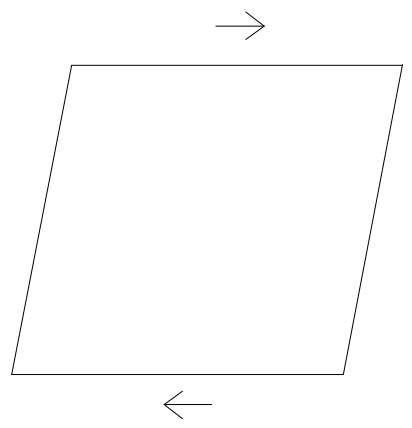

parede

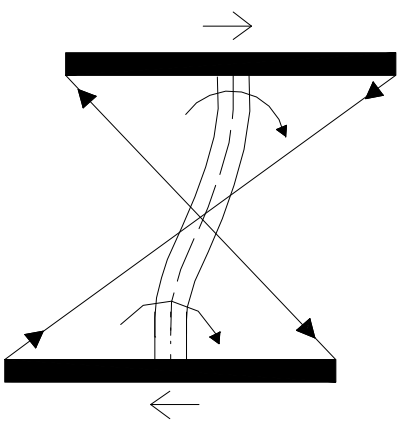

modelo

Figura 24 - Parede sujeita à cisalhamento puro - GUILARDI (1999)

Somando as resistências produzidas pelos momentos fletores da coluna central e as componentes horizontais das forças normais nas diagonais que aparecem devido às deformações a que são submetidas, obtém-se a rigidez do modelo. Igualando a resistência ao cisalhamento do modelo à do segmento de parede, temos: 


$$
\frac{12 E I_{C}}{h^{3}}+\frac{2 E A_{d} \cos ^{2} \theta}{l}=\frac{b t G}{h}
$$

A partir da consideração das expressões de E, $l$ e da variável B, explicitadas a seguir, torna-se possível a determinação da área das barras diagonais.

$$
E=2(1+v) G
$$

onde $v$ é o coeficiente de Poisson.

$$
\begin{aligned}
& \operatorname{tg} \theta=\frac{h}{b} ; \quad l=\frac{h}{\operatorname{sen} \theta} \\
& B=\frac{h^{2}}{4 b^{2}(1+v)}
\end{aligned}
$$

Assim,

$$
A_{d}=\frac{b t}{\operatorname{sen}^{3} \theta}(B-0,5)
$$

\subsubsection{3 - Rigidez Axial}

A nova área da coluna será obtida sujeitando a parede e o modelo a esforços axiais, conforme figura 25 , e comparando as suas rigidezes axiais. 


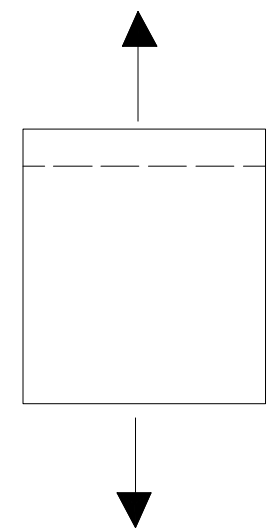

a) parede

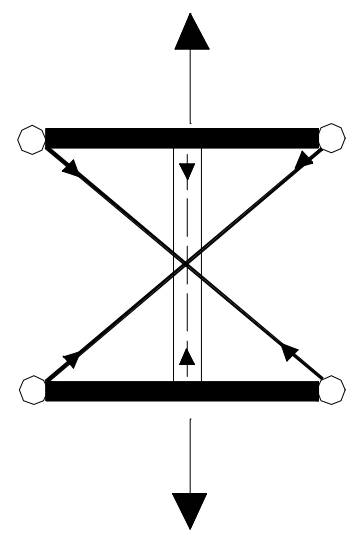

b) modelo

Figura 25 - Parede sujeita à esforços axiais - GUILARDI (1999)

$$
\frac{E A_{c}}{h}+\frac{2 E A_{d} \operatorname{sen}^{2} \theta}{l}=\frac{E b t}{h}
$$

Conhecido $\mathrm{A}_{\mathrm{d}}$ fornecido pela expressão 12, a área da coluna resulta em:

$$
A_{c}=2 b t(1-B)
$$

Portanto, as novas características geométricas necessárias à confecção da matriz de rigidez do novo modelo, encontram-se resumidas na Tabela 1:

Tabela 1 - Características da coluna e diagonais

\begin{tabular}{|c|c|c|}
\cline { 2 - 3 } \multicolumn{1}{c|}{} & COLUNA & DIAGONAIS \\
\hline Inércia & $I c=\frac{t b^{3}}{12}$ & $A d=\frac{b t}{\operatorname{sen}^{3} \theta}(B-0,5)$ \\
\hline Área & $A c=2 b t(1-B)$ & \\
\hline Variável & $B=\frac{h^{2}}{4 b^{2}(1+v)}$ \\
Auxiliar & \\
\hline
\end{tabular}




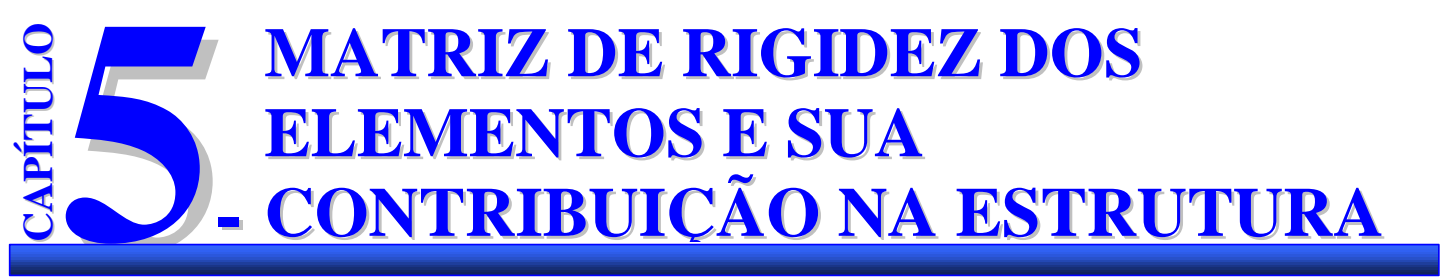

Temos tendência para não escolher o desconhecido, que pode revelar-se um choque ou um desapontamento ou simplesmente algo difícil de resolver. No entanto, é o desconhecido, com todas as suas desilusões e surpresas, aquilo que mais nos enriquece.

\section{1 - INTRODUÇÃO}

Serão apresentadas neste capítulo as matrizes de rigidez dos elementos estruturais utilizados em cada uma das modelagens propostas, bem como alguns dos procedimentos necessários para se levar a contribuição da rigidez destes elementos na estrutura global.

Para a determinação da matriz de rigidez dos elementos utilizados nas modelagens por pilar parede isolado e barra de seção delgada considerando ou não a teoria de flexo-torção, foi utilizado o método da energia, com o o princípio da energia potencial total mínima (P.E.P.T.M). Cabe salientar que processos mais simplificados, utilizados na determinação das matrizes de rigidez de elementos de pórtico espacial, como por exemplo o elemento utilizado na modelagem por pilar parede isolado, levariam a resultados semelhantes aos apresentados neste capítulo.

Em seu trabalho MATIAS (1997) utiliza o P.E.P.T.M. na obtenção das matrizes de rigidez, para diferentes elementos estruturais, e propõe uma sequência de procedimentos considerados necessários à obtenção destas matrizes de rigidez. Algumas das expressões desenvolvidas em MATIAS (1997) serão utilizadas e apresentadas neste trabalho. Porém, com a consideração de fundação rígida para as 
estruturas processadas, algumas simplificações e adaptações foram realizadas, adequando as expressões, obtidas por aquele autor, ao presente trabalho desenvolvido.

Para as modelagens utilizando os modelos propostos por YAGUI (1971) e SMITH et al (1981/1984), foi utilizado o processo dos deslocamentos. SERRA (1994) e GUILARDI (1999), apresentam em seus trabalhos todo o desenvolvimento de cálculo para a determinação das matriz dos elementos planos, propostos para estas modelagens. Cabe salientar que, quando forem utilizadas estas modelagens para o núcleo, os demais elementos componentes da estrutura de contraventamento, as vigas e pilares, serão modelados como elementos de barra. Estes elementos são apresentados em MATIAS (1997), bem como as suas matrizes de rigidezes.

Para a contribuição dos elementos de núcleo na rigidez da subestrutura serão apresentadas as matrizes de rotação de coordenadas e as matrizes de translação de coordenadas, sendo estas últimas necessárias à simulação da laje como diafragma perfeitamente rígido no seu plano.

\section{2 - DETERMINAÇÃO DA MATRIZ DE RIGIDEZ DOS ELEMENTOS}

\subsection{1 - MODELAGEM POR BARRA DE SEÇÃO DELGADA CONSIDERANDO A TEORIA DE FLEXO-TORÇÃO}

Como já mencionado anteriormente, para a determinação da matriz de rigidez deste elemento, foi utilizado o princípio da energia potencial total mínima. Neste processo, de acordo com as considerações de rigidez e vinculação, no caso vinculação rígida, a matriz de rigidez pode ser determinada utilizando a expressão (15), da energia potencial total, para o elemento da figura 08.

$$
\begin{aligned}
& U_{t Y}=\frac{1}{2} \int_{0}^{L}\left(E . S . u^{2}+E . I z \cdot v^{\prime 2}+E . I y \cdot w^{\prime 2}+E . I \omega \cdot \phi^{\prime 2}\right) d x+\frac{1}{2} \int_{0}^{L}\left(G . I x \cdot \phi^{2}\right) d x- \\
& \left(P x \cdot u_{1}+m_{Z} \cdot v_{1}^{\prime}+m_{y} \cdot w_{1}^{\prime}+B . \phi_{1}\right)
\end{aligned}
$$


onde:

$I x=$ Momento de inércia a torção

$I y=$ Momento de inércia à flexão no plano $\mathrm{x} / \mathrm{z}$

$I z=$ Momento de inércia à flexão no plano x/y

$I \omega=$ Momento setorial de inércia

$E=$ Módulo de elasticidade longitudinal

$S=$ Área da seção transversal dos elementos

$G=\quad$ Módulo de elasticidade transversal

$L=$ Comprimento dos elementos existentes na subestrutura

$u=$ Função que define a translação na direção do eixo $\mathrm{x}$

$v=$ Função que define a translação na direção do eixo y

$w=$ Função que define a translação na direção do eixo $\mathrm{z}$

$\phi=$ Função que define os deslocamentos de rotação em torno do eixo $\mathrm{x}$

$P x=$ Ação vertical aplicada na extremidade superior do elemento

$m_{y}=$ Momento fletor aplicado na direção do eixo y aplicado na extremidade superior

$m_{z}=$ Momento fletor aplicado na direção do eixo $\mathrm{z}$ aplicado na extremidade superior

$\mathrm{B}=$ Bimomento aplicado na extremidade superior

$u_{1}=$ Deslocamento na direção do eixo $\mathrm{x}$ na extremidade superior

$v_{l}=$ Deslocamento na direção do eixo y na extremidade superior

$w_{1}=$ Deslocamento na direção do eixo $\mathrm{z}$ na extremidade superior

$\phi_{1}=$ Rotação em torno do eixo $\mathrm{x}$ na extremidade superior

$v_{1}^{\prime}=$ Rotação em torno do eixo y na extremidade superior

$w_{1}{ }^{\prime}=$ Rotação em torno do eixo z na extremidade superior

$\mathrm{x}, \mathrm{y}, \mathrm{z}$ Eixos referentes ao sistema de coordenadas locais do elemento 
As equações diferenciais regentes do problema são:

$$
\begin{aligned}
& \text { E.S.u" = } 0
\end{aligned}
$$

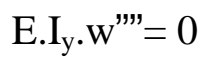

$$
\begin{aligned}
& \text { E. } I_{\mathrm{Z}} \cdot \mathrm{V} \text { "'” }=0 \\
& \text { E. } I_{\omega} . \phi " '-G . I_{x} . \phi "=0
\end{aligned}
$$

Adotando as funções polinomiais que determinam a forma da elástica obtémse a solução geral das equações diferenciais. Ao aplicar as condições de contorno, deslocamentos nas extremidades do elemento, chega-se a um sistema de equações lineares, que quando resolvido leva à determinação da função polinomial em função dos deslocamentos. Derivando a expressão em relação a cada um dos deslocamentos, obtem-se a matriz de rigidez $\left[\operatorname{Rel}_{\mathrm{f}}\right]_{\mathrm{J}}$ :

$$
\left[\operatorname{Rel}_{\mathrm{f}}\right]_{\mathrm{J}}=\left[\begin{array}{ll}
{[\mathrm{re}]_{\mathrm{SS}}} & {[\mathrm{re}]_{\mathrm{SI}}} \\
{[\mathrm{re}]_{\mathrm{IS}}} & {[\mathrm{re}]_{\mathrm{II}}}
\end{array}\right]
$$

Onde:

$$
\begin{aligned}
& {[r e]_{S I}=\left[\begin{array}{ccccccc}
w_{y}-w_{x} \cdot Z_{g t} & w_{x} \cdot Y_{g t} \cdot Z_{g t} & -w_{x} \cdot Z_{g t} & 0 & -3 \cdot w_{y} / L & 0 & 0 \\
w_{x} \cdot Y_{g t} \cdot Z_{g t} & 2 \cdot w_{z}-w_{x} \cdot Y_{g t}{ }^{2} & w_{x} \cdot Y_{g t} & 3 \cdot w_{z} / L & 0 & 0 & 0 \\
-w_{x} \cdot Z_{g t} & w_{x} \cdot Y_{g t} & -w_{x} & 0 & 0 & 0 & 0 \\
0 & -3 \cdot w_{y} / L & 0 & -6 \cdot w_{z} / L^{2} & 0 & 0 & 0 \\
3 \cdot w_{y} / L & 0 & 0 & 0 & -6 \cdot w_{y} / L^{2} & 0 & 0 \\
0 & 0 & 0 & 0 & 0 & -\gamma . \alpha \cdot s h & \gamma(c h-1) \\
0 & 0 & 0 & 0 & 0 & \gamma(c h-1) & \gamma \cdot(\operatorname{sh} / \alpha-L)
\end{array}\right]} \\
& {[r e]_{I I}=\left[\begin{array}{ccccccc}
2 \cdot w_{y}-w_{x} \cdot Z_{g t}^{2} & -w_{x} \cdot Y_{g t} \cdot Z_{g t} & w_{x} \cdot Z_{g t} & 0 & -3 \cdot w_{y} / L & 0 & 0 \\
-w_{x} \cdot Y_{g t} \cdot Z_{g t} & 2 \cdot w_{z}+w_{x} \cdot Y_{g t}^{2} & -w_{x} \cdot Y_{g t} & 3 \cdot w_{z} / L & 0 & 0 & 0 \\
w_{x} \cdot Z_{g t} & -w_{x} \cdot Y_{g t} & w_{x} & 0 & 0 & 0 & 0 \\
0 & 3 \cdot w_{y} / L & 0 & 6 \cdot w_{y} / L^{2} & 0 & 0 & 0 \\
-3 \cdot w_{y} / L & 0 & 0 & 0 & 6 . w_{y} / L^{2} & 0 & 0 \\
0 & 0 & 0 & 0 & 0 & \gamma . \alpha . s h & \gamma(c h-1) \\
0 & 0 & 0 & 0 & 0 & \gamma(\text { ch }-1) & \gamma .(\text { L.ch }- \text { sh } / \alpha)
\end{array}\right]}
\end{aligned}
$$


Onde:

$$
\begin{aligned}
& w_{\mathrm{x}}=\mathrm{E} \cdot \mathrm{S} / \mathrm{L} \\
& w_{\mathrm{y}}=2 \cdot \mathrm{E} \cdot \mathrm{I}_{\mathrm{y}} / \mathrm{L} \\
& w_{\mathrm{Z}}=2 \cdot \mathrm{E} \cdot \mathrm{I}_{\mathrm{Z}} / \mathrm{L} \\
& \alpha=\sqrt{\frac{G . I x}{E . I \omega}} \\
& \gamma=\frac{G . I x}{2-2 . c h+L \cdot \alpha \cdot s h} \\
& \operatorname{sh}=\operatorname{senh}(\alpha \cdot \mathrm{L}) \\
& \operatorname{ch}=\cosh (\alpha . \mathrm{L}) \\
& Y_{\mathrm{gt}}=\text { Distância y do "C.T” ao "C.G." da seção transversal } \\
& \mathrm{Z}_{\mathrm{gt}}=\text { Distância z do "C.T" ao "C.G." da seção transversal }
\end{aligned}
$$

A submatriz $[\mathrm{re}]_{\mathrm{SS}}$ é igual a $[\mathrm{re}]_{\mathrm{II}}$, exceto os coeficientes referentes às coordenadas $(1,5)$ e $(2,4)$, bem como seus simétricos, que têm sinal inverso. A matriz $[\mathrm{re}]_{\mathrm{SI}}$ é igual à sua transposta: $[\mathrm{re}]_{\mathrm{SI}}=[\mathrm{re}]_{\mathrm{IS}}^{\mathrm{T}}$

Para a obtenção da matriz de rigidez em teoria de segunda ordem, foi utilizado um processo semelhante ao apresentado anteriormente, sendo considerado, no cálculo dos coeficientes, além do momento fletor e do bimomento, a influência do esforço axial. Por se tratar de um desenvolvimento extenso, optou-se por não apresentar-lo neste trabalho, podendo ser encontrado, juntamente com a matriz de rigidez final do elemento, em MATIAS(1997).

\subsection{2 - BARRA DE SEÇÃO DELGADA SEM A CONSIDERAÇÃO DA TEORIA DE FLEXO-TORÇÃO}

A matriz de rigidez deste elemento, foi determinada utilizando o mesmo princípio anterior, P.E.P.T.M, porém já com algumas simplificações devido às 
características do elemento. A expressão da energia potencial total, para este elemento de núcleo, é dada por:

$$
\begin{aligned}
& U_{t Y}=\frac{1}{2} \int_{0}^{L}\left(E . S . u^{\prime 2}+E . I z \cdot v^{\prime 2}+E . I y \cdot w^{\prime \prime 2}\right) d x+\frac{1}{2} \int_{0}^{L}\left(G . I x \cdot \phi^{\prime 2}\right) d x- \\
& \left(\text { PX. } u_{1}+m_{Z} \cdot v_{1}^{\prime}+m_{y} \cdot w_{1}^{\prime}\right)
\end{aligned}
$$

Os procedimentos subseqüentes necessários à determinação da matriz de rigidez deste elemento assemelham-se aos utilizados para o elemento do item 5.2.1, porém com alteração da expressão 19 , referente às equações diferencias, onde o primeiro termo, E.I I. $^{\prime \prime \prime \prime \prime}$, é eliminado da expressão, obtendo então como resultado a seguinte matriz:

$$
\begin{aligned}
& {\left[\operatorname{Rel}_{s f}\right]_{J}=\left[\begin{array}{ll}
{\left[r e_{S f}\right]_{S S}} & {\left[r e_{S f}\right]_{S I}} \\
{\left[r e_{S f}\right]_{I S}} & {\left[r e_{S f}\right]_{I I}}
\end{array}\right]} \\
& {\left[r e_{s f}\right]_{S I}=\left[\begin{array}{cccccc}
w_{y}-w_{x} \cdot Z_{g t} & w_{x} \cdot Y_{g t} \cdot Z_{g t} & -w_{x} \cdot Z_{g t} & 0 & -3 \cdot w_{y} / L & 0 \\
w_{x} \cdot Y_{g t} \cdot Z_{g t} & 2 \cdot w_{z}-w_{x} \cdot Y_{g t}^{2} & w_{x} \cdot Y_{g t} & 3 \cdot w_{z} / L & 0 & 0 \\
-w_{x} \cdot Z_{g t} & w_{x} \cdot Y_{g t} & -w_{x} & 0 & 0 & 0 \\
0 & -3 \cdot w_{z} / L & 0 & -6 . w_{z} / L^{2} & 0 & 0 \\
3 . w_{y} / L & 0 & 0 & 0 & -6 . w_{y} / L^{2} & 0 \\
0 & 0 & 0 & 0 & 0 & -G \cdot I_{x} / L
\end{array}\right]}
\end{aligned}
$$

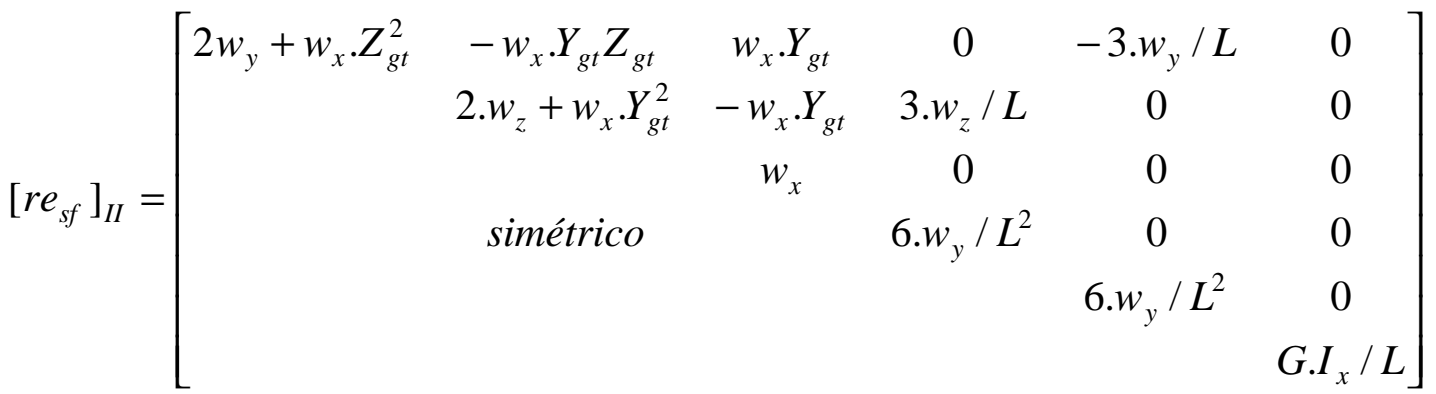


A submatriz $\left[r e_{s f}\right]_{S S}$ é igual a $\left[r e_{s f}\right]_{I I}$, exceto os coeficientes referentes às coordenadas $(1,5)$ e $(2,4)$, bem como seus simétricos, que têm sinal inverso. A matriz $\left[r e_{s f}\right]_{I S}=\left[r e_{s f}\right]_{S I}^{T}$

Para este elemento, foi utilizado o mesmo procedimento na determinação da matriz de rigidez em teoria de segunda ordem, sendo todo desenvolvimento apresentado em MATIAS(1997).

\subsection{3 - MODELAGEM POR PILAR PAREDE ISOLADO}

A matriz de rigidez do elemento utilizado nesta modelagem, denominada de $\left[\operatorname{Rel}_{\mathrm{p}}\right]$, foi determinada utilizando o mesmo princípio, o P.E.P.T.M.. Sua matriz final, devido às diversas simplificações consequentes das características do elemento, levou à obtenção de uma matriz de rigidez bem mais simplificada que a obtida para os elementos dos itens 5.2.1 e 5.2.2. A matriz de rigidez deste elemento assemelha-se à matriz do elemento da modelagem 5.2., sendo porém nulos os valores das distâncias y e z entre o centro de torção e o centro de gravidade, Ygt e Zgt, respectivamente.

A matriz de rigidez em teoria de segunda ordem, pode ser encontrada também em MATIAS(1997).

\subsection{4 - MODELO PROPOSTO POR YAGUI (1971).}

Para a determinação da matriz de rigidez do elemento plano proposto por YAGUI (1971), foi considerado inicialmente o elemento de barra apresentado na

figura 26 e suas coordenadas locais de deslocamentos $\overline{1}, \overline{2}, \ldots \ldots . ., \overline{8}$. A matriz de rigidez deste elemento de barra será denominada de $\bar{S}_{e}$. 


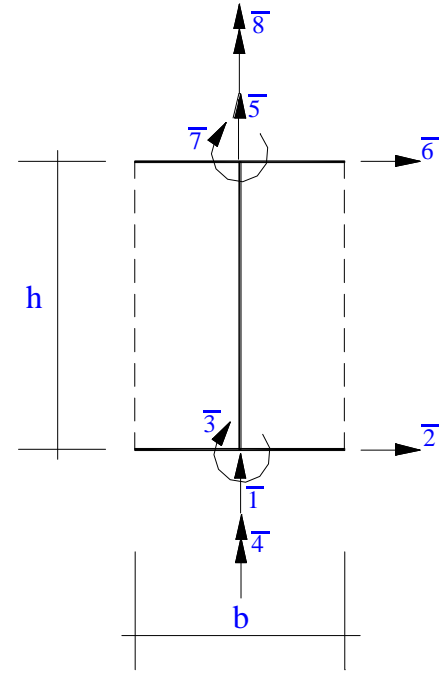

Figura 26 -Coordenadas do elemento de parede

O vetor de carga (esforços), para essas mesmas coordenadas, será denominado de $\bar{F}_{e}$ e o vetor de deslocamentos correspondentes será dado por $\bar{D}_{e}$, de acordo com as expressões em (28):

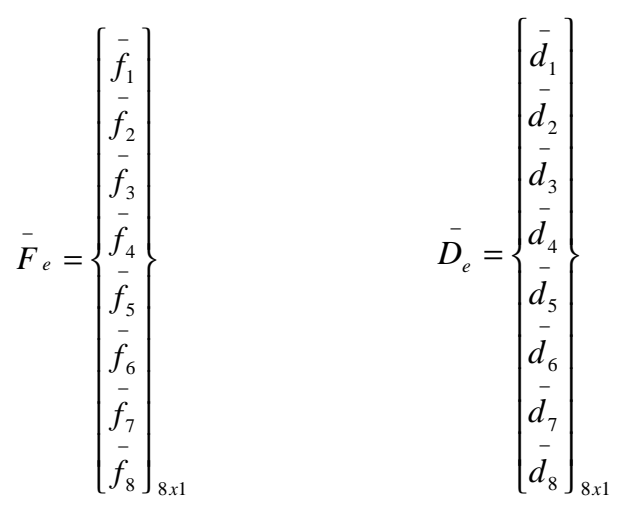

onde $\bar{f}_{1}$ e $\bar{f}_{5}$ são os esforços normais, $\bar{f}_{2}$ e $\bar{f}_{6}$ são os esforços cortantes, $\bar{f}_{3}$ e $\bar{f}_{7}$ são os momentos fletores e $\bar{f}_{4}$ e $\bar{f}_{8}$ são os momentos torçores. Para o vetor dos deslocamentos, $\bar{d}_{i}$ é o deslocamento do pilar segundo a coordenada $\bar{i}$ da figura 26. 
Escrevendo-se as equações dadas em (28), na forma matricial, obtém-se a expressão:

$$
\bar{F}_{e}=\bar{S}_{e} \bar{D}_{e}
$$

Inicialmente, para a determinação dos coeficientes de rigidez, são consideradas apenas as deformações por força cortante e momento fletor, desprezando-se a deformação por força normal nos deslocamentos de rotação e transversais à parede.

Com as formulações obtidas por YAGUI (1971), obtém-se a matriz de rigidez do elemento $\bar{S}_{e}$, dada pela expressão (30), lembrando que o elemento da linha $\mathrm{i}$ e coluna $\mathrm{j}(\mathrm{i}, \mathrm{j}=1,2, \ldots, 8)$ é numericamente igual ao esforço segundo a coordenada $\bar{i}$, da figura 26, quando imprime-se um deslocamento unitário segundo a coordenada $\bar{j}$, mantendo-se nulos os deslocamentos nas demais coordenadas.

$$
\bar{S}_{e}=\left[\begin{array}{cccccccc}
S 1 & 0 & 0 & 0 & -S 1 & 0 & 0 & 0 \\
0 & S 2 & S 3 & 0 & 0 & -S 2 & S 3 & 0 \\
0 & S 3 & S 4 & 0 & 0 & -S 3 & S 5 & 0 \\
0 & 0 & 0 & S 6 & 0 & 0 & 0 & -S 6 \\
-S 1 & 0 & 0 & 0 & S 1 & 0 & 0 & 0 \\
0 & -S 2 & -S 3 & 0 & 0 & S 2 & -S 3 & 0 \\
0 & S 3 & S 5 & 0 & 0 & -S 3 & S 4 & 0 \\
0 & 0 & 0 & -S 6 & 0 & 0 & 0 & S 6
\end{array}\right]
$$

onde os valores apresentados na expressão (30) são definidos no quadro 1.

Quadro 1 - Coeficientes de rigidez do modelo proposto por YAGUI (1971)

\begin{tabular}{|c|c|c|c|c|c|}
\hline $\mathrm{S} 1$ & $\mathrm{~S} 2$ & $\mathrm{~S} 3$ & $\mathrm{~S} 4$ & $\mathrm{~S} 5$ & $\mathrm{~S} 6$ \\
\hline$\frac{E A}{h}$ & $\frac{12 E I^{\prime}}{h^{3}}$ & $\frac{6 E I^{\prime}}{h^{2}}$ & $(4+k) \frac{E I^{\prime}}{h}$ & $(2-k) \frac{E I^{\prime}}{h}$ & $\frac{G J_{t}}{h}$ \\
\hline
\end{tabular}


sendo os demais valores definidos pelo conjunto de expressões (31):

$$
\begin{array}{lll}
I^{\prime}=\frac{I}{1+k} & \mathrm{k}=\frac{12 c E I}{G A h^{2}} & \mathrm{~A}=\mathrm{t} . \mathrm{b} \\
\mathrm{I}=\mathrm{tb}^{3} / 12 & \mathrm{~J}_{\mathrm{t}}=\mathrm{C} 1 \cdot \mathrm{bt}^{3} & \mathrm{C} 1=\frac{1}{3}\left(1-0,63 \frac{\mathrm{t}}{\mathrm{b}}\right) \\
\mathrm{c}=\text { fator de forma } & \mathrm{t}=\text { espessura da parede }
\end{array}
$$

De acordo com as alterações adotadas para esta modelagem, propostas por SERRA (1987), o fator de forma referido ao conjunto de expressões (31) tem valor unitário pré-estabelecido. No caso de ser desprezada a deformação por cortante, a este mesmo fator deverá ser arbitrado valor nulo.

A partir da matriz $\bar{S}_{e}$, dada por (30), a matriz do elemento da figura 15 , denominada de $S_{e}$, será obtida utilizando as relações dadas pelas seguintes expressões:

$$
\bar{D}_{e}=T_{e} D_{e}
$$

$$
F_{e}=S_{e} D_{e}
$$

$S_{e}=T_{e}^{t} \bar{S}_{e} T_{e}$

onde $\mathrm{T}_{\mathrm{e}}$, dada por (35), é a matriz de transformação, utilizada para a determinação da matriz $S_{e}$, a partir da mudança de coordenadas: 


$$
\mathrm{T}_{\mathrm{e}}=\left[\begin{array}{cccccccc}
0 & 0 & 0 & 0 & \frac{1}{2} & \frac{1}{2} & 0 & 0 \\
0 & 0 & 0 & 0 & 0 & 0 & 1 & 0 \\
0 & 0 & 0 & 0 & \frac{1}{\mathrm{~b}} & -\frac{1}{\mathrm{~b}} & 0 & 0 \\
0 & 0 & 0 & 0 & 0 & 0 & 0 & 1 \\
\frac{1}{2} & \frac{1}{2} & 0 & 0 & 0 & 0 & 0 & 0 \\
0 & 0 & 1 & 0 & 0 & 0 & 0 & 0 \\
\frac{1}{\mathrm{~b}} & -\frac{1}{\mathrm{~b}} & 0 & 0 & 0 & 0 & 0 & 0 \\
0 & 0 & 0 & 1 & 0 & 0 & 0 & 0
\end{array}\right]_{8 \times 8}
$$

Os vetores $F_{e}$ e $D_{e}$ são respectivamente o vetor de carga (esforços) e o vetor de deslocamentos, do elemento da figura 15.

Sendo assim, com a utilização da expressão (34), é possível se chegar à matriz de rigidez do elemento de parede para o modelo proposto por YAGUI (1971).

Quadro 2 - Coeficientes de rigidez do modelo proposto por YAGUI (1971)

\begin{tabular}{|c|c|c|c|c|c|c|c|c|c|}
\hline \multirow{8}{*}[\mathrm{Se}]{$=$} & E1 & E2 & -E3 & 0 & $\mathrm{E} 4$ & E5 & E3 & 0 & 1 \\
\hline & E2 & E1 & E3 & 0 & E5 & E4 & -E3 & 0 & 2 \\
\hline & $-\mathrm{E3}$ & E3 & E6 & 0 & $-\mathrm{E} 3$ & E3 & -E6 & 0 & 3 \\
\hline & 0 & 0 & 0 & E7 & 0 & 0 & 0 & -E7 & 4 \\
\hline & E4 & E5 & -E3 & 0 & E1 & E2 & E3 & 0 & 5 \\
\hline & E5 & $\mathrm{E} 4$ & E3 & 0 & E2 & E1 & -E3 & 0 & 6 \\
\hline & E3 & -E3 & -E6 & 0 & E3 & -E3 & E6 & 0 & 7 \\
\hline & 0 & 0 & 0 & -E7 & 0 & 0 & 0 & E7 & 8 \\
\hline & 1 & 2 & 3 & 4 & 5 & 6 & 7 & 8 & \\
\hline
\end{tabular}


onde os valores apresentados na expressão (35) são definidos através do conjunto de expressões (36):

$$
\begin{array}{lll}
E 1=\frac{S 1}{4}+\frac{S 4}{b^{2}} & E 2=\frac{S 1}{4}-\frac{S 4}{b^{2}} & E 3=\frac{S 3}{b} \\
E 4=-\frac{S 1}{4}+\frac{S 5}{b^{2}} & E 5=-\frac{S 1}{4}-\frac{S 5}{b^{2}} & \text { E6 }=\text { S2 } \\
\text { E7 }=\text { S6 } &
\end{array}
$$

\subsubsection{1 - Consideração do Efeito de Segunda Ordem na Matriz de Rigidez dos Elementos de Parede}

Em alguns casos os esforços normais, devido aos seus valores elevados, podem influenciar consideravelmente nos coeficientes de rigidez das colunas. Sua presença em uma barra fletida (equilíbrio na posição deslocada da estrutura), ocasiona uma variação no momento fletor, sendo este efeito denominado efeito de segunda ordem.

SERRA (1994) apresenta em seu trabalho todo o desenvolvimento para a determinação dos coeficientes de rigidez de uma barra fletida, considerando os efeitos do momento fletor, força cortante, força normal e momento torçor. Sendo esse desenvolvimento muito extenso, optou-se por não apresentá-lo na íntegra, indicando apenas alguns procedimentos e um quadro contendo de forma resumida as expressões obtidas para os casos de força $\mathrm{P}$ de compressão, força $\mathrm{P}$ de tração e força $\mathrm{P}$ nula, aplicados à barra. Todo esse desenvolvimento pode ser visto em SERRA (1994), páginas 66 a 77.

Utilizando a barra da figura 26, com o sistema de coordenadas indicado, e de acordo com considerações de simetria, equilíbrio de esforços e aplicação do Teorema da Reciprocidade, conclui-se que, para as oito coordenadas deslocamentos, a matriz de rigidez que relaciona os deslocamentos $\bar{D}_{e}$ com os esforços $\bar{F}_{e}$, tem a forma mostrada na figura 27. 


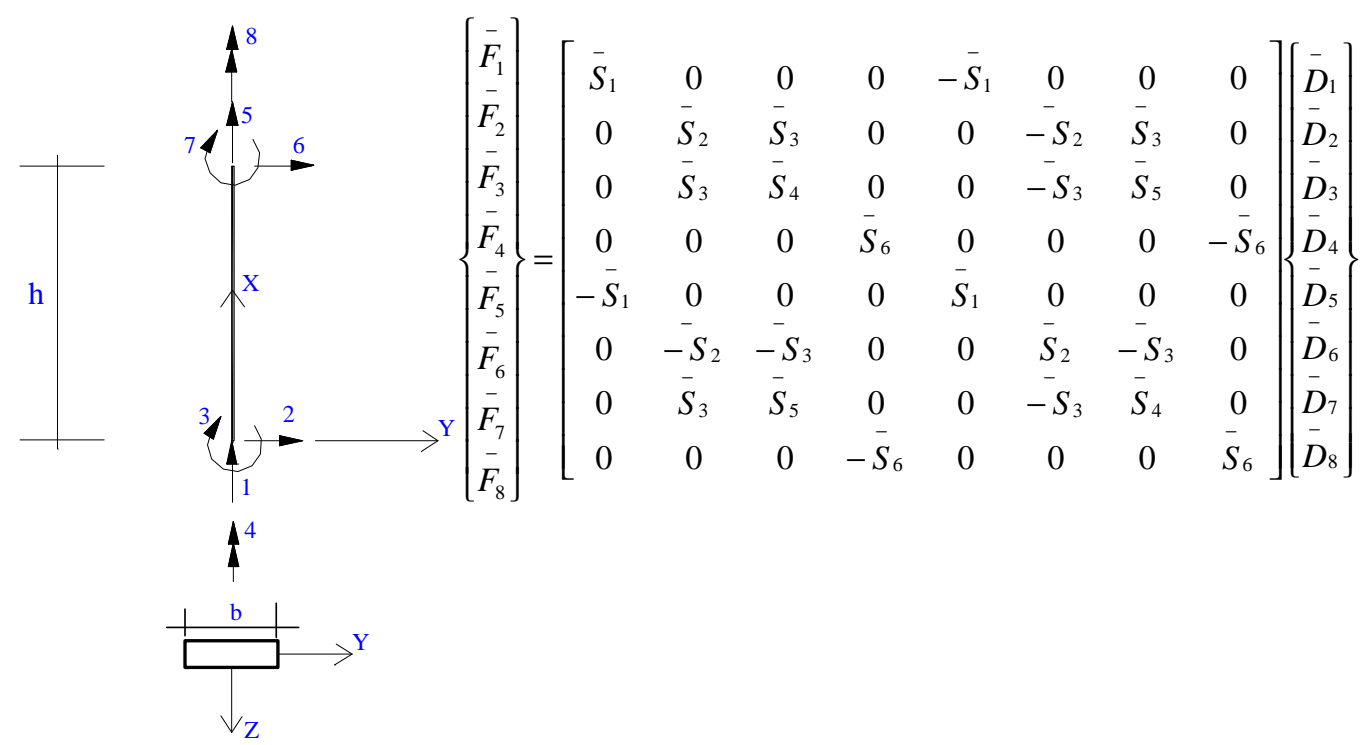

Figura 27 -Coordenadas do elemento de barra e coeficientes de rigidez

A figura 28 ilustra os quatro "estados de deslocamentos" básicos utilizados para a determinação dos coeficientes de rigidez.

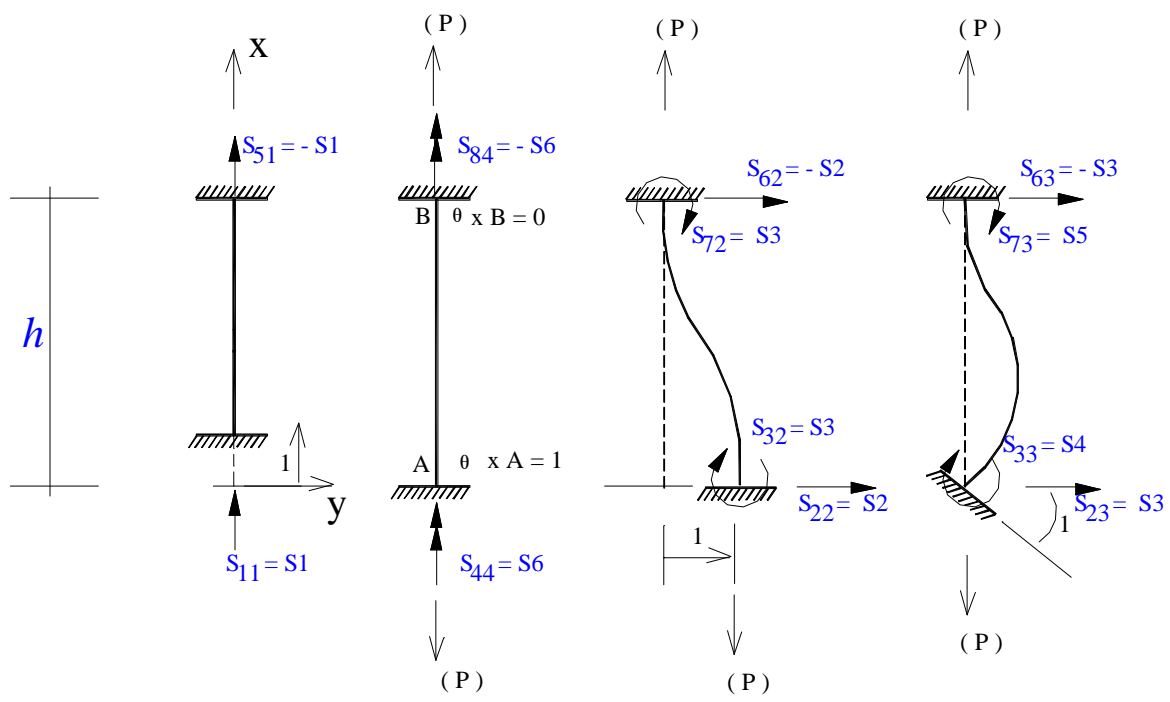

Figura 28 -Estados básicos de deslocamentos. 
A partir da utilização destes coeficientes, do desenvolvimento extenso de diversas equações e da resolução dos sistemas, foram obtidas as expressões de rigidez para o elemento de barra da figura 26, apresentados no quadro 2.

\section{Quadro 2 -Expressões de rigidez - Formulário}

\begin{tabular}{|c|c|c|c|}
\hline & Compressão $(\mathrm{P}<0)$ & Zero & Tração ( P > 0 ) \\
\hline \multirow{2}{*}{$\bar{S} 1$} & $E A$ & $E A$ & $E A$ \\
\hline & $h$ & $h$ & $h$ \\
\hline \multirow{2}{*}{$\bar{S} 2$} & $a^{2} \alpha^{3} \operatorname{sen} \alpha . h$ & $12 E I$ & $a^{2} \alpha^{3} \operatorname{senh} \alpha . h$ \\
\hline & $\phi_{c}$ & $h^{3}$ & $\phi_{t}$ \\
\hline \multirow{2}{*}{$S 3$} & $a \alpha^{2}(1-\cos \alpha . h)$ & $6 E I^{\prime}$ & $a \alpha^{2}(\cosh \alpha \cdot h-1)$ \\
\hline & $\phi_{c}$ & $h^{2}$ & $\phi_{t}$ \\
\hline \multirow{2}{*}{$\overline{S 4}$} & $\alpha{ }^{\alpha} \cdot(\operatorname{sen} \alpha \cdot h-a \alpha \cdot h \cos 0$ & \multirow{2}{*}{$(4+k) \frac{E I^{\prime}}{h}$} & \multirow{2}{*}{$E I \frac{\alpha \cdot(a \alpha \cdot h \cosh \alpha \cdot h-\operatorname{senh} \alpha}{\phi_{t}}$} \\
\hline & $\phi_{c}$ & & \\
\hline \multirow{2}{*}{$S 5$} & $E I \alpha .(a \alpha . h-\operatorname{sen} \alpha . h)$ & $(2-k) \frac{E I^{\prime}}{}$ & \multirow[t]{2}{*}{$E I \frac{\alpha .(\operatorname{senh} \alpha \cdot h-a \alpha . h)}{2}$} \\
\hline & $\phi_{c}$ & & \\
\hline \multirow{2}{*}{ S6 } & $G J_{t}+\operatorname{Pr}^{2}$ & $G J_{t}$ & $G J_{t}+\operatorname{Pr}^{2}$ \\
\hline & $h$ & $h$ & $h$ \\
\hline
\end{tabular}

onde tem-se o conjunto de equações (37):

$$
\begin{array}{lll}
\phi_{\mathrm{c}}=2-2 \cos \alpha|-\mathrm{a} \alpha| \operatorname{sen} \alpha \mid & \phi_{\mathrm{t}}=2-2 \cosh \alpha|+\mathrm{a} \alpha| \operatorname{senh} \alpha \\
\mathrm{a}=1+\frac{c P}{G A} & \mathrm{~A}=\mathrm{t} . \mathrm{b} & I^{\prime}=\frac{I}{1+k} \\
\alpha=\sqrt{\frac{|P|}{a E I}} & \mathrm{I}=\mathrm{tb}^{3} / 12 & k=\frac{12 c E I}{G A h^{2}} \\
J_{t}=C 1 . b t^{3} & \mathrm{r}^{2}=\mathrm{I} / \mathrm{A} & C 1=\frac{1}{3}\left(1-0,63 \frac{t}{b}\right)
\end{array}
$$


De acordo com o mesmo procedimento utilizado na análise em teoria de primeira ordem, a matriz de rigidez do elemento de parede da figura $15 \mathrm{em}$ teoria de segunda ordem poderá ser obtida aplicando-se à expressão (34) a matriz de rigidez da figura 27 e a matriz de transformação de coordenadas dada pela expressão (35).

\subsection{5 - MODELO PROPOSTO POR SMITH et al}

Devido a semelhança observada entre os modelos, a matriz de rigidez do modelo proposto por SMITH et al (1981/1984), ver figura 29, pôde ser determinada utilizando os mesmos procedimentos adotados no modelo proposto por YAGUI (1971). Porém, para esta modelagem, devido a presença das diagonais no modelo, houve a necessidade da determinação de novas características geométricas para a coluna central.

Para o desenvolvimento dos cálculos, necessários à determinação da matriz de rigidez do elemento, foram considerados apenas os efeitos de uma análise elástico-linear de primeira ordem. Para este elemento não será considerada a deformação por esforço cortante na determinação da matriz de rigidez. 


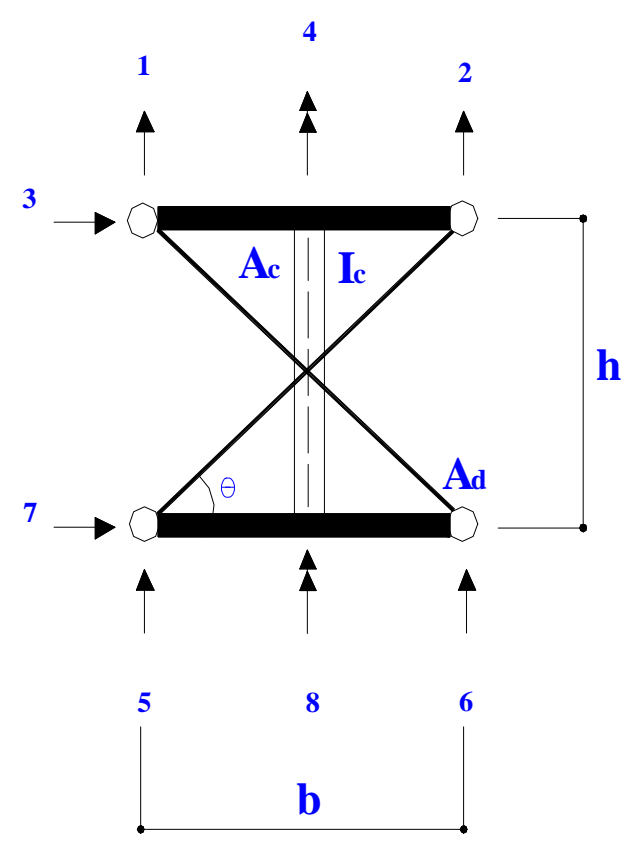

Figura 29 - Modelo e suas coordenadas - GUILARDI (1999)

Os valores finais dos coeficientes de rigidez, do modelo com as diagonais, foram obtidos a partir dos coeficientes do modelo sem a presença das barras. $\mathrm{O}$ processo consiste, basicamente, na adição da contribuição da rigidez das diagonais nos respectivos coeficientes do modelo sem a presença destes elementos.

Analisando o modelo pode-se perceber que, para as coordenadas 4 e 8 , a adição das diagonais não afeta seus correspondentes coeficientes. Assim, para esses valores originariamente nulos e em virtude da simetria do modelo, a análise dos dois estados de deslocamentos unitários, dados pelas coordenadas 7 e 5, ilustrados na figura 30, são suficientes para a determinação da matriz de rigidez do modelo com as diagonais. 


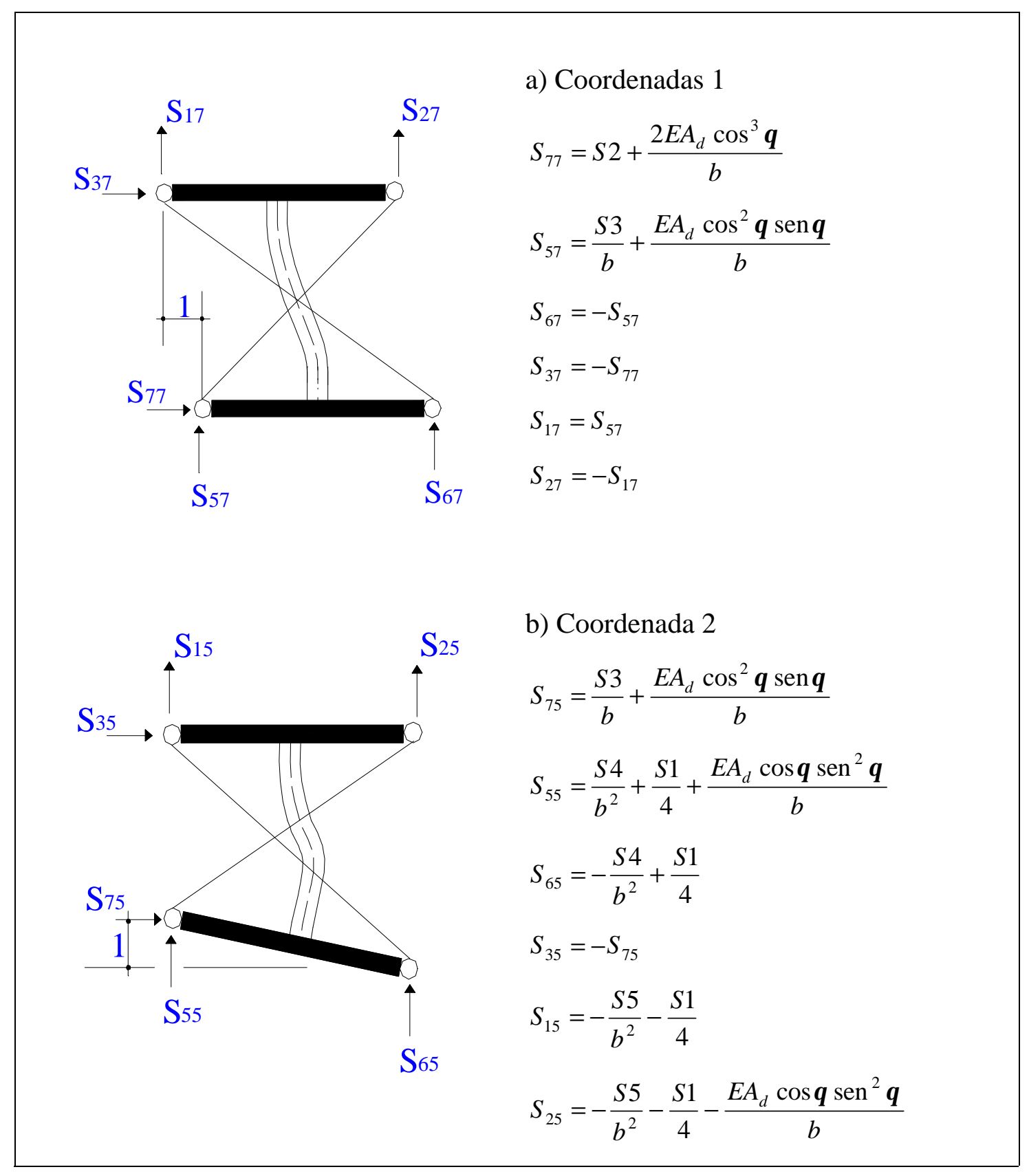

Figura 30 - Expressões de rigidez - GUILARDI (1999)

Procurando facilitar as consultas e o processo de programação, GUILARDI (1999), apresenta em seu trabalho um resumo dos coeficientes de rigidez para este modelo. Este resumo pode ser observado no quadro 3, valendo alertar sobre as alterações referentes à numeração estabelecida para as coordenadas, sendo 
apresentadas neste trabalho em ordem numérica diferente das adotadas anteriormente pelo autor.

\section{Quadro 3 - Matriz de rigidez do modelo - GUILARDI (1999)}

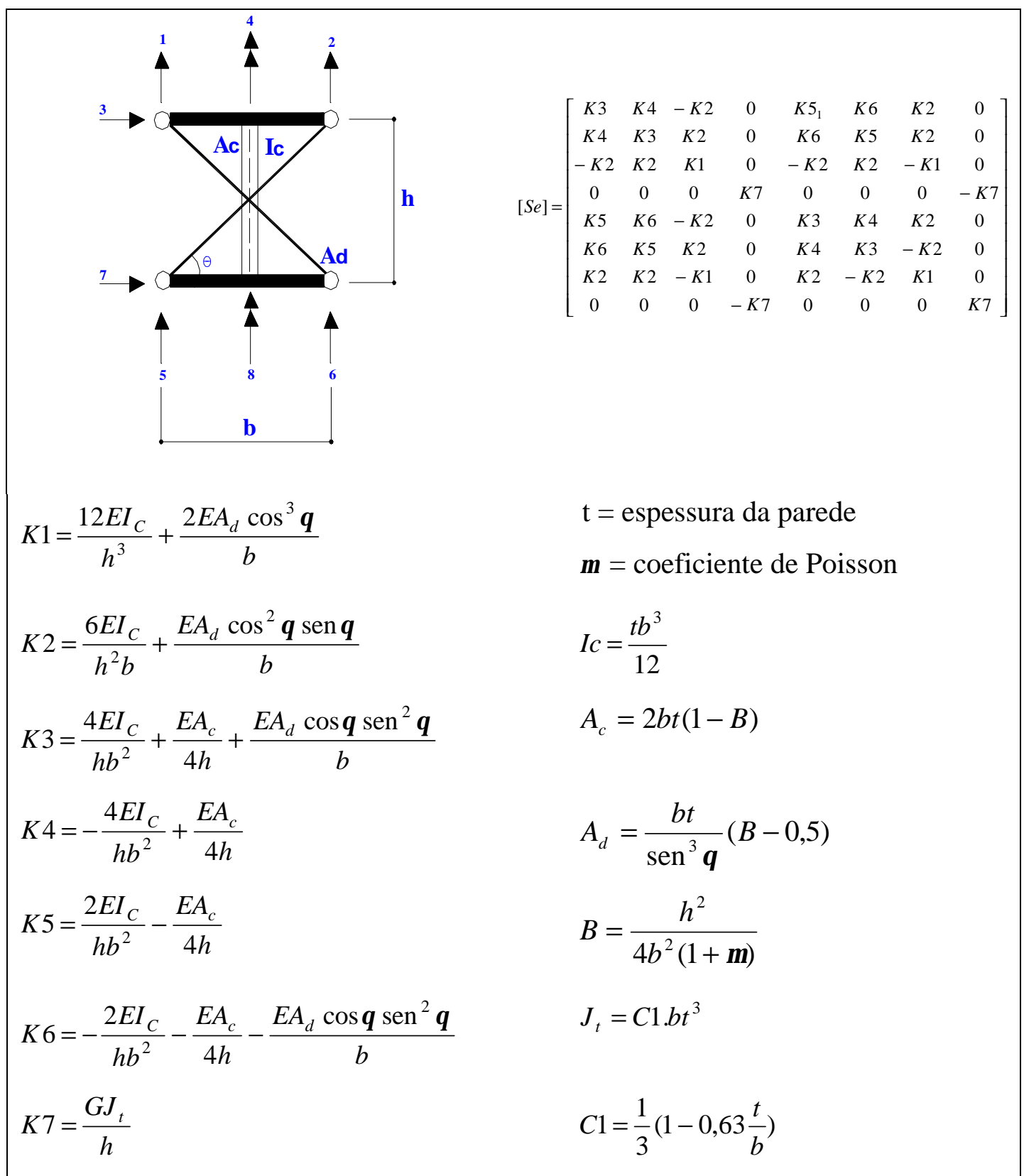

Para estas expressões o sub-índice "c" indica valores para a coluna e o subíndice "d" valores para as diagonais. 


\section{3 -CONTRIBUIÇÃO DOS ELEMENTOS NA SUBESTRUTURA}

\subsection{1 - GENERALIDADES}

Para a realização das análises estruturais, considerando as diversas modelagens propostas, foi utilizado o processo discreto, com o processo dos deslocamentos. Foi utilizada ainda uma outra modelagem pelo método dos elementos finitos.

Para as análises efetuadas em teoria de segunda ordem, foram adotados processos da estática clássica. No processo, a estrutura é considerada inicialmente na posição indeformada e a ela são aplicadas as ações verticais e horizontais. Após o carregamento todos os esforços resistentes e deslocamentos da estrutura são determinados.

Como na análise em segunda ordem as equações formuladas, em termos dos esforços, não são lineares é utilizado, para resolução da estrutura, um processo iterativo. O processo adotado, denominado de técnica da iteração direta, promove diversas atualizações da matriz de rigidez. A cada iteração os esforços calculados na etapa anterior são utilizados na atualização da matriz de rigidez, contribuindo na degenerescência gradativa da matriz da estrutura. Esse fator ocasiona um aumento nas deformações que, após um certo limite, começam a introduzir esforços adicionais significativos na estrutura, denominados de esforços de segunda ordem.

A verificação da convergência dos resultados é feita em termos dos deslocamentos, sendo necessária a determinação prévia de um valor de tolerância. $\mathrm{Na}$ realidade este valor funcionará como um indicador da posição de equilíbrio da estrutura após a realização de várias iterações.

Para o processamento das estruturas será utilizado o processo de subestruturação, baseado na divisão da estrutura em diversas subestruturas, as quais são resolvidas por partes.

Para as lajes será adotado um comportamento estrutural de corpo rígido, ou seja, o plano da laje permanecerá indeformável nessa direção. Isto faz com que, todos os pontos sobre a laje, apresentem o mesmos deslocamentos relativos de 
translação, neste plano, e rotação, normal à ele. A rigidez transversal da laje não será considerada.

\subsubsection{1 - PROCESSO DE SUBESTRUTURAÇÃO}

A automação dos cálculos dos deslocamentos e esforços resistentes das estruturas de edifícios altos pode, muitas vezes, constituir um problema computacional. Isto porque tal análise envolve um elevado número de elementos que, aliado à limitação da memória central dos microcomputadores, torna necessário o emprego de técnicas computacionais que sejam capazes de viabilizar o processamento.

Para resolver este problema, muitos pesquisadores adotam o processo de subestruturação. Este processo consiste na subdivisão da estrutura em subestruturas, as quais são resolvidas por partes utilizando a memória central, armazenando na memória auxiliar dados necessários à complementação dos cálculos, tornando possível a resolução de estruturas de edifícios de elevado número de pavimentos.

Para as análises desenvolvidas neste trabalho, uma substrutura será constituída por um único pavimento.

As subestruturas são calculadas segundo sistema de coordenadas globais. Essas coordenadas são classificadas como internas e externas. De acordo com o processo, as coordenadas denominadas internas podem ser reduzidas às externas através de um processo de decomposição matricial. Realizado para cada subestrutura, o processo inicia na laje superior e se desenvolve até o primeiro pavimento. MATIAS (1997), procura esquematizar de maneira simplificada o processo através de uma estrutura plana constituída de três subestruturas, ver figura 31 . O exemplo apresenta uma subestrutura formada por dois pavimentos apenas para facilitar a ilustração do processo. 


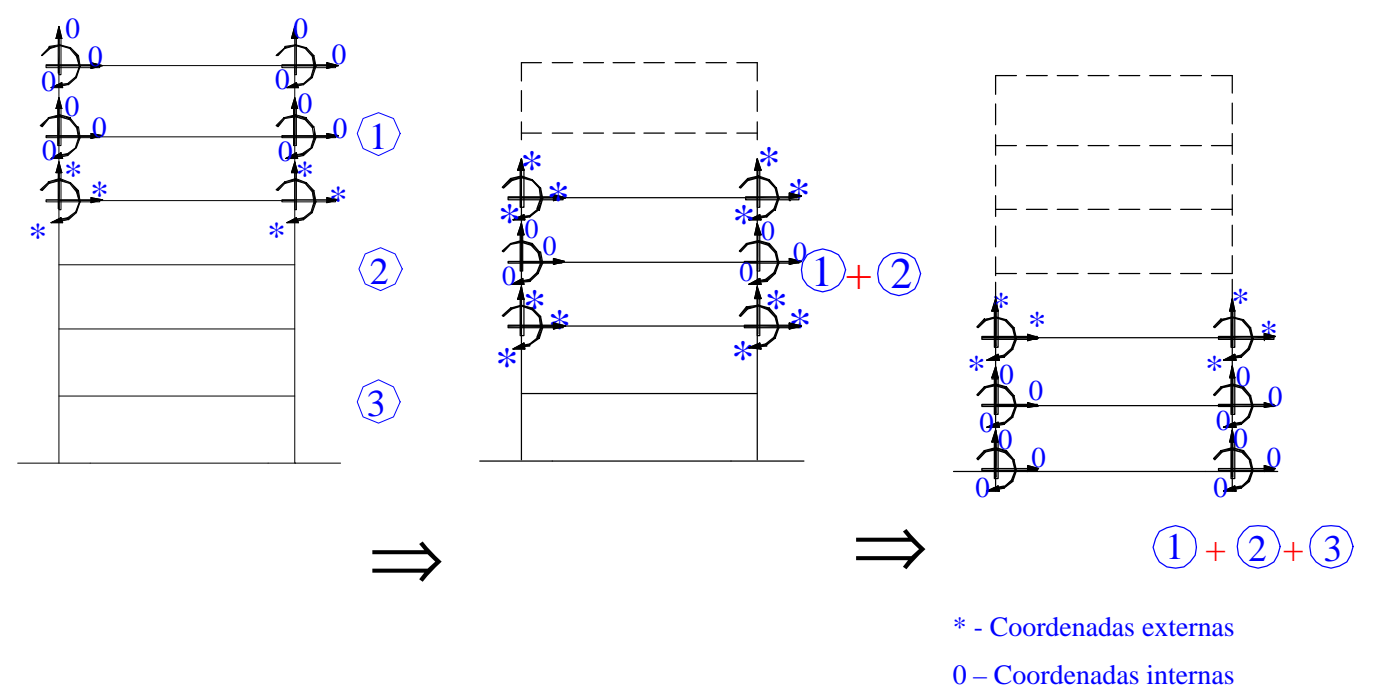

Figura 31 - Esquema simplificado do processo de subestruturação - MATIAS(1997)

\subsubsection{2 - COORDENADAS DA SUBESTRUTURA}

Como é adotado para as lajes um comportamento de corpo rígido, todos os elementos incidentes na substrutura terão suas coordenadas, dependentes desse movimento, transladadas para um ponto escolhido de forma arbitrária e denominado de nó mestre. O nó mestre nada mais é que o ponto onde estão contidas todas as coordenadas de translação horizontal e rotação normal ao plano da laje, podendo ocupar qualquer ponto deste plano.

Em seu trabalho, MATIAS (1997) apresenta toda a formulação necessária à consideração da rigidez de alguns dos elementos utilizados nas modelagens propostas. As modelagens referidas são: modelagem por pilar parede isolado e modelagem por barra de seção delgada considerando ou não teoria de flexo-torção.

Na figura 32 encontra-se ilustrada uma subestrutura modelo e seu sistema de coordenadas. Nesta subestrutura estão presentes o elemento YAGUI, denominado por ELM-0Y, e um elemento, denominado de ELM-04, capaz de simular o comportamento dos segmentos de núcleo para a modelagem por pilar parede isolado, modelagem por barra de seção delgada não considerando a teoria de flexo-torção ou demais pilares existentes na estrutura de contraventamento. 


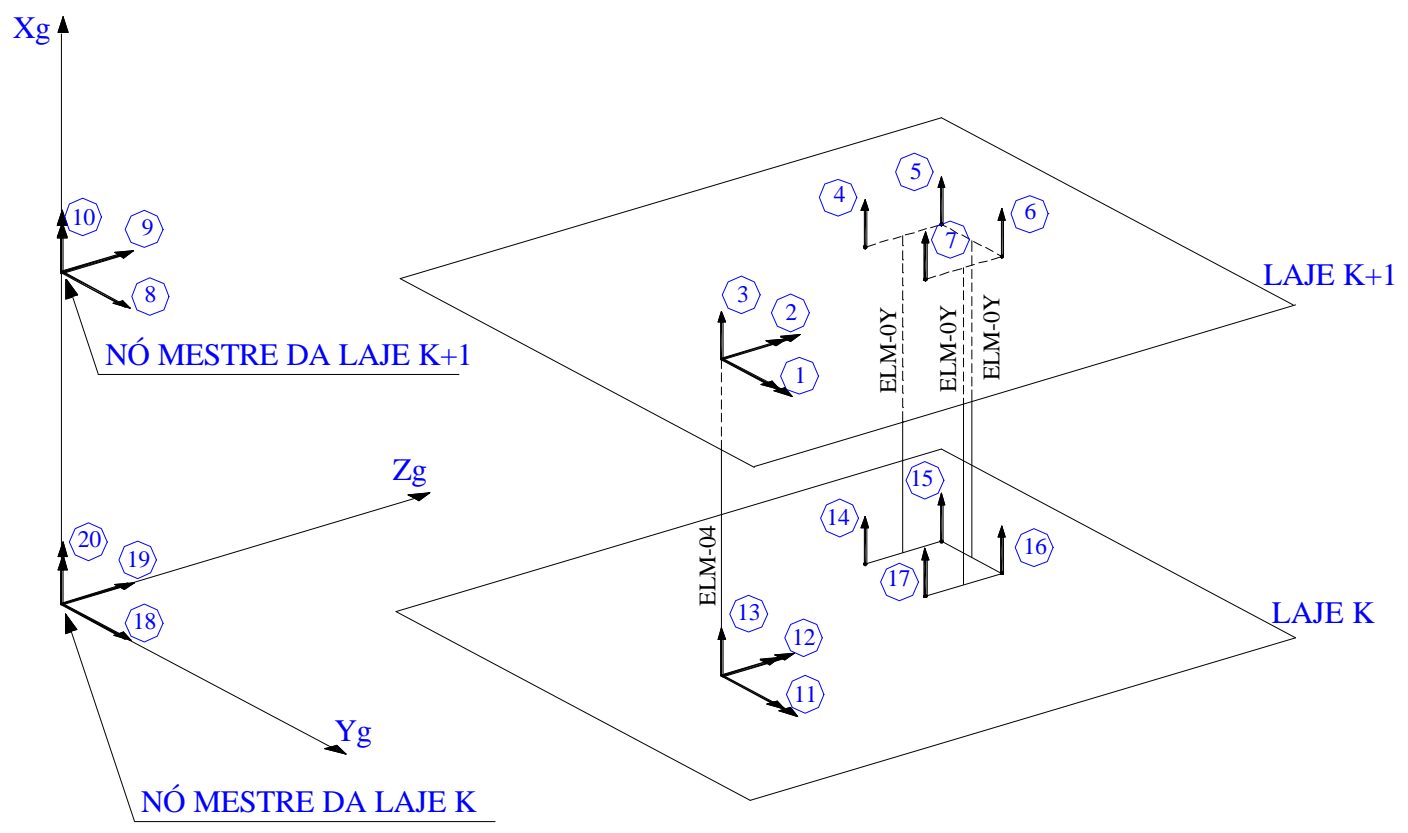

Figura 32 - Sistema de coordenadas de uma subestrutura modelo

\subsection{2 - CONTRIBUIÇÃO DO ELEMENTO NA SUBESTRUTURA PARA A MODELAGEM POR BARRA DE SEÇÃO DELGADA CONSIDERANDO A TEORIA DE FLEXO-TORÇÃO}

Podendo ser qualquer o ângulo de incidência do núcleo na subestrutura, ver figura 33, suas coordenadas deverão ser rotacionadas do sistema de referência local para o global com o auxílio da matriz de rotação $\left[B e_{f}\right]$. 

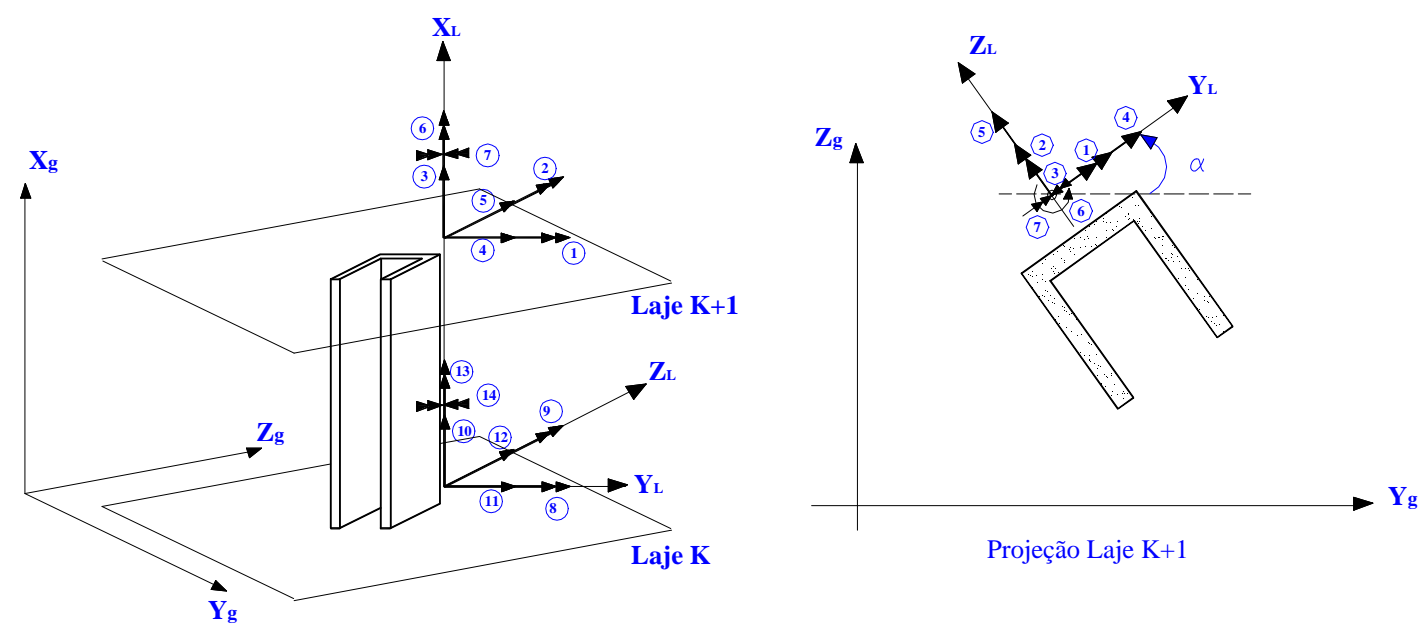

Figura 33 - Rotação das coordenadas do elemento - Modelagem por barra de seção delgada considerando a flexo-torção

$$
\left[B e_{f}\right]_{j}=\left[\begin{array}{cccccc}
{\left[b e_{f}\right]} & {[0]} & {[N]} & {[0]} & {[0]} & {[N]} \\
{[0]} & {\left[b e_{f}\right]} & {[N]} & {[0]} & {[0]} & {[N]} \\
{[L]} & {[L]} & {[1]} & {[L]} & {[L]} & {[1]} \\
{[0]} & {[0]} & {[N]} & {\left[b e_{f}\right]} & {[0]} & {[N]} \\
{[0]} & {[0]} & {[N]} & {[0]} & {\left[b e_{f}\right]} & {[N]} \\
{[L]} & {[L]} & {[1]} & {[L]} & {[L]} & {[1]}
\end{array}\right]_{(14 \times 14)}
$$

Onde:

$\left[b e_{f}\right]=\left[\begin{array}{ccc}\cos \alpha & \operatorname{sen} \alpha & 0 \\ -\operatorname{sen} \alpha & \cos \alpha & 0 \\ 0 & 0 & 1\end{array}\right]_{(3 \times 3)}$

[0] - matriz quadrada nula de dimensão 3

[L] - matriz linha de ordem 3 nula

$[\mathrm{N}]$ - matriz coluna de ordem 3 nula

[1] - matriz identidade de ordem1

A matriz de rigidez e o vetor de força equivalente, referidos ao sistema de eixos global, serão fornecidos pelas equações (38) e (39): 


$$
\begin{aligned}
& {\left[\operatorname{Reg}_{f}\right]=\left[\mathrm{Be} e_{f}\right]_{j}^{T}\left[\operatorname{Rel}_{f}\right]_{j}\left[\mathrm{Be} e_{f}\right]_{j}} \\
& {\left[\mathrm{Feg}_{f}\right]=\left[\mathrm{Be} e_{f}\right]_{j}^{T}\left[\mathrm{Fel} l_{f}\right]_{j}}
\end{aligned}
$$

Onde:

$\left[\operatorname{Re} g_{f}\right]$ - Matriz de rigidez do elemento de dimensão 14 na direção das coordenadas globais

$\left[\operatorname{Re} l_{y}\right]$ - Matriz de rigidez do elemento de dimensão 14 na direção das coordenadas locais

$\left[\mathrm{Feg}_{f}\right]$ - Vetor de forças equivalentes na direção das coordenadas globais

$\left[\mathrm{Fel}_{f}\right]$ - Vetor de forças equivalentes na direção das coordenadas locais

Todas as coordenadas, do elemento, que forem dependentes do movimento de corpo rígido da laje, serão transladas para o nó mestre através da matriz de translação $\left[m t_{f}\right]$, de acordo com a equação 40 .

$$
\begin{aligned}
& {\left[m t_{f}\right]_{j}=\left[\begin{array}{ccc}
1 & 0 & -Z_{j} \\
0 & 1 & Y_{j} \\
0 & 0 & 1
\end{array}\right]} \\
& {\left[\overline{\operatorname{Re}_{f}}\right]_{j}=\left[m t_{f}\right]_{j}^{T} \cdot\left[r e_{f}\right]_{j} \cdot\left[m t_{f}\right]_{j}}
\end{aligned}
$$

Onde:

$Y j$ - Distância y do nó mestre ao elemento j

$Z j$ - Distância z do nó mestre ao elemento j 
$\left[r e_{f}\right]_{\mathrm{j}}$ - Representa as quatro submatrizes quadradas de dimensão 3, que reúnem os coeficientes de rigidez relacionados com o movimento de corpo rígido da laje.

A contribuição do elemento e suas ações aplicadas na matriz de rigidez e no vetor de forças nodais da subestrutura, são fornecidos pelas equações 41 e 42 respectivamente.

$$
\begin{aligned}
& {\left[K_{f}\right]=\sum_{j=1}^{N f}\left[\operatorname{Re}_{g f}\right]_{j}} \\
& \left\{F_{f}\right\}=\sum_{j=1}^{N f}\left[F e_{g f}\right]_{j}
\end{aligned}
$$

$\left[K_{f}\right]$ - Matriz de rigidez da subestrutura apenas com a rigidez dos elementos de núcleo.

$\left\{F_{f}\right\}$ - Vetor de forças nodais da subestrutura apenas com as ações aplicadas nos elementos de núcleo.

$N f$ - Número de elementos de núcleo na substrutura.

\subsection{3 - CONTRIBUIÇÃO DO ELEMENTO NA SUBESTRUTURA PARA A MODELAGEM POR BARRA DE SEÇÃO DELGADA NÃO CONSIDERANDO A TEORIA DE FLEXO-TORÇÃO}

Como já mencionado anteriormente, podendo ser qualquer a incidência do elemento de núcleo na subestrutura, é necessária a utilização de uma matriz de rotação $\left[B e_{p}\right]$ capaz de rotacionar o sistema de referência local, do elemento, para o global, da subestrutura. 

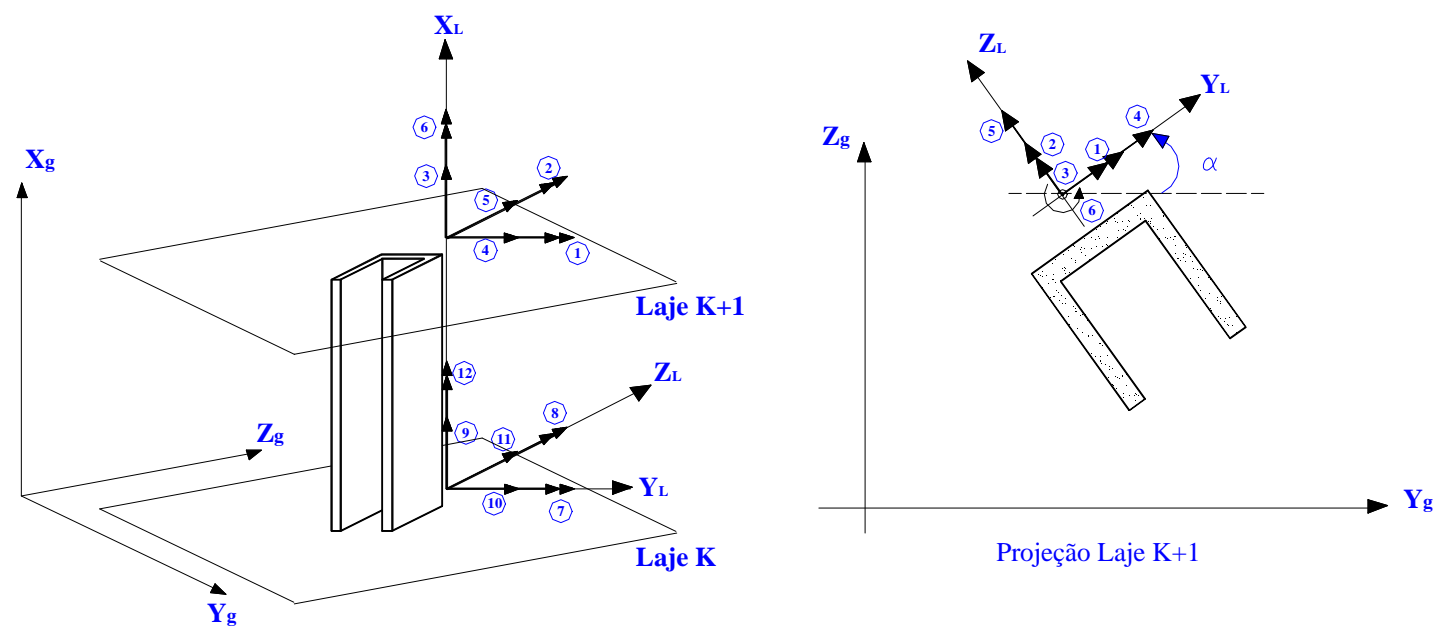

Figura 34 - Rotação das coordenadas do elemento - Modelagem de barra de seção delgada sem a consideração da teoria flexo-torção

$\left[B e_{s f}\right]=\left[\begin{array}{cccc}{\left[b e_{s f}\right]} & {[0]} & {[0]} & {[0]} \\ {[0]} & {\left[b e_{s f}\right]} & {[0]} & {[0]} \\ {[0]} & {[0]} & {\left[b e_{s f}\right]} & {[0]} \\ {[0]} & {[0]} & {[0]} & {\left[b e_{s f}\right]}\end{array}\right]$

Onde:

$\left[b e_{s f}\right]=\left[\begin{array}{ccc}\cos \alpha & \operatorname{sen} \alpha & 0 \\ -\operatorname{sen} \alpha & \cos \alpha & 0 \\ 0 & 0 & 1\end{array}\right]$

A matriz de rigidez e o vetor de força equivalente, referidos ao sistema de eixos global, serão fornecidos pelas equações (43) e (44):

$$
\begin{aligned}
& {\left[\operatorname{Reg}_{s f}\right]=\left[\mathrm{Be} e_{s f}\right]_{j}^{T}\left[\operatorname{Rel}_{s f}\right]_{j}\left[\mathrm{Be}_{s f}\right]_{j}} \\
& {\left[\mathrm{Feg}_{s f}\right]=\left[\mathrm{Be} e_{s f}\right]_{j}^{T}\left[\mathrm{Fel} l_{s f}\right]_{j}}
\end{aligned}
$$


Onde:

$\left[\operatorname{Re} g_{s f}\right]$ - Matriz de rigidez do elemento de dimensão 12 na direção das coordenadas globais

$\left[\operatorname{Re} l_{s f}\right]$ - Matriz de rigidez do elemento de dimensão 12 na direção das coordenadas locais

$\left[\mathrm{Feg}_{s f}\right]$ - Vetor de forças equivalentes na direção das coordenadas globais

$\left[\mathrm{Fel}_{s f}\right]$ - Vetor de forças equivalentes na direção das coordenadas locais

Como todas as modelagens consideram a laje como um diafragma rígido, também nesta modelagem todas as coordenadas que forem dependentes deste movimento, serão transladas para o nó mestre através de uma matriz de translação $\left[m t_{s f}\right]$, de acordo com a equação (45).

$$
\begin{aligned}
& {\left[m t_{s f}\right]_{j}=\left[\begin{array}{ccc}
1 & 0 & -Z_{j} \\
0 & 1 & Y_{j} \\
0 & 0 & 1
\end{array}\right]} \\
& {\left[\overline{\operatorname{Re}_{s f}}\right]_{j}=\left[m t_{s f}\right]_{j}^{T} \cdot\left[r e_{s f}\right]_{j} \cdot\left[m t_{s f}\right]_{j}}
\end{aligned}
$$

Onde:

$\left[r e_{s f}\right]_{j}$ - Representa as quatro submatrizes quadradas de dimensão 3, que reúnem os coeficientes de rigidez relacionados com o movimento de corpo rígido da laje. 
A contribuição da rigidez deste elemento e suas ações aplicadas na matriz de rigidez e no vetor de forças nodais da subestrutura, é fornecida pelas equações (46) e (47) respectivamente.

$$
\begin{aligned}
& {\left[K_{s f}\right]=\sum_{j=1}^{N s f}\left[\operatorname{Re}_{g s f}\right]_{j}} \\
& \left\{F_{s f}\right\}=\sum_{j=1}^{N s f}\left[F e_{g s f}\right]_{j}
\end{aligned}
$$

Onde:

$\left[K_{s f}\right]$ - Matriz de rigidez da subestrutura apenas com a rigidez dos elementos de núcleo.

$\left\{F_{s f}\right\}$ - Vetor de forças nodais da subestrutura apenas com as ações aplicadas nos elementos de núcleo.

$N_{s f}-$ Número de elementos de núcleo na subestrutura.

\subsection{4 - CONTRIBUIÇÃO DO ELEMENTO NA SUBESTRUTURA PARA A MODELAGEM POR PILAR PAREDE ISOLADO}

Para a rotação do sistema de referência nesta modelagem será utilizada a matriz de rotação $\left[B e_{p}\right]$.

onde:

$\left[B e_{p}\right]=\left[B e_{s f}\right]$ 

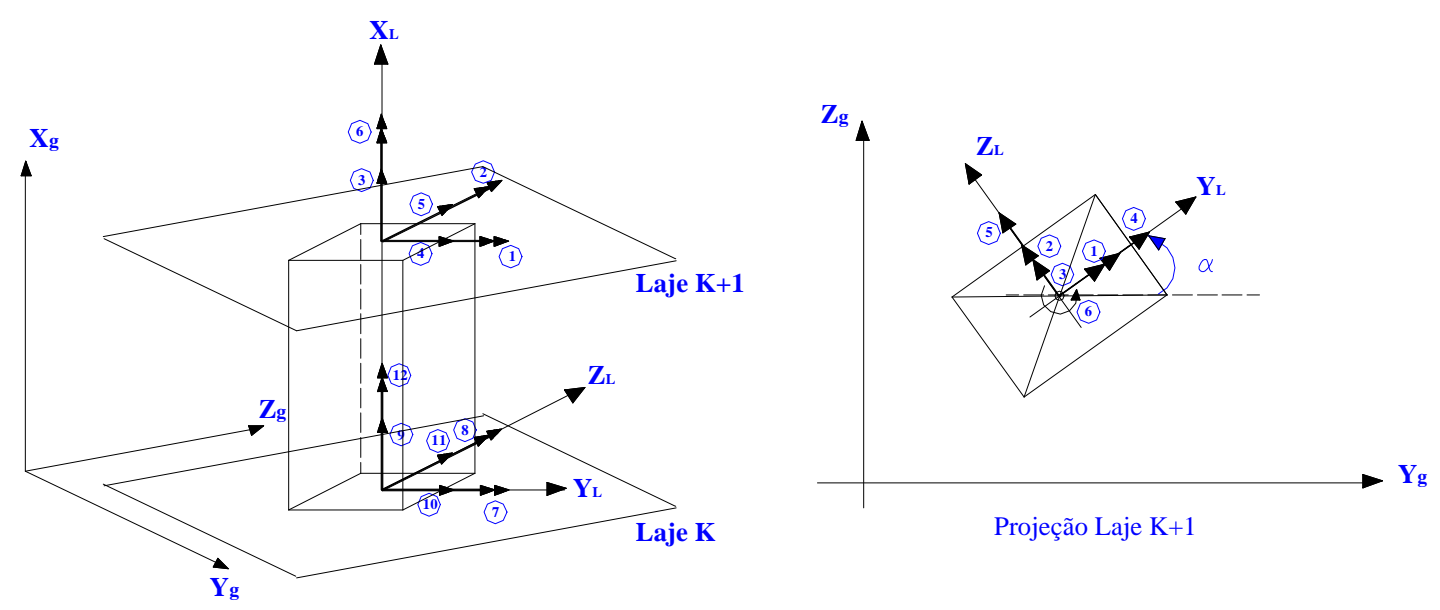

Figura 35 - Rotação das coordenadas do elemento - Modelagem por pilar parede isolado - Representação de apenas um segmento de parede de núcleo

A matriz de rigidez e o vetor de força equivalente, referidos ao sistema de eixos global, serão fornecidos pelas equações (48) e (49):

$$
\begin{aligned}
& {\left[\operatorname{Reg} g_{p}\right]=\left[B e_{p}\right]_{j}^{T}\left[\operatorname{Rel}_{p}\right]_{j}\left[B e_{p}\right]_{j}} \\
& {\left[\mathrm{Feg}_{p}\right]=\left[\mathrm{Be}_{p}\right]_{j}^{T}\left[\mathrm{Fel}_{p}\right]_{j}}
\end{aligned}
$$

onde:

$\left[\operatorname{Re} g_{p}\right]$ - Matriz de rigidez do elemento de dimensão 12 na direção das coordenadas globais

$\left[\operatorname{Re} l_{p}\right]$ - Matriz de rigidez do elemento de dimensão 12 na direção das coordenadas locais

$\left[\mathrm{Feg}_{p}\right]$ - Vetor de forças equivalentes na direção das coordenadas globais

$\left[\mathrm{Fel}_{p}\right]-$ Vetor de forças equivalentes na direção das coordenadas locais 
Nesta modelagem a translação das coordenadas, que forem dependentes do movimento de corpo rígido para o nó mestre, será feita através da matriz de translação $\left[m t_{p}\right]$, de acordo com a equação (50).

$$
\begin{aligned}
& {\left[m t_{p}\right]_{j}=\left[\begin{array}{ccc}
1 & 0 & -Z_{j} \\
0 & 1 & Y_{j} \\
0 & 0 & 1
\end{array}\right]} \\
& {\left[\overline{\operatorname{Re}_{p}}\right]_{j}=\left[m t_{p}\right]_{j}^{T} \cdot\left[r e_{p}\right]_{j} \cdot\left[m t_{p}\right]_{j}}
\end{aligned}
$$

onde:

$\left[\mathrm{re}_{\mathrm{p}}\right]_{\mathrm{j}}$ - Representa as quatro submatrizes quadradas de dimensão 3, que reúnem os coeficientes de rigidez relacionados com o movimento de corpo rígido da laje.

Para o elemento desta modelagem a contribuição da rigidez e suas ações aplicadas na matriz de rigidez e no vetor de forças nodais da subestrutura, serão realizadas utilizando as equações dadas em (51) e (52), respectivamente.

$$
\begin{aligned}
& {\left[K_{p}\right]=\sum_{j=1}^{N p}\left[\operatorname{Re} g_{p}\right]_{j}} \\
& \left\{F_{p}\right\}=\sum_{j=1}^{N p}\left[F e g_{p}\right]_{j}
\end{aligned}
$$

$\left[K_{p}\right]$ - Matriz de rigidez da subestrutura apenas com a rigidez dos elementos de núcleo.

$\left\{F_{p}\right\}$ - Vetor de forças nodais da subestrutura apenas com as ações aplicadas nos elementos de núcleo.

$N_{p}$ - Número de segmentos dos elementos de núcleo na subestrutura. 


\subsection{5 - CONTRIBUIÇÃO DO ELEMENTO PARA O MODELO PROPOSTO POR YAGUI}

De acordo com o eixo de referência global adotado para a estrutura, o elemento YAGUI (ELM-0Y) poderá incidir na substrutura de um ângulo qualquer $\alpha_{Y}$ (ver figura 36).

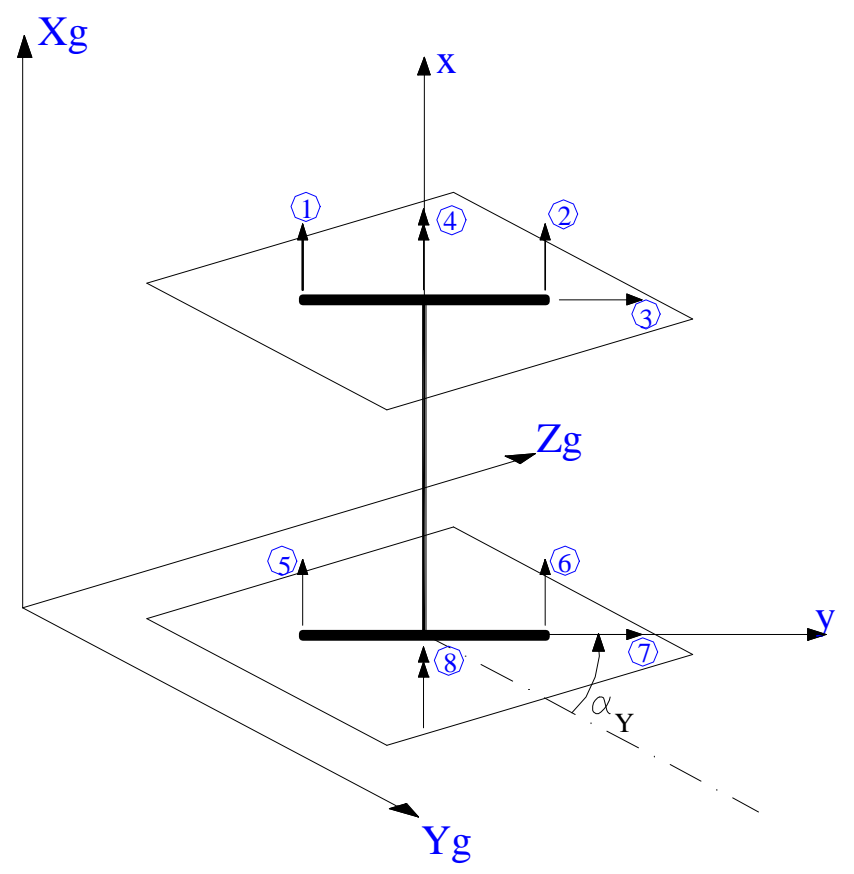

Figura 36 - Sistema de eixo local do elemento ELM-0Y

Para este elemento é necessária a rotação do seu sistema local de eixos para o sistema global da substrutura, feita através da matriz de rotação $\left[\mathrm{Be}_{\mathrm{Y}}\right]_{\mathrm{j}}$, apresentada a seguir, para o elemento genérico j:

$$
\left[B e_{Y}\right]_{j}=\left[\begin{array}{cc}
{\left[b e_{y}\right]} & {[0]} \\
{[0]} & {\left[b e_{y}\right]}
\end{array}\right]_{(8 \times 10)}
$$


Onde:

$$
\left[b e_{Y}\right]=\left[\begin{array}{ccccc}
1 & 0 & 0 & 0 & 0 \\
0 & 1 & 0 & 0 & 0 \\
0 & 0 & \cos \alpha_{Y} & \operatorname{sen} \alpha_{Y} & 0 \\
0 & 0 & 0 & 0 & 1
\end{array}\right]_{(4 X 5)}
$$

A matriz de rigidez e o vetor de força equivalente, referidos ao sistema de eixos global, serão fornecidos pelas equações (53) e (54):

$$
\begin{aligned}
& {\left[\operatorname{Re} g_{y}\right]=\left[B e_{Y}\right]_{j}^{T}\left[\operatorname{Re} l_{Y}\right]_{j}\left[B e_{Y}\right]} \\
& {\left[F e g_{y}\right]=\left[B e_{Y}\right]_{j}^{T}\left[\mathrm{Fel}_{Y}\right]_{j}}
\end{aligned}
$$

Onde:

$\left[\operatorname{Re} g_{y}\right]$ - Matriz de rigidez do elemento de dimensão (10X10) na direção das coordenadas globais

$\left[\operatorname{Re} l_{y}\right]$ - Matriz de rigidez do elemento de dimensão (8X8) na direção das coordenadas locais

$\left[\mathrm{Feg}_{y}\right]$ - Vetor de forças equivalentes na direção das coordenadas globais

$\left[\mathrm{Fel}_{y}\right]-$ Vetor de forças equivalentes na direção das coordenadas locais

Ao se considerar a laje com um comportamento estrutural semelhante ao diafragma rígido, as coordenadas do elemento, ELM-0Y, dependentes do movimento de corpo rígido (3\4 e $7 \backslash 8)$, serão transladadas para o nó mestre (C1,C2 e C3), ver figura 37. 


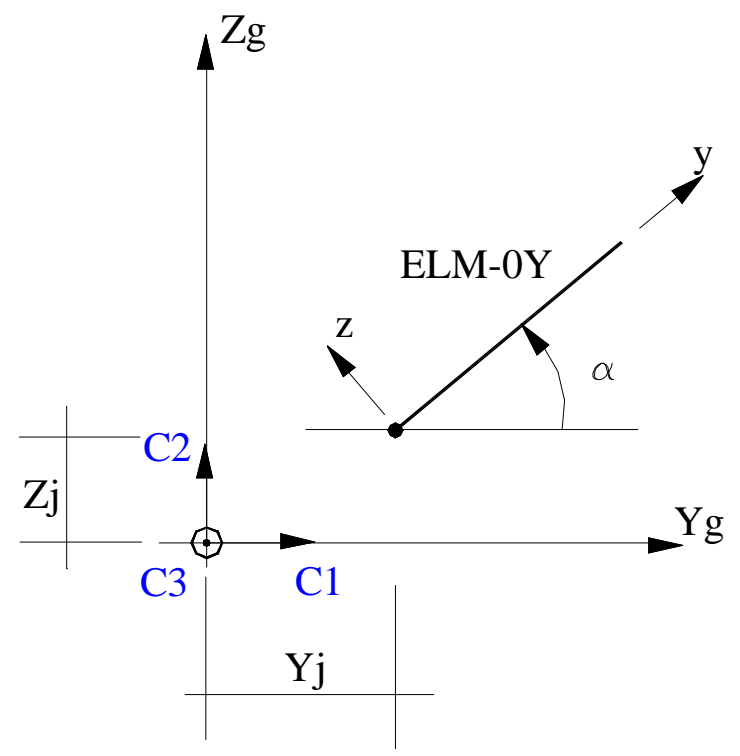

Figura 37 - Translação de coordenadas do ELM-OY para o nó mestre

Para essa translação será utilizada a matriz de translação $\left[M t_{y}\right]_{\mathrm{j}}$, de acordo com a equação (55).

$\left[\overline{r e}_{y}\right]_{j}=\left[M t_{Y}\right]_{j}^{T}\left[r e_{Y}\right]_{j}\left[M t_{Y}\right]_{j}$

Onde:

$$
\left[M t_{y}\right]=\left[\begin{array}{ccc}
1 & 0 & -Z j \\
0 & 1 & Y j \\
0 & 0 & 1
\end{array}\right]_{(3 \times 3)}
$$

Yj - Distância 'y ' do nó mestre ao elemento j

$\mathrm{Zj}$ - Distância ' $\mathrm{z}$ ' do nó mestre ao elemento j

$\left[\overline{r e_{y}}\right]-$ Representa as quatro submatrizes quadradas de dimensão 3, que reúnem os coeficientes de rigidez relacionados com o movimento de corpo rígido da laje 
A contribuição da rigidez destes elementos e de suas ações, aplicadas na matriz de rigidez e no vetor de forças nodais da subestrutura, será realizada utilizando as equações (56) e (57), respectivamente.

$$
\begin{aligned}
& {[K y]=\sum_{j=i}^{N E Y}\left[\operatorname{Re} g_{y}\right]_{j}} \\
& \{F y\}=\sum_{j=i}^{N E Y}\left\{F e g_{y}\right\}_{j}
\end{aligned}
$$

Onde:

$[K y]$ - Matriz de rigidez da substrutura apenas com a rigidez dos elementos ELM-0Y.

$\{F y\}$ - Vetor de forças nodais da substrutura apenas com as ações aplicadas nos ELM-0Y.

NEY - Número de elementos ELM-0Y na substrutura.

\subsection{6 - CONTRIBUIÇÃO DO ELEMENTO PARA O MODELO PROPOSTO} POR SMITH et al

Como já pôde ser observado, o modelo proposto por SMITH et al possui as mesmas coordenadas do elemento proposto por YAGUI. A diferença existente entre as modelagens está na presença das barra diagonais no modelo proposto por SMITH et al, levando à obtenção de matrizes de rigidez com coeficientes diferentes para ambas as modelagens. 


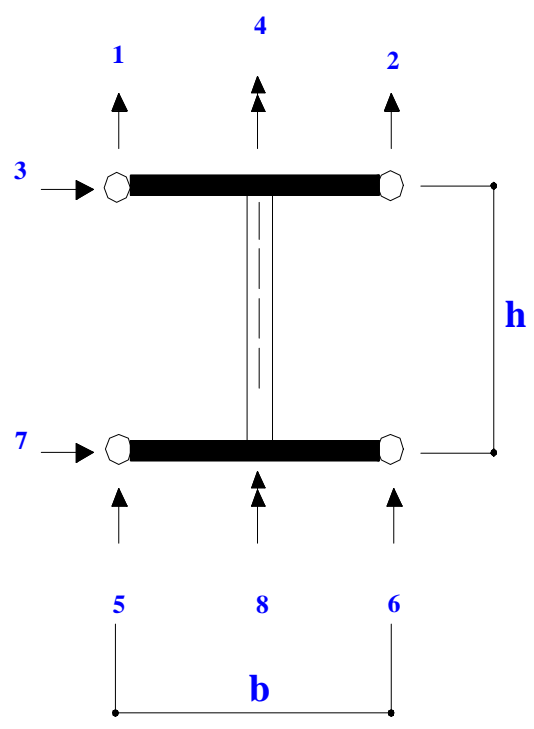

a) Modelo proposto por YAGUI (1971)

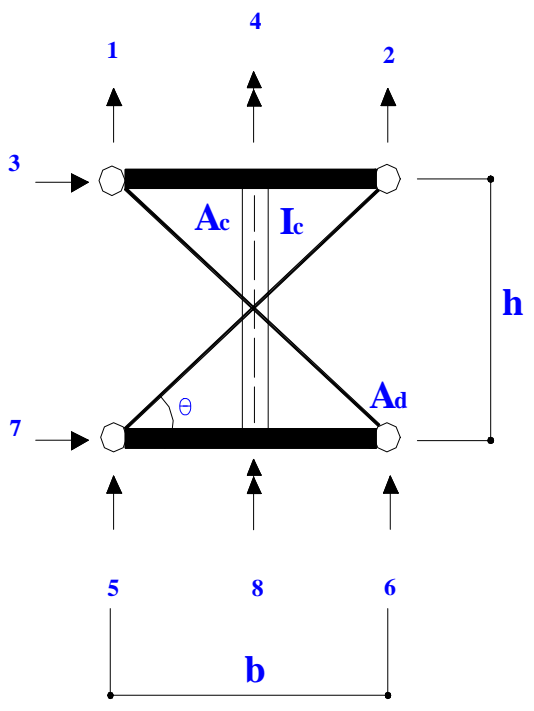

b) Modelo proposto por SMITH et al (1981/1984)

\section{Figura 38 - Semelhança entre as modelagens}

Porém, a diferença obtida nos coeficientes de rigidez das matrizes, para ambas as modelagens, não interfere na contribuição dos elementos na subestrutura. Portanto, sendo a esquematização estrutural do elemento e os tipos de coordenadas adotadas idênticas para ambas as modelagens, a contribuição do elemento na modelagem proposta por SMITH et al será efetuada de maneira semelhante à da modelagem proposta por YAGUI, sendo apenas alterada a matriz de rigidez do elemento. 


\section{6. análise das estruturas}

"Chegará uma altura que você acreditará que tudo acabou. Isso será o começo."

Louis L'Amour

\section{1 - INTRODUÇÃO}

Para o processamento das estruturas, com a finalidade de analisar $o$ comportamento das estruturas de contraventamento de edifícios altos, diante das diferentes modelagens propostas para o núcleo resistente, foi desenvolvimento um programa, em linguagem FORTRAN 90. Este programa permite a escolha da modelagem a ser adotada para o núcleo resistente, com a opção entre 4 modelos diferentes.

Foram analisadas três estruturas de edifícios retiradas de teses e dissertações pesquisadas durante o período de estudo e realização deste trabalho. As estruturas foram escolhidas com o objetivo de facilitar o processo comparativo, uma vez que estruturas muito complexas não permitiriam facilmente a interpretação do comportamente assumido pela estrutura de contraventamento diante de cada um dos modelos adotados.

A primeira estrutura, um núcleo isolado, foi processada objetivando a verificação da coerência dos resultados fornecidos pelo programa desenvolvido. Por se tratar de uma estrutura simplificada, a verificação pôde ser feita de maneira imediata com a constatação da coincidência existente entre os resultados fornecidos pelo programa aqui desenvolvido e demais programas existentes. Os programas 
utilizados para a comparação dos resultados foram: programa desenvolvido por YAGUI (1971) e atualizado por SERRA (1989), programa desenvolvido por MATIAS (1997) e o programa desenvolvido por GUILARDI (1999). Os programas desenvolvidos por YAGUI (1971) e por GUILARDI (1999), realizam apenas o processamento de estruturas de núcleo isolado, utilizando as modelagens propostas por YAGUI e por SMITH, respectivamente. Como não é objetivo deste trabalho a comparação entre programas, mas sim a comparação entre os diversos modelos adotados para o núcleo, os resultados extraídos dos demais programas não serão apresentados neste capítulo, uma vez que coincidem com os apresentados pelo programa aqui desenvolvido.

O segundo exemplo, extraído de SILVA (1989), também foi utilizado no processo de avaliação dos resultados fornecidos pelo programa aqui desenvolvido. Para este exemplo, foi introduzida a análise da estrutura considerando a modelagem do núcleo por pilares paredes isolados. Este tipo de modelagem foi adotada durante muito tempo por diversos escritórios de cálculo, devido a inexistência de softwares, no mercado, capazes de modelar o núcleo de uma maneira mais eficaz. A utilização desta modelagem pretende avaliar o desempenho deste modelo na simulação do comportamento do núcleo resistente, bem como, a sua influência sobre os demais elementos da estrutura de contraventamento (pilares e vigas). Para este exemplo será avaliado também o comportamento da estrutura diante das demais modelagens.

O terceiro exemplo, uma estrutura formada pela composição de pórticos e núcleos resistentes, foi extraído de TORRES (1999). Para este exemplo serão utilizadas as modelagens consideradas de melhor comportamento e processamento, verificadas a partir da análise dos exemplos anteriores.

Para o tratamento das modelagens serão adotadas as seguintes denominações:

YAGUI - Modelagem proposta por YAGUI

SMITH - Modelo prosposto por SMITH

SEM FLEXO - Modelagem por barra de seção delgada não considerando a teoria de flexo-torção.

COM FLEXO - Modelagem por barra de seção delgada considerando a teoria de flexo-torção.

P. ISOLADO - Modelagem por Pilar parede isolado 


\section{2 - EXEMPLO 1}

O primeiro exemplo escolhido é um modelo teórico de núcleo, tratado como uma viga em balanço. Esta estrutura foi retirada de YAGUI (1971), possuindo originariamente quatro pavimentos. Para a realização das análises, neste exemplo, será considerado um número maior de pavimentos a fim de verficar melhor o comportamento da estrutura ao longo da sua altura.

Para este exemplo foi admitido como carregamento somente um momento torçor teórico externo, aplicado no nó mestre da extremidade livre, com valor de 10,0 tf.cm. Foram supostos 10 diafragmas rígidos, com afastamento de $50 \mathrm{~cm}$. Os valores de E e G, módulos de elasticidade longitudinal e transversal respectivamente serão $2100 \mathrm{tf} / \mathrm{cm}^{2}$ e $800 \mathrm{tf} / \mathrm{cm}^{2}$. As paredes da estrutura possuem espessura de $1 \mathrm{~cm}$.
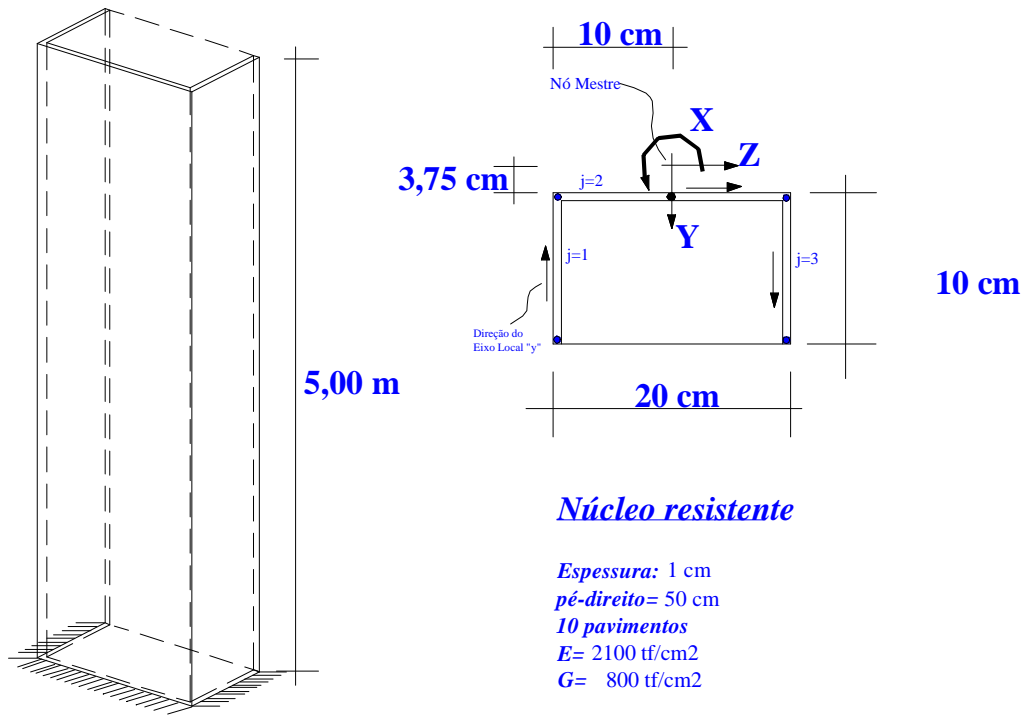

$$
\begin{aligned}
& \text { Núcleo resistente } \\
& \text { Espessura: } 1 \mathrm{~cm} \\
& \text { pé-direito }=50 \mathrm{~cm} \\
& \text { 10 pavimentos } \\
& E=2100 \mathrm{t} / \mathrm{cm} 2 \\
& G=800 \mathrm{tf} / \mathrm{cm} 2
\end{aligned}
$$

Figura 39-Estrutura teórica de núcleo idealizada por YAGUI(1971)

Como já comentado anteriormente, este primeiro exemplo teve como caráter primordial a verificação da confiabilidade dos resultados fornecidos pelo programa aqui desenvolvido. Esta constatação pôde ser verificada com a comparação entre os resultados fornecidos pelo programa desenvolvido e demais existentes, já relacionados.

Para as modelagens considerando ou não a teoria de flexo-torção, modelos $3 \mathrm{e}$ 4, a estrutura apresentou ausência de deslocamentos de translação em ambas as 
direções, Y e Z. Como os modelos 1 e 2, YAGUI e SMITH, não conseguem simular bem este comportamento, os deslocamentos na direção Z, de acordo com a tabela 2 , que deveriam ser nulos, apresentaram pequenos valores.

Tabela 02 - Valores da translação na direção $\mathrm{Zg}(\mathrm{cm})$, em cada pavimento

\begin{tabular}{|c|c|c|}
\hline \hline Pavimento & YAGUI & SMITH \\
\hline \hline 0 & 0.0000000 & 0.0000000 \\
\hline 1 & -0.0080171 & -0.0008815 \\
\hline 2 & -0.0122147 & -0.0013346 \\
\hline 3 & -0.0144125 & -0.0015675 \\
\hline 4 & -0.0155634 & -0.0016872 \\
\hline 5 & -0.0161663 & -0.0017488 \\
\hline 6 & -0.0164827 & -0.0017805 \\
\hline 7 & -0.0166496 & -0.0017969 \\
\hline 8 & -0.0167395 & -0.0018056 \\
\hline 9 & -0.0167912 & -0.0018104 \\
\hline 10 & -0.0168273 & -0.0018138 \\
\hline
\end{tabular}

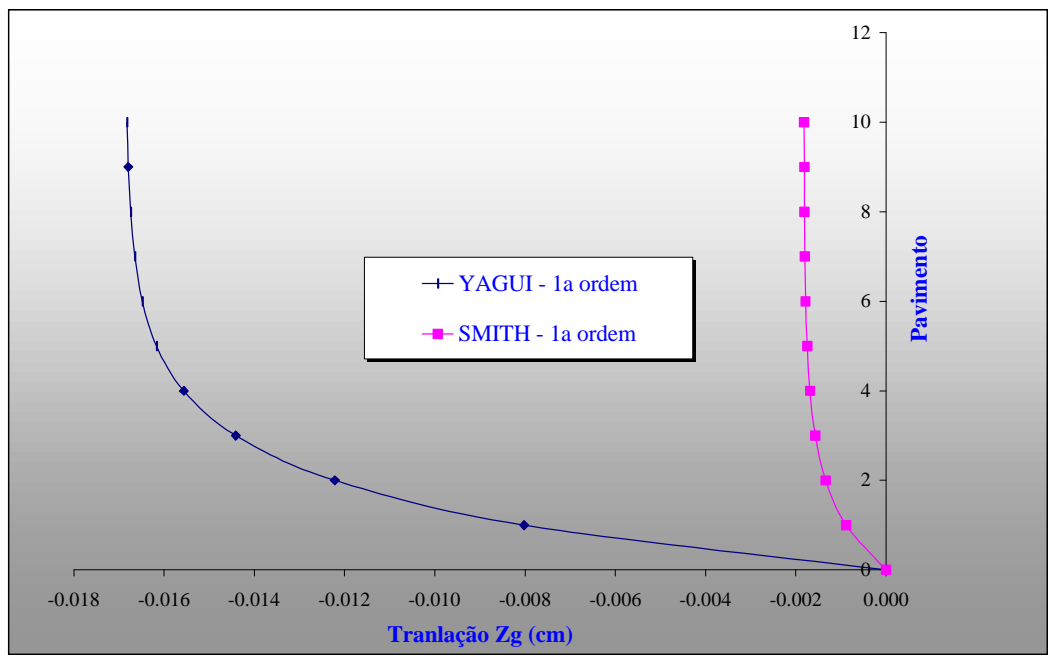

Figura 40 - Translação na direção Zg (cm) do centro de torção - 1 ${ }^{a}$ Ordem

Como pode ser observado, na figura 40, os resultados fornecidos pelo modelo 2, apresentam-se bem melhores que os fornecidos pelo modelo 1 , devido a maior proximidade com os deslocamentos nulos apresentado pelas demais teorias. Com base nestes resultados pôde ser constatada a ocorrência de uma perda de parte da rigidez ao cisalhamento do núcleo ocasionado pelo efeito do momento parasita, 
presente neste tipo de modelagem, e acentuado no modelo proposto por YAGUI. Pode-se concluir também que na modelagem proposta por SMITH, ao menos neste exemplo, o efeito do momento parasita é realmente minimizado pela presença das diagonais acrescidas ao modelo.

Para os resultados em rotação foram feitas análises em teoria de primeira e segunda ordem. Os resultados extraídos para cada um dos modelos são apresentados nas tabelas 3 e 4 , e na figura 41 .

Tabela 03 - Valores de rotação em torno do eixo $\mathrm{Xg}$, em cada pavimento - $\mathbf{1}^{\mathrm{a}}$ ordem

\begin{tabular}{|c|c|c|c|c||}
\hline \hline Andar & YAGUI & SMITH & SEM FLEXO & COM FLEXO \\
\hline \hline 0 & 0.0000000 & 0.0000000 & 0.000000 & 0.000000 \\
\hline 1 & 0.0138579 & 0.012191 & 0.046875 & 0.012558 \\
\hline 2 & 0.0445535 & 0.042368 & 0.093750 & 0.041693 \\
\hline 3 & 0.0840646 & 0.081789 & 0.140625 & 0.079397 \\
\hline 4 & 0.1281908 & 0.12596 & 0.187500 & 0.121530 \\
\hline 5 & 0.1747326 & 0.17258 & 0.234375 & 0.165950 \\
\hline 6 & 0.2225377 & 0.22045 & 0.281250 & 0.211560 \\
\hline 7 & 0.2710015 & 0.26896 & 0.328125 & 0.257770 \\
\hline 8 & 0.3198051 & 0.31779 & 0.375000 & 0.304300 \\
\hline 9 & 0.3687765 & 0.36679 & 0.421875 & 0.350970 \\
\hline 10 & 0.4178170 & 0.41585 & 0.468751 & 0.397710 \\
\hline
\end{tabular}

Tabela 04 - Valores de rotação em torno do eixo $\mathrm{Xg}$, em cada pavimento - $2^{\mathrm{a}}$ ordem

\begin{tabular}{|c|c|c|c|c||}
\hline Andar & YAGUI & SMITH & SEM FLEXO & COM FLEXO \\
\hline \hline 0 & 0.0000000 & 0.0000000 & 0.0000000 & 0.0000000 \\
\hline 1 & 0.0138650 & 0.0121979 & 0.0468750 & 0.0125578 \\
\hline 2 & 0.0445835 & 0.0423948 & 0.0937500 & 0.0416927 \\
\hline 3 & 0.0841210 & 0.0818409 & 0.1406250 & 0.0793968 \\
\hline 4 & 0.1282695 & 0.1260351 & 0.1875000 & 0.1215303 \\
\hline 5 & 0.1748277 & 0.1726655 & 0.2343750 & 0.1659530 \\
\hline 6 & 0.2226441 & 0.2205448 & 0.2812500 & 0.2115579 \\
\hline 7 & 0.2711153 & 0.2690625 & 0.3281250 & 0.2577715 \\
\hline 8 & 0.3199236 & 0.3179031 & 0.3750000 & 0.3042955 \\
\hline 9 & 0.3688980 & 0.3669007 & 0.4218750 & 0.3509713 \\
\hline 10 & 0.4179405 & 0.4159620 & 0.4687500 & 0.3977091 \\
\hline
\end{tabular}



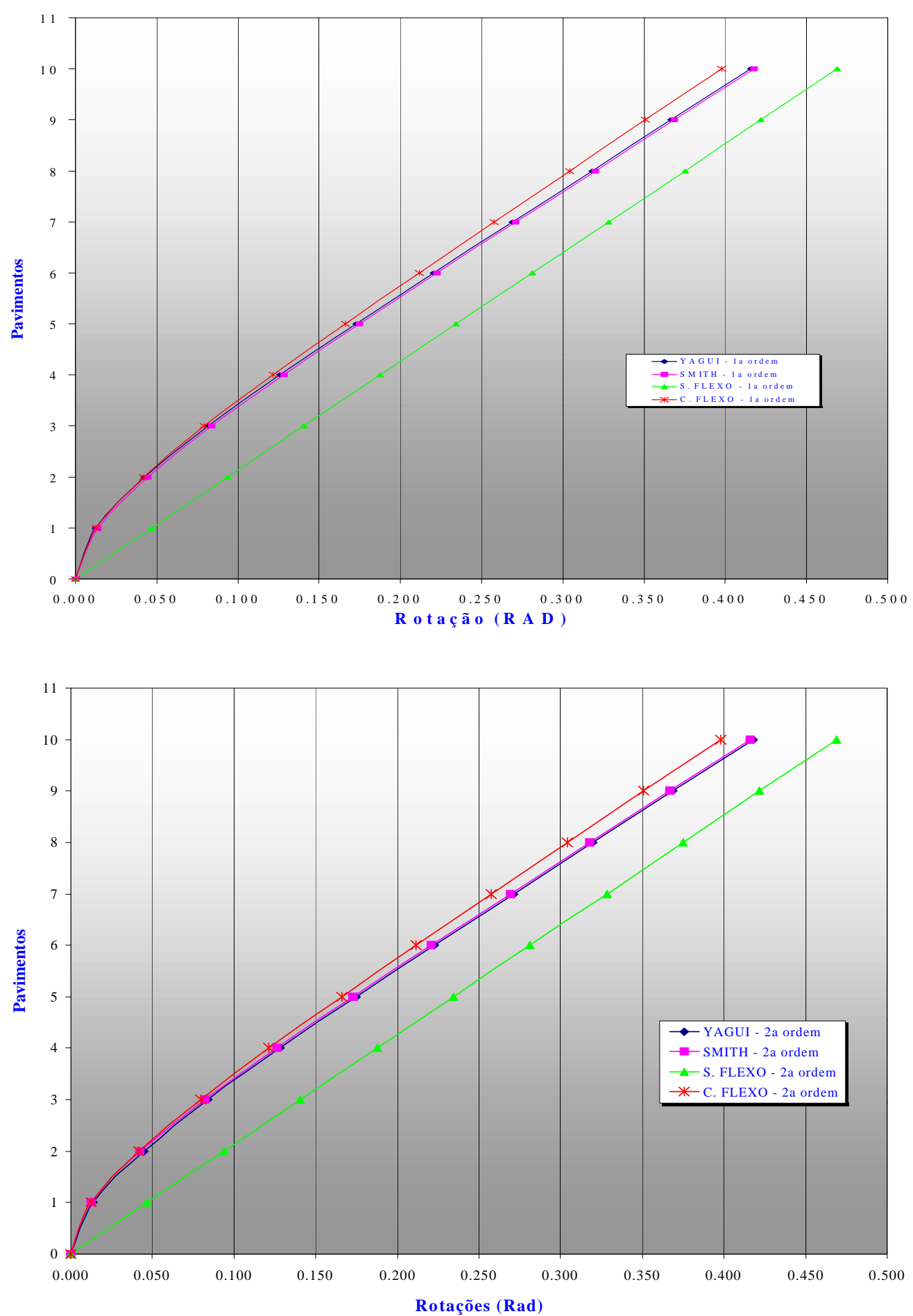

Figura 41 - Valores de rotação em torno do eixo Xg, em cada pavimento - (rad) Superior $-\mathbf{1}^{\mathrm{a}}$ ordem / Inferior $-\mathbf{2}^{\mathrm{a}}$ ordem 
Os modelos 1 e 2, modelagem por YAGUI e por SMITH, respectivamente, apresentaram pequena diferença numérica, entre seus resultados, de acordo com as tabelas 3 e 4, além de um comportamento em rotação semelhante ao apresentado pelo modelo 4 , de acordo com a figura 41 .

O modelo 3 apresentou, de acordo com a figura 41, um comportamento linear, bem diferente dos demais modelos. Este comportamento já era esperado, uma vez que, de acordo com as hipóteses de cálculo adotada pelo modelo, o efeito do empenamento da seção é desprezado. Esse resultado comprova a ineficiência do modelo 3, na representação do comportamento do núcleo, diante da torção.

Neste exemplo foram analisados também os deslocamentos longitudinais apresentados pela seção transversal do núcleo adotando as seguintes modelagens: modelo proposto por YAGUI, modelo proposto por SMITH e modelagem por barra de seção delagada considerando a teoria de flexo-torção, modelos 1,2 e 4 respectivamente. Os pontos a que se referem os valores em deslocamentos estão especificados na figura 42 e os resultados finais, para o último pavimento, na tabela 5.

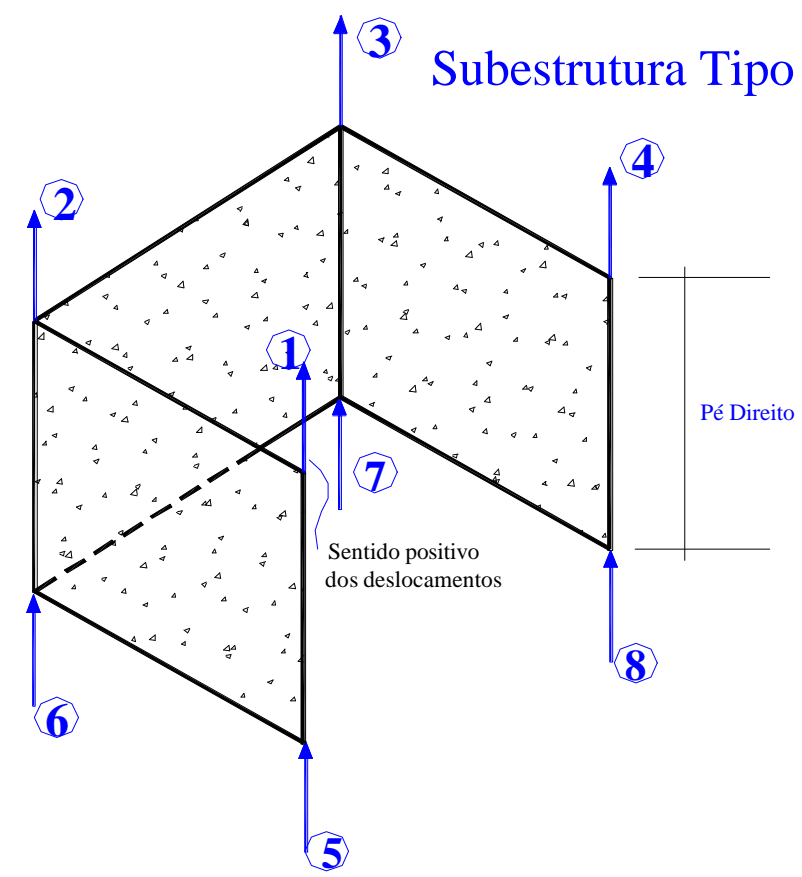

Figura 42 - Pontos sobre o esqueleto do núcleo - Sentido positivo dos deslocamentos 
Tabela 05 - Deslocamento Longitudinal dos pontos sobre o núcleo no $10^{\circ}$ pavimento $(\mathrm{E}-01 \mathrm{~cm})-2^{\mathrm{a}}$. Ordem

\begin{tabular}{||c|c|c|c||}
\hline Pontos & YAGUI & SMITH & C. FLEXO \\
\hline \hline $\mathbf{1}$ & -0.61305 & -0.61341 & -0.58434 \\
\hline $\mathbf{2}$ & 0.36780 & 0.36805 & 0.35060 \\
\hline $\mathbf{3}$ & -0.36780 & -0.36805 & -0.35060 \\
\hline $\mathbf{4}$ & 0.61305 & 0.61341 & 0.58434 \\
\hline $\mathbf{5}$ & -0.61263 & -0.61300 & -0.58398 \\
\hline $\mathbf{6}$ & 0.36758 & 0.36783 & 0.35039 \\
\hline $\mathbf{8}$ & -0.36758 & -0.36783 & -0.35039 \\
\hline & 0.61263 & 0.61300 & 0.58398 \\
\hline
\end{tabular}

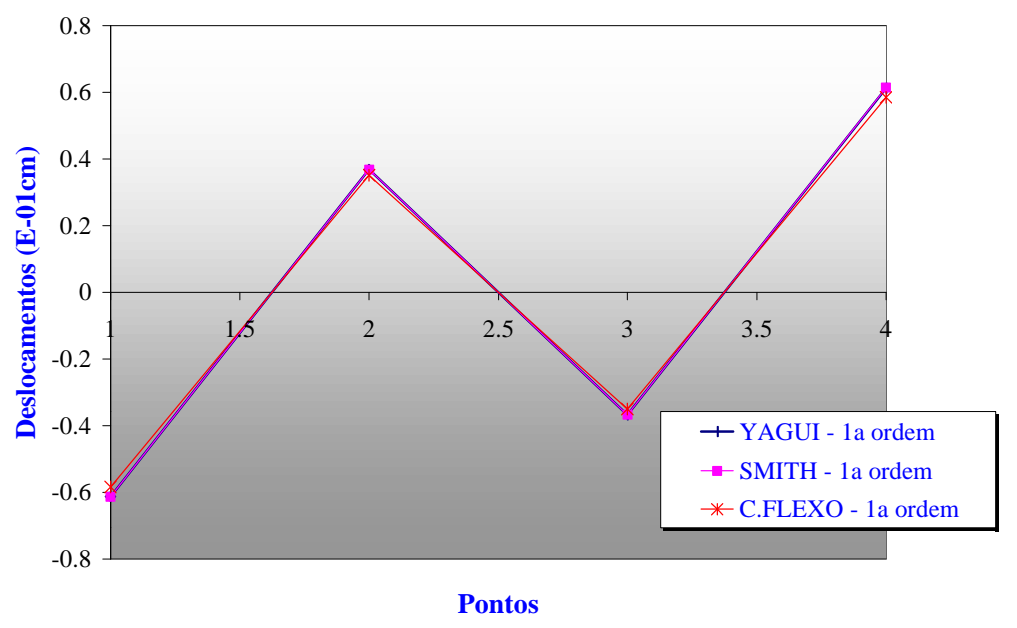

Figura 43 - Deslocamento Longitudinal dos pontos sobre o núcleo $10^{\circ}$ Pavimento - Borda superior

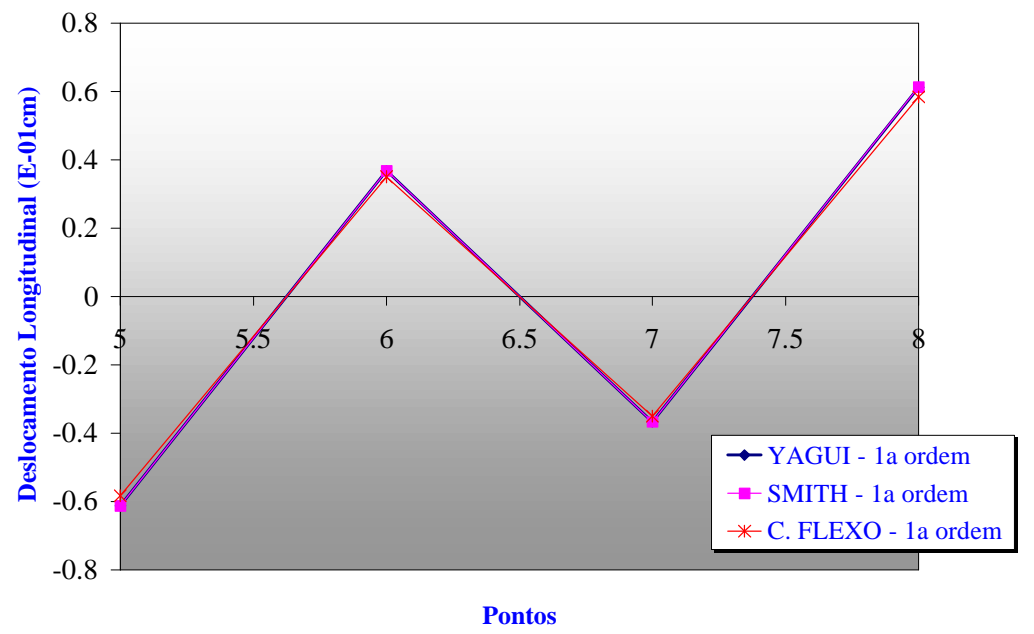

Figura 44 - Deslocamento Longitudinal dos pontos sobre o núcleo $10^{\circ}$ Pavimento - Borda inferior 
De acordo com os resultados, as três modelagens apresentaram pouca diferença, em valores numéricos, para todos os deslocamentos longitudinais da seção transversal.

Baseado nestas análises, fica verificado que para este tipo de estrutura, a modelagem por elementos planos conseguiu simular bem o comportamento do núcleo resistente. Esta constatação valoriza a utilização de um modelo mais simplificado capaz de proporcionar resultados igualmente seguros.

Foi realizada também, para este exemplo, a modelagem pelo M.E.F., utilizando o software Ansys. O elemento utilizado para modelar o núcleo foi o Shell 63, um elemento de casca com seis graus de liberdade por nó. A figura 45 apresenta um detalhe da estrutura de núcleo discretizada em elementos finitos, bem como a restrição em deslocamentos adotada para a extermidade inferior.
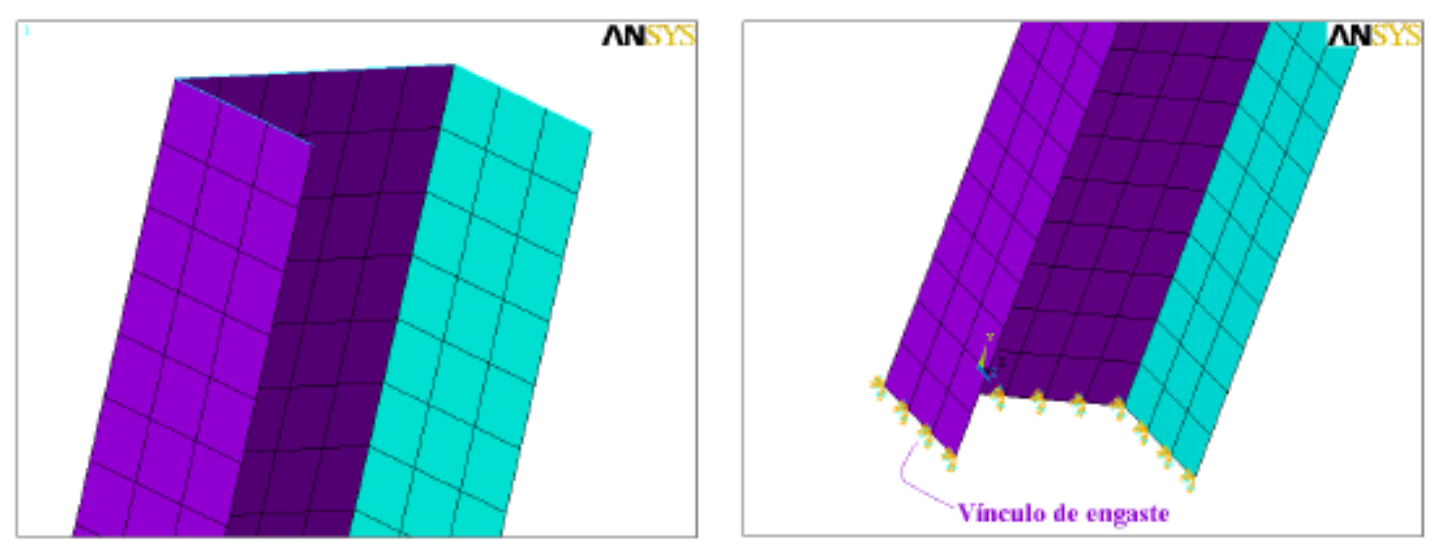

Figura 45 - Detalhe da estrutura de núcleo discretizada e sua vinculação - Ansys

Procurando amenizar as perturbações ocorridas na extremidade superior do núcleo, devido a aplicação do carregamento, foram necessárias algumas adaptações realizadas durante a modelagem. Essas adaptações objetivaram a garantia de uma melhor representatividade do comportamento estrutural deste elemento diante da ação prevista: 
- Para substituir o momento torçor, de valor 10 tf.cm, foi utilizado um binário, formado por cargas distribuídas, capaz de produzir efeito semelhante ao torçor de origem. Esse procedimento amenizou as pertubações causas pela aplicação do carregamento de forma pontual.

- Para a extremidade superior, região de aplicação do binário, foi conciderada a existência de três barras de rigidez elevada, o que impediu parte da distorção da seção devido a aplicação do carregamento distribuído.

A figura 46 apresenta a extremidade superior do elemento de núcleo ilustrando as adaptações realizadas para o modelo.

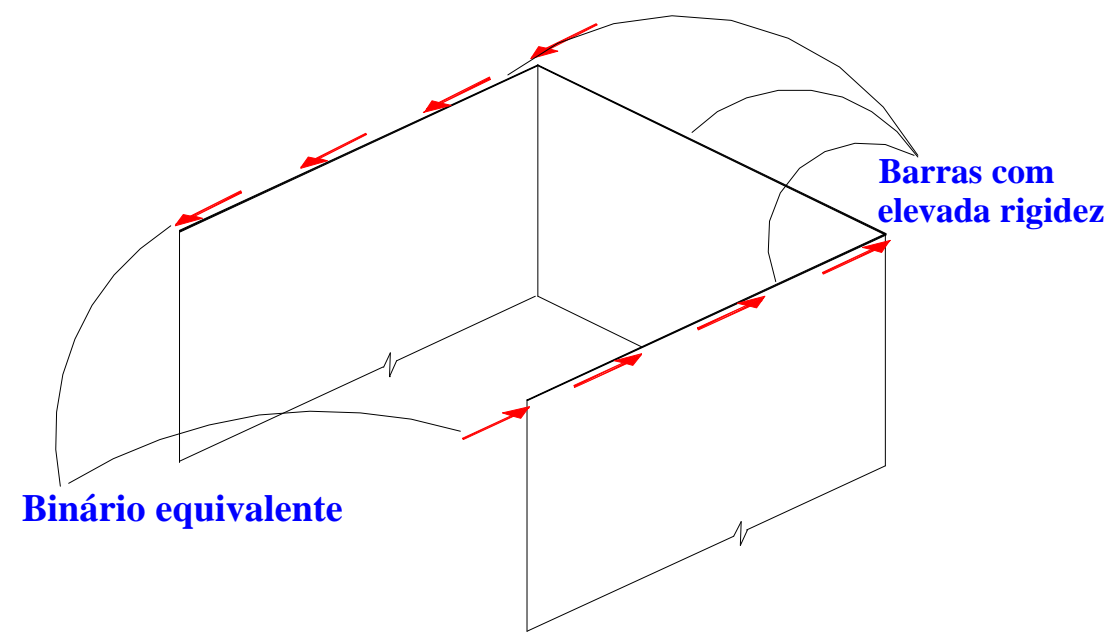

Corte da extremidade superior do núcleo

Figura 46 - Detalhe da estrutura de Núcleo Discretizada - Ansys

Os resultados fornecidos pelas tabelas 6 e 7, foram extraídos de um ponto, no plano dos diafragmas, cujas coordenadas eram coincidentes com as coordenadas do centro de torção da seção do núcleo. Esses valores foram obtidos para cada um dos diafragmas.

Os deslocamentos de translação na direção do eixo $\mathrm{Y}$, apresentaram valores da ordem de E-05. De acordo com a unidade adotada, translações em $\mathrm{cm}$, os deslocamentos da estrutura nesta direção puderam ser considerados nulos. 
As direções dos deslocamentos, translação e rotação, fornecidas nas tabelas 6 e 7 obedecem os eixos adotados inicialmente para a estrutura da figura 14, porém equivalentes aos adotadas pelo software Ansys.

Tabela 06 - Translação na direção Zg para cada pavimento $(\mathbf{E}-03 \mathrm{~cm})$

\begin{tabular}{|c|c||}
\hline Pavimento & Ansys \\
\hline \hline $\mathbf{1}$ & -0.6511 \\
\hline $\mathbf{2}$ & -1.3570 \\
\hline $\mathbf{3}$ & -1.8247 \\
\hline $\mathbf{4}$ & -2.1720 \\
\hline $\mathbf{5}$ & -2.4689 \\
\hline $\mathbf{6}$ & -2.7650 \\
\hline $\mathbf{7}$ & -3.1087 \\
\hline $\mathbf{8}$ & -3.5700 \\
\hline $\mathbf{9}$ & -4.2660 \\
\hline $\mathbf{1 0}$ & -4.8980 \\
\hline
\end{tabular}

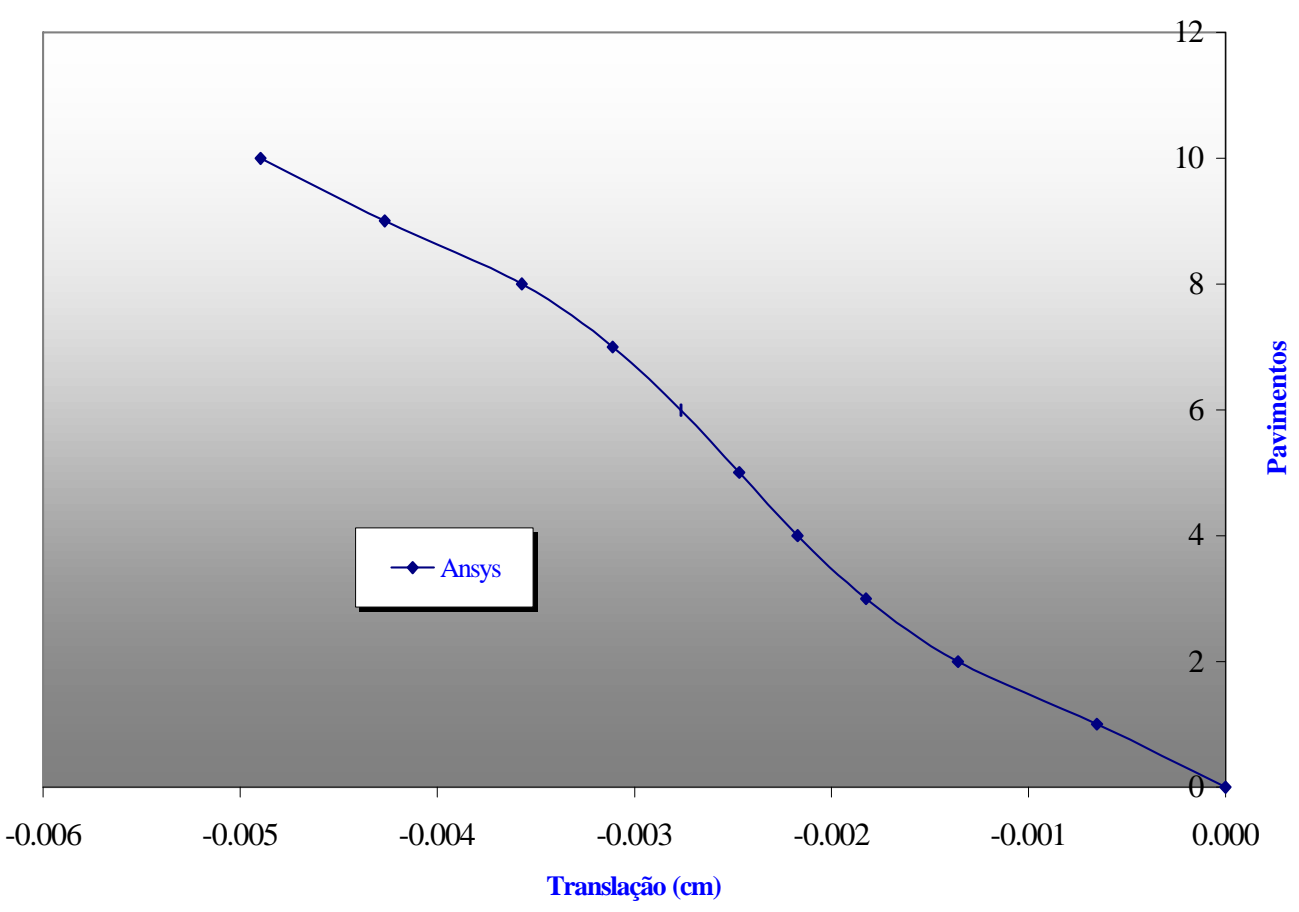

Figura 47 - Translação na direção Zg para cada pavimento 
Tabela 07 - Rotação em torno do eixo Xg para cada pavimento

\begin{tabular}{||c|c||}
\hline Pavimento & Ansys \\
\hline \hline $\mathbf{1}$ & 0.012214 \\
\hline $\mathbf{2}$ & 0.040490 \\
\hline $\mathbf{3}$ & 0.076851 \\
\hline $\mathbf{4}$ & 0.117169 \\
\hline $\mathbf{5}$ & 0.159105 \\
\hline $\mathbf{6}$ & 0.201052 \\
\hline $\mathbf{7}$ & 0.241400 \\
\hline $\mathbf{8}$ & 0.277834 \\
\hline $\mathbf{9}$ & 0.306250 \\
\hline $\mathbf{1 0}$ & 0.318740 \\
\hline
\end{tabular}

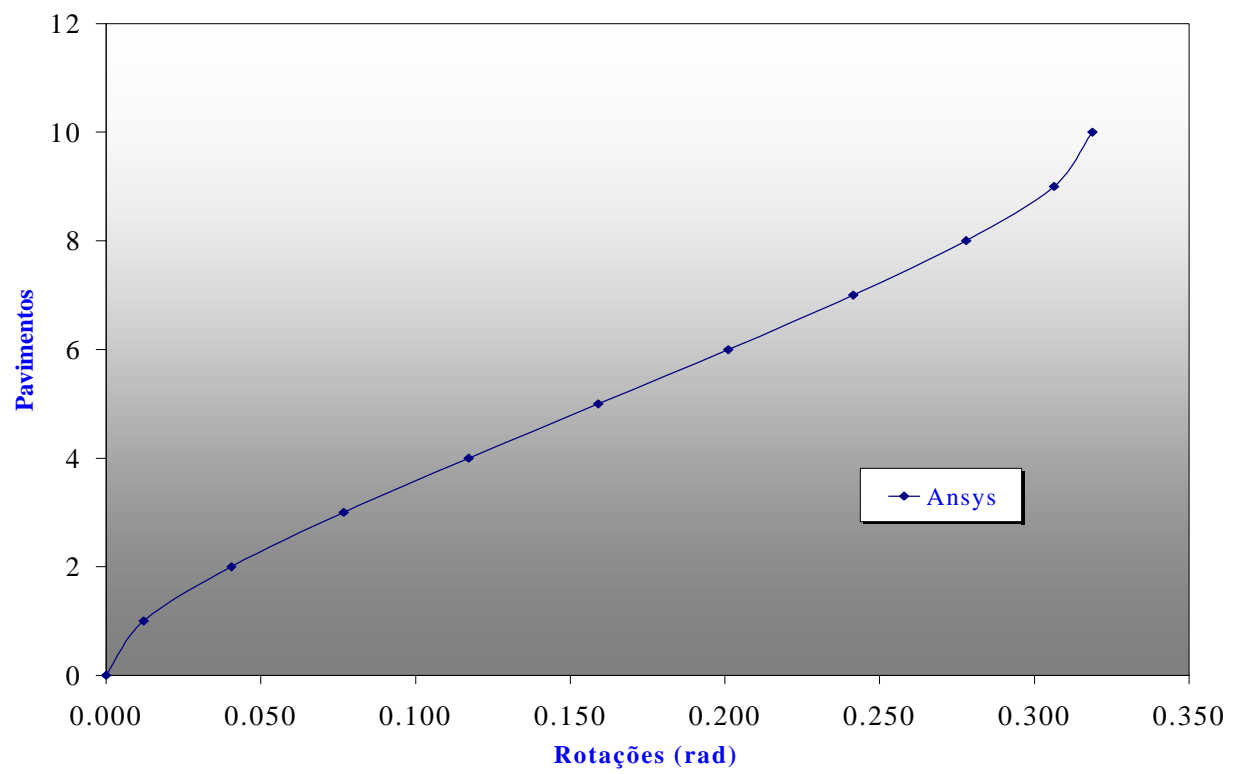

Figura 48 - Rotação em torno de Xg para cada pavimento

Analisando e comparando estes resultados com os fornecidos pelo programa desenvolvido, podemos perceber que somente os valores em rotação, fornecidos pelo Ansys, apresentaram proximidade, em valores númericos, com as demais modelagens. Porém é importante ressaltar que para a extremidade superior do núcleo, a modelagem pelo M.E.F. apresentou uma pequena perturbação decorrente da aplicação do carregamento. 


\section{3 - EXEMPLO 2}

A estrutura de edifício utilizada neste exemplo, figura 49, foi desenvolvida por SILVA (1989) e utilizada posteriormente por diversos outros autores. O edifício é composto de 15 pavimentos com pé-direito de 4,0 m. As vigas e pilares possuem seções retangulares de $20 \mathrm{~cm}$ x $60 \mathrm{~cm}$ e $25 \mathrm{~cm}$ x $50 \mathrm{~cm}$ respectivamente. Os módulos de elasticidade longitudinal e transversal são de $2000 \mathrm{kN} / \mathrm{cm}^{2}$ e $800 \mathrm{kN} / \mathrm{cm}^{2}$, respectivamente.

O carregamento aplicado na estrutura é definido à seguir:

Ações verticais aplicadas no último pavimento:

Carga uniformemente distribuídas ao longo das vigas $\rightarrow 10 \mathrm{kN} / \mathrm{m}$

Cargas aplicadas nos pontos 1,2,3 e 4 situados na seção transversal do núcleo:

Ponto $1 \rightarrow 35 \mathrm{kN}$

Ponto $2 \rightarrow 90 \mathrm{kN}$

Ponto $3 \rightarrow 90 \mathrm{kN}$

Ponto $4 \rightarrow 35 \mathrm{kN}$

Ação horizontal aplicada na direção e sentido do eixo $\mathrm{Y}_{\mathrm{g}} \rightarrow 25,5 \mathrm{kN}$

Ações verticais aplicadas nos demais pavimentos:

Cargas uniformemente distribuídas ao longo da vigas $\rightarrow 20 \mathrm{kN} / \mathrm{m}$

Carga aplicada nos pontos 1,2,3 e 4 situados na seção transversal do núcleo :

Ponto $1 \rightarrow 70 \mathrm{kN}$

Ponto $2 \rightarrow 180 \mathrm{kN}$

Ponto $3 \rightarrow 180 \mathrm{kN}$

Ponto $4 \rightarrow 70 \mathrm{kN}$

Ações horizontais aplicadas na direção e sentido do eixo $\mathrm{Y}_{\mathrm{g}} \rightarrow 51 \mathrm{kN}$ 


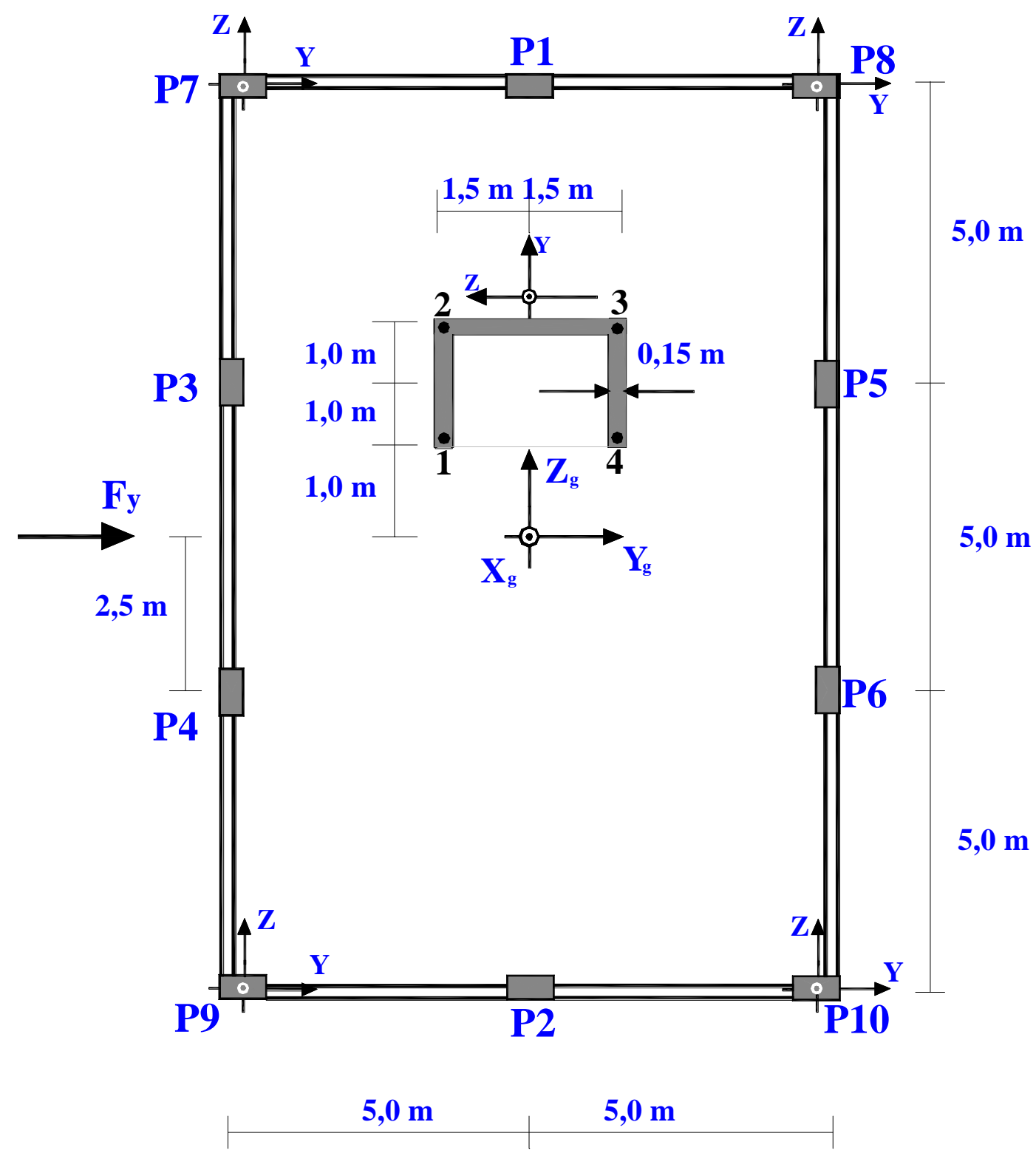

Figura 49 - Planta baixa da estrutura de contraventamento idealizada por SILVA (1989)

Os diversos pilares e vigas foram modelados utilizando os seguintes elementos:

- Para os pilares P7, P8, P9 e P10 foi utilizado um elemento capaz de simular o comportamento dos elementos verticais dos pórticos espaciais, considerando a 
rigidez na direção de todos os deslocamentos no espaço. Os esforços considerados foram: dois momentos fletores na direção dos eixos principais de inércia, duas forças cortantes, uma força axial e um momento torçor. O elemento com suas seis coordenadas deslocamento por extremidade pode ser visualizado na figura 50.

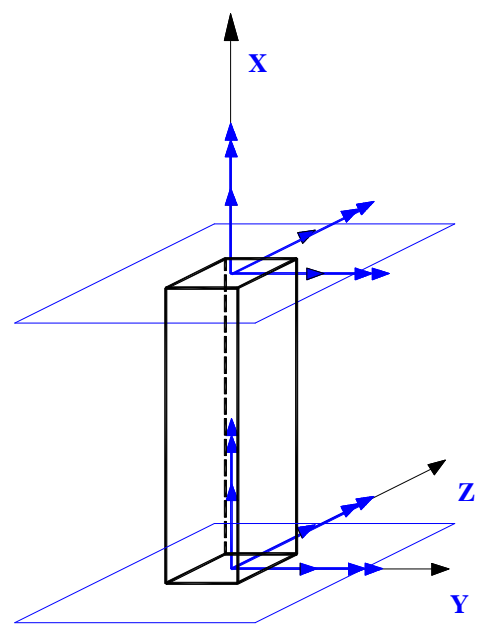

Figura 50 - Elemento vertical de pórtico espacial

- Para os pilares P1, P2, P3, P4, P5 e P6 foi utilizado um elemento plano com rigidez axial e à flexão apenas no seu plano, simulando o comportamento estrutural dos elementos verticais de pórtico plano. Os esforços considerados foram: um momento fletor, uma força cortante e um esforço axial. Portanto. Seu sistema de coordenadas, três por extremidade pode ser visualizado na figura 51 .

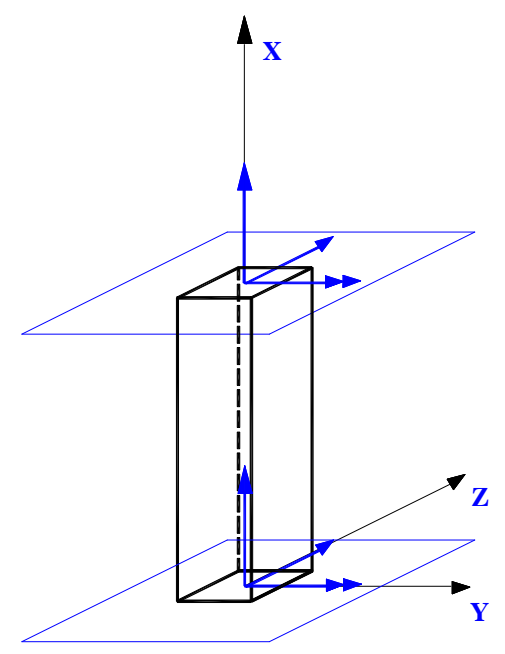

Figura 51 - Elemento vertical de pórtico plano 
- Para as vigas foi utilizado um elemento horizontal que considera a rigidez à flexão, desprezando a rigidez axial. Este elemento simula o comportamento dos membros horizontais de pórticos planos. Os esforços internos considerados foram: um momento fletor e uma força cortante. O elemento de duas coordenadas por extremidade pode ser visualizado na figura 52.

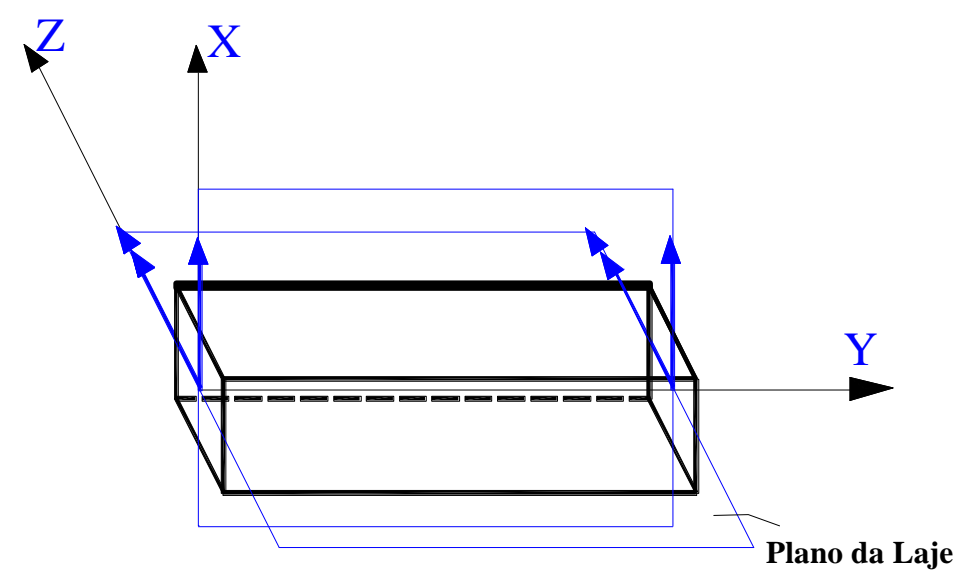

Figura 52 - Elemento horizontal de pórtico plano

Todos os processamentos realizados utilizarão estes elementos de barra, para a modelagem da estrutura de contraventamento (vigas e pilares) da figura 49, variando apenas os modelos utilizados para modelagem o núcleo.

Os resultados apresentados nos gráficos das figuras 53 a 56, relativos aos processamentos utilizando cada uma das modelagens propostas, já definidos anteriormente, foram separados de acordo com as análises em teoria de $1^{\mathrm{a}}$ ordem e $2^{\mathrm{a}}$ ordem, uma vez que o objetivo maior deste trabalho é a análise dos resultados entre as diferentes modelagens propostas para o núcleo resistente

Serão apresentados ainda, neste exemplo, alguns resultados extraídos por SILVA (1989), decorrente do processamento da estrutura utilizando programa desenvolvido pelo autor. É importante salientar que em seu trabalho, SILVA (1989) realiza as análise do núcleo, adotando para este elemento o mesmo modelo proposto por YAGUI (1971), porém considerando, no processo de cálculo, a estrutura formada pela associação dos seus diversos pórticos. 
Tabela 08 - Translação em Yg do nó mestre - $1^{\text {a }}$ Ordem - (cm)

\begin{tabular}{|c|c|c|c|c|c|c||}
\hline & YAGUI & SMITH & S. FLEXO & C. FLEXO & P.ISOLADO & SILVA \\
\hline \hline 0 & 0.0000 & 0.0000 & 0.0000 & 0.0000 & 0.0000 & 0.0000 \\
\hline 1 & 0.5113 & 0.5213 & 0.5599 & 0.5111 & 0.7230 & 0.5900 \\
\hline 2 & 1.4667 & 1.4873 & 1.5454 & 1.4868 & 2.2430 & 1.6400 \\
\hline 3 & 2.6003 & 2.6247 & 2.7369 & 2.6775 & 4.1520 & 2.9000 \\
\hline 4 & 3.8320 & 3.8595 & 4.0613 & 4.0031 & 6.2480 & 4.2700 \\
\hline 5 & 5.1109 & 5.1405 & 5.4664 & 5.4093 & 8.4040 & 5.7200 \\
\hline 6 & 6.3984 & 6.4294 & 6.9105 & 6.8542 & 10.5360 & 7.1900 \\
\hline 7 & 7.6640 & 7.6959 & 8.3597 & 8.3040 & 12.5880 & 8.6500 \\
\hline 8 & 8.8841 & 8.9166 & 9.7870 & 9.7318 & 14.5230 & 10.0900 \\
\hline 9 & 10.0413 & 10.0741 & 11.1718 & 11.1170 & 16.3170 & 11.4900 \\
\hline 10 & 11.1235 & 11.1563 & 12.4989 & 12.4440 & 17.9550 & 12.8100 \\
\hline 11 & 12.1236 & 12.1562 & 13.7584 & 13.7040 & 19.4300 & 14.0700 \\
\hline 12 & 13.0396 & 13.0718 & 14.9455 & 14.8900 & 20.7430 & 15.2500 \\
\hline 13 & 13.8742 & 13.9056 & 16.0602 & 16.0050 & 21.9040 & 16.3600 \\
\hline 14 & 14.6348 & 14.6653 & 17.1078 & 17.0520 & 22.9330 & 17.3900 \\
\hline 15 & 15.3398 & 15.3679 & 18.1012 & 18.0480 & 23.8720 & 18.3600 \\
\hline \hline
\end{tabular}

Tabela 09 - Translação em Yg do nó mestre - $2^{\mathrm{a}}$ Ordem - (cm)

\begin{tabular}{|c|c|c|c|c|c|c||}
\hline & YAGUI & SMITH & S. FLEXO & C. FLEXO & P.ISOLADO & SILVA \\
\hline \hline 0 & 0.0000 & 0.0000 & 0.0000 & 0.0000 & 0.0000 & 0.0000 \\
\hline 1 & 0.5387 & 0.5484 & 0.6025 & 0.5475 & 0.7820 & 0.6400 \\
\hline 2 & 1.5475 & 1.5683 & 1.6677 & 1.5999 & 2.4260 & 1.7900 \\
\hline 3 & 2.7376 & 2.7625 & 2.9525 & 2.8835 & 4.5810 & 3.1700 \\
\hline 4 & 4.0222 & 4.0505 & 4.3777 & 4.3102 & 6.9190 & 4.6800 \\
\hline 5 & 5.3482 & 5.3787 & 5.8881 & 5.8219 & 9.3290 & 6.2600 \\
\hline 6 & 6.6757 & 6.7078 & 7.4391 & 7.3740 & 11.7120 & 7.8800 \\
\hline 7 & 7.9734 & 8.0067 & 8.9945 & 8.9301 & 14.0020 & 9.4800 \\
\hline 8 & 9.2174 & 9.2514 & 10.5254 & 10.4615 & 16.1560 & 11.0600 \\
\hline 9 & 10.3898 & 10.4241 & 12.0096 & 11.9460 & 18.1460 & 12.5700 \\
\hline 10 & 11.4787 & 11.5132 & 13.4310 & 13.3676 & 19.9560 & 14.0200 \\
\hline 11 & 12.4776 & 12.5119 & 14.7795 & 14.7161 & 21.5810 & 15.3900 \\
\hline 12 & 13.3851 & 13.4190 & 16.0501 & 15.9865 & 23.0230 & 16.6700 \\
\hline 13 & 14.2051 & 14.2382 & 17.2435 & 17.1797 & 24.2960 & 17.8700 \\
\hline 14 & 14.9465 & 14.9787 & 18.3661 & 18.3020 & 25.4250 & 18.9800 \\
\hline 15 & 15.6300 & 15.6597 & 19.4317 & 19.3697 & 26.4560 & 20.0400 \\
\hline \hline
\end{tabular}



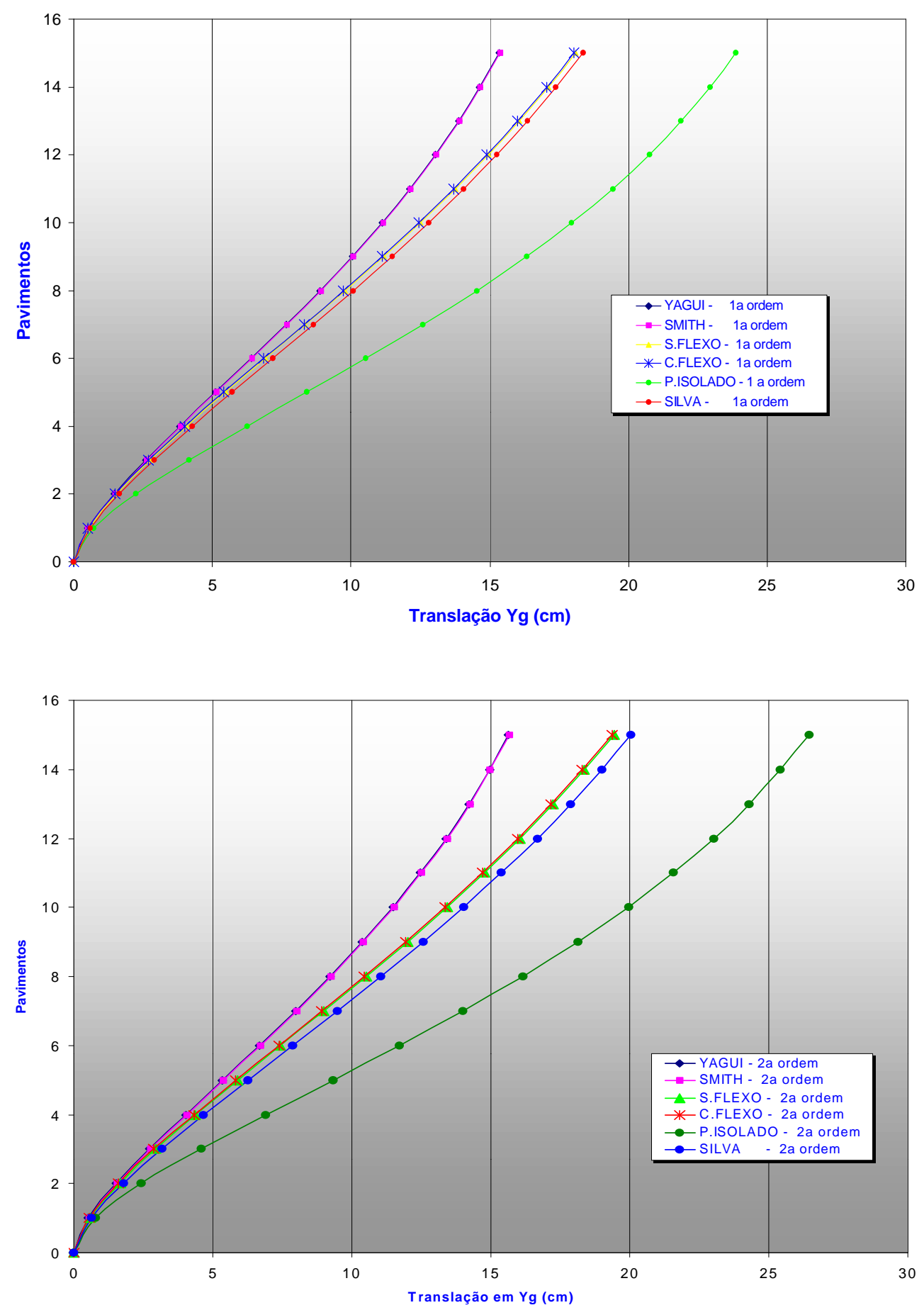

Figura 53 - Translação em Yg do nó mestre

Superior $-\mathbf{1}^{\mathrm{a}}$ ordem / Inferior $-\mathbf{2}^{\mathrm{a}}$ ordem 
Tabela 10 - Rotação Xg do nó mestre $-1^{\mathrm{a}}$ Ordem $-\left(10^{-3} \mathrm{rad}\right)$

\begin{tabular}{|c|c|c|c|c|c|c||}
\hline & YAGUI & SMITH & S. FLEXO & C. FLEXO & P.ISOLADO & SILVA \\
\hline \hline 0 & 0.0000 & 0.0000 & 0.0000 & 0.0000 & 0.0000 & 0.0000 \\
\hline 1 & 0.6688 & 0.6505 & 0.8073 & 0.6912 & 0.5159 & 0.6500 \\
\hline 2 & 1.6014 & 1.5892 & 1.7738 & 1.6310 & 1.0847 & 1.5400 \\
\hline 3 & 2.4341 & 2.4196 & 2.5961 & 2.4500 & 1.4790 & 2.3300 \\
\hline 4 & 3.1424 & 3.1269 & 3.2759 & 3.1300 & 1.7430 & 2.9900 \\
\hline 5 & 3.7396 & 3.7229 & 3.8325 & 3.6880 & 1.9190 & 3.5400 \\
\hline 6 & 4.2407 & 4.2233 & 4.2830 & 4.1390 & 2.0370 & 3.9800 \\
\hline 7 & 4.6580 & 4.6400 & 4.6410 & 4.4980 & 2.1160 & 4.3300 \\
\hline 8 & 5.0005 & 4.9822 & 4.9168 & 4.7750 & 2.1670 & 4.6100 \\
\hline 9 & 5.2746 & 5.2561 & 5.1180 & 4.9760 & 2.1990 & 4.8100 \\
\hline 10 & 5.4844 & 5.4659 & 5.2496 & 5.1080 & 2.2130 & 4.9400 \\
\hline 11 & 5.6317 & 5.6133 & 5.3143 & 5.1730 & 2.2110 & 5.0100 \\
\hline 12 & 5.7162 & 5.6980 & 5.3128 & 5.1710 & 2.1920 & 5.0100 \\
\hline 13 & 5.7360 & 5.7183 & 5.2434 & 5.1020 & 2.1480 & 4.9500 \\
\hline 14 & 5.6867 & 5.6694 & 5.1030 & 4.9620 & 2.0720 & 4.8100 \\
\hline 15 & 5.5794 & 5.5628 & 4.8894 & 4.7530 & 1.9540 & 4.6200 \\
\hline \hline
\end{tabular}

Tabela 11 - Rotação Xg do nó mestre - 2 Ordem - $\left(10^{-3}\right.$ rad $)$

\begin{tabular}{||c|c|c|c|c|c|c||}
\hline & YAGUI & SMITH & S. FLEXO & C. FLEXO & P.ISOLADO & SILVA \\
\hline \hline 0 & 0.0000 & 0.0000 & 0.0000 & 0.0000 & 0.0000 & 0.0000 \\
\hline 1 & 0.7190 & 0.7074 & 0.8800 & 0.7500 & 0.5600 & 0.7200 \\
\hline 2 & 1.7200 & 1.7493 & 1.9500 & 1.7900 & 1.1880 & 1.7300 \\
\hline 3 & 2.6400 & 2.6786 & 2.8700 & 2.7000 & 1.6210 & 2.6400 \\
\hline 4 & 3.4200 & 3.4694 & 3.6200 & 3.4500 & 1.9020 & 3.4000 \\
\hline 5 & 4.0700 & 4.1339 & 4.2300 & 4.0600 & 2.0790 & 4.0300 \\
\hline 6 & 4.6200 & 4.6896 & 4.7200 & 4.5600 & 2.1870 & 4.5400 \\
\hline 7 & 5.0800 & 5.1506 & 5.1000 & 4.9400 & 2.2490 & 4.9500 \\
\hline 8 & 5.4600 & 5.5281 & 5.4000 & 5.2300 & 2.2810 & 5.2600 \\
\hline 9 & 5.7600 & 5.8301 & 5.6000 & 5.4400 & 2.2920 & 5.4800 \\
\hline 10 & 5.9900 & 6.0622 & 5.7300 & 5.5700 & 2.2870 & 5.6200 \\
\hline 11 & 6.1600 & 6.2275 & 5.7900 & 5.6300 & 2.2660 & 5.7000 \\
\hline 12 & 6.2600 & 6.3270 & 5.7800 & 5.6100 & 2.2290 & 5.7000 \\
\hline 13 & 6.3000 & 6.3597 & 5.6900 & 5.5300 & 2.1700 & 5.6200 \\
\hline 14 & 6.2600 & 6.3223 & 5.5300 & 5.3700 & 2.0790 & 5.4700 \\
\hline 15 & 6.1600 & 6.2280 & 5.3000 & 5.1400 & 1.9470 & 5.2600 \\
\hline \hline
\end{tabular}



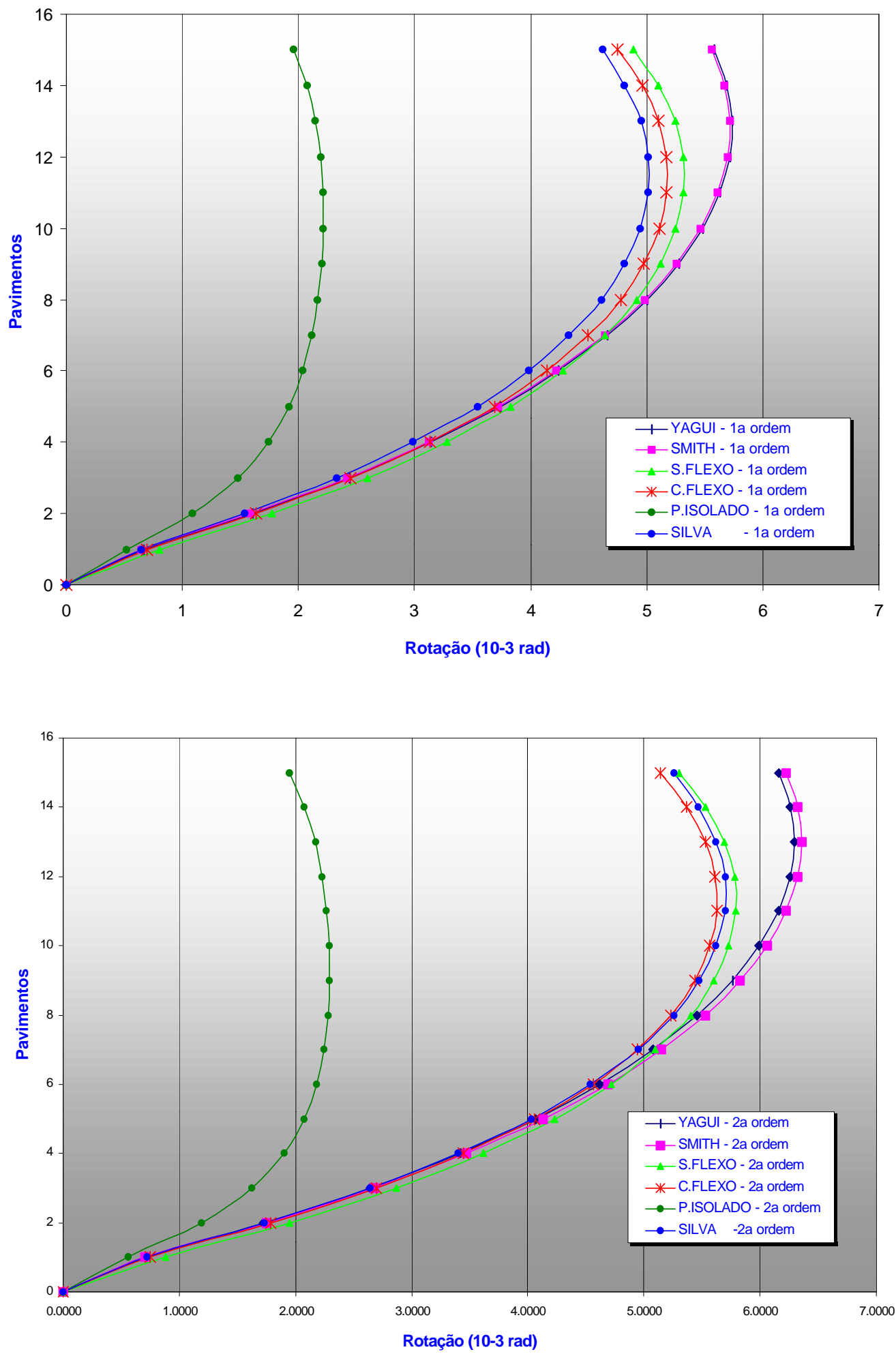

Figura 54 - Rotação das lajes em torno de Xg Superior $-\mathbf{1}^{\mathrm{a}}$ ordem / Inferior $-\mathbf{2}^{\mathrm{a}}$ ordem 
Observando os resultados em translação, podemos verificar que os modelos YAGUI e SMITH conferiram à estrutura de contraventamento processada uma maior rigidez, enquanto que o modelo por pilar parede isolado levou, essa mesma estrutura, à um comportamento mais flexível. Para o último pavimento o modelo YAGUI apresentou deslocamento $35,74 \%$ inferior ao apresentado pelo modelo por pilar parede isolado, em primeira ordem, e 40,92\% em segunda ordem. Baseado na divergência dos resultados apresentados pelos gráficos da figura 53, fica visivelmente clara a influência da consideração de uma menor inércia à flexão para o elemento de núcleo, obtida com a modelagem por pilar parede isolado.

Para os resultados em rotação, já era esperado que maiores valores fossem obtidos para os modelos onde fossem constatadas as menores translações. Esse fato pode ser atribuído à diferença de rigidez do núcleo, definida por cada modelagem, e acentuado pela não simetria de planta apresentada pela estrutura. De acordo com os resultados apresentados, o modelo por pilar parede isolado, modelagem por pilar parede isolado, apresentou rotação, para o último pavimento, 68,34 \% inferior à mesma obtida para modelo YAGUI. Esse resultado, analisado isoladamente, poderia dar a impressão errada de que a estrutura teria uma maior rigidez à torção com a utilização do modelo por pilar parede isolado, o que não é verdade. Na realidade a menor rigidez admitida para o núcleo pelo modelo por pilar parede isolado acabou permitindo uma translação maior e mais uniforme de todos os pontos.

Ao analisar os resultados fornecidos por SILVA (1989) e os resultados fornecidos pelo processamento utilizando o modelo YAGUI, pôde-se observar que, apesar de ambas as análises utilizarem a mesma modelagem para o núcleo, os resultados finais apresentaram-se com uma razoável diferença em valores numéricos. Essa diferença pode ser atribuída ao processamento de cálculo estrutural adotado por SILVA (1989), que processa a estrutura global do edifício a partir da associação dos pórticos que o formam. Analisar uma estrutura através da associação de seus pórticos implica em não se levar em conta parte da rigidez à torção, proveniente da associação tridimensional dos diversos elementos estruturais, o que acaba resultando em uma diminuição da rigidez global da estrutura.

Para esta estrutura, as translações na direção $\mathrm{Y}$ e as rotações da laje, originadas da modelagem proposta por SMITH, não apresentaram diferenças 
substanciais das fornecidas pela modelagem por YAGUI. O mesmo ocorreu entre os modelos com e sem flexo-torção, que não apresentaram diferenças significativas de valores para os deslocamentos de corpo rígido da laje.

As análises em teoria de segunda ordem, apresentaram comportamento estrutural semelhante ao observado nas análises em teoria primeira ordem, porém com resultados, em valores numéricos, superiores, o que já era esperado.

Tabela 12 - Momento Fletor em torno do eixo z do PILAR 9 - $1^{\text {a }}$ Ordem

\begin{tabular}{||c|c|c|c|c|c||}
\hline & YAGUI & SMITH & S. FLEXO & C. FLEXO & P.ISOLADO \\
\hline \hline 1 & 131.64 & 130.66 & 155.58 & 133.78 & 141.57 \\
\hline 2 & 112.28 & 114.27 & 109.58 & 113.39 & 133.46 \\
\hline 3 & 105.00 & 104.46 & 107.84 & 107.58 & 133.95 \\
\hline 4 & 100.31 & 100.57 & 104.07 & 104.44 & 131.57 \\
\hline 5 & 94.24 & 94.244 & 99.406 & 99.51 & 125.01 \\
\hline 6 & 87.20 & 87.247 & 93.433 & 93.54 & 116.06 \\
\hline 7 & 79.33 & 79.352 & 86.519 & 86.59 & 105.49 \\
\hline 8 & 70.90 & 70.906 & 78.889 & 78.94 & 93.98 \\
\hline 9 & 62.08 & 62.083 & 70.759 & 70.79 & 81.96 \\
\hline 10 & 53.08 & 53.07 & 62.318 & 62.33 & 69.73 \\
\hline 11 & 44.05 & 44.039 & 53.746 & 53.74 & 57.59 \\
\hline 12 & 35.14 & 35.116 & 45.199 & 45.17 & 45.79 \\
\hline 13 & 26.64 & 26.61 & 36.924 & 36.92 & 34.77 \\
\hline 14 & 18.13 & 18.099 & 28.636 & 28.53 & 24.52 \\
\hline 15 & 13.59 & 13.409 & 24.183 & 24.86 & 19.41 \\
\hline
\end{tabular}

Tabela 13 - Momento Fletor em torno do eixo z do PILAR 9 - $2^{\mathrm{a}}$ Ordem

\begin{tabular}{|c|c|c|c|c|c||}
\hline & YAGUI & SMITH & S. FLEXO & C. FLEXO & P.ISOLADO \\
\hline \hline 1 & 139.41 & 138.12 & 166.75 & 142.4 & 151.98 \\
\hline 2 & 121.34 & 123.49 & 120.07 & 123.87 & 147.42 \\
\hline 3 & 112.67 & 112.13 & 117.24 & 117.06 & 148.54 \\
\hline 4 & 106.65 & 106.92 & 112.61 & 113.04 & 146.11 \\
\hline 5 & 99.40 & 99.40 & 107.13 & 107.27 & 138.82 \\
\hline 6 & 91.26 & 91.31 & 100.33 & 100.47 & 128.66 \\
\hline 7 & 82.37 & 82.40 & 92.59 & 92.69 & 116.58 \\
\hline 8 & 72.99 & 73.01 & 84.15 & 84.22 & 103.43 \\
\hline 9 & 63.32 & 63.32 & 75.25 & 75.3 & 89.76 \\
\hline 10 & 53.54 & 53.54 & 66.09 & 66.11 & 75.97 \\
\hline 11 & 43.84 & 43.83 & 56.87 & 56.87 & 62.41 \\
\hline 12 & 34.37 & 34.34 & 47.76 & 47.74 & 49.4 \\
\hline 13 & 25.42 & 25.39 & 39.03 & 39.03 & 37.42 \\
\hline 14 & 16.63 & 16.61 & 30.38 & 30.28 & 26.42 \\
\hline 15 & 11.89 & 11.69 & 25.93 & 26.63 & 21.14 \\
\hline
\end{tabular}



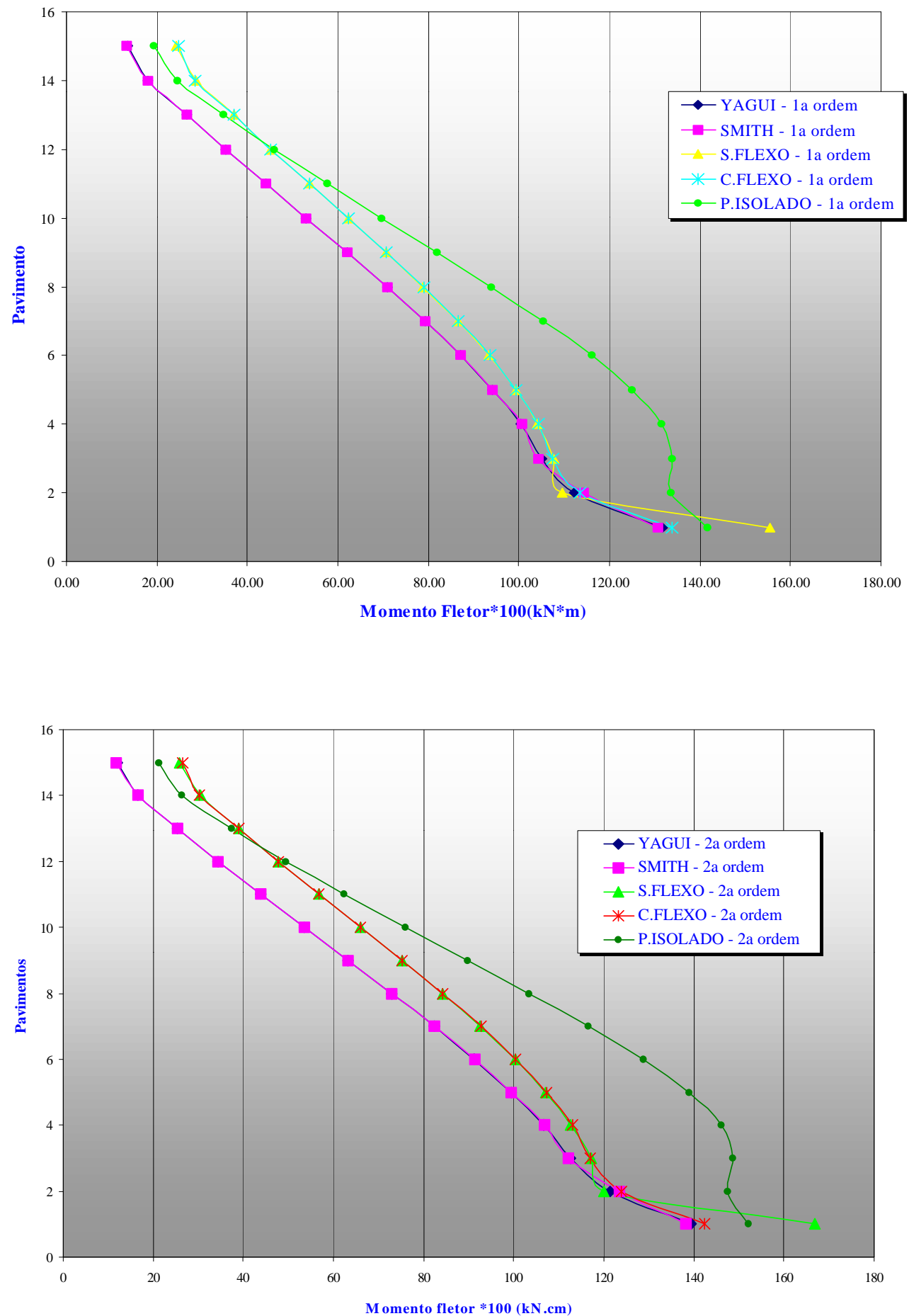

Figura 55 - Momento fletor em torno do eixo $\mathrm{z}$ na base do pilar 9 Superior -1a ordem / Inferior - 2a ordem 
Tabela 14 - Esforço cortante na direção do eixo y do pilar 8 - $1^{\text {a }}$ Ordem

\begin{tabular}{|c|c|c|c|c|c||}
\hline & YAGUI & SMITH & S. FLEXO & C. FLEXO & P.ISOLADO \\
\hline \hline 1 & -3.201 & -1.505 & -7.815 & -5.096 & 7.680 \\
\hline 2 & 7.329 & 7.166 & 6.287 & 6.131 & 33.660 \\
\hline 3 & 15.041 & 15.279 & 14.631 & 14.723 & 47.104 \\
\hline 4 & 20.629 & 20.729 & 20.670 & 20.665 & 53.355 \\
\hline 5 & 24.300 & 24.385 & 24.666 & 24.674 & 55.037 \\
\hline 6 & 26.503 & 26.558 & 27.091 & 27.092 & 53.779 \\
\hline 7 & 27.547 & 27.583 & 28.283 & 28.283 & 50.673 \\
\hline 8 & 27.713 & 27.734 & 28.538 & 28.536 & 46.419 \\
\hline 9 & 27.243 & 27.252 & 28.110 & 28.108 & 41.494 \\
\hline 10 & 26.352 & 26.350 & 27.226 & 27.224 & 36.236 \\
\hline 11 & 25.243 & 25.231 & 26.102 & 26.098 & 30.926 \\
\hline 12 & 24.081 & 24.063 & 24.895 & 24.893 & 25.800 \\
\hline 13 & 23.199 & 23.159 & 24.025 & 24.015 & 21.310 \\
\hline 14 & 21.878 & 21.862 & 22.347 & 22.361 & 16.963 \\
\hline 15 & 27.149 & 27.014 & 28.916 & 28.806 & 19.246 \\
\hline
\end{tabular}

Tabela 15 - Esforço cortante na direção do eixo y do pilar 8 - $1^{\text {a }}$ Ordem

\begin{tabular}{|c|c|c|c|c|c||}
\hline & YAGUI & SMITH & S. FLEXO & C. FLEXO & P.ISOLADO \\
\hline \hline 1 & -3.901 & -2.273 & -8.305 & -5.503 & 6.243 \\
\hline 2 & 5.564 & 5.371 & 4.811 & 4.649 & 30.401 \\
\hline 3 & 12.634 & 12.856 & 12.511 & 12.597 & 43.663 \\
\hline 4 & 17.993 & 18.085 & 18.348 & 18.336 & 50.592 \\
\hline 5 & 21.729 & 21.812 & 22.443 & 22.446 & 53.236 \\
\hline 6 & 24.184 & 24.240 & 25.164 & 25.162 & 52.920 \\
\hline 7 & 25.587 & 25.625 & 26.762 & 26.759 & 50.595 \\
\hline 8 & 26.154 & 26.178 & 27.469 & 27.466 & 46.917 \\
\hline 9 & 26.083 & 26.095 & 27.499 & 27.495 & 42.371 \\
\hline 10 & 25.559 & 25.560 & 27.050 & 27.045 & 37.326 \\
\hline 11 & 24.767 & 24.757 & 26.324 & 26.318 & 32.104 \\
\hline 12 & 23.866 & 23.849 & 25.476 & 25.472 & 26.984 \\
\hline 13 & 23.178 & 23.139 & 24.949 & 24.938 & 22.480 \\
\hline 14 & 22.053 & 22.037 & 23.514 & 23.527 & 18.062 \\
\hline 15 & 27.304 & 27.164 & 30.917 & 30.804 & 20.823 \\
\hline
\end{tabular}



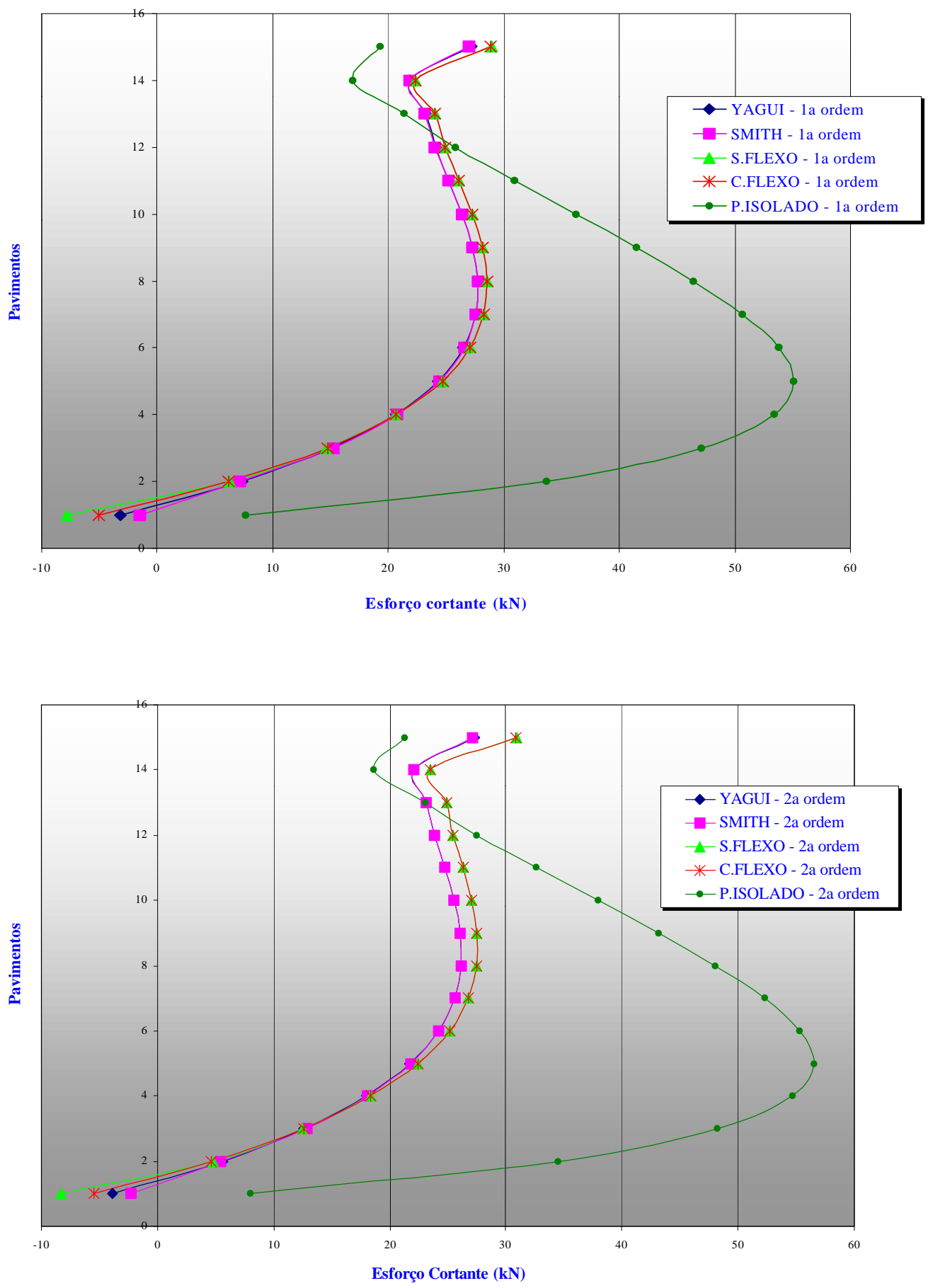

Figura 56 - Esforço cortante na direção do eixo y do pilar 7 Superior $-\mathbf{1}^{\mathrm{a}}$ ordem / Inferior $-\mathbf{2}^{\mathrm{a}}$ ordem 
De acordo com as análises realizadas anteriormente e a constatação das diferentes rigidezes atribuídas à mesma estrutura com a utilização dos diferentes modelos, podemos supor para o elemento de núcleo um importante papel na absorção dos esforços. Esta afirmativa pôde ser verificada durante a observação dos resultados apresentados nas tabelas 12,13,14 e 15, onde para os modelos YAGUI e SMITH os resultados em esforços apresentaram-se inferiores aos demais modelos. Esse comportamento já era esperado uma vez que para os modelos YAGUI E SMITH a estrutura apresentou uma rigidez superior à apresentada pelos demais modelos, implicando em um elemento de núcleo mais rígido capaz de absorver uma parcela maior dos esforços.

Os modelos YAGUI e SMITH, no que diz respeito aos seus resultados em esforços, não apresentaram diferenças significativa de valores. Esse fato leva a crer que para esta estrutura, o efeito do momento parasita não exerceu grande influência no comportamento do núcleo. Sabendo que este efeito é acentuado pela presença de tensões cisalhantes significativas nas interfaces dos elementos que formam o núcleo, podemos concluir que para esta estrutura, em conjunto com as ações à ela aplicada, a ordem de grandeza desse esforço não se fez pronunciada.

Observando as curvas das figuras 53 a 56, pode-se notar que com a utilização dos modelos com e sem flexo-toção também não ocorreram diferenças significativas de valores em deslocamento e esforços. De acordo com estes resultados podemos concluir que a consideração do efeito do empenamento, para esta estrutura de edifício, não exerceu grande influência nos resultados finais quando aplicadas as ações previstas.

Para o modelo por pilar parede isolado, modelagem por pilar parede isolado, observou-se que ao longo da estrutura, com exceção da base e do topo, os resultados em esforços foram sempre muito superiores aos apresentados pelos demais modelos. Sabendo que a interação entre os segmentos de parede do núcleo resistente é a sua principal característica, a não consideração dessa interação faz da modelagem por pilar parede isolado a mais simplificada, porém a de menor aproveitamento da rigidez real do núcleo resistente. 
Os resultados em esforços, obtidos com a análise da estrutura em teoria de $2^{\mathrm{a}}$ ordem, como já esperado, apresentaram valores superiores aos obtidos com a análise em $1^{\mathrm{a}}$ ordem.

Para a modelagem considerando o método dos elementos finitos - M.E.F., SOUSA JUNIOR (2000), cujo trabalho encontra-se em andamento, utiliza o software Ansys 5.5 para discretizar e processar a mesma estrutura analisada neste exemplo. Deste processamento foram extraídos resultados que permitiram conclusões interessantes relacionadas ao comportamento estrutural do edifício.

As figuras 57 e 58 ilustram a discretização da estrutura adotada neste exemplo. Para as vigas e pilares foi utilizado o elemento beam4 e para as lajes e núcleo resistente o elemento denominado shell63. Nesta modelagem não será considerada a hipótese de diafragma rígido no seu plano, uma vez que as laje serão discretizadas utilizando as mesmas características elásticas das vigas e pilares.

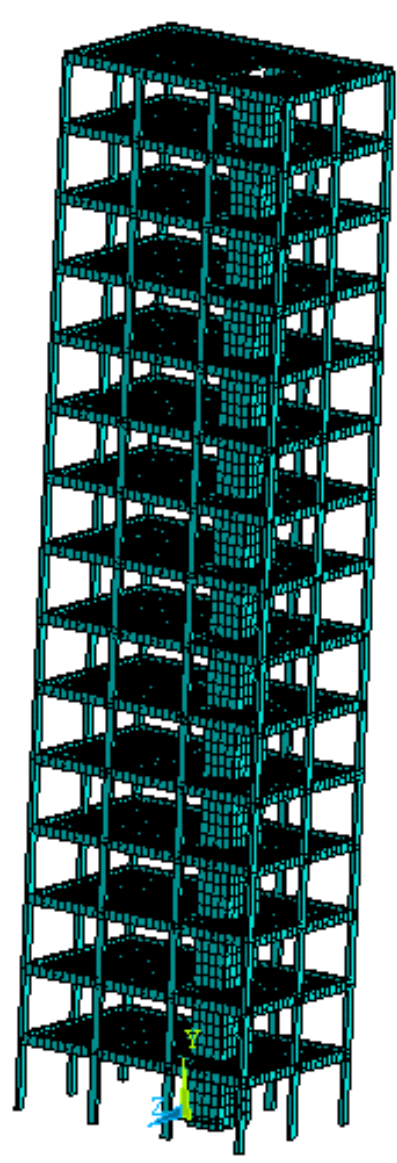

Figura 57 - Vista geral da estrutura discretizada em elementos finitos Ansys5.5. 


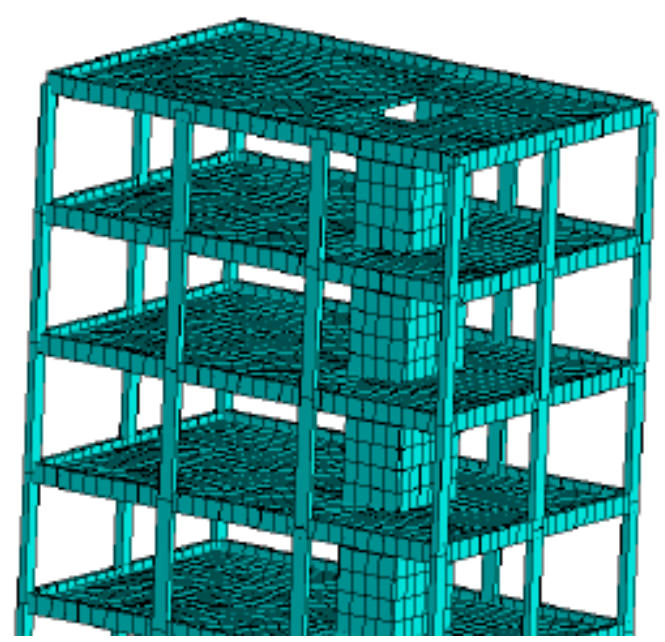

Figura 58 - Detalhe da estrutura discretizada - Ansys 5.5.

Os resultados extraídos do processamento da estrutura podem ser visualizados na tabela 16 e nas figura 59 e 60 . Todos os resultados apresentados na tabela 16 foram extraídos do mesmo ponto para cada um dos pavimentos. Para tanto, foi determinado inicialmente no último pavimento o valor máximo em translação na direção de aplicação do vento, sendo a partir daí determinado os deslocamentos para os demais pavimentos relativos às mesmas coordenadas.

Tabela 16 - Deslocamentos máximos das lajes a cada pavimento.

\begin{tabular}{||c|c|}
\hline Pavimentos & $\begin{array}{c}\text { Translação na direção } \\
\text { do vento }(\mathrm{cm})\end{array}$ \\
\hline \hline 0 & 0,000 \\
\hline 1 & 0,745 \\
\hline 2 & 1,943 \\
\hline 3 & 3,232 \\
\hline 4 & 4,532 \\
\hline 5 & 5,810 \\
\hline 6 & 7,047 \\
\hline 7 & 8,228 \\
\hline 8 & 9,341 \\
\hline 9 & 10,378 \\
\hline 10 & 11,331 \\
\hline 11 & 12,195 \\
\hline 12 & 12,970 \\
\hline 13 & 13,653 \\
\hline 14 & 14,249 \\
\hline 15 & 14,763 \\
\hline
\end{tabular}




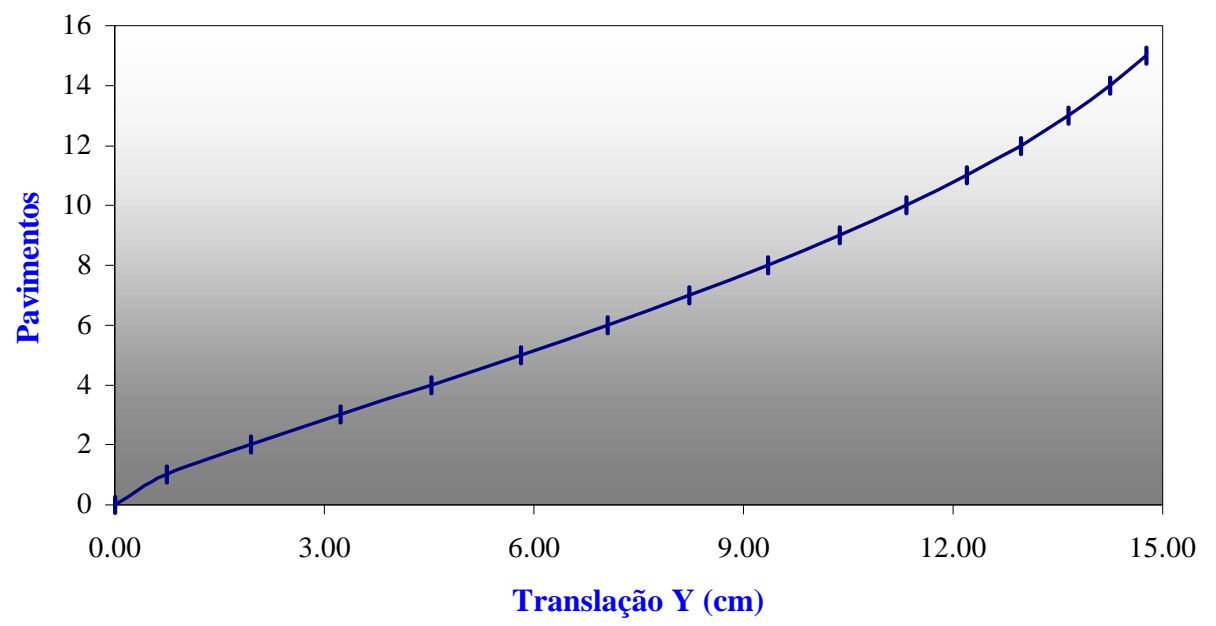

Figura 59 - Translação na direção de aplicação do vento - (cm)

A configuração final da estrutura em deslocamentos e deformações pode ser visualizada na figura 60. De acordo com esta figura, pode ser visto claramente que na região da laje onde está presente o núcleo ocorrem as menores translações, ressaltando a importância da rigidez deste elemento no controle dos deslocamentos. Devido à não simetria desta estrutura na direção de aplicação do vento, a presença do núcleo faz com que ocorram maiores rotações, isto porque o elemento de núcleo acaba simulando um eixo de rotação, fazendo com que a região considerada livre tenha deslocamentos maiores, aumentando assim os deslocamentos relativos entre as duas regiões 


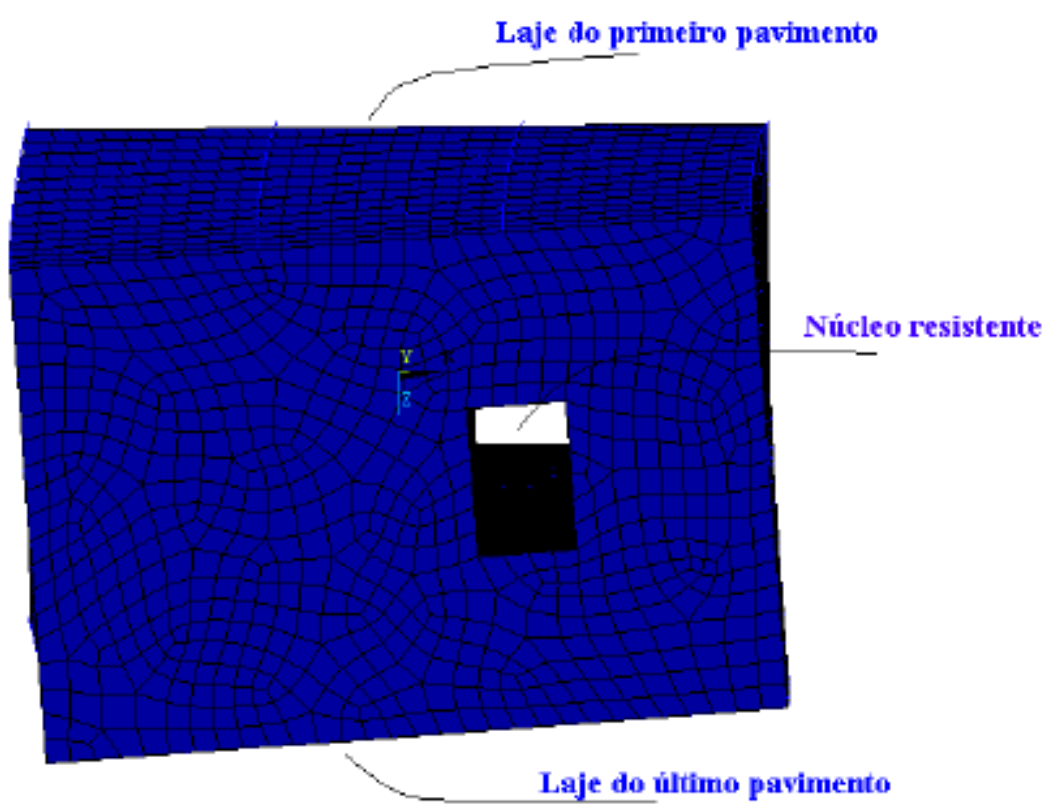

Figura 60 - Deformação final da estrutura - Ansys 5.5.

$\mathrm{Na}$ figura 61 estão apresentados os resultados em rotação para as lajes do segundo, sétimo e do último pavimento. Ao analisar os resultados, pode-se observar que os valores em rotação, observados no mesmo pavimento, apresentam uma variação muito pequena de um ponto para outro. Esta constatação leva a crer que ao se admitir um comportamento de corpo rígido para as lajes, hipótese adotada nas demais modelagens deste trabalho, os resultados obtidos podem ser considerados coerentes, uma vez que os valores de rotação resultantes, observados nesta modelagem, indicaram um comportamento para as lajes semelhante ao de um corpo rígido. 


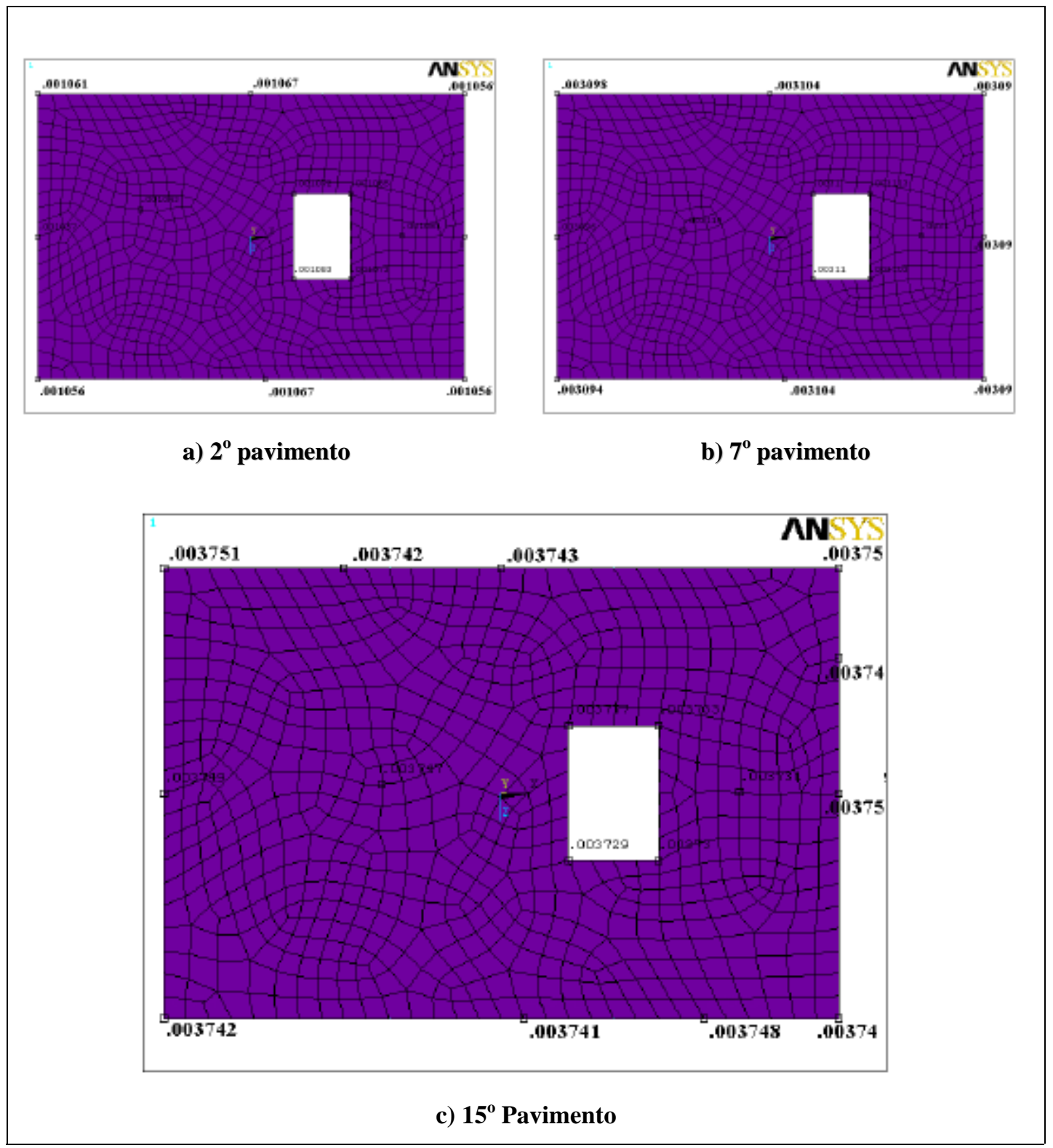

Figura 61 - Rotação em torno de y - Ansys 5.5.

A realidade de mercado exige a adoção de ferramentas computacionais com características práticas, capazes de proporcionar um andamento fluente do trabalho. Durante a modelagem deste exemplo pelo M.E.F. essas características não foram observadas uma vez que, os processos de discretização dos elementos da estrutura e a leitura dos resultados apresentaram uma certa complexidade. Diante disto fica clara a importância da escolha adequada do software a ser utilizado na modelagem da estrutura pelo M.E.F., podendo este atenuar ou agravar a complexidade constatada. 


\section{4 - EXEMPLO 3}

Este exemplo, desenvolvido por TORRES (1999) e apresentado na figura 63, trata de um edifício de 25 andares com pé-direito de $2,80 \mathrm{~m}$. A estrutura apresenta dois núcleos resistentes com espessuras de $25 \mathrm{~cm}$. Para os módulos de elasticidade longitudinal e transversal foram adotados os valores de $2.800 \mathrm{kN} / \mathrm{cm}^{2}$ e 1.120 $\mathrm{kN} / \mathrm{cm}^{2}$, respectivamente.

Todas as características geométricas dos elementos, que compõem a estruturas, são apresentadas nas tabelas 17 e 18:

Tabela 17 - Dimensões dos Pilares

\begin{tabular}{|c|c|}
\hline Pilares & Dimensões (cm) \\
\hline $1,4,17,20$ & $50 \times 60$ \\
\hline $2,3,18,19$ & $20 \times 60$ \\
\hline $6,8,13,15$ & $25 \times 70$ \\
\hline $5,9,12,16$ & $30 \times 90$ \\
\hline 10,11 & $20 \times 80$ \\
\hline 7,14 & $25 \times 80$ \\
\hline
\end{tabular}

Tabela 18 - Dimensões das vigas

\begin{tabular}{|c|c|}
\hline Vigas & Dimensões (cm) \\
\hline $1,2,11,12$ & $20 \times 65$ \\
\hline $3,4,5,6,7,8,9,10,17,18$ & $15 \times 30$ \\
\hline $13,14,15,16,22,23,24,25$ & $20 \times 40$ \\
\hline 19 & $20 \times 50$ \\
\hline
\end{tabular}


- Para todos os pilares foram utilizados os elementos verticais de pórtico espacial, ilustrado na figura 50. Os esforços considerados são dois momentos fletores na direção dos eixos principais de inércia, duas forças cortantes, uma força axial e um momento torçor.

- Para todas as vigas foram utilizados elementos horizontais de grelha espacial, que consideram a rigidez à torção e à flexão, desprezando a rigidez axial. Os esforços internos considerados são: um momento fletor, uma força cortante e um momento torçor. O elemento pode ser visualizado na figura 62 .

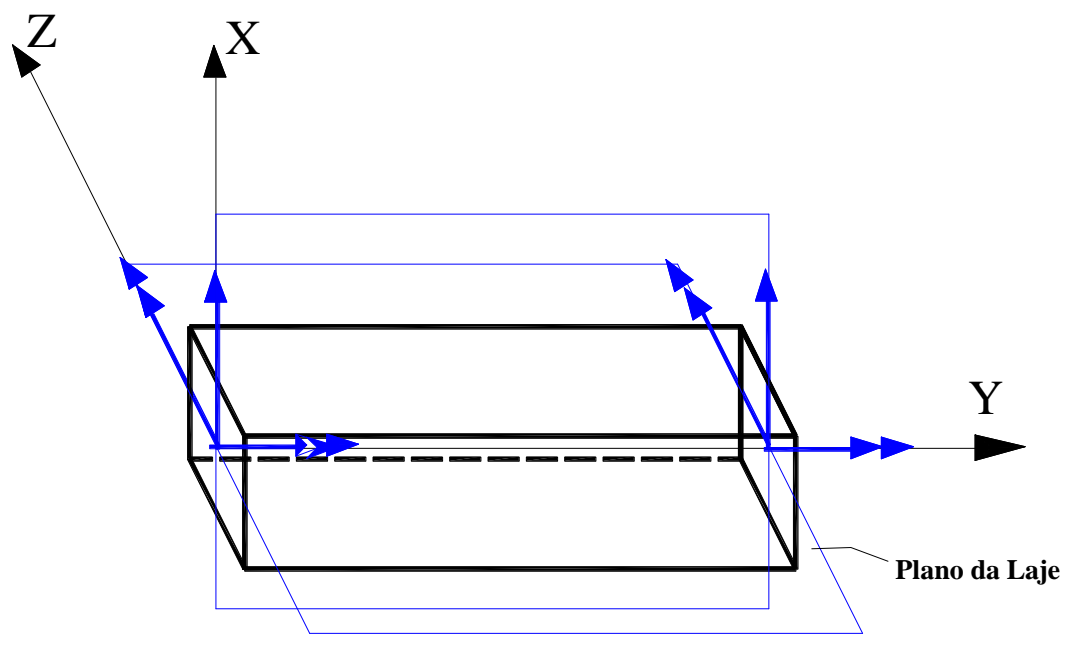

Figura 62 - Elemento de Viga - Elemento vertical de pórtico espacial 


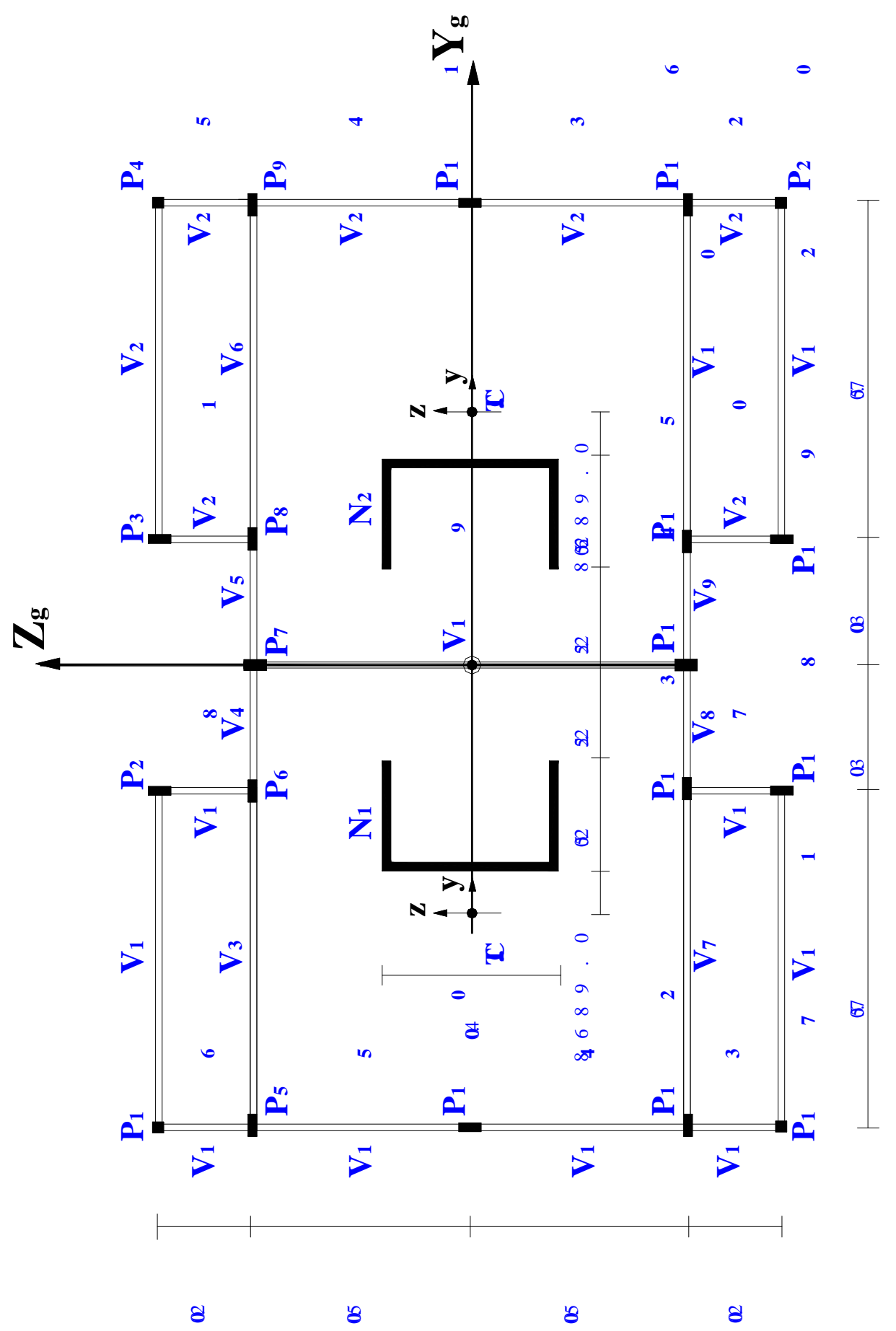

Figura 63 - Planta baixa da estrutura de contraventamento - TORRES (1999)

Para este exemplo foram fornecidas as forças devidas à ação do vento, calculadas pelo autor conforme NBR 6123, da ASSOCIAÇÃO BRASILEIRA DE NORMAS TÉCNICAS - ABNT (1987). Como resultado, o carregamento final aplicado à estrutura é apresentado na tabela 19: 
Tabela 19 - Carregamento aplicado à estrutura

\begin{tabular}{|c|c|c|}
\hline Laje & $\overline{F z}(\mathbf{k N})$ & Mx (kN.cm) \\
\hline 1 & 80,70 & $13.315,49$ \\
\hline 2 & 88,95 & $14.667,28$ \\
\hline 3 & 93,91 & $15.494,71$ \\
\hline 4 & 97,40 & $16.070,86$ \\
\hline 5 & 100,05 & $16.507,48$ \\
\hline 6 & 102,13 & $16.852,08$ \\
\hline 7 & 103,82 & $17.130,94$ \\
\hline 8 & 105,21 & $17.360,25$ \\
\hline 9 & 106,37 & $17.550,71$ \\
\hline 10 & 107,33 & $17.709,83$ \\
\hline 11 & 108,14 & $17.843,06$ \\
\hline 12 & 108,82 & $17.954,52$ \\
\hline 13 & 109,38 & $18.047,37$ \\
\hline 14 & 109,84 & $18.124,13$ \\
\hline 15 & 110,22 & $18.186,83$ \\
\hline 16 & 110,53 & $18.237,12$ \\
\hline 17 & 110,77 & $18.276,38$ \\
\hline 18 & 110,94 & $18.305,76$ \\
\hline 19 & 111,07 & $18.326,24$ \\
\hline 20 & 111,14 & $18.338,66$ \\
\hline 21 & 111,17 & $18.343,75$ \\
\hline 22 & 111,16 & $18.324,13$ \\
\hline 23 & 111,12 & $18.334,37$ \\
\hline 24 & 111,04 & $18.320,95$ \\
\hline 25 & 55,46 & $9.151,15$ \\
\hline
\end{tabular}

Para o processamento desta estrutura foram utilizados os modelos YAGUI, SMITH, COM FLEXO e SEM FLEXO sendo eliminadas as análises com o modelo por pilar isolado, devido a ineficiência apresentada pelo modelo na representação mais fiel do comportamento estrutural do núcleo, e a análise pelo M.E.F. utilizando o software Ansys, que mostrou ser de pouca praticidade no tratamento de estruturas de edifícios.

Os diversos resultados extraídos, em deslocamentos e esforços, são apresentados a seguir na forma de tabelas e gráficos, separados também de acordo com as análises em teoria de $1^{\mathrm{a}}$ e $2^{\mathrm{a}}$ ordem. 
Tabela 20 - Translação Zg do nó mestre - $1^{\mathrm{a}}$ ordem - $(\mathrm{cm})$

\begin{tabular}{||c|c|c|c|c||}
\hline & YAGUI & SMITH & S.FLEXO & C.FLEXO \\
\hline \hline 0 & 0.00000 & 0.00000 & 0.00000 & 0.00000 \\
\hline 1 & 0.05826 & 0.08237 & 0.06714 & 0.06714 \\
\hline 2 & 0.21190 & 0.26208 & 0.25840 & 0.25840 \\
\hline 3 & 0.44679 & 0.52133 & 0.55943 & 0.55943 \\
\hline 5 & 0.75262 & 0.84963 & 0.95693 & 0.95693 \\
\hline 6 & 1.11990 & 1.23745 & 1.43868 & 1.43870 \\
\hline 7 & 1.53990 & 1.67624 & 1.99338 & 1.99340 \\
\hline 8 & 2.00470 & 2.15820 & 2.61067 & 2.61070 \\
\hline 9 & 2.50710 & 2.67620 & 3.28106 & 3.28110 \\
\hline 10 & 3.04050 & 3.22378 & 3.99586 & 3.99590 \\
\hline 11 & 3.59890 & 3.79507 & 4.74717 & 4.74720 \\
\hline 12 & 4.17710 & 4.38479 & 5.52783 & 5.52780 \\
\hline 13 & 4.77030 & 4.98821 & 6.33140 & 6.33140 \\
\hline 14 & 5.37410 & 5.60112 & 7.15211 & 7.15210 \\
\hline 15 & 6.59920 & 6.84108 & 8.82525 & 8.82520 \\
\hline 16 & 7.21460 & 7.46218 & 9.66942 & 9.66940 \\
\hline 17 & 7.82850 & 8.08085 & 10.51418 & 10.51400 \\
\hline 18 & 8.43930 & 8.69527 & 11.35696 & 11.35700 \\
\hline 19 & 9.04560 & 9.30406 & 12.19576 & 12.19600 \\
\hline 20 & 9.64630 & 9.90632 & 13.02921 & 13.02900 \\
\hline 21 & 10.24100 & 10.50156 & 13.85651 & 13.85700 \\
\hline 22 & 10.83000 & 11.08980 & 14.67750 & 14.67800 \\
\hline 23 & 11.41300 & 11.67141 & 15.49261 & 15.49300 \\
\hline 24 & 11.99200 & 12.24761 & 16.30287 & 16.30300 \\
\hline 25 & 12.56800 & 12.81804 & 17.11003 & 17.11000 \\
\hline
\end{tabular}

Tabela 21 - Translação Zg do nó mestre - $2^{\mathrm{a}}$ ordem - (cm)

\begin{tabular}{||c|c|c|c|c||}
\hline & YAGUI & SMITH & S.FLEXO & C.FLEXO \\
\hline \hline 0 & 0.0000 & 0.0000 & 0.0000 & 0.0000 \\
\hline 1 & 0.0583 & 0.0824 & 0.0671 & 0.0671 \\
\hline 2 & 0.2120 & 0.2621 & 0.2584 & 0.2584 \\
\hline 3 & 0.4469 & 0.5214 & 0.5594 & 0.5594 \\
\hline 4 & 0.7528 & 0.8498 & 0.9569 & 0.9569 \\
\hline 5 & 1.1201 & 1.2377 & 1.4387 & 1.4387 \\
\hline 6 & 1.5402 & 1.6766 & 1.9934 & 1.9934 \\
\hline 7 & 2.0051 & 2.1587 & 2.6107 & 2.6107 \\
\hline 8 & 2.5076 & 2.6768 & 3.2811 & 3.2810 \\
\hline 9 & 3.0411 & 3.2245 & 3.9959 & 3.9958 \\
\hline 10 & 3.5997 & 3.7959 & 4.7472 & 4.7471 \\
\hline 11 & 4.1780 & 4.3857 & 5.5278 & 5.5278 \\
\hline 12 & 4.7713 & 4.9892 & 6.3314 & 6.3314 \\
\hline 13 & 5.3752 & 5.6022 & 7.1521 & 7.1521 \\
\hline 14 & 5.9860 & 6.2210 & 7.9849 & 7.9848 \\
\hline 15 & 6.6005 & 6.8424 & 8.8252 & 8.8252 \\
\hline 16 & 7.2160 & 7.4636 & 9.6694 & 9.6694 \\
\hline 17 & 7.8300 & 8.0824 & 10.5142 & 10.5140 \\
\hline 18 & 8.4409 & 8.6968 & 11.3570 & 11.3570 \\
\hline 19 & 9.0472 & 9.3057 & 12.1958 & 12.1960 \\
\hline 20 & 9.6480 & 9.9081 & 13.0292 & 13.0290 \\
\hline 21 & 10.2430 & 10.5034 & 13.8565 & 13.8560 \\
\hline 22 & 10.8320 & 11.0917 & 14.6775 & 14.6770 \\
\hline 23 & 11.4150 & 11.6734 & 15.4926 & 15.4930 \\
\hline 24 & 11.9940 & 12.2496 & 16.3029 & 16.3030 \\
\hline 25 & 12.5700 & 12.8201 & 17.1100 & 17.1100 \\
\hline
\end{tabular}



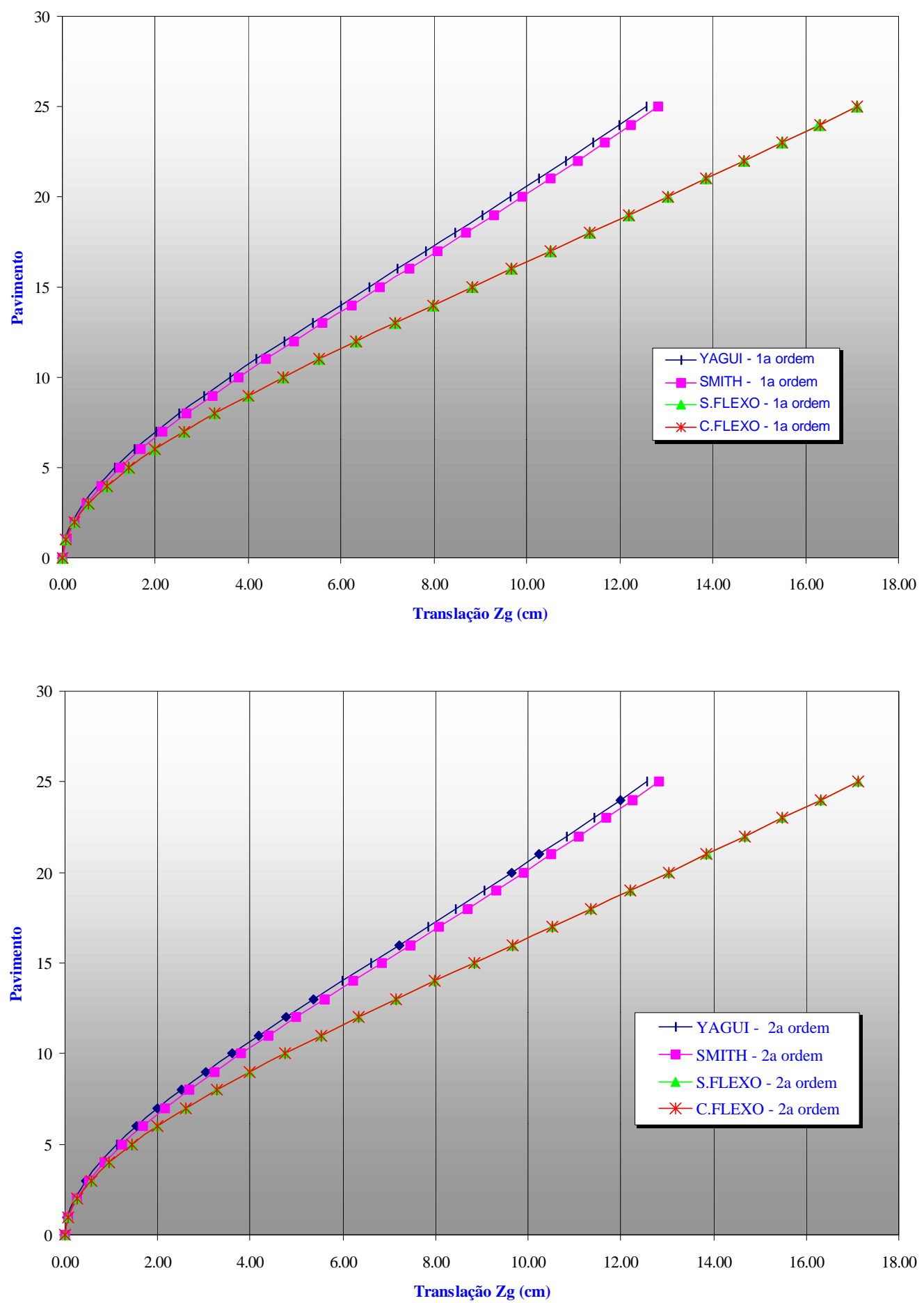

Figura 64 - Translação do nó mestre na direção Zg Superior $-\mathbf{1}^{\mathrm{a}}$ ordem / Inferior $-\mathbf{2}^{\mathrm{a}}$ ordem 
Tabela 22 - Rotação em torno do eixo Xg do nó mestre - $1^{\text {a }}$ ordem (E-03 rad)

\begin{tabular}{||c|c|c|c|c||}
\hline & YAGUI & SMITH & S.FLEXO & C.FLEXO \\
\hline \hline 0 & 0.00000 & 0.00000 & 0.00000 & 0.00000 \\
\hline 1 & 0.01497 & 0.02252 & 0.01219 & 0.01206 \\
\hline 3 & 0.04912 & 0.06348 & 0.04434 & 0.04391 \\
\hline 4 & 0.09684 & 0.11556 & 0.09101 & 0.09018 \\
\hline 5 & 0.15427 & 0.17586 & 0.14794 & 0.14667 \\
\hline 6 & 0.21833 & 0.24170 & 0.21184 & 0.21014 \\
\hline 7 & 0.28657 & 0.31100 & 0.28016 & 0.27804 \\
\hline 8 & 0.35711 & 0.38211 & 0.35088 & 0.34838 \\
\hline 9 & 0.42844 & 0.45369 & 0.42247 & 0.41963 \\
\hline 10 & 0.49940 & 0.52469 & 0.49369 & 0.49055 \\
\hline 11 & 0.56904 & 0.59426 & 0.56360 & 0.56020 \\
\hline 12 & 0.63665 & 0.66174 & 0.63144 & 0.62783 \\
\hline 13 & 0.70166 & 0.72658 & 0.69666 & 0.69287 \\
\hline 14 & 0.76363 & 0.78839 & 0.75880 & 0.75487 \\
\hline 15 & 0.82224 & 0.84685 & 0.81754 & 0.81350 \\
\hline 16 & 0.87724 & 0.90173 & 0.87264 & 0.86852 \\
\hline 17 & 0.92850 & 0.95288 & 0.92395 & 0.91978 \\
\hline 18 & 0.97591 & 1.00021 & 0.97138 & 0.96719 \\
\hline 19 & 1.01950 & 1.04371 & 1.01494 & 1.01080 \\
\hline 20 & 1.05930 & 1.08344 & 1.05468 & 1.05050 \\
\hline 21 & 1.09540 & 1.11951 & 1.09076 & 1.08670 \\
\hline 22 & 1.12810 & 1.15212 & 1.12341 & 1.11940 \\
\hline 23 & 1.15780 & 1.18157 & 1.15298 & 1.14910 \\
\hline 24 & 1.18480 & 1.20825 & 1.17995 & 1.17620 \\
\hline 25 & 1.20980 & 1.23271 & 1.20495 & 1.20130 \\
\hline
\end{tabular}

Tabela 23 - Rotação em torno do eixo Xg do nó mestre $-2^{\text {a }}$ ordem (E-03 rad)

\begin{tabular}{|c|c|c|c|c||}
\hline & YAGUI & SMITH & S.FLEXO & C.FLEXO \\
\hline \hline 0 & 0.00000 & 0.00000 & 0.00000 & 0.00000 \\
\hline 1 & 0.01504 & 0.02259 & 0.01219 & 0.01206 \\
\hline 2 & 0.04942 & 0.06378 & 0.04435 & 0.04391 \\
\hline 3 & 0.09750 & 0.11623 & 0.09101 & 0.09017 \\
\hline 4 & 0.15541 & 0.17701 & 0.14794 & 0.14667 \\
\hline 5 & 0.22003 & 0.24342 & 0.21184 & 0.21014 \\
\hline 6 & 0.28891 & 0.31336 & 0.28016 & 0.27804 \\
\hline 7 & 0.36013 & 0.38515 & 0.35089 & 0.34840 \\
\hline 8 & 0.43216 & 0.45742 & 0.42247 & 0.41964 \\
\hline 9 & 0.50381 & 0.52912 & 0.49369 & 0.49057 \\
\hline 10 & 0.57414 & 0.59937 & 0.56360 & 0.56022 \\
\hline 11 & 0.64242 & 0.66750 & 0.63145 & 0.62786 \\
\hline 12 & 0.70806 & 0.73297 & 0.69667 & 0.69289 \\
\hline 13 & 0.77063 & 0.79536 & 0.75881 & 0.75490 \\
\hline 14 & 0.82978 & 0.85436 & 0.81755 & 0.81352 \\
\hline 15 & 0.88529 & 0.90973 & 0.87265 & 0.86855 \\
\hline 16 & 0.93700 & 0.96133 & 0.92396 & 0.91980 \\
\hline 17 & 0.98483 & 1.00906 & 0.97139 & 0.96722 \\
\hline 18 & 1.02880 & 1.05293 & 1.01495 & 1.01080 \\
\hline 19 & 1.06890 & 1.09297 & 1.05469 & 1.05060 \\
\hline 20 & 1.10530 & 1.12932 & 1.09077 & 1.08670 \\
\hline 21 & 1.13830 & 1.16218 & 1.12342 & 1.11940 \\
\hline 22 & 1.16820 & 1.19185 & 1.15299 & 1.14910 \\
\hline 23 & 1.19540 & 1.21874 & 1.17996 & 1.17620 \\
\hline 24 & 1.22060 & 1.24338 & 1.20496 & 1.20130 \\
\hline 25 & 1.24450 & 1.26637 & 1.22885 & 1.22540 \\
\hline
\end{tabular}



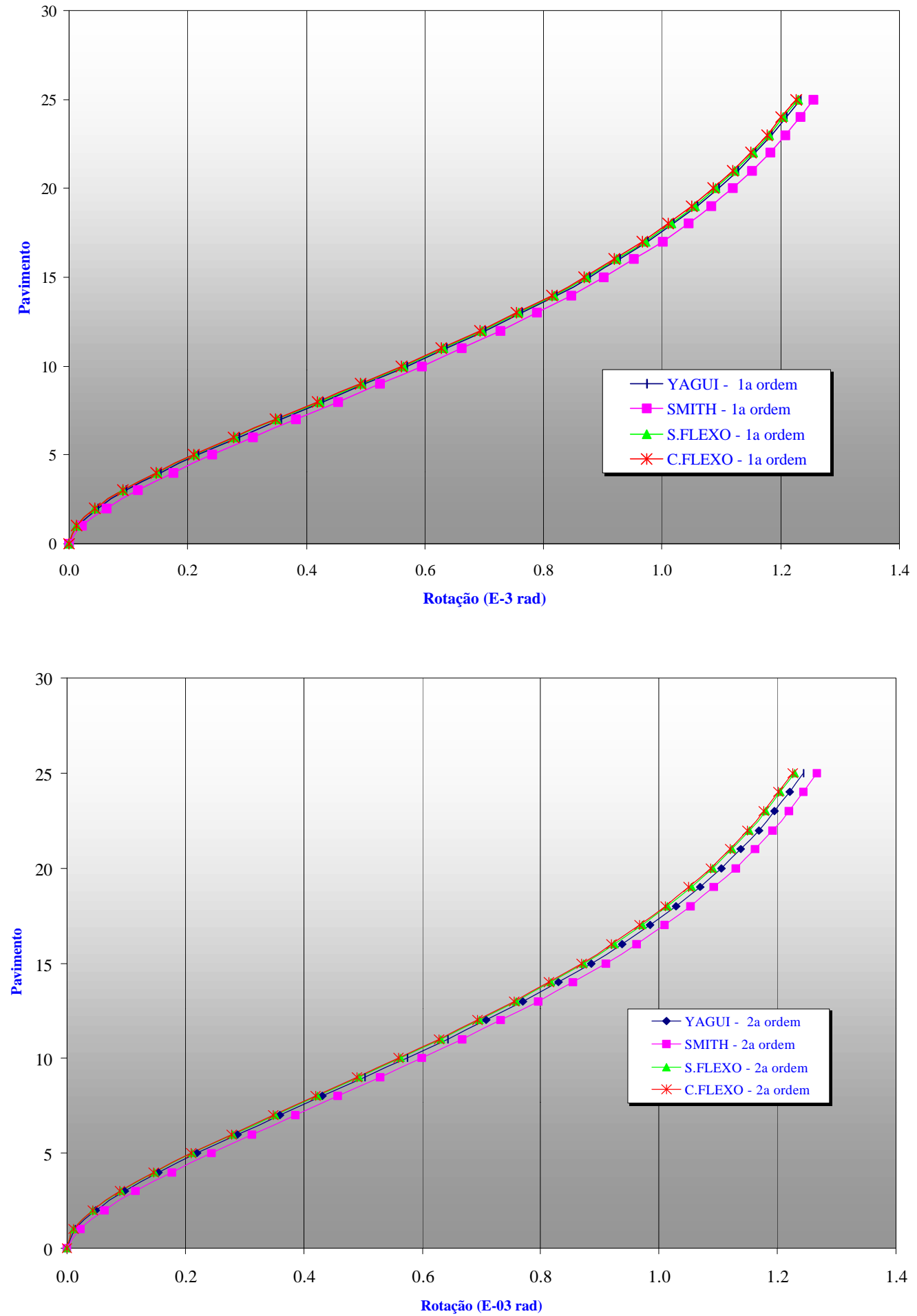

Figura 65 - Rotação do nó mestre em torno do eixo Xg Superior $-\mathbf{1}^{\mathrm{a}}$ ordem / Inferior $-\mathbf{2}^{\mathrm{a}}$ ordem 
Ao analisar os deslocamentos em translação apresentados pela estrutura, tabelas 20 e 21 , podemos observar a maior rigidez, apresentada pela mesma, ao serem utilizados os modelos YAGUI e SMITH. Pode ser observada também a pequena diferença numérica existente entre os resultados em rotação obtidos para todos os modelos e fornecidos pelas tabelas 22 e 23 .

Analisando o modelo com flexo observamos que este apresentou para o último pavimento um deslocamento $26,5 \%$ superior ao apresentado pelo modelo YAGUI, e em rotação 1,49\% inferior ao modelo YAGUI. Novamente a constatação de menores rotações para os modelos de maiores translações pôde ser verificada e atribuída principalmente à rigidez do núcleo.

Os modelos YAGUI e SMITH apresentaram pequena diferença, entre seus resultados, para os deslocamentos em translação e rotação. Esta mesma verificação pode ser observada entre os modelos com e sem flexo-torção que apresentaram valores idênticos para os deslocamentos de translação, e uma pequena diferença para os valores em rotação.

A pequena diferença constatada entre os modelos que utilizam elementos planos e entre os modelos que utilizam elementos de barra pode ser atribuída, provavelmente à pequena solicitação à torção a que ficou sujeita a estrutura. Sabe-se que para os modelos que utilizam elementos planos a diferença existente entre ambas, modelos YAGUI e SMITH, está relacionada ao momento parasita existente sempre que existirem tensões cisalhantes nas interfaces do elementos. Como estas tensões acentuam-se a partir do momento que acentuam os esforços de torção, a consideração acima se faz justificada. Já para os modelos que utilizam elementos de barra, modelos com e sem flexo-torção, a própria rigidez a torção do elemento é o que caracteriza a diferença entre ambas as modelagens, devido ao efeito do empenamento da seção que está relacionada principalmente à torção do elemento.

A estrutura de contraventamento do edifício, processada neste exemplo, mostrou possuir elevada rigidez estrutural, verificada com a análise dos processamentos em teoria de $1^{\mathrm{a}}$. e $2^{\mathrm{a}}$. ordem. Entre estes resultados ficou constatada uma diferença numérica muito pequena, para todos os modelos adotados. Isso leva a crer que os deslocamentos resultantes das iterações numéricas, provenientes das ações impostas à estrutura, resultaram muito pequenos de uma iteração para a outra. 
Tabela 24 - Momento Fletor do pilar 7, direção do eixo Yg - $1^{\mathrm{a}}$ ordem - (kN.cm)

\begin{tabular}{||c|c|c|c|c||}
\hline & YAGUI & SMITH & S.FLEXO & C.FLEXO \\
\hline \hline 1 & 5170.80 & 8356.70 & 5580.70 & 5580.70 \\
\hline 3 & 4290.20 & 3813.20 & 5755.60 & 5755.60 \\
\hline 4 & 4437.00 & 4670.30 & 5870.90 & 5870.90 \\
\hline 5 & 4453.00 & 4480.80 & 5949.70 & 5949.80 \\
\hline 6 & 4467.00 & 4528.40 & 5991.50 & 5991.50 \\
\hline 7 & 4452.70 & 4498.70 & 6001.20 & 6001.20 \\
\hline 8 & 4369.80 & 4462.70 & 5982.30 & 5982.40 \\
\hline 9 & 4304.80 & 4336.20 & 5938.20 & 5938.20 \\
\hline 10 & 4227.40 & 4253.40 & 5788.30 & 570.30 \\
\hline 11 & 4140.00 & 4160.70 & 5689.00 & 5689.00 \\
\hline 12 & 4044.80 & 4060.10 & 5577.90 & 5577.80 \\
\hline 13 & 3944.30 & 3954.20 & 5458.10 & 5458.00 \\
\hline 14 & 3840.70 & 3845.20 & 5332.80 & 5332.80 \\
\hline 15 & 3736.40 & 3735.40 & 5205.30 & 5205.40 \\
\hline 16 & 3633.90 & 3627.10 & 5078.90 & 5078.90 \\
\hline 17 & 3535.50 & 3522.90 & 4956.80 & 4956.80 \\
\hline 18 & 3443.60 & 3425.00 & 4842.20 & 4842.10 \\
\hline 19 & 3361.30 & 3336.30 & 4739.10 & 4739.20 \\
\hline 20 & 3289.40 & 3258.30 & 4648.60 & 4648.60 \\
\hline 21 & 3237.60 & 3198.10 & 4584.30 & 4584.30 \\
\hline 22 & 3182.30 & 3140.90 & 4510.70 & 4510.60 \\
\hline 23 & 3230.70 & 3163.00 & 4585.60 & 4585.50 \\
\hline 24 & 2976.20 & 2957.50 & 4210.90 & 4210.90 \\
\hline 25 & 4038.20 & 3859.70 & 5744.90 & 5744.90 \\
\hline
\end{tabular}

Tabela 25 - Momento Fletor do pilar 7, direção do eixo $\mathrm{Yg}-2^{\mathrm{a}}$ ordem - (kN.cm)

\begin{tabular}{||c|c|c|c|c|}
\hline & YAGUI & SMITH & S.FLEXO & C.FLEXO \\
\hline \hline 1 & 5172.00 & 8358.80 & 5580.70 & 5580.70 \\
\hline 3 & 4291.10 & 3813.60 & 5755.60 & 5755.60 \\
\hline 4 & 4438.10 & 4671.40 & 5870.90 & 5870.90 \\
\hline 5 & 4454.00 & 4481.80 & 5949.70 & 5949.70 \\
\hline 6 & 4468.00 & 4529.50 & 5991.50 & 5991.50 \\
\hline 7 & 4453.70 & 4499.60 & 6001.20 & 6001.20 \\
\hline 8 & 4421.00 & 4463.60 & 5982.30 & 5982.40 \\
\hline 9 & 4370.70 & 4407.30 & 5938.20 & 5938.10 \\
\hline 10 & 4228.60 & 4337.00 & 5872.50 & 5872.50 \\
\hline 11 & 4140.60 & 4254.10 & 5788.30 & 5788.30 \\
\hline 12 & 4045.40 & 4161.30 & 5689.00 & 5688.90 \\
\hline 13 & 3944.80 & 3954.70 & 5577.90 & 5577.90 \\
\hline 14 & 3841.10 & 3845.60 & 5458.10 & 5458.10 \\
\hline 15 & 3736.90 & 3735.80 & 5205.30 & 5332.80 \\
\hline 16 & 3634.30 & 3627.50 & 5078.90 & 5205.30 \\
\hline 17 & 3535.80 & 3523.20 & 4956.80 & 4956.80 \\
\hline 18 & 3443.90 & 3425.30 & 4842.20 & 4842.10 \\
\hline 19 & 3361.60 & 3336.60 & 4739.10 & 4739.20 \\
\hline 20 & 3289.70 & 3258.60 & 4648.60 & 4648.60 \\
\hline 21 & 3237.90 & 3198.40 & 4584.30 & 4584.30 \\
\hline 22 & 3182.60 & 3141.20 & 4510.70 & 4510.70 \\
\hline 23 & 3231.10 & 3163.30 & 4585.60 & 4585.60 \\
\hline 24 & 2976.50 & 2957.80 & 4210.90 & 4210.90 \\
\hline 25 & 4038.60 & 3860.20 & 5744.90 & 5744.90 \\
\hline \hline
\end{tabular}



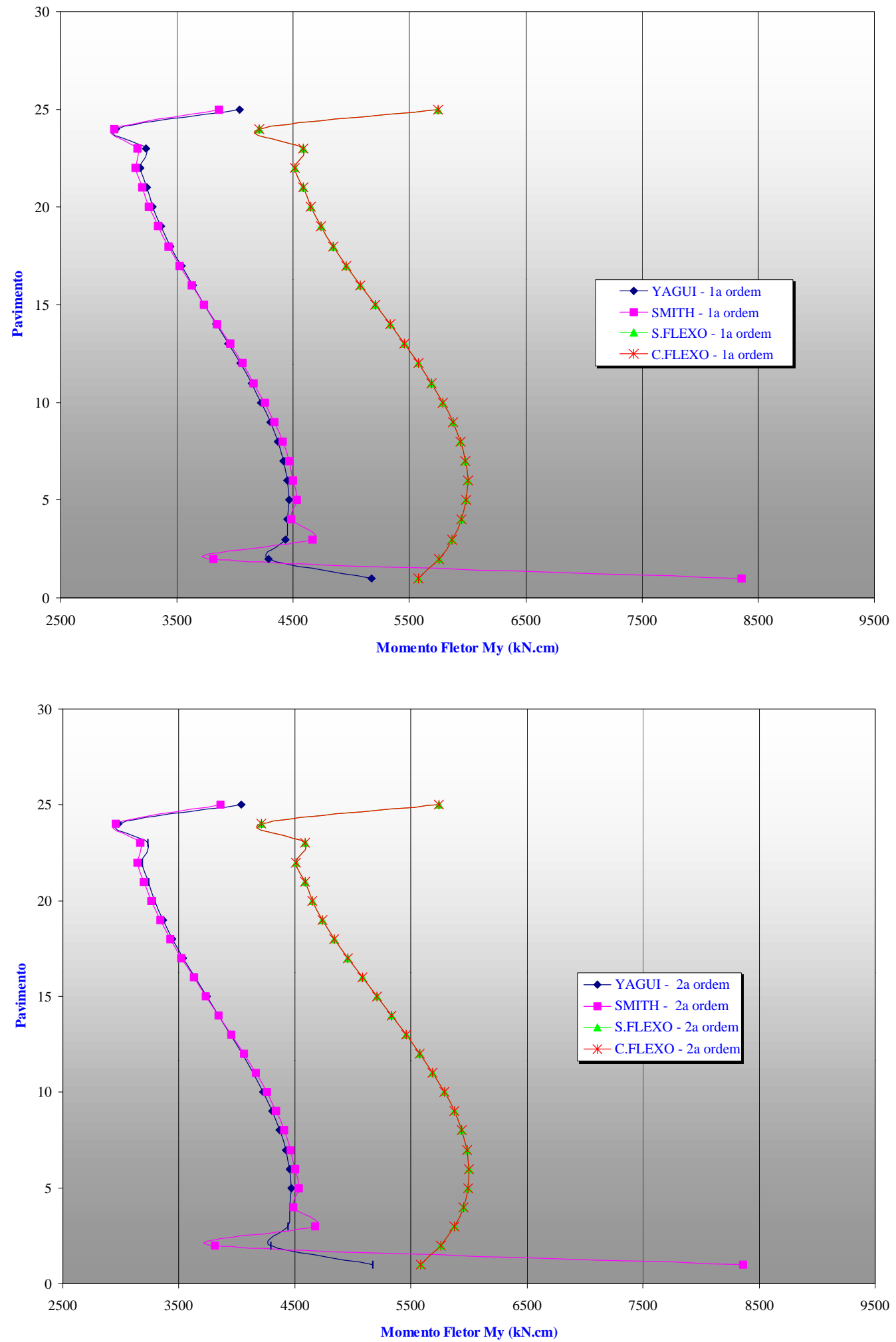

Figura 66 - Momento Fletor do pilar 7 na direção do eixo Yg Superior $-\mathbf{1}^{\mathrm{a}}$ ordem / Inferior $-2^{\mathrm{a}}$ ordem 
Tabela 26 - Esforço cortante no pilar 20, direção do eixo Zg - $1^{\text {a }}$ ordem - (kN.cm)

\begin{tabular}{|c|c|c|c|c||}
\hline & YAGUI & SMITH & S.FLEXO & C.FLEXO \\
\hline \hline 1 & 11.3090 & 29.4000 & 6.8613 & 6.8336 \\
\hline 2 & 11.4120 & 11.6470 & 13.7280 & 13.6890 \\
\hline 3 & 15.5870 & 18.3230 & 18.7440 & 18.7030 \\
\hline 5 & 18.0230 & 19.6380 & 22.4630 & 22.4230 \\
\hline 6 & 19.7400 & 21.1410 & 25.0940 & 25.0580 \\
\hline 7 & 20.7580 & 21.8610 & 26.8540 & 26.8230 \\
\hline 8 & 21.2480 & 22.1440 & 27.9090 & 27.8820 \\
\hline 9 & 21.3140 & 22.0400 & 28.3930 & 28.3710 \\
\hline 10 & 21.0460 & 21.6360 & 28.4150 & 28.3970 \\
\hline 11 & 20.5140 & 20.9940 & 28.0650 & 28.0500 \\
\hline 12 & 19.7760 & 20.1660 & 27.4150 & 27.4040 \\
\hline 13 & 18.8790 & 19.1940 & 26.5260 & 26.5180 \\
\hline 14 & 17.8610 & 18.1120 & 25.4500 & 25.4440 \\
\hline 15 & 16.7530 & 16.9480 & 24.2290 & 24.2250 \\
\hline 16 & 15.5830 & 15.7280 & 22.9020 & 22.9010 \\
\hline 17 & 14.3750 & 14.4730 & 21.5030 & 21.5030 \\
\hline 18 & 13.1490 & 13.2030 & 20.0630 & 20.0650 \\
\hline 19 & 11.9270 & 11.9370 & 18.6140 & 18.6170 \\
\hline 20 & 10.7300 & 10.6920 & 17.1840 & 17.1880 \\
\hline 21 & 9.5826 & 9.4993 & 15.8080 & 15.8130 \\
\hline 22 & 8.4951 & 8.3364 & 14.5140 & 14.5210 \\
\hline 23 & 7.5529 & 7.3941 & 13.3600 & 13.3690 \\
\hline 24 & 6.5997 & 6.1362 & 12.3630 & 12.3740 \\
\hline 25 & 6.1834 & 6.2990 & 11.3470 & 11.3580 \\
\hline & 6.1259 & 4.6916 & 13.6000 & 13.6190 \\
\hline
\end{tabular}

Tabela 27 - Esforço cortante no pilar 20, direção do eixo Zg - $2^{\mathrm{a}}$ ordem - (kN.cm)

\begin{tabular}{||c|c|c|c|c||}
\hline & YAGUI & SMITH & S.FLEXO & C.FLEXO \\
\hline \hline 1 & 11.6020 & 29.8390 & 7.1934 & 7.1650 \\
\hline 2 & 12.1430 & 12.5260 & 14.6390 & 14.5990 \\
\hline 3 & 16.6410 & 19.4980 & 20.1120 & 20.0690 \\
\hline 4 & 19.3170 & 21.0370 & 24.1720 & 24.1300 \\
\hline 5 & 21.1920 & 22.6780 & 27.0360 & 26.9980 \\
\hline 6 & 22.2970 & 23.4680 & 28.9360 & 28.9040 \\
\hline 7 & 22.8150 & 23.7640 & 30.0490 & 30.0210 \\
\hline 9 & 22.8600 & 23.6270 & 30.5240 & 30.5020 \\
\hline 10 & 22.5340 & 23.1540 & 30.4860 & 30.4670 \\
\hline 11 & 21.9160 & 22.4180 & 30.0340 & 30.0200 \\
\hline 12 & 21.0740 & 21.4770 & 29.2530 & 29.2410 \\
\hline 13 & 20.0590 & 20.3810 & 28.2120 & 28.2040 \\
\hline 14 & 18.9170 & 19.1690 & 26.9730 & 26.9680 \\
\hline 15 & 17.6840 & 17.8770 & 25.5840 & 25.5800 \\
\hline 16 & 16.3910 & 16.5290 & 24.0900 & 24.0890 \\
\hline 17 & 15.0630 & 15.1540 & 22.5270 & 22.5270 \\
\hline 18 & 13.7280 & 13.7720 & 20.9340 & 20.9360 \\
\hline 19 & 12.4040 & 12.4030 & 19.3410 & 19.3440 \\
\hline 20 & 11.1140 & 11.0650 & 17.7790 & 17.7840 \\
\hline 21 & 9.8843 & 9.7895 & 16.2830 & 16.2890 \\
\hline 22 & 8.7236 & 8.5540 & 14.8800 & 14.8880 \\
\hline 23 & 7.7170 & 7.5484 & 13.6300 & 13.6390 \\
\hline 24 & 6.7066 & 6.2348 & 12.5460 & 12.5580 \\
\hline 25 & 6.2423 & 6.3516 & 11.4520 & 11.4630 \\
\hline & 6.1296 & 4.6912 & 13.6230 & 13.6430 \\
\hline
\end{tabular}



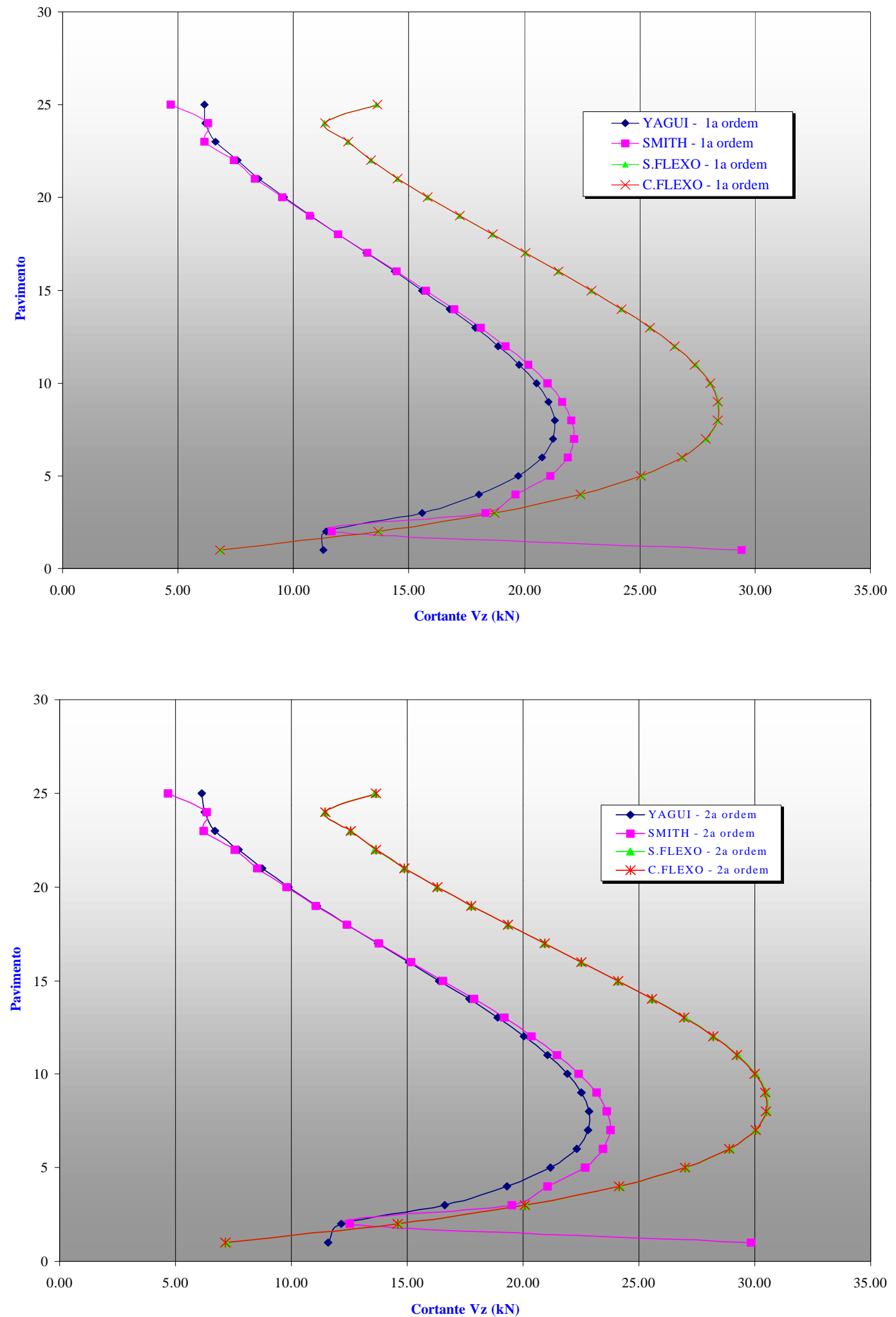

Figura 67 - Esforço cortante no pilar 20, direção do eixo Zg Superior $-\mathbf{1}^{\mathrm{a}}$ ordem / Inferior $-\mathbf{2}^{\mathrm{a}}$ ordem 
De acordo com os resultados em esforços, apresentados pelos modelos com e sem flexo, novamente, não foram constadas diferenças significativas entre seus valores. Observando o pilar 20, desta mesma estrutura, podemos verificar a obtenção de valores idênticos, para os esforços em momentos fletores, com a utilização destes modelos.

Ao longo da estrutura, com exceção dada à extremidade superior e inferior, os modelos YAGUI e SMITH apresentaram um comportamento semelhante, inclusive em valores numéricos, para os esforços solicitantes, nos pilares especificados. Mesmo adotando algumas considerações diferentes para as modelagens, com o objetivo de amenizar os efeitos do momento parasita, ficou constatado, também para este exemplo, que a existência deste momento não provocou alterações significativas nos resultados, fornecidos pelo modelo YAGUI.

Ao analisar os gráficos das figuras 66 e 67, pôde ser verificado um comportamento diferenciado apresentado entre os modelos YAGUI, SMITH e sem flexo-torção ou entre os modelos YAGUI, SMITH e com flexo-torção. Observando os resultados extraídos de TORRES (1999), para essa mesma estrutura, quando a deformação por cortante é considerada, a estrutura apresenta um comportamento distinto da análise obtida sem a consideração deste efeito. Ao analisar o comportamento dos gráficos em esforços, com a utilização do modelo SMITH, foi observado, para os pilares, um comportamento semelhante ao obtido por TORRES (1999), quando a deformação por cortante no núcleo era levada em consideração. Baseado nestas informações, foram traçados os gráficos, em esforços, a fim analisar e avaliar melhor este comportamento. Na realidade o modelo SMITH, mesmo não considerando a deformação por cortante no núcleo, levou à resultados semelhantes ao modelo YAGUI quando essa deformação é considerada. 
Tabela 28 - Momento Fletor do pilar 7, direção do eixo Yg - $1^{\mathrm{a}}$ ordem (kN.cm)

\begin{tabular}{||c|c|c|c|c||}
\hline & YAGUI & SMITH & C.FLEXO/DPC & YAGUI/DPC \\
\hline \hline 1 & 5170.80 & 8356.70 & 9808.90 & 9142.40 \\
\hline 2 & 4290.20 & 3813.20 & 5095.50 & 3803.50 \\
\hline 4 & 4437.00 & 4670.30 & 6014.30 & 4754.90 \\
\hline 5 & 4453.00 & 4480.80 & 5951.40 & 4512.90 \\
\hline 6 & 4467.00 & 4528.40 & 6010.90 & 4556.30 \\
\hline 7 & 4452.70 & 4498.70 & 6011.80 & 4521.40 \\
\hline 8 & 4420.10 & 4462.70 & 5989.00 & 4482.70 \\
\hline 9 & 4369.80 & 4406.50 & 5940.50 & 4424.20 \\
\hline 10 & 4304.80 & 4336.20 & 5870.50 & 4351.70 \\
\hline 11 & 4227.40 & 4253.40 & 5782.20 & 4266.70 \\
\hline 12 & 4140.00 & 4160.70 & 5678.80 & 4171.70 \\
\hline 13 & 4044.80 & 4060.10 & 5563.40 & 4069.00 \\
\hline 14 & 3944.30 & 3954.20 & 5439.30 & 3960.90 \\
\hline 15 & 3840.70 & 3845.20 & 5309.70 & 3849.60 \\
\hline 16 & 3736.40 & 3735.40 & 5177.50 & 3737.60 \\
\hline 17 & 3533.90 & 3627.10 & 5046.00 & 3627.00 \\
\hline 18 & 3443.60 & 3522.90 & 4918.50 & 3520.50 \\
\hline 19 & 3361.30 & 3325.00 & 4798.10 & 3420.20 \\
\hline 20 & 3289.40 & 3258.30 & 4688.30 & 3329.10 \\
\hline 21 & 3237.60 & 3198.10 & 4592.10 & 3248.70 \\
\hline 22 & 3182.30 & 3140.90 & 4451.60 & 3185.60 \\
\hline 23 & 3230.70 & 3163.00 & 4447.50 & 3142.60 \\
\hline 24 & 2976.20 & 2957.50 & 4286.60 & 2945.80 \\
\hline 25 & 4038.20 & 3859.70 & 5207.50 & 3815.40 \\
\hline
\end{tabular}

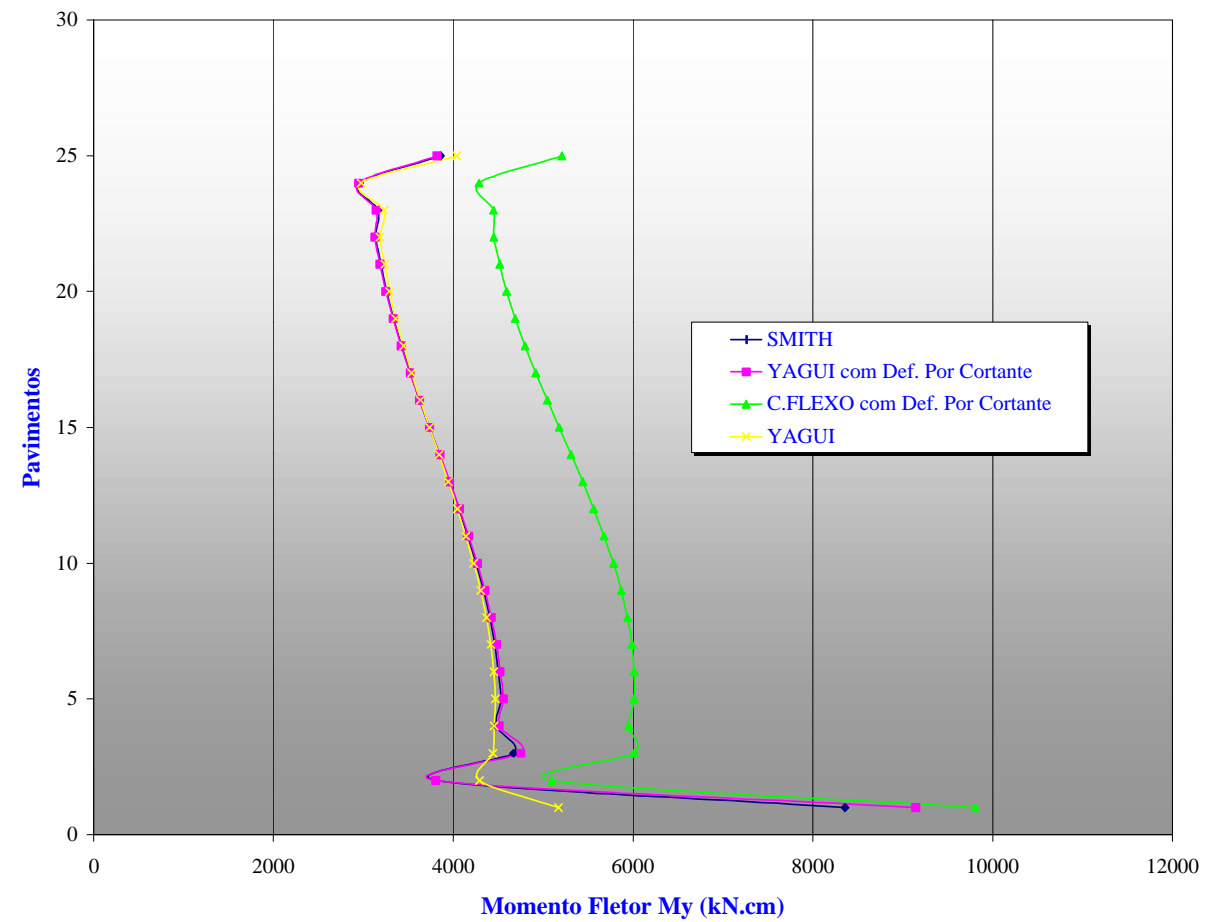

Figura 68 - Momento Fletor do pilar 7 na direção do eixo Yg-1a ordem 
Tabela 29 - Esforço cortante no pilar 20, direção do eixo $\mathrm{Zg}-\mathbf{1}^{\mathrm{a}}$ ordem -

(kN.cm)

\begin{tabular}{||c|c|c|c|c||}
\hline & YAGUI & SMITH & C.FLEXO/DPC & YAGUI/DPC \\
\hline \hline 1 & 11.3090 & 29.4000 & 31.057 & 33.4360 \\
\hline 2 & 11.4120 & 11.6470 & 14.279 & 12.3010 \\
\hline 4 & 15.5870 & 18.3230 & 21.758 & 19.2140 \\
\hline 5 & 18.0230 & 19.6380 & 24.317 & 20.2960 \\
\hline 6 & 19.7400 & 21.1410 & 26.58 & 21.6810 \\
\hline 7 & 20.7580 & 21.8610 & 27.967 & 22.3020 \\
\hline 8 & 21.2480 & 22.1440 & 28.756 & 22.5080 \\
\hline 9 & 21.3140 & 22.0400 & 29.034 & 22.3420 \\
\hline 10 & 21.0460 & 21.6360 & 28.9 & 21.8870 \\
\hline 11 & 20.5140 & 20.9940 & 28.429 & 21.2030 \\
\hline 12 & 19.7760 & 20.1660 & 27.686 & 20.3400 \\
\hline 13 & 18.8790 & 19.1940 & 26.726 & 19.3380 \\
\hline 14 & 17.8610 & 18.1120 & 25.592 & 18.2290 \\
\hline 15 & 16.7530 & 16.9480 & 24.327 & 17.0420 \\
\hline 16 & 15.5830 & 15.7280 & 22.962 & 15.8010 \\
\hline 17 & 14.3750 & 14.4730 & 21.53 & 14.5270 \\
\hline 18 & 13.1490 & 13.2030 & 20.059 & 13.2370 \\
\hline 19 & 11.9270 & 11.9370 & 18.578 & 11.9520 \\
\hline 20 & 10.7300 & 10.6920 & 17.112 & 10.6870 \\
\hline 21 & 9.5826 & 9.4993 & 15.699 & 9.4740 \\
\hline 22 & 8.4951 & 8.3364 & 14.335 & 8.2850 \\
\hline 23 & 7.5529 & 7.3941 & 13.198 & 7.3274 \\
\hline 24 & 6.5997 & 6.1362 & 11.785 & 5.9956 \\
\hline 25 & 6.1834 & 6.2990 & 11.825 & 6.2600 \\
\hline \hline
\end{tabular}

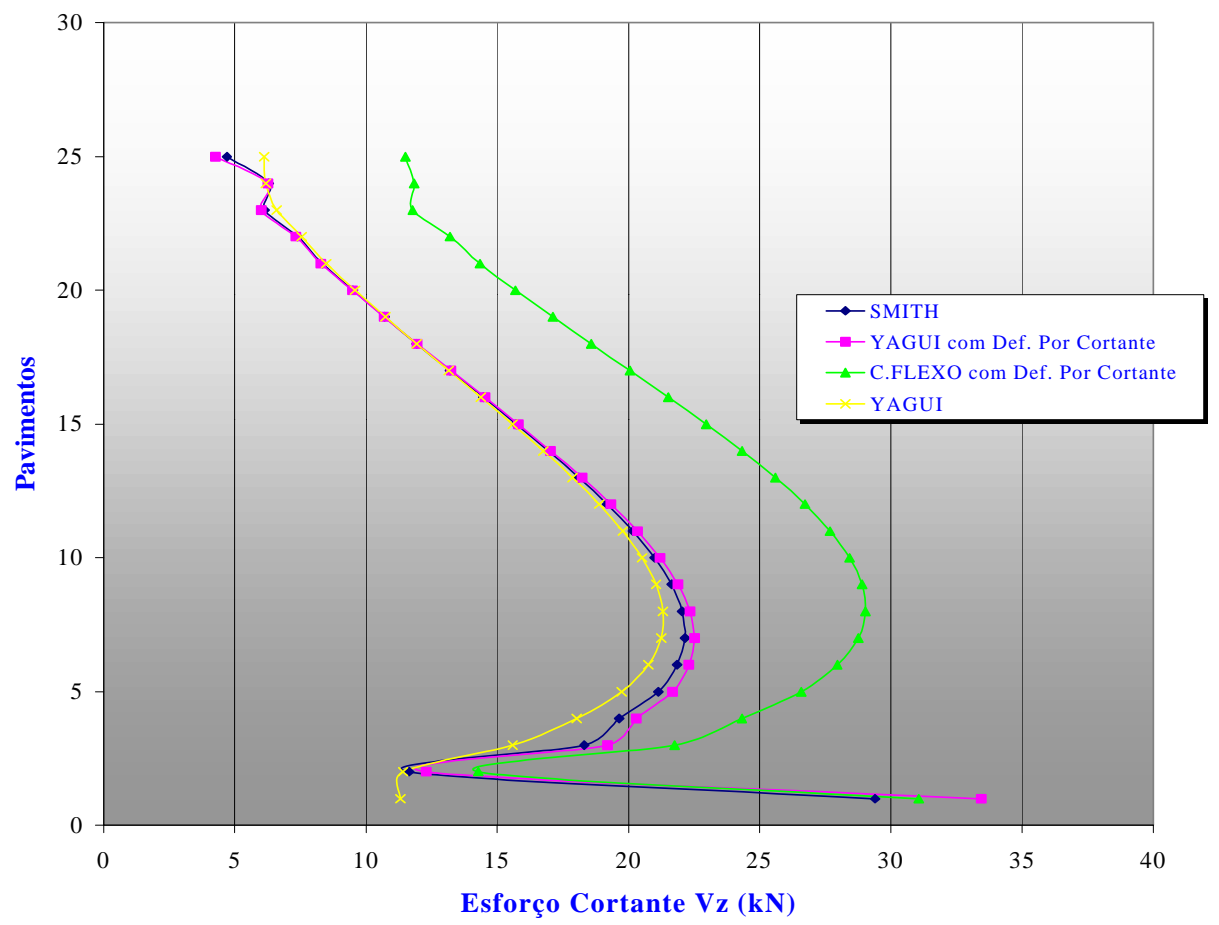

Figura 69 - Esforço cortante no pilar 20, direção do eixo Zg - 1a ordem 
Devido a elevada rigidez da estrutura processada neste exemplo, ao se efetuar as análises em teoria $2^{\mathrm{a}}$ ordem não foram obtidos resultados diferentes dos fornecidos pela análise em teoria de $1^{\mathrm{a}}$ ordem conforme já constatado. 


\section{CONSIDERAÇÕES FINAIS E SUGESTÕES}

"Nunca se deve pensar que se chegou ao topo, mas, pelo contrário, que se tem muito ainda para aprender...."

Alicia Alonso

Ao longo de todo o capítulo 6, foram realizados alguns comentários referentes aos diversos resultados obtidos, para cada uma das estruturas, frente às diversas modelagens adotadas. Com base nestes comentários puderam ser tiradas algumas conclusões consideradas pertinentes ao trabalho proposto.

É importante lembrar que, devido às hipóteses de cálculo adotadas para o processamento das estruturas, algumas perturbações podem ser observadas na extremidade superior e inferior da estrutura, principalmente nos resultados fornecidos em esforços. Essas perturbações são causadas pela perda de continuidade, quer na extremidade superior do edifício, onde os deslocamentos, incluindo o empenamento, são completamente livres, quer na sua extremidade inferior ou base, onde a hipótese de fundação rígida simula um engastamento perfeito, com impedimento total dos empenamentos. Com base nestas informações é considerado prudente que, todas as análises efetuadas sejam, preferencialmente, aplicadas aos pavimentos intermediários. Esse procedimento tem a finalidade de evitar que as perturbações de extremidade, acentuadas nos resultados em esforços, influenciem no processo comparativo desenvolvido para as modelagens, distorcendo assim as conclusões finais. 
Inicialmente, foi verificado um comportamento mais rígido, da estrutura de contraventamento, diante da modelagem do núcleo por meio de elementos planos. Essa afirmação pode ser verificada com a análise dos resultados fornecidos para as estruturas processadas nos exemplos 2 e 3, de acordo com os modelos YAGUI e SMITH. Este fenômeno pode ser atribuído à não consideração, por parte deste tipo de modelagem, de algumas das coordenadas deslocamentos geralmente consideradas pelas demais modelagens. Essa não consideração implica em uma diminuição do grau de deslocabilidade da estrutura tornando-a, assim, um pouco mais rígida.

Entre as modelagens por elementos planos, modelos YAGUI e SMITH, somente para o exemplo 1, ficou constatada uma influência significativa do momento parasita nos resultados finais da estrutura. Para os demais exemplos, os resultados mostraram-se praticamente os mesmos entre as modelagens. Porém, no exemplo 3, o modelo SMITH apresentou um comportamento diferenciado nas extremidades superior e inferior da estrutura. De acordo com os resultados, esta modelagem apresentou-se semelhante ao modelo YAGUI quando, neste modelo, é levada em consideração a deformação por cortante na determinação da rigidez do elemento. Com base nestes dados podemos supor que, dentre ambas as modelagens por elementos planos, talvez o modelo SMITH contribua melhor na representação do comportamento estrutural do edifício, quando este estiver sujeito à esforços de torção elevados.

Para as modelagens por barra de seção delgada considerando ou não a teoria de flexo-torção, quando comparados os resultados fornecidos para os exemplos 2 e 3, podemos observar que não ocorreram diferenças significativas de valores, entre os dois modelos. Sabendo que a diferença entre ambas as modelagens está na consideração ou não da rigidez ao empenamento do núcleo, e sendo este diretamente relacionado à sua rotação, podemos supor que a rigidez à torção das estruturas de contraventamento, exemplo 2 e 3, obtidas com a utilização do modelo com e sem flexo-torção, não apresentaram diferença significativa entre estes modelos. Analisando numericamente ficou constatado que, a rigidez à torção, para cada pavimento, obtida com o modelo sem flexo foi 2,22\% inferior à mesma rigidez agora 
obtida com a utilização do modelo com flexo-torção. Já para o exemplo 3 essa redução foi de 1,98\%. Baseado nestas análises ficou confirmado que, para estas duas estruturas de edifício estudadas, o efeito do empenamento não exerceu grande influência nos resultados finais, principalmente nos elementos de pilares.

A modelagem por pilar parede isolado mostrou ser, dentre as diversas modelagens analisadas, a de menor eficiência no processo de simulação do comportamento do núcleo resistente. Esta modelagem atribuiu à estrutura uma rigidez muito inferior, levando à resultados diferenciados quando comparados às demais modelagens. Para se ter uma idéia da discrepância entre os resultados fornecidos, são apresentadas, na tabela 30, as diferenças em porcentagem entre a modelagem do núcleo por pilar parede isolado e as demais adotadas.

Tabela 30 - Diferença em porcentagem entre a modelagem do núcleo por pilar parede isolado e demais modelagens adotadas (Exemplo 2- $2^{\mathrm{a}}$ ordem).

\begin{tabular}{lr|r|r|r|r}
\hline \multirow{2}{*}{$\begin{array}{l}\text { RESULTADOS } \\
\text { (pavimentos) }\end{array}$} & \multicolumn{5}{|c}{ MODELAGENS } \\
\cline { 2 - 6 } & $\begin{array}{c}\text { Modelo YAGUI } \\
\text { Dif. \% }\end{array}$ & $\begin{array}{c}\text { Modelo SMITH } \\
\text { Dif. \% }\end{array}$ & $\begin{array}{c}\text { Modelo S. flexo } \\
\text { Dif. \% }\end{array}$ & $\begin{array}{c}\text { Modelo C. flexo } \\
\text { Dif. \% }\end{array}$ \\
\hline Translação Y & $15^{\circ}$ & 40.92 & 40.80 & 26.55 & 26.79 \\
\cline { 3 - 6 } & $7^{\circ}$ & 43.06 & 42.82 & 35.76 & 36.22 \\
\hline Rotação X & $15^{\circ}$ & -216.00 & -219.87 & -172.21 & -164.00 \\
\cline { 3 - 6 } & $7^{\circ}$ & -125.90 & -129.02 & -126.77 & -119.65 \\
\hline M. Fletor $M z$ & $7^{\circ}$ & 29.34 & 29.32 & 20.58 & 20.49 \\
\hline Es. Cortante $V z$ & $7^{\circ}$ & 49.43 & 49.35 & 47.11 & 47.11 \\
\hline
\end{tabular}

Apesar da discrepância apresentada pelos resultados, de acordo com a tabela 30, a consideração do núcleo a partir da modelagem por pilar parede isolado, não representa um risco, uma vez que a rigidez obtida para o núcleo é inferior à sua rigidez real. Porém, esse comportamento resulta, para a maioria dos elementos estruturais, em esforços geralmente superiores aos que realmente os solicitam, podendo levar à um dimensionamento anti-econômica. 
A distribuição estrutural dos elementos, apresentada pela estrutura de contraventamento, e as ações incidentes sobre ela, são capazes de influenciar diretamente no comportamento apresentado por cada uma das modelagens.

Analisando os modelos com e sem flexo, foi observado que, para o exemplo 3 , as diferenças de resultados obtidas entre estas modelagens apresentaram-se menores que as mesmas observadas no exemplo 2. Para uma melhor visualização é apresentado, nas figuras 70, 71, 72 e 73, as diferenças percentuais entre os resultados fornecidos para os modelos com e sem flexo, dos exemplos 2 e 3.

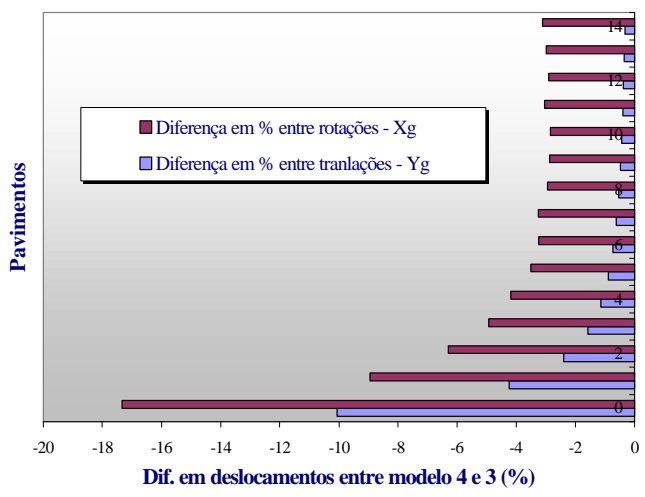

Figura 70 Diferença percentual em deslocamentos entre os modelos 4 e 3 - exemplo 2

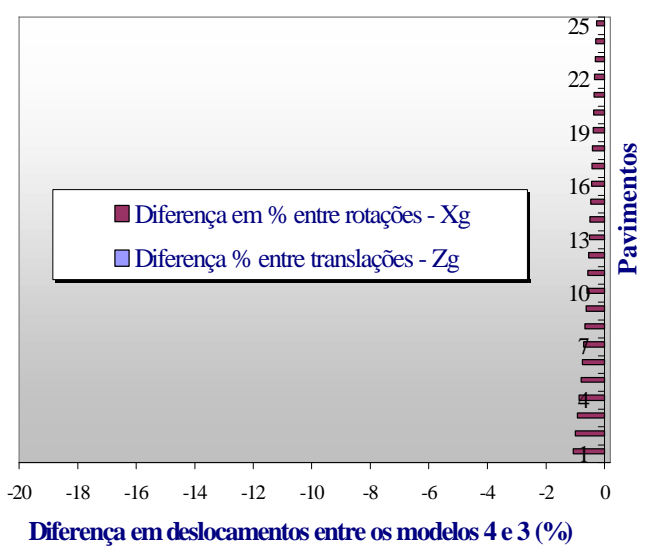

Figura 72 Diferença percentual em deslocamentos entre os modelos 4 e 3 - exemplo 3

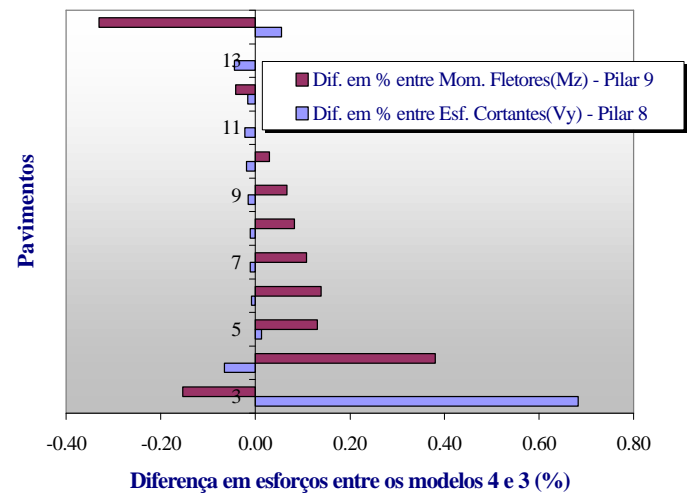

Figura 71 Diferença percentual em esforços entre os modelos 4 e 3 - exemplo 2

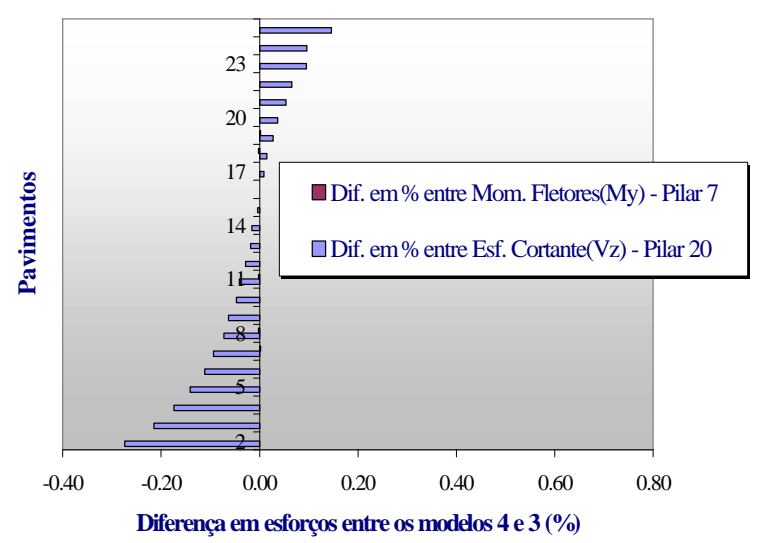

Figura 73 Diferença percentual em esforços entre os modelos 4 e 3 - exemplo 3

Com base nestes resultados e nos resultados fornecidos pelo exemplo 1, podemos concluir que, para as estruturas que possam apresentar rotações elevadas, devido as características estruturais e ações incidentes, não é recomendada a 
utilização do modelo sem flexo-torcão na simulação do núcleo uma vez que o elemento adotado, nesta modelagem, não consegue representar bem seu o comportamento.

As análise comparativas entre as estruturas cujos modelos de núcleo utilizem elementos com características semelhantes, por exemplo entre os modelos YAGUI e SMITH, ou entre os modelos com e sem flexo, podem ser realizadas de uma maneira mais direta. Porém, um estudo capaz de fornecer relações comparativas entre estruturas que utilizem os modelos YAGUI e com flexo-torção, é muito mais complexa. Uma maneira de comparar e avaliar as modelagens que adotam elementos com características tão diferentes, pode ser feita através da análise das diferenças de resultados existente entre elas. As figuras 74 e 75 apresentam as diferenças percentuais entre os resultados fornecidos para os modelos YAGUI e com flexotorção, nos exemplos 2 e 3.
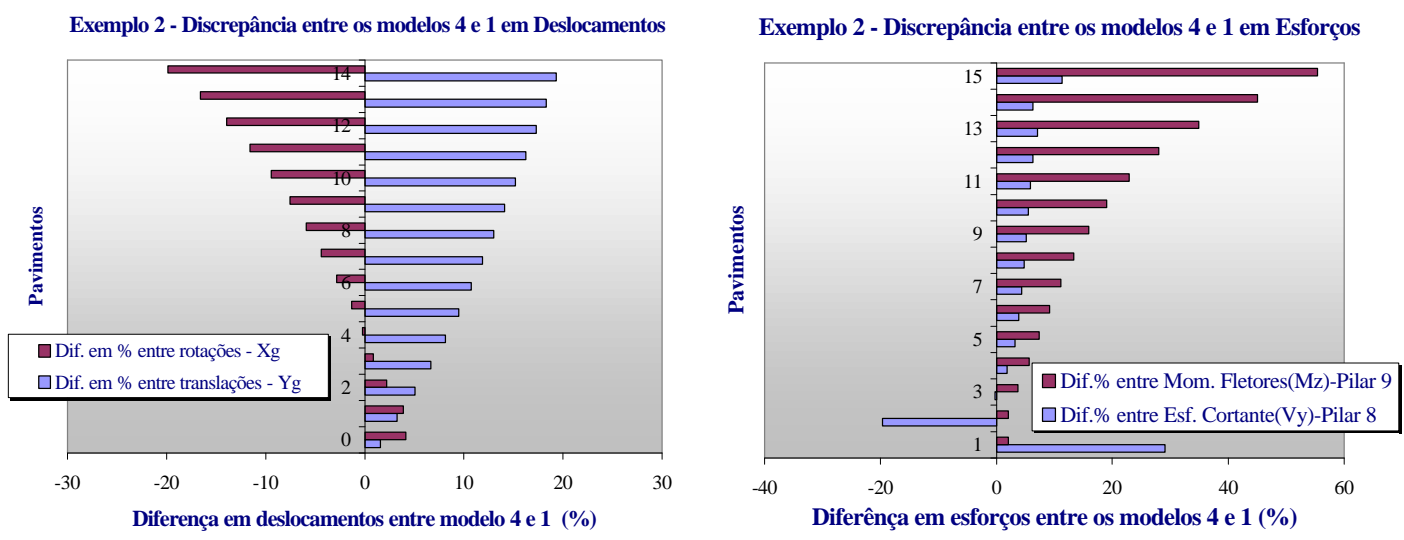

Figura 74 - Diferenças em \% entre os resultados dos modelos 4 e 1 - Exemplo2
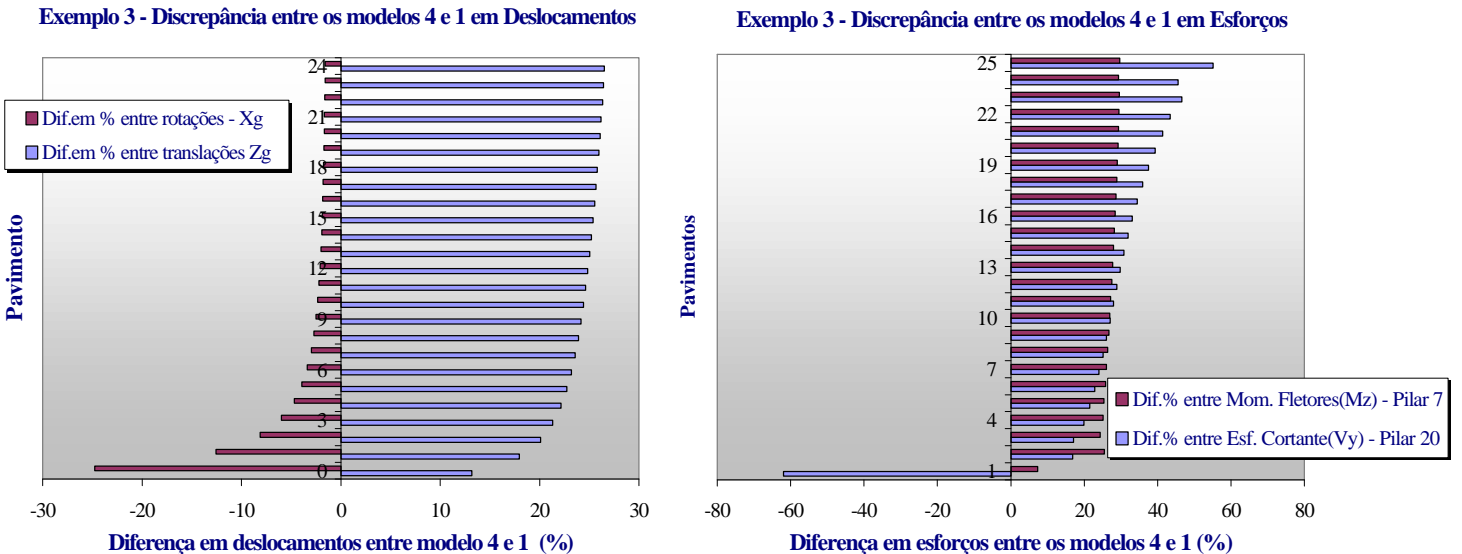

Figura 75 - Diferenças em \% entre os resultados dos modelos 4 e 1 - Exemplo3 
De acordo com as diferenças apresentadas, pelos gráficos das figuras 74 e 75, podemos constatar que o modelo com flexo apresentou esforços, na maioria dos pavimentos, superiores aos fornecidos pelo modelo YAGUI. Se considerarmos que a teoria de barras longas e seção delgada é a teoria que melhor define o comportamento do núcleo, podemos afirmar que, dentre os vários modelos adotados, o modelo com flexo é o que melhor representa o comportamento do núcleo. Baseado nesta afirmativa e analisando as diferenças em esforços fornecidas pelos modelos YAGUI e com flexo-torção, podemos concluir que, com a utilização da modelagem proposta por YAGUI, alguns elementos da estrutura poderão estar sendo dimensionados para esforços inferiores aos que realmente atuam no elemento. Em linguagem técnica, os elementos componentes da estrutura de contraventamento, onde para o núcleo se utilize a modelagem proposta por YAGUI ou proposta por SMITH, poderão estar sendo dimensionados contra a segurança.

A modelagem utilizando o M.E.F., através do software Ansys, mostrou pouca praticidade para a realização das análises efetuadas neste trabalho. Alguns tipos de softwares, que utilizam o M.E.F. para o processamento de estruturas de edifícios altos, podem apresentar certas dificuldades tanto na simulação do comportamento da estrutura como na retirada de dados. Estes fatores podem ser considerados a maior desvantagem, decorrente da utilização deste método, uma vez que para este tipo de modelagem a utilização de um software é imprescindível. Sendo assim, podemos afirmar que, as análises desenvolvidas com a utilização do M.E.F., pode conduzir à excelentes resultados, porém as dificuldades encontradas, até que se chegue aos resultados finais, confirmam a sua pouca praticidade e, consequente, pequena utilização, no processamento de estruturas de edifícios altos.

Finalizando as análises e procurando apresentar, de forma resumida, algumas das informações coletadas durante a realização deste trabalho, optou-se pela apresentação em forma de tabela das vantagens e desvantagens observadas durante a utilização de cada uma das modelagens propostas. 
Tabela 31 - Resumo das vantagens e desvantagens observadas com a utilização das modelagens de núcleo proposta

\begin{tabular}{|c|c|c|c|c|c|}
\hline 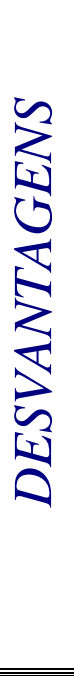 & 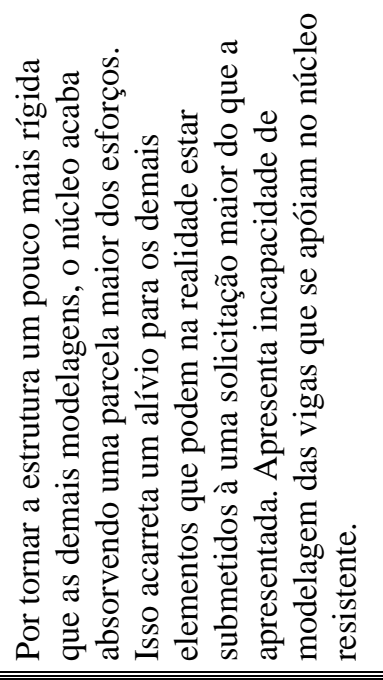 & 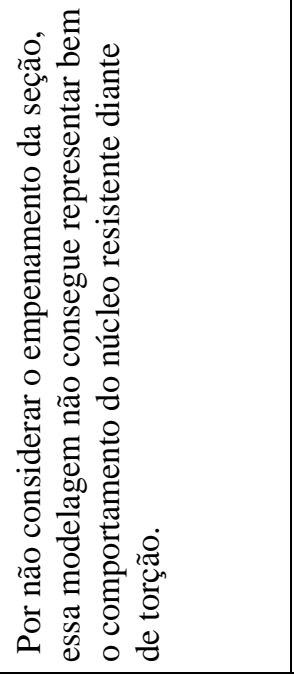 & 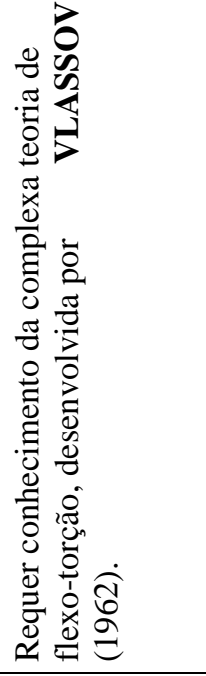 & 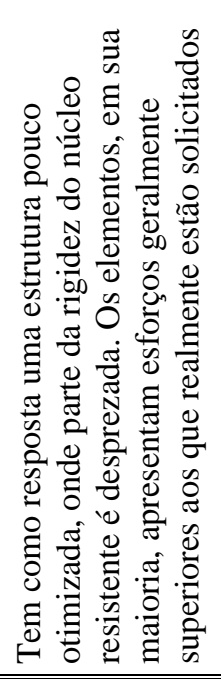 & 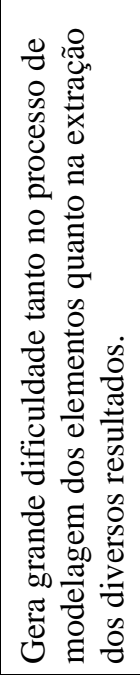 \\
\hline$\frac{\sum_{0}^{\infty}}{3}$ & 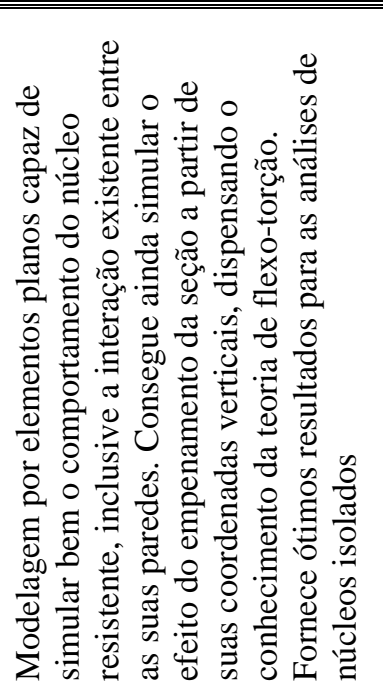 & 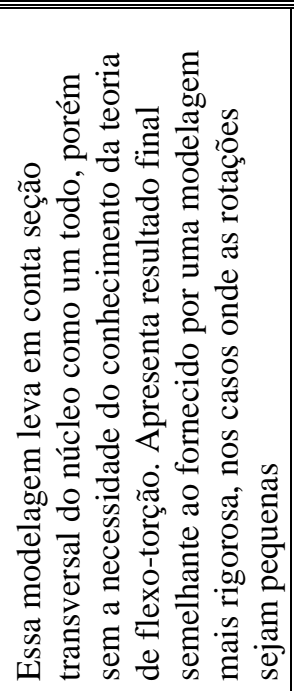 & 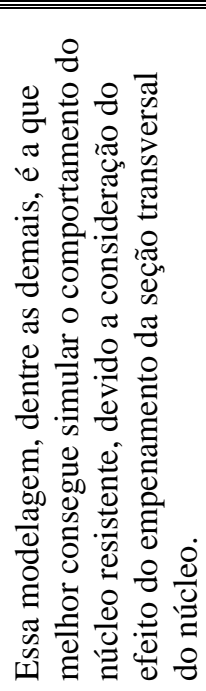 & 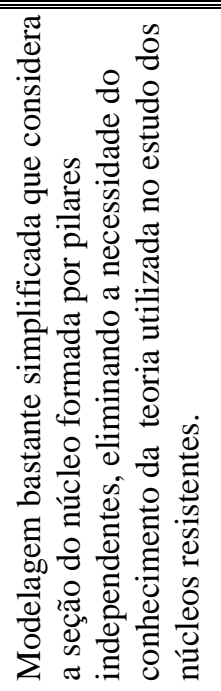 & 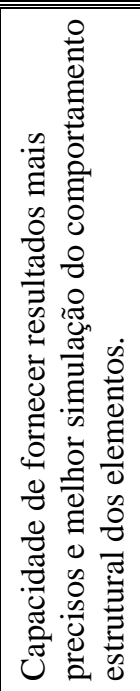 \\
\hline 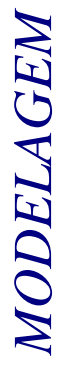 & 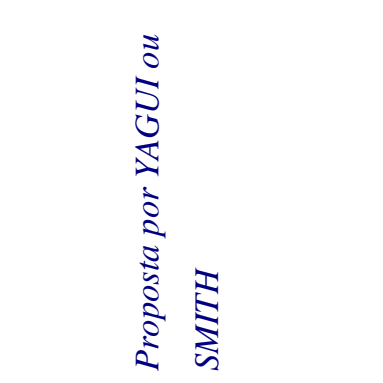 & 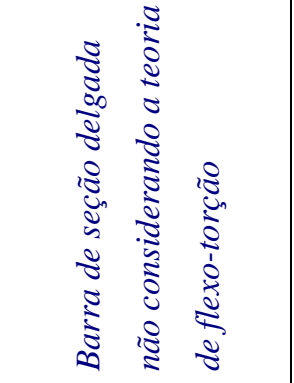 & 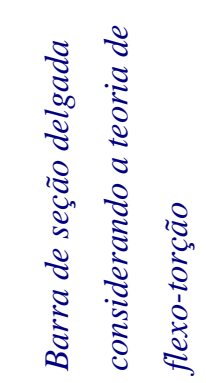 & 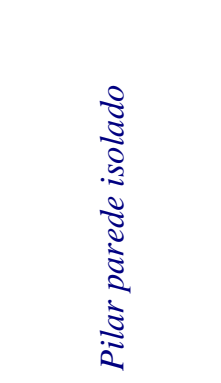 & 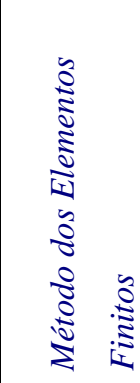 \\
\hline
\end{tabular}


Entre as sugestões para trabalhos futuros podem ser citados:

- Análise da estrutura de contraventamento considerando a sua interação com a fundação. Esta análise poderia contribuir com informações mais reais sobre o comportamento das estruturas diante das modelagens, principalmente para modelagem do núcleo utilizando elementos planos.

- Desenvolver estudo e rotina, para a modelagem por elementos planos, que possibilite a análise de estruturas de contraventamento que apresentem elementos de vigas apoiadas no núcleo resistente, uma vez que a presença destas vigas é preocupação comum em escritórios de cálculo estrutural.

- Desenvolver análises, em teoria de primeira e segunda ordem, para todas as modelagens propostas, considerando a influência da deformação por cortante em todos os elementos da estrutura, principalmente no núcleo resistente.

-Propor nova formulação, para as modelagens propostas por YAGUI e SMITH et al, para as análises das estruturas em teoria de segunda ordem, uma vez que estas são consideradas aproximadas.

-Com a constatação da presença de deslocamentos de translação, para momentos torçores aplicados, nas modelagens propostas por YAGUI e SMITH, apresentados no capítulo 6, referente ao exemplo 1, é proposto também um estudo destas modelagens, com o intuito de melhorar o comportamento deste elemento diante da torção. Dessa forma pretende-se garantir, que neste tipo de análise, a estrutura se aproxime mais do comportamento obtido com a utilização da teoria de flexo-torção. Ao mesmo tempo deve-se analisar o modelo, de forma que este não se apresente tão rígido, proporcionando uma distribuição de esforços mais coerente e segura entre os elementos estruturais.

- Análise da influência da consideração da não linearidade física do material, no comportamento global da estrutura de contraventamento, juntamente com a consideração da não linearidade geométrica da estrutura. Esta última já admitida no presente trabalho. 


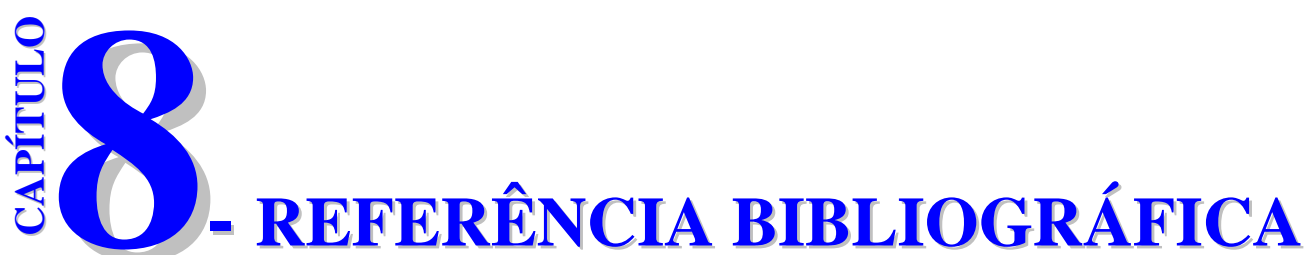

ANSYS INTERACTIVE (1994) - Release 5.5 -University high option -

ANTUNES, H.M.C.C.,(1978). Carregamento crítico de instabilidade geral para estruturas tridimensionais de edifícios altos. Tese (Doutorado) - Escola de Engenharia de São Carlos - EESC -USP.

ANTUNES, H.M.C.C.; MORI, D.D.; SOUZA, J.C.A.O. Núcleos estruturais. In: JORNADAS SUDAMERICANAS DE INGENIERIA ESTRUCTURAL, 27. Tucumán, Argentina, 18-22 septiembre 1995. Memorias. Tucumán, ASAIE/Laboratorio de Estructuras-FCET-UNT, 1995. v.3, p.123 -134.

ASSOCIAÇÃO BRASILEIRA DE NORMAS TÉCNICAS (1980). NBR 6120 Cargas para cálculo de estruturas de edificações. Rio de Janeiro, ABNT.

ASSOCIAÇÃO BRASILEIRA DE NORMAS TÉCNICAS (1984). NBR 8681 Ações e segurança nas estruturas. Rio de Janeiro, ABNT.

ASSOCIAÇÃO BRASILEIRA DE NORMAS TÉCNICAS (1988). NBR 6123 Forças devidas ao vento em edificações. Rio de Janeiro, ABNT. 
BARBOSA, J.A., (1978). Edifícios com paredes de seção aberta contraventadas por lintéis, sob carga lateral. Dissertação (Mestrado) - Escola de Engenharia de São Carlos - EESC -USP.

BECKER, E.P., (1989). Edifícios altos: interação tridimensional das peças de contraventamento. Dissertação (Mestrado) - Escola de Engenharia de São Carlos - EESC - USP.

COSTA, J. L., (1984). Núcleos estruturais sobre fundações flexíveis. Dissertação (Mestrado) - Escola de Engenharia de São Carlos - EESC - USP.

FRANCO, M. Problemas de estabilidade nos edifícios de concreto armado. In: COLÓQUIO SOBRE ESTABILIDADE GLOBAL DAS ESTRUTURAS DE CONCRETO ARMADO, São Paulo, julho 1985. São Paulo: IBRACON, 1985. $27 \mathrm{p}$.

GUILARDI, S. L. M., (1999). Sobre os problemas inerentes aos processos discretos na análise de núcleos estruturais. Campinas: Faculdade de Engenharia de Civil -UNICAMP

HEIDEBRECHT, A.C., SWIFT, R.D. Analysis of asymmetric coupled shear walls. Journal of the Structural Division, ASCE, v.97, n.5, p.1407-22, May, 1971.

MICROSOFT (1994). FORTRAM PowerStation: user's guide:. Profecional developtment system, version 4.0

MATIAS JUNIOR, I.G. (1997). Análise não-linear de estruturas tridimensionais de edifícios altos com núcleos resistentes sobre fundações flexíveis. Dissertação (Mestrado ) - Escola de Engenharia de São Carlos, Universidade de São Paulo.

MATIAS JR., I.G.; MORI, D.D. Núcleos resistentes sobre fundações flexíveis. In: JORNADAS SUL-AMERICANAS DE ENGENHARIA ESTRUTURAL, 28., São Carlos, 1-5 set. 1997. Estruturas e fundações. São Carlos, Departamento 
de Engenharia de Estruturas-EESC-USP / Associação Sulamericana de Engenharia Estrutural, 1997. v.4, p.1387-1396.

MORI, D.D.; SOUZA, J.C.A.O.; ANTUNES, H.M.C.C. A flexo-torção na análise em segunda ordem de núcleos resistentes em estruturas de edifícios altos. In: CONGRESSO IBERO LATINO-AMERICANO SOBRE MÉTODOS COMPUTACIONAIS PARA ENGENHARIA, 13., Porto Alegre, 23-25 nov. 1992. Anais. Porto Alegre, CPGEC-UFRGS, 1992. v.2, 174-183 (XIII CILAMCE)

MORI, D.D.; MATIAS JR., I.G. Não linearidade geométrica nos núcleos resistentes. In: CONGRESSO IBERO LATINO-AMERICANO DE MÉTODOS COMPUTACIONAIS PARA ENGENHARIA, 18., Brasília, 29-31 out. 1997. Anais. Brasília, AMC / UnB, 1997. v.1, p. 159-166.

MORI, D.D.; SOUZA, J.C.A.O.; ANTUNES, H.M.C.C. Os núcleos estruturais e sua contribuição na absorção de esforços de 1a. e 2a. ordens em estruturas de edifícios altos. In: JORNADAS SUDAMERICANAS DE INGENIERÍA ESTRUCTURAL, 26., Montevideo, Uruguay, 15-19 nov. 1993. Memorias. Montevideo, CLAES/ ASAIE, 1993. v.2, p.475-484

MORI, D.D.; SOUZA, J.C.A.O.; ANTUNES, H.M.C.C. Tall buildings with cores. In: INTERNATIONAL CONFERENCE ON TALL BUILDINGS, Rio de Janeiro, Brazil, May 17-19, 1993. Proceedings. Bethlehem, Council on Tall Buildings and Urban Habitat, 1994. p.289-300

MORI, D. D. (1992); Os núcleos estruturais e a não-linearidade geométrica na análise de estruturas tridimensionais de edifícios altos. Tese de doutorado, EESC-USP 
PEREIRA, G. S., (1997). Contribuições à Análise de Estruturas de Contraventamento de Edifícios em Concreto Armado; Dissertação de Mestrado, EESC-USP

SERRA, J. L. F. A. (1994). Contribuição ao estudo de núcleos resistentes de concreto armado. Tese (doutorado) - Escola de Engenharia de São Carlos, Universidade de São Paulo - EESC - USP

SILVA, R.M. (1989). Análise de estruturas tridimensionais de edifícios altos com núcleo resistentes considerando o efeito $P$ - $\delta$. Dissertação (Mestrado) - Escola de Engenharia de São Carlos - EESC-USP

SOUSA JUNIOR. E., Análise da interação entre núcleos estruturais e lajes em edifícios altos. Tese de doutorado em desenvolvimento - Escola de Engenharia de São Carlos - EESC-USP

SMITH, B.S., GIRGIS, A., ABATE, A. Anaolgous frames for the analysis of tall shear wall structure. Can. Journal of Civ. Engeners, v.8, n.2, p.179-181, 1981.

SMITH, B.S., GIRGIS,. Simple analogous frames for shear wall analysis. Journal of Structrure. Engineering, ASCE, v.110, n.11, p.2655-2666, nov. 1984.

SMITH, B.S., TARANATH, B.S. The analysis of tall core-supported structures subject to torsion. Proc. Institution of Civil Engineers, v.53, p.173-87, Sept.1972.

STAMATO, M. C., (1971). Associação Contínua de painéis de contraventamento, São Carlos, Escola de Engenharia de São Carlos - EESC - USP

TARANATH, B.S. Analysis of interconnected open section shear wall structures. Journal of the Structural Division, ASCE, v.101, p.2367-84, Nov. 1975. 
TIMOSHENKO, S.P.; GERE, J.M. (1961). Theory of elastic stability. Tokyo, McGraw-Hill.

TORRES, I. (1999). Efeito da deformação por cortante no cálculo de edifícios de andares múltiplos com núcleos estruturais. Dissertação (mestrado) - Escola de Engenharia de São Carlos - EESC - USP

VASCONCELLOS, A.C. Como se pode enrijecer edifícios muito flexíveis. In: LA INGENIERIA ESTRUCTURAL SUDAMERICANA EN LA DECADA DEL 80, Montevideo, Uruguai, 1986. Anais. v.1, p.237-68

VLASSOV, B.Z. Pieces longues en voiles minces. Paris: Eyrolles, 1962. 655p.

WEAVER JR., W. Computer programs for structural analysis. Princeton: S. Van Nostrand, 1967. 300p.

YAGUI , T., (1971). Estruturas constituídas de paredes delgadas com diafragmas transversais. Tese (Doutorado - Escola de Engenharia de São Carlos - EESC USP.

YAGUI, T., (1978). Análise de estruturas de edifícios constituídas de núcleo de concreto armado e pilares ou pendurais de aço (carregamento crítico de instabilidade geral). Limeira: Faculdade de Engenharia de LimeiraUNICAMP. 


\section{- BIBLIOGRAFIA COMPLEMENTAR}

ATAIDE. M.O.P.,(1981). Aplicação do modelo de Ritz-Aglerkin à análise de estruturas de edifícios altos pela técnica do meio contínuo. Dissertação de mestrado - Escola de Engenharia de São Carlos - EESC -USP.

BATTISTELLA,R.A.G., (1991). Cálculo dos deslocamentos laterais de painéis planos considerando as deformações axiais dos pilares e o efeito de Segunda ordem. Dissertação (Mestrado) - Escola de Engenharia de São Carlos - EESC - USP.

CARVAlHO, F. A. C., (1980). Instabilidade de edifícios com paredes de seção aberta contraventados po lintéis. São Carlos,. Dissertação (Mestrado) - Escola de Engenharia de São Carlos - EESC - USP.

CORRÊA, M.R.S., (1991). Aperfeiçoamento de modelos usualmente empregados no projeto de sistemas estruturais de edifícios. Tese (Doutorado) - Escola de Engenharia de São Carlos - EESC - USP.

HEIDEBRECHT, A.C., SMITH, B.S. Aproximate analysis of open-section shear walls subject to torsional loading. Journal of the Structural Division, ASCE, v.99, n.5, p.2355-2373, Dec. 1973. 
LAIER, J.E., (1976). Análise da vibrações livres de edifícios pela técnica do meio contínuo. Tese de Doutorado. Escola de Engenharia de São Carlos - EESC USP.

MANCINI, E., (1972). Associação contínua tridimensional de pórticos e paredes com engastamento elástico. Dissertação de Mestrado. Escola de Engenharia de São Carlos - EESC -USP.

MANCINI, E.;BATTISTELLE, R. A. G. Associação plana de pórticos e paredes. In: CONGRESSO IBERO LATINO-AMERICANO DE MÉTODOS COMPUTACIONAIS PARA ENGENHARIA, 10., Porto, Portugal. Anais. p. 415-430.

MANCINI E.; (1995). Aplicação da técnica do meio contínuo à problemas relativos à estruturas de edifícios altos. Tese (Livre-Docência). Escola de Engenharia de São Carlos - EESC -USP.

MORI, D. D. (1988); Flexo-torção: barras com seção transversal aberta e paredes delgadas. EESC-USP

OLIVEIRA, D.S., (1982). Aplicação do método de Rayleigh - Ritz na integração numérica das equações da técnica do meio contínuo. Dissertação de Mestrado. Escola de Engenharia de São Carlos - EESC -USP.

PROENÇA, S.P.,(1981). Diferenças finitas na integração das equações das equações da técnica do meio contínuo. Dissertação de Mestrado. Escola de Engenharia de São Carlos - EESC -USP.

RAMALHO, M. A., (1983). Integração das equações da técnica do meio contínuo. Dissertação de Mestrado. Escola de Engenharia de São Carlos- EESC - USP. 
SAVASSI, W., (1975). Aplicação do método dos elementos finitos aos edifícios altos. In: JORNADAS SUL-AMERICANAS DE ENGENHARIA ESTRUTURAL, 17., Caracas. Anais.

SCHIEL, F. Barras de seção delgada. São Carlos: EESC-USP, 1964/65. 72p.

SMITH, B. S.; COULL, A., (1991). Tall Building Structures. Analysis and Design; A Wiley - Interscience Publication.

SORIANO, H. L., (1971). Cálculo automático do efeito do vento em estruturas de edifícios. Dissertação (Mestrado). Universidade Federal do Rio de JaneiroCOPPE.

SORIANO, H. L., LIMA, S. S.,(2000). Método dos Elementos Finitos em Análise de Estruturas. Rio de Janeiro. (em prole)

TARANATH, B.S. (1988). Structural analysis and design of tall buildings. New York, McGraw-Hill.

YOSHIDA, G.K., (1988). Análise de estruturas de edifícios constituídas de núcleo de concreto armado e pilares ou pendurais de aço. Dissertação (Mestrado) Escola de Engenharia de São Carlos - EESC - USP.

ZIENKIEWICS, O.C.;PAREKH, C.J.;TEPLY, B. (1971), Three-dimensional analysis of buildings composed of floor and wall panels. Proc. Instn. Civ. Engrs., v.2, p.316-332, July. 